
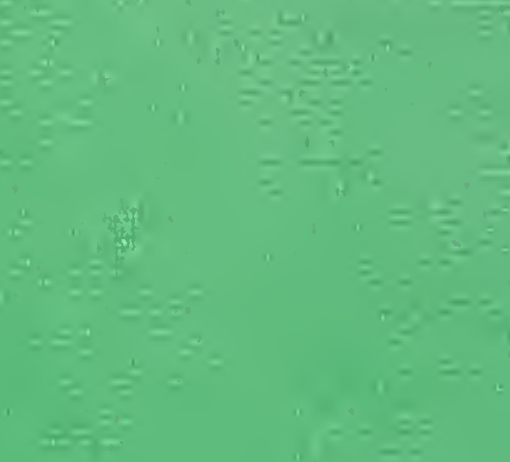
Digitized by the Internet Archive in 2008 with funding from Microsoft Corporation 

The Sea-Trout 




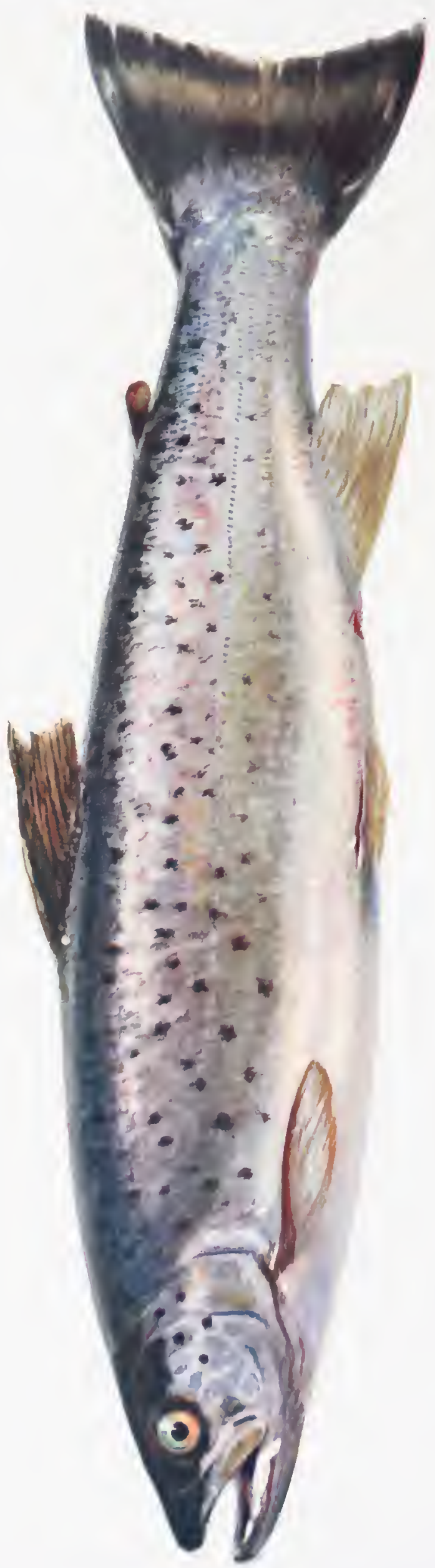

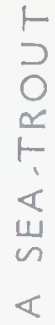


The Sea-Trout

A Study in Natural History

BV

\section{HENRY LAMOND}

Secretary of the Loch Lomond Angling Improvement Association

London

Sherratt \& Hughes

Manchester : 34 Cross Street

I 9 1 6 

To

L. B. $M$. 



\section{Contents.}

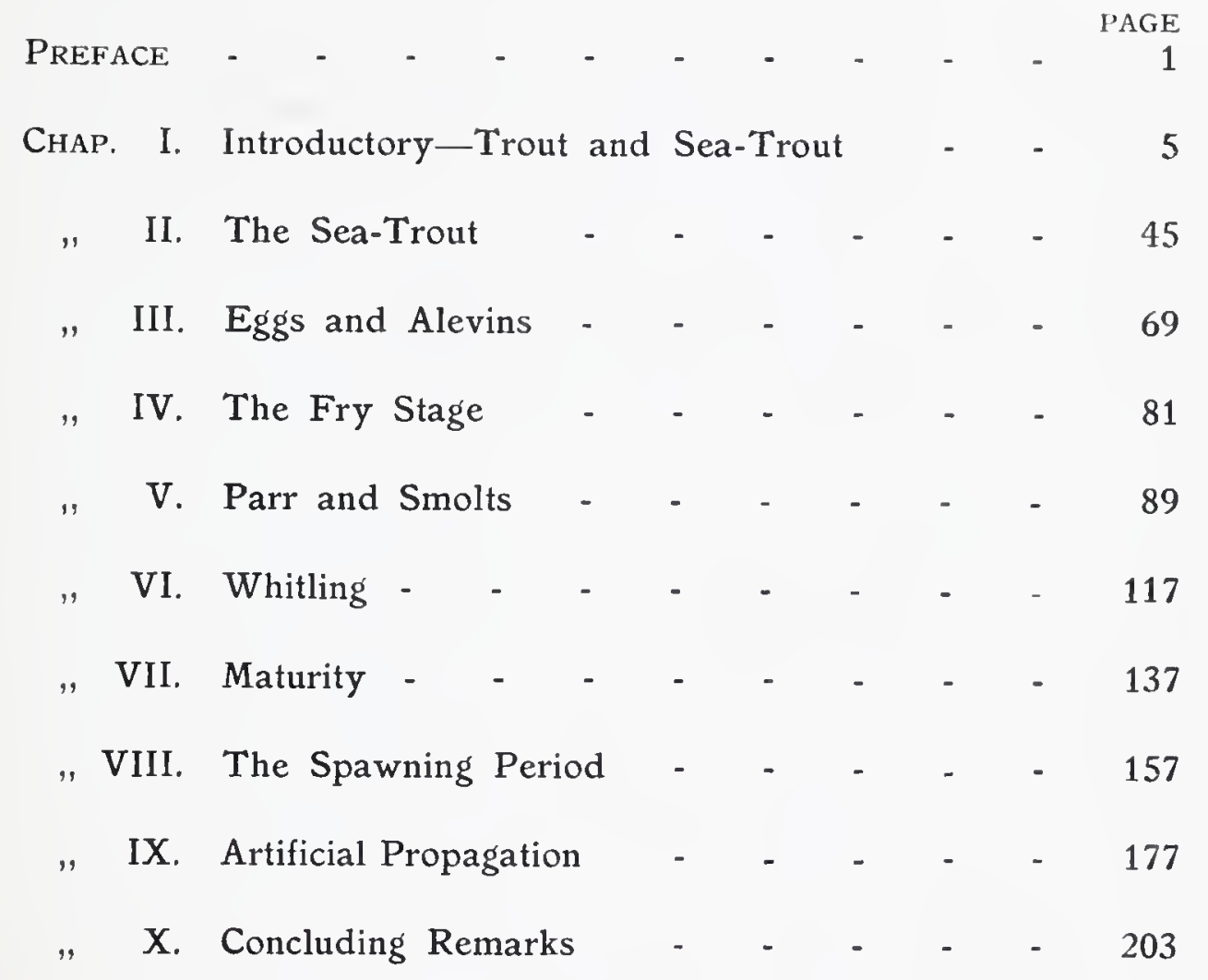

INDEX - - $\quad-\quad-\quad-\quad-\quad-\quad-\quad-\quad$ - 209 



\section{List of Illustrations.}

Plate 1. A Sea-Trout (in Colour) - - - - - Frontispiece

Face page

1, II. Development of the Salmon from the Egg to the Smolt

Stage (in Colour) - • - • - • - $\quad$ - 72

" 111. Development of the Sea-Trout from the Egg to the Smolt Stage (in Colour) - - - - - - - $\quad$ - 76

IV. A Trout, a Loch Leven 'Trout, a Sea-Trout, and a Salmon as "Yearlings" (in Colour) - - - - $\quad 92$

V. A Trout, a Loch Leven Trout, a Sea-Trout, and at Salmon as "Two Year Olds" (in Colour) - - - - 94

V1. A Silvery Loch Lomond Trout (in Colvur) - - - 100

" VII. A Young Salmon assuming the Smolt Dress (in Colour) Ior

" VIII. An Exceptionally Large Sea-Trout Smolt (in Colour) - I04

" IX. A Spawning Male Sea-Trout (in Colour) - • - I59

"Fresh Run from the Sea" . - . . - . Face page 40 FIG.

1. A Salmon, showing normal spots of the "maiden" fish - - 42

2. A Salmon, showing speckled appearance of a fish which has previously spawned - • - • - • - 42

3. Two Loch Lomond Sea-trout, showing typically distinctive markings - - - • - • - - - • 44

4. A male Sea-trout at spawning time - - - - - 44

5. A "two year old" Trout (fario) with "halo" surrounding the spots strongly accentuated - • - • • • • • 46

6. Two " two year old " Trout (fario) showing normal markings • 46

7. A Norwegian river Trout (fario) - . - . - . . 47

8. A Clyde river Trout (fario) - - • - - • • 47

9. A Loch Lomond Trout (fario) showing spots geometrically arranged 48

10. A Loch Lomond Sea-trout showing spots geometrically arranged 48

11. Diagram showing arrangement of the fins of Salmon, Sea-trout and Trout - - • - • • - • - • 54

12. Diagram contrasting tails of Salmon and Sea-trout - - $\quad 55$

13. Diagram contrasting heads of male Salmon and Sea-trout - $\quad 58$ ix 
FIG.

14. Diagram contrasting heads of female Salmon and Sea-trout

15. Diagram of gill-covers of Salmon 'Trout, Grey Trout, and Salmon (after Yarrell, reversed)

16. Scales of a Sea-trout and a Grilse of equal weights contrasted to show different rates of growth - . - . - . 62

17. Vomer of a Clyde river Trout showing dentition - . - $\quad 6_{3}$

18. Vomer of a Loch Lomond Sea-trout showing dentition - - 63

19. Diagram contrasting outlines of tail of a Tweed "Bull Trout" and of a Loch Lomond Sea-trout - . - . - . 66

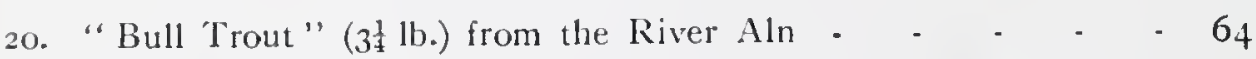

21. Scale of River Aln "Bull Trout" ( $31 \mathrm{lb}$.) indicating growth

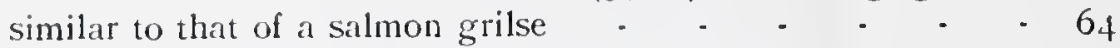

22. "Bull Trout" (8 lb.) from the River Aln - • - • - 68

23. Scale of River Aln "Bull Trout" (8 lb.) indicating growth similar to that of a small summer salmon - . - . - 68

24. A Norwegian "Bull Trout" $\left(8 \frac{1}{2} \mathrm{lb}\right.$. $)$ - . - . - . 68

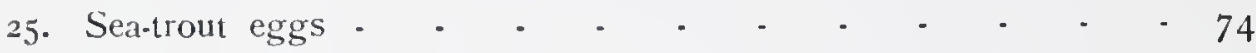

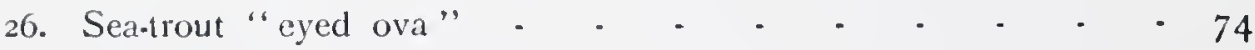

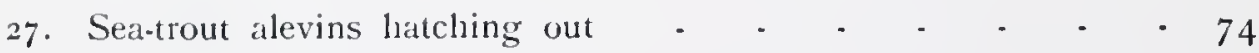

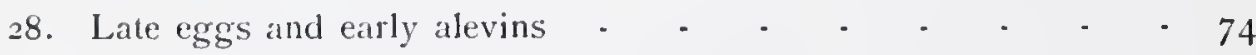

29. Sea-trout "monstrosities" (after Ciemmill) - - - 78

30. Scale of a late-descending Sea-trout smolt - . - - . IO2

31. Scale of Sea-trout indicating a 2 -winters' residence in fresh water prior to migration - • • • • • • • - • 106

32. Scale of Sea-trout indicating a 3-vinters' residence in fresh water prior to migration - • • - - • - • • 106

33. Scalc of Sea-trout indicating a 4-winters' residence in fresh water

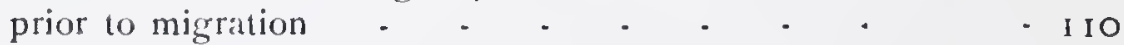

34. Scale of Sea-trout Smolt indicating a 4-winters' residence in fresh water prior to migration - - . - - . - - - I I0

35. Scale of Sea-trout indicating a 5-winters' residence in fresh water

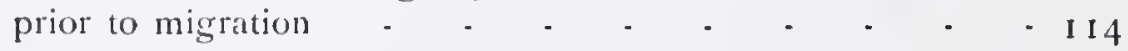

36. Scale of Norwegian Sea-trout indicating a 5-winters' residence in fresh water prior to migration . - . - . - - I14

37. A typical Whitling - . - . - - - . - - II 8

38. Scale of Sea-trout illustrating period spent in the sca after descent as a smolt and prior to return as a whitling 
FIG.

39. Scale of a very small Norwegian Sea-trout - - • - - 123

40. Scale of a small Norwegian Sea-trout - - - - • - I 23

41. Scale of Sea-trout indicating that the fish spawned as a whitling - I 26

42. Scale of Sea-trout indicating that the fish had spawned as a whitling 126

43. Scale of Sea-trout indicating that the fish had spawned as a whitling I 30

44. Scale of Sea-trout indicating that the fish had not spawned as a

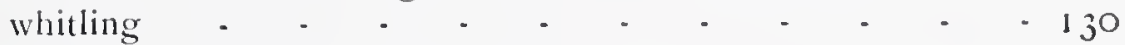

45. Scale of Sea-trout indicating that the fish did not remain over winter in the sea after its descent as a smolt . - . I $_{3} S$

46. Scale of Sea-trout indicating that the fish passed I winter in the seat after its descent as a smolt - . - . - . I $_{3} \delta$

47. Scale of Sea-trout indicating that the fish passed 2 winters in the sea after its descent as a smolt - . - . - . $\quad 142$

48. Scale of Sea-trout indicating that the fish passed 3 winters in the sea after its descent as a smolt - . - • - . - 142

49. Scale of Sea-trout which, although i y years old, weighed only $2 \frac{1}{2}$ lb. 143

50. A Salmon leaping at a fall - - - - - • - - 152

51. A male Salmon in spawning dress - . - . - . - - 160

52. A female and male Salmon on the eve of spawning - - - i60

53. A male Sea-trout in spawning dress - - . - - - 164

54. A female kelt Sea-trout - - - • - • - - 164

55. Scale of Sea-trout indicating spawning in 2 consecutive years - 168

56. Scale of Sea-trout indicating spawning in 3 consecutive years - 168

57. Scale of Sea-trout indicating spawning in 4 consecutive years - I 70

58. Scale of Sea-trout indicating spawning in 5 consecutive years - 172

59. Scale of Norwegian Sea-trout indicating spawning in 7 consecutive

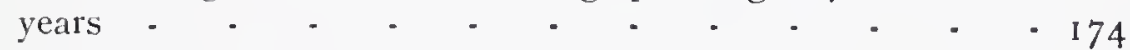

6o. A Norwegian Sea-trout (11 $\frac{1}{2}$ lb.) - . - . . - . 174

61. Scale of Sea-trout, recaptured when spawning in 3 consecutive years i 76

62. Scale of Sea-trout indicating that the fish spent 3 consecutive years in the sea after migration as a smolt - . - . - . I76

Plan of Luss Hatchery - • - • - . . 



\section{PREFACE}

IT may, I think, be gathered from the general conversation of one's friends who are anglers, and, indeed, from much that one finds in the literature of angling, that considerably less is definitely known regarding the sea-trout than is popularly known nowadays regarding the salmon. The truth is, that the salmon has, until very recently, practically monopolised the serious attention of investigators of the life-history of our more sporting fishes.

I do not of course mean to say that the sea-trout has hitherto been wholly neglected. Much useful and interesting information regarding it may be found scattered here and there in the pages of books on fish and fishing, but I do not know of any recent work which bears to be primarily a study of the gamest of fishes.

Dr. Francis Day, in his "British and Irish Salmonidæ," published in I 887, gave us perhaps the most exhaustive study of the sea-trout that has yet been written, and, more recently, Mr. C. Tate Regan, in his excellent treatise on "The Freshwater Fishes of the British Isles," published in I9I I, emphasised some of the more striking of Dr. Day's views. But Dr. Day, when he wrote, was not in a position to take any very great advantage of such evidence as we know can be gleaned from a study of the scales of the Salmonidx, and he had not before him, when he wrote, such definite data as we now know can be gathered from the systematic marking of individual fish. Both of these lines of inquiry, as I hope to show, help to shed a clearer light upon much that is obscure, or that rests merely upon theory, in the life-history of the sea-trout, and it is, I think, on the evidence that will be obtained from further investigation along these lines that a complete 
understanding of the life-history of the sea-trout-if not also of the trout-will ultimately be arrived at.

These pages pretend to give only a bare outline of what is known concerning the sea-trout's career; only in a few instances have I ventured, lightly and tentatively, to fill in the details of the picture. As Mr. W. L. Calderwood says, "We require rather fuller knowledge of the habits of this minor salmon." His note upon "Sea-trout" in the most recent Report of the Fishery Board for Scotland (namely that for the year 1914) leads one to hope that his careful and painstaking work as Inspector of Salmon Fisheries for Scotland will in time bring us to that fuller knowledge. A "Life of the Sea-trout" from his pen would be an appropriate and acceptable companion picture to his "Life of the Salmon."

I think I have in most instances in the text made suitable acknowledgment of such information as has been freely and courteously given me; here, in a word, I may briefly and generally thank all those to whom I am indebted for valuable assistance in the preparation of this book.

A more definite tribute, however, must be paid to my friend, Mr. J. Arthur Hutton, of Manchester, who has been so largely instrumental in bringing the Wye to its present state of productivity. Mr. Hutton's experience in the reading of salmon scales is, it is safe to say, now probably unequalled, and he has been so generous as to apply his knowledge definitely on my behalf to the elucidation of a large number of sea-trout scales. He was, in particular, good enough to examine for me a series of scales of Loch Lomond fish with which I supplied him during the season of 1914. Without the data so derived this book would have been lacking both in interest and value. I may explain that we jointly agreed as to the accuracy of the reading of each scale examined, and if it would be not wholly fair to myself to say that all my conclusions based upon such readings are merely Mr. Hutton's conclusions, it is at least fair to him to say that his greater experience 
led him to suggest to me wherein scale reading might be of value in confirming as fact what had otherwise remained very much in the region of theory. For example, I do not think I could have realised how protracted the young sea-trout's residence in fresh water might be before migration without Mr. Hutton's valuable help. I am further indebted to him and to his skill with the camera for all photographs of scales and for most of the photographs of fish reproduced. To him, also, and to the Rev. Alex. Slater Dunlop, B.D., Minister of Luss, I am indebted for a revision of the proof sheets.

As to the other illustrations, failing any skill with the camera, I have perforce had to fall back upon such drawings as I could myself accomplish with pen and brush. They are intended to be viewed rather as diagrams than pictures, diagrams which can be conveniently compared one with another.

In spite of its many defects I hope this monograph may help to induce others to apply themselves to a study of one of the most interesting of our British fishes.

H. L.

Glasgow, ist February, I9I6. 



\section{Introductory}

Trout and Sea-Trout 
. 


\section{CHAPTER I.}

\section{INTRODUCTORY-TROUT AND SEA-TROUT}

THERE is one question-not quite so simple as it looks-that appears to me to require some investigation before any inquiry into the lifehistory of the sea-trout is undertaken, and that question is-What is a sea-trout? It is, one must admit, a question which has not yet been very satisfactorily answered by anybody, nor can I pretend to give a very satisfactory answer myself; but several writers appear to me to have sought for the answer in the right direction, and I shall endeavour in this introductory chapter to indicate to the reader what that direction is.

In a difficulty it is often prudent to consult a lawyer, and as our question is one of admitted difficulty, I think I cannot do better at the outset than take the opinion of an eminent Scottish legal authority who gave this matter some consideration. In the well-known "Treatise on the Law of Scotland relating to the Rights of Fishing," by Mr. Charles Stewart, Advocate, where the extent of the Crown's right at common law to the ownership of salmon and salmon fishing is under discussion, there occurs this note:- " The Crown holds the right of fishing salmon, but it may be questioned whether that right extends to all fish of the salmon kind. In recent salmon legislation, the word 'salmon' is expressly declared to possess the wider significance, but natural history and the common interpretation scarcely warrant the construction. Sea-trout and bull trout are perhaps 'fish of the salmon kind,' and the Salmon Acts expressly declare them to be included in their operation; but in a question of title, can the right to fish for them be held to be inter regalia? The rationale of the Crown's right to salmon is . . . . . the value of the fish, an argument which does not apply with equal force to bull trout, herling, etc. These fish, along with the salmonidae of 
smaller size, inhabit the lesser rivers and streamlets in common with the yellow trout, from which they are almost indistinguishable in size, and it seems anomalous that to fish for the one a Crown charter should be necessary, while the right of fishing for the other is an accessory of the soil. If the whole race of salmonida, including bull trout, herlings, etc., are to be considered as inter regalia, the best practical test of royal property would be the migratory habits of the fish."

It will be observed that this legal authority, even so recently as 1892 , found himself faced with the difficulty of accounting in a rational manner for the inclusion of "sea-trout and bull trout" and "herlings, etc.," by implication along with salmon in the Crown's right of salmon fishing. He seems to have doubted whether the implication could really be justified, notwithstanding the migratory test, and he clearly considered that "natural history and the common interpretation" did not warrant the inclusion of the fishes he somewhat tentatively named within the term "salmon," although "recent salmon legislation" so included them.

His hesitation was commendable, because even yet the Crown's rights at common law, in Scotland, so far as the inclusion of the sea-trout is concerned, do not secm to have been definitely established by a decision of the Courts. In a case which was decided by Lord Johnston, one of the judges of the Court of Session, in $1907,{ }^{1}$ the question at issue was whether salmon fishings in Orkney were inter regalia, and it was held that they were not. But the question was incidentally mooted whether sea-trout are "salmon" according to the common law of Scotland. Lord Johnston devoted some part of his judgment to the point (which, however, for the purposes of the case it was unnecessary to decide), and said that, according to his own impression, a right of salmon fishing did cmbrace the right of sea-trout fishing. But at the same time he remarked that it was not conclusive on the point that the whole migra-

1. Lord Advoente v. Bnlfour, July 20, 1907. Session Cases, 1907, 1. 1360. 
tory Salmonide were protected by statute, although the migratory element helped to influence the affirmative view which he expressed. It was this same element which had already prevailed in fixing the definition of the word "salmon" in the Scottish statutes, and one may trace the history of that definition in a very few words.

Salmon fishing appears to have been, in early times in Scotland, a favourite topic of legislation, for the subject is dealt with in very many of the Acts of the old Scots Parliament. One does not find many references, however, in these old Acts, to "other fish of the salmon kind" than salmon. The earliest reference apparently occurs in an Act of 1318 , in the Bruce's reign, where regulations are made as to various kinds of obstructions in tidal waters which prevent the ascent or descent "salmunculi vel smolti seu fria alterius generis piscium maris vel aque dulcis," that is to say, young salmon or smolts or the fry of "other kinds" of sea or fresh-water fishes. Another Act, that of I426, refers to "salmondis and uthir fische." The Act of 1469, again, more definite, refers to "fisch, salmon grilses and trowtis." Beyond such rather vague references, in a series of some twenty Statutes, I know of nothing in the old Acts which would extend the whole scope of the laws relating to the salmon and its young to other fish than salmon.

It is in the modern series of Statutes that a definite extension of the meaning of the word "salmon" first appears. In the Act of 1828 , the first of the series, the fish are grouped as "salmon, grilse, sea-trout, or other fish of the salmon kind." Then the Act of 1844 applies to "salmon, grilse, sea-trout, whitling, or other fish of the salmon kind," whitling being thus specifically mentioned. But the Act of I862, in the definition now in force, dropped the whitling, added bull trout, smolts and parr, and introduced the term "migratory." Thus, since I 862, the word "salmon" has, in statutory law, meant and included "salmon, grilse, sea-trout, bull trout, smolts, parr, and other migratory fish of the salmon kind." 
My object is, of course, to emphasise the fact that our knowledge of the natural history of the sea-trout, as reflected in the law of the land, is of a somewhat vague and indeterminate kind, the only characteristic of the fish relied upon to establish its identity being the migratory habit-a habit shared in an equal degree by the salmon, and, as is well known, in a less degree by the trout. It occurs to me to inquire whether the importance which has been attached by the legislature to the idea involved in the term "migratory," and the consequent legal classification of the fish as a "salmon," has not helped to some extent to obscure our perception of the real nature of the sea-trout.

I do not deny that in some respects the legal definition has served its purpose admirably, even if, as some have hinted, the rights of salmon fishery proprietors have incidentally been greatly enhanced thereby, but in many respects I think the sea-trout has suffered from being classed as a kind of poor relation of the salmon. The sea-trout fisheries of Scotland, whether alone or supplementary to salmon fisheries, are of great commercial value, and yet in almost every particular, as regards legislation, the interests of the sea-trout have been relegated to a subordinate position-if they have not, indeed, sometimes been wholly lost sight of - the assumption apparently being that any enactment appropriate to the salmon must be equally appropriate to the seatrout. So much, hitherto, has the salmon dominated the situation, that the Royal Commissioners of 1902, upon whose recommendations any fresh salmon fishery legislation will in all likelihood be based, virtually apologised for exceeding their commission in considering the case of the sea-trout at all. Noreover, it was only in 1913 that any specific information regarding sea-trout began to be returned to the Fishery Board for Scotland by the Clerks of the District Fishery Boards in their annual reports. If the change came about partly owing to representations on the subject which I had made from time to time to 
my friend Mr. W. L. Calderwood, H.M. Inspector of Salmon Fisheries -as to which I have no information-I shall be the better pleased.

In another direction also I think the sea-trout has suffered from the idea that it is a sort of inferior salmon-an idea, still based, I have no doubt, upon its migratory habit.

Every writer on salmon fishing-there is hardly any exceptionused to feel it incumbent upon him to refer to sea-trout fishing, and apparently most of these writers imagined, as Mr. John Bickerdyke in "The Book of the All-round Angler" does, "that to fish for large fresh-run sea-trout is to fish for salmon on a small scale." Mr. Francis Francis, in devoting two pages of "A Book on Angling" to sea-trout fishing, concedes that "the sport is little inferior to the best grilsefishing." Sir Herbert Maxwell himself is hardly more generous to the gamest of fishes. The net result has generally been rather a travesty of the character of the sea-trout and of the methods of fishing for it.

I must not be understood to say that no writer who treats of salmon and salmon fishing is to be debarred from treating of sea-trout and sea-trout fishing at the same time, but I think that before doing so in a perfunctory chapter at the end of his book, the writer should consider fairly whether the sea-trout does not, if not on its own account, at least on account of the relationship it bears to each, deserve some greater share of the recognition which has been so freely lavished on the salmon on the one hand, and on the trout on the other. There are signs, however, that this state of indifference regarding the character of the seatrout, both as a sporting fish and as a study in natural history, will not long continue, for I think that many have recently had their interest aroused and their curiosity awakened in the subject.

If lawyers, then, and, as I fear, many angling writers, by concentrating their attention too fixedly upon the "migratory" habits of the sea-trout-or in sheer ignorance-have tended to confuse the mental 
picture which we form of it, one may now inquire how far the student of natural history has helped to bring the picture into proper focus.

Here again, at the very beginning, one who, like myself, is accustomed to the practical rather than the scientific aspect of fish life, will encounter a difficulty, and perhaps I can best explain it by quoting from a letter on the subject which I have received from one of the students aforesaid.

"If you look," writes my friend, "at the Article "Ichthyology' in the 'Encyclopredia Britannica' (last edition), you will see that it is divided into two sections, one on the morphology of fishes and one on the classification of fishes. Now this division is a simple expression of the fact that the whole subject is so divided and that the workers upon it are similarly divided. The two types of workers occupy somewhat different standpoints towards such conceptions as variety, species, family, and so on. The morphologist looks on them as merely convenient groups into which to arrange animals, expressive of their blood-relationship in an evolutionary sense. He is interested in the features of the various groups in so far as they are evidences of this blood-relationship. He does not admit that there exists in nature any gencral grouping of animals agreeing with what we call genera, families, and so on. He says that you can only form a conception of 'genus,' or 'family,' or 'order,' if you restrict your view to one isolated group of animals. Thus within the group 'Birds,' you may have a fairly clear idea of what you mean by each of these terms; similarly within the group 'Dipterous Flies,' or within any other group. But he does not see any evidence that 'family,' or 'genus,' means the same thing in these different groups. In each case it is simply a convenience evolved by specialised systematists within the particular group. The systematist, on the other hand, tends to look on such groups as representing, so to speak, well-defined conceptions in nature. His interest is in cataloguing animals and separating them into the various groups. $\mathrm{He}$ 
works away at minute differences in detail which the morphologist is apt to regard as relatively trivial. The whole outlook is different."

Now it seems to me to be necessary, in the inquiry to which we have addressed ourselves, namely, What is a sea-trout? to recognise that there are, in fact, two schools holding such very divergent aims, because it may quite conceivably be important that we should be able to distinguish at any time whether a particular writer is discussing a particular specimen as a morphologist or as a systematist. I can readily understand that a failure to recognise this distinction may have led to a misunderstanding of a particular writer's views, and I think that if a writer has not made it clear in what capacity at the moment he is discussing any specimen of the Salmonida a certain confusion of thought may have unwittingly been engendered in the minds of his readers.

It occurs to me, for example, that much of the uncertainty which at present exists as to the identity of the "bull trout" with the seatrout-one party strongly contending for identity and another party as strongly contending for variety-rests upon the point of view of the disputant as a morphologist or a systematist. If the former, he will consider the "bull trout" as a sea-trout and of interest as being of the Salmonida; if the latter, he will discover a marked distinction between the two fish on the alleged ground that in mature specimens of the sea-trout the tail is square whereas the "bull trout" has a tail so convex in its margin that the fish has, in consequence, in certain localities, been popularly designated the "round tail." The morphologist will agree that the family Salmonida is an interesting study; but the systematist, intent on cataloguing his " bull trout," will classify it, if not as a separate "species" of the "genus" Salmo, at least as the "variety" eviox of the "species" trutta.

To take now another example of even greater pertinency to our subject. Viewing the family Salmonida, the morphologist will, for his 
own convenience, accept the systematist's division of the family into four genera, and of the genus Salmo will perhaps readily agree to a distinction being drawn between two species, namely, Salmo salar and Salmo trutta; but it will not interest him further to take cognisance of minor distinctions, and discuss or dispute the existence or nonexistence of variations of the species trutta which may lead one systematist to classify certain specimens as different species of Salmo and another systematist to classify certain other specimens as other species of Salmo, nor will he be much interested in whether there are varieties of such alleged species, migratory or non-migratory, roundtailed or square-tailed, plain or speckled. The systematist, for his part, is ridden by the necessity of his point of view, and he discovers in the genus Salmo first one species and then another, and thereafter proceeds to find varieties and even sub-varieties in each.

I think it is not improbable that, coupled with the confusion of thought already alluded to, this industry of the systematist, in dividing and sub-dividing the grouping of the subject of his study, has accounted for a great deal of misunderstanding in the popular mind regarding the sea-trout. For, consider, of the genus Salmo, while the authorities are agreed that, in European waters at least, there are no varieties of the species salar, in other words that there is only one salmon, yet of the trout, trutta, there are endless varieties alleged, if they are not indeed held to be other species of Salmo. And, besides the migratory seatrout, Salmo trutta, one finds constant reference being made to Salmo criox, Salmo cambricus, and Salmo albus as other migratory varieties of trutla if not species of Salmo; and, besides Salmo fario, generally and somewhat arbitrarily accepted as a non-migratory fish, one finds cverywhere references to Salmo ferox, Salmo levenensis, Salmo nigripinnis and Salmo stomachicus as other non-migratory trout; and even an estuarine trout has been differentiated by the name of Salmo 
orcadensis, though whether it is claimed as a migratory or non-migratory trout is not clear.

Now it long ago occurred to me that there was a welter of confusion in all this differentiation which might possibly be accounted for by the fact that scientific systematists, who had no great practical knowledge of the actual ways of fish, had lent too credulous an ear to local popular beliefs in exceptional types, while, on the other hand, practical men who had no scientific training at all had acquired the habit of claiming as the attributes of some new species what were really after all only superficial differences in some known species.

The somewhat specialised nature of my work with the Loch Lomond Angling Improvement Association, carried on for over fifteen years, has made it possible for me to appreciate the efforts of those who have made simplication, and not complication, of our subject their aim and study.

Some few writers had already conceived of there being only one species of our British trout, and perhaps Dr. Francis Day, the author of "British and Irish Salmonide," published in 1887 , is the most representative of those whose views tended in that direction. In his preface he says:-_ It has been increasingly evident to me for some years that one of the main reasons militating against the successful cultivation of trout (and possibly char) in this kingdom by riparian proprietors, has been the confusion into which these forms have been thrown by naturalists, who, in order to give greater accuracy to their descriptive treatises on Museum specimens, have subdivided them into many species. The consequence of this has been, that fish-culturists who have accepted the statements made, have been constantly attempting to introduce new species into their waters in order to improve the native race. For the zoologists who have been most active in raising local varieties to specific rank have been compelled to admit that they all very commonly interbreed, but that the young revert to one of the 
original parents." In spite, however, of Day's painstaking and exhaustive treatise, which every angler ought to make a point of reading for the wealth of information it contains regarding the sporting Salmonidce, I do not think that many anglers were prepared to learn, as they did from an excellent work on "The Freshwater Fishes of the British Isles," by Mr. C. Tate Regan, Assistant in the Zoological Department of the British Museum, which was published in I9I I, that "In the British Isles there is only one species of Trout."

This authoritative pronouncement came with something of a shock upon all but those anglers who had devoted some little study to the more scientific literature of their craft, or who, from their personal observations made upon fish life, had formed conclusions leading in the same direction. Others were frankly sceptical, and I for one see no reason to blame them, nor indeed need anyone hastily jump at conclusions. The whole subject demands more complete investigation at the hands of competent students. Meantime it has to be noted that Mr. Regan regards the single species as a "variable species," and anglers who recognise the fact that trout are well-nigh infinite in their markings and vary extraordinarily in their general characteristics according to environment, will agree with his qualification, whether they accept his main proposition or not.

Mr. P. D. Malloch, in his "Life-History and Habits of the Salmon, Sea-Trout, Trout, and other Freshwater Fish," first published in I9IO, a work justly popular on account of the excellence of its illustrations, had, of course, already prepared our minds to some extent. With reference to the "Sca-trout" (Salmo trulla) he writes:- "Having made a careful study of this subject for thirty years, and having collected all the information I could bearing upon it, I have come to the conclusion that the sea-trout is the same fish as that which is called white trout, bull-trout, gray trout, peel, sewin, brith-dail, salmon-trout, and many other names." Then of "The Brown Trout" (Salmo fario), which he 
also designates "the common yellow trout," he writes:- "Many naturalists maintain that there are different species of trout in the British Islands-Loch Leven trout, Gillaroo trout, tidal trout, and many others; but from a close study of all these trout for the last forty years, I have come to the conclusion that there is only one specics of trout in Great Britain, and that in the different varieties the differences are caused by the nature of the water in which they are found and by the food they eat." These views are valuable as being those of a practical man, who, had he studied the sea-trout as long as he had studied the trout, might have simplified matters still further. It was left to Mr. Regan, as a scientific man, to take the more advanced step. "Although the silvery Sea-trout and non-migratory Brown Trout," he writes, "differ so much in habits and appearance, there are no structural differences, and the young are indistinguishable."

I may say here that in my account of the life-history of the sea-trout which follows I shall have occasion from time to time to comment on the main theory that in the British Isles there is only one species of trout, and I hope that such observations as I am able to make will help the reader to decide for himself how far the theory is in accordance with fact. Without doing so in so many words, in connection with every point discussed, I will, I trust with perfect fairness and apparent reason, substantiate the theory where in my opinion it is capable of being substantiated, and refute it with equal candour if $I$ find it necessary to refute it. But, in the meantime, standing thus as I have quoted it, the theory of which Mr. Regan has been the most recent authoritative exponent is so striking in itself that it will be interesting to consider the views by which he supports it.

As a good systematist, Mr. Regan gives us first a scheme of classification of our British freshwater fishes, and those who prefer order and method in their approach to any subject will naturally wish it to be outlined, however briefly. The reader who is deeply interested in such 
matters may compare with it, say, the scheme of classification which the late Mr. H. Cholmondeley-Pennell, in r863, adopted and set forth in his well-known book, "The Angler-Naturalist." I hope I do not misrepresent Mr. Regan's scheme, but I gather that of the great number of British vertebrate fresh-water animals known as fishes there are two classes, with the first of which, Marsipobranchii, having one order, and one family (represented by the lampreys), we have nothing to do. Of the other class, Pisces, there are two sub-classes, and with the first of these, Chondrostei, which has one order, and one family (represented by the sturgeons), we have also nothing to do. The other sub-class, Teleostei, is our concern. In this sub-class Mr. Regan predicates seven orders, each of which comprises one or more families; but it is only the first of these orders, Isospondyli, which interests us here, for in it are comprised three families, the important one for us being the family Salmonida, of which the salmon and trout are more particularly the representatives. Mr. Regan has courteously furnished me with the reprint of a Paper, of which he is the author, on "The Systematic Arrangement of the Fishes of the Family Salmonida," which enables us to carry the classification a step further.

To the family of the Salmonida, then, in its universal aspect, Mr. Regan is able to refer four genera:-(I) Salmo, Linn., which includes, he says, "all the fish commonly known as Salmon and Trout." The other three, though not to the purpose, may be stated:-(2) Salvelinus, Nilss., including the char; (3) Hucho, Günth., including the hucho of the Danube, etc., and (4) Brachymystax, Günth., including a species of Siberian hucho. In the synopsis of the four genera given in this paper, Mr. Regan states their general characteristics thus:-

"Parictals not meeting in middle line. Teeth well developed in jaws, on vomer and palatines, and in a double series on tongue. Scales small, 19 or more in a transverse series from origin of dorsal fin to lateral line. Dorsal fin short, with not more than 16 rays, I 2 or fewer branched"; 
and particularly those of the genus Salmo:-

"A double or zigzag series of teeth along shaft of vomer, sometimes deciduous in the adult."

It is interesting to note in passing that from a study of their skeletons, and in particular their skulls, Mr. Regan finds that no doubt is left that the Pacific species of salmon and trout "form a perfectly natural group that differs in several characters from the Salmon and Trout of the Atlantic."

In restricting himself in his book, however, to the British members of the family Salmonidce, Mr. Regan again distinguishes four, but a different four, genera, namely: (I) Salmo (Salmon and Trout), (2) Salvelimes (Char), (3) Coregonus (Whitefish), and (4) Thymallus (Grayling), a fact which reminds one of the morphologist's caution in viewing systems of classification, and the special features of Salmo and Salvelimus are given thus:-

"Mouth rather large, the maxillary extending at least to below the middle of the eye; teeth well developed; scales small or moderate; dorsal fin with Io to I6 rays";

and particularly those of the genus Salmo:-

"No depression behind the head of the vomer, and a double or zigzag series of teeth present on the shaft of that bone, at least in the young."

It only remains to complete this classification by noting that the genus Salmo embraces two species, and two species only, namely, (I) Salmo salar, which is, of course, the salmon; and (2) Salmo trutta, which is the trout-be that what it may, sea-trout or trout, one or other, or both. Thus we arrive at the basis of the theory that there is only one species of trout in these islands.

Except in so far as many, up to this point, may, like myself, have been treading on somewhat unfamiliar ground, I see no room for criticism, and we have certainly arrived at a bare systematic conception, if not of the fish itself, at least of the limits within which further particulars may be sought for, and these we may now proceed to seek. 
I have indicated that the migratory habits of certain fish have been taken by lawyers as the test of their nature, and, further, that angling writers, in their writings, have at least been strongly influenced by these habits. Indeed, no more strikingly marked feature of distinction would probably occur to a superficial observer. But Mr. Regan, discussing the trout, tells us that there "is sufficient evidence that the migratory and non-migratory fish are not distinct species, nor even races." It is necessary to examine the evidence which Mr. Regan adduces in support of this assertion; and I think the reader will agree that the evidence, if not conclusive, is at any rate extremely suggestive and interesting. I shall take the various points in their order.

\section{1.-There are no Structural Differences between Sea-trout and Trout.}

I cannot believe that any investigator would commit himself to so sweeping a statement as this unless he had, from exact study of many specimens, fully convinced himself of the fact. I am not competent to dispute Mr. Regan's accuracy of observation, and, indeed, would prefer to credit its correctness rather than attach weight to the numerous alleged points of difference which other observers have professed to discover in specimens submitted to them.

Apart from superficial colouring (which is of course a structural difference though on a microscopical scale), differences in the form of the gill-covers, differences in the arrangement of the teeth, and differences in the shape and size of the fins, have all been claimed at different times as constituting typical and characteristic distinctions. But even admitting these and similar points of difference to occur in certain specimens with more or less frequency and constancy, it seems to me possible to attach more weight to them than they deserve in the discussion as to whether migratory and non-migratory habits are conclusive as to species-or even race. Until a marked structura? difference, constantly necurring, is proved to exist, I think we must 
agree that there are no known structural differences sufficiently pronounced to warrant the placing of sea-trout and trout in distinct categories.

\section{2.--The Young of Sea-trout and Trout are Indistinguishable.}

Mr. Regan does not here clearly indicate what he means by "the young," whether eggs, alevins, fry, parr, or smolts, or all or any of them; and if he means indistinguishable in structure $I$ must repeat that I am not in a position to question his accuracy. But if he means in other and more superficial respects - which I assume he does not mean-his statement is too sweeping. I shall later, when discussing each stage in the life-history of the sea-trout, indicate various points wherein I have observed apparently characteristic differences between the young, in all stages, of migratory sea-trout and, presumably, nonmigratory trout. Indeed, as I shall show later, it is rather in the mature state that sea-trout and trout tend to become "indistinguishable." But at any rate, as to the young, failing proved differences in structure, I would not be disposed to accept variable superficial differences as evidence of distinction of species, or race, as between migratory and non-migratory trout. Here again, therefore, we may accept Mr. Regan as being substantially sound in his views.

3.-Sea-trout, if prevented from going to the Sea, will Live and Breed in Fresh Water.

This is very important. It is, of course, the normal habit of seatrout to live at least temporarily in fresh water and to breed there. It would, in the present inquiry, be necessary to show either ( $\mathrm{r}$ ) that male and female smolts of sea-trout, having been prevented from migrating to the sea, had been so far contented with their fresh-water environment as to thrive there and in due season propagate their species, or (2) that mature fish, having ascended to fresh water and there spawned, had been prevented from returning to the sea and had thereafter spawned c 
in the next succeeding spawning season, or at least some subsequent spawning season, and (3) that the eggs in both instances had developed into healthy fry which had thereafter thriven.

Mr. Regan, however, only states in his book, that the fact " has been shown experimentally," the precise nature and results of the experiment, or experiments, not being more definitely indicated. But he has kindly informed me that the experiments he had in view were those mentioned by Dr. Day in his book on the "British and Irish Salmonida," already referred to. In a footnote to page I 46 of that work, I find it stated that:- " In November, I 886, Sir James Maitland, at Howietoun, laid down some eggs of the sea-trout in order to follow out their life-history if kept in fresh-water ponds; 350 hatched in 1887." Dr. Day's book was published in $\mathrm{r} 887$, and I am not aware whether he traced the career of these sea-trout in any subsequent publication; but, on my making inquiry on my own account as to the result of these experiments, Mr. John Thomson, who has been so long connected with the hatchery work carried on at Howietoun, courteously sent me the following very interesting statement :-

"My notes on this experiment and recollections of it are shortly as follows:-The parents were caught in a tributary of the River Forth, brought to Howietoun and spawned on November 23, 1886. There were about 450 ova laid down to hatch of which some $35^{\circ}$ hatched out successfully in February, I887, and the fry (some 250) were shifted from the hatching-house to one of our ponds in June of the same year and there fed the same as other fry. The young fish were again shifted into a larger pond in June, I888, when the average size was found to be about 3 inches.

"In August, r889, some specimen fish, about 6 inches in length, were taken from the pond by Dr. Day for examination and comparison with common trout, $S$. fario, and I remember we were all agrecd that it was impossible to distinguish them by the eye from $S$. fario. In 
April, I 890, the fish were again moved to another pond, and I spawned some of the females in November of the same year, crossing the ova with milt from S. levenensis and $S$. fontinalis. A few fry of the former were hatched out and reared but were afterwards mixed with other fry.

"The remainder of the parent sea-trout were afterwards, I think, turned out into a reservoir when about five years old. They never attained to any great size."

The facts relevant to the discussion may, I think, be stated thus:-

(I) That the parr of the original sea-trout lived in fresh-water quarters for four years, namely, during 1887, I888, I 889 and 1890, without apparent discomfort;

(2) That in their third year neither an expert ichthyologist like Dr. Day, nor a practical hatchery manager like Mr. Thomson, could distinguish them from common trout;

(3) That in their fourth year the females developed ova capable of being fertilised by male trout (S. levenensis) but not by male char ( $S$. fontinalis);

(4) That the resulting "cross" breed was " mixed with other fry" as apparently being to all intents and purposes ordinary trout fry; and

(5) That the parent true sea-trout brood lived on beyond 1890 in a reservoir although they "never attained to any great size."

In view of these facts, which I give thus fully because they have an important bearing upon certain passages which will follow in my life-history of the sea-trout, it would be difficult to dispute the proposition that "sea-trout, if prevented from going to the sea, will live and breed in fresh water."

I may add that I do not believe that Loch Leven trout are descendants of "land-locked" sea-trout, and therefore a peculiar breed of trout. In my view they are simply trout which enjoy a specially favourable environment, and their origin need be in no way different 
from the origin of other trout which people our waters. Therefore the main inquiry has no occasion to turn aside to consider their case in detail, although any contention that they are descendants of "landlocked" fish, if capable of proof, would go far to substantiate this branch of Mr. Regan's argument.

4.-Conversely, Trout exported to New Zealand have found their way to the Sea and have given rise to an Anadromous RACE.

The term "anadromous" means "migratory," but in the restricted sense of migration upwards from the sea for the purpose of spawningas in the case of the salmon and sea-trout-just as "katadromous" refers to migration downwards to the sea for the purpose of spawningas in the case of the eel. Mr. Regan is here on safe ground for the case of the New Zealand fish is now common knowledge, mainly through the instrumentality of Mr. Calderwood's admirable book, "The Life of the Salmon," which was published in 1907. There he tells us that "Brown trout taken from Dorsetshire to New Zealand quickly acquired a migratory habit and became large silvery fish, inhabiting the sea for the most part, and ascending rivers to spawn."

5.-Estuarine Trout are often intermediate in appearance and habits between the Migratory and Non-migratory Fish.

I have no great belief in this so-called "estuarine" trout, and I am surprised to find Mr. Regan thus countenancing the idea of its existence. He seems in this to follow Mr. Calderwood who, in the work already cited, states:- "In localities such as Orkney and Shetland and the Outer Hebrides we have the established tidal variety which has been called S. orcadensis; and in the West of Ireland we have $S$. estuarius, the so-called slob trout. I do not agree that there is any specific distinction, any more than I agree that a ferox is not a brown trout." The italics, which are minc, emphasise what I think is Mr. 
Calderwood's real view, namely, that the estuarine trout is a variety, but not a species, of trout. He had just written, however, in adverting to the estuarial habits of the sea-trout :- "Nany common brown trout are to be found under precisely similar conditions and feeding on a purely marine diet; in the estuary of the Tay near the Tay Bridge, I have found large silvery common brown trout with freshly swallowed herring as well as much digested herring in their stomachs and intestines." It is not very clear whether Mr. Calderwood means to distinguish these "common brown trout" from "the established tidal variety."

The late Mr. Hamish Stuart, in his well-known book on "Lochs and Loch Fishing," wrote much that was suggestive, and something that has a bearing on this discussion. In the Howmore River in South Uist he states that he distinguished the sea-trout and the bull trout. "The very first cast I ever made in the river," he wrote, "I rose a large bull trout, with my second cast I rose, hooked, and lost an eriox of perhaps 12 lbs." In the river he also found, he says, "a few small yellow trout, of a particularly pretty colour, fine flavour, and shape, peculiar to the river." Then he adds, "There are two other kinds of fish in this river, namely, the estuary, slob or tidal trout, and a remarkably beautiful hybrid-apparently either between the said tidal trout and the sea-trout, or between the latter and the common trout .... It reaches occasionally the weight of I lb., but is rarely over, and generally under, $\frac{1}{2} \mathrm{lb}$. This fish does not appear to spawn, but is numerous." And of the Strome Dearg, the connecting semi-artificial, semi-tidal link between Loch Hallan, also in South Uist, and the sea, he writes:- "Besides sea-trout this salt-water river is frequented by a species of yellow trout with extremely large spots," which he attributes generally "to the slob or tidal variety." He concludes:- "As the Strome is frequented by yellow trout originally from Loch Hallan and other lochs, the peculiarities of its environment have practically 
succeeded in producing a new species - or at least a variety of the trout of the loch referred to. This new species or variety attains a recorded size of at least $6 \mathrm{lbs}$, , or three times the size which the trout, from which it is a specific environment-born off-shoot, is known to attain." It is interesting and suggestive to consider all this alleged wealth of variety of fish life in these small, out-of-the-way corners of the Hebrides in the light of the theory promulgated by Mr. Regan.

This subject is worth pursuing a little further. That praiseworthy publication, "The Sportsman's and Tourist's Guide," describes the Dhu Loch, near Inveraray, as "an excellent loch for sea-trout and yellow trout." Moreover, it says, "The Dhu Loch is a tidal water, within a few hundred yards of the sea, and an unusual species of plump tidal trout are occasionally to be found in it," thus recognising sea-trout, yellow trout and tidal trout. It is common knowledge, again, that trout, as well as sea-trout, are frequently caught in the salt-water basin of Loch Etive; and, indeed, I imagine that there are few districts in Scotland, when opportunities of observation are possible, where common brown trout will not be found in estuarial waters.

Now I have never seen it anywhere recorded that these alleged species, or varieties, of trout which have in so many places been detected by angler-naturalists and angling writers in salt and brackish water, have been seen on the spawning redds or that the progeny of them, distinguished by features characteristic of the parents, have been observed in the spawning streams. I for one am inclined to believe that such progeny will never be discovered. The facts to my mind rather point to this, that one and all of these alleged tidal trout are individual specimens of the ordinary fresh-water trout of the district, which, descending the river until they have come within tidal influence, have gradually become acclimatised to a salt-water environment. Moreover, I believe that the greatest number of these trout will be found in those localities such as the Orkneys and Shetland, and some 
of the Hebrides, where the streams are so trifling, or elsewhere in the Highlands, where the streams are such barren, rocky, mountain torrents, that there is neither security nor sustenance for trout in them.

It is rather corroborative of this view than inimical to it, that trout are to be found, as Mr. Calderwood found them, in the estuary of the great river Tay. The fact merely proves that even in such rich streams some trout will so descend to the sea. In the estuary of the Clyde, below the junction of the river Leven with it, such trout have frequently been captured in the salmon nets. I take it that these fish had gradually dropped down stream from the upper reaches of the Leven, or perhaps even from Loch Lomond, because I am informed by a local boatman, of whose capabilities of judging I have personal knowledge, that on one occasion he caught with rod and line in the loch a trout which had tide-lice on it. I give this incident for what it may be considered worth, for it suggests not only that a trout had descended to salt water but that it had returned to fresh water again, as such trout must do if they propose to spawn.

If it is objected that in all this I am only stating grounds for the belief that estuarine trout are really ordinary non-migratory trout that have become more or less migratory, it may be recalled that this is the particular point in Mr. Regan's thesis that is at the moment under discussion. But to revert now to the main argument, I shall simply confine myself to the suggestion that, having regard to the foregoing facts, the offspring of these enterprising trout, given favourable circumstances, may easily become indistinguishable from migratory sea-trout, though this savours not a little of taking matters for granted. The suggestion, however, leads naturally to the discussion of Mr. Regan's sixth, and perhaps most interesting, proposition, which I shall now submit. 
6.-There is good reason to believe that in Nature the Ranks of the Sea-trout are Reinforced by the off-spring of the RIVER-TROUT AND VICE-VERSA.

The previous passage suggests how the ranks of the sea-trout may be reinforced "by the off-spring of the River-trout," and, subsequently, throughout my account of the life-history of the fish, it will be seen how at nearly every stage the influence of the sea-trout-not to put it any more strongly-dominates the trout.

It remains now to examine how the ranks of the trout may be reinforced by the off-spring of the sea-trout, which is a deeper and more wide-reaching question. It is so deep, indeed, that I do not think its depths will soon be plumbed, but the theories to which the question has given rise have occasioned much instructive speculation.

Mr. Regan, then, asks us to consider the distribution of the trout. "There are," he writes, "no true fresh-water fishes-Roach, Perch, etc.,-in the Hebrides, Orkneys, or Shetlands; yet in these islands every river and loch is full of Brown Trout, which is only to be explained by the supposition that the latter have been derived from the Sea-trout, which have lost their migratory instinct in different places and at different times." In other words, Mr. Regan's view is that the trout is a sea-trout; not that the sea-trout is a trout. He ascribes to the trout, in fact, a marine origin.

Now it seems fairly certain that in order to arrive at the origin of any species we must travel back a considerable distance, possibly through aeons of evolution, into the dim and distant past. To establish his point, however, Mr. Regan does not go so far back as that, but, taking it for grantcd that trout then existed in the shape we know them to-day, he carrics us back to the Glacial Epoch.

"It would be out of place here," he writes, "to enter into the causes of this climatic change, but it scems clear that at a comparatively recent date the whole of Northern Europe, including our islands cxcept the 
South of England, became covered with ice; then a submergence of the land perhaps brought the sea right to the edge of the ice-sheets, so that any true fresh-water fishes which may have been in our rivers would have perished. At the end of this cold period, a gradual elevation of the land took place, culminating in the union of our islands with each other and with the Continent, and then a subsidence followed which gave to our islands approximately their present outline.

"Speculations as to the exact time occupied by these changes are futile, but it is probable that the whole duration of the Tertiary Period should be expressed in tens of millions of years and that of the Glacial Epoch in tens, or at most hundreds of thousands. Possibly about 100,000 years may have elapsed since the end of the Glacial Epoch, and our final separation from the Continent was of still more recent date.

"As soon as the ice-sheet had begun to disappear char must have commenced running up into the lakes which were formed, and as the elevation of the land proceeded new lakes appeared and in turn became inhabited by Char. All this time the climate was gradually getting warmer, and the southern limit of anadromous Char was receding northward; then the sea-trout reached our islands, and these in turn began to form fluviatile colonies in our lakes and rivers."

It is clear from the foregoing that Mr. Regan asks us to believe, and to me at least his reasoning is as plausible as it is interesting, that all the trout which to-day throng our waters, trout great and small, migratory and non-migratory, are the immediate lineal descendants of certain enterprising trout which came up out of the prehistoric Atlantic Ocean into our rivers to spawn when the great ice-sheet began to recede before more genial climatic conditions. It seems to me, however, relevant to observe that although $\mathrm{Mr}$. Regan thus reasonably credits our British trout with a marine origin, he has not thereby settled the question of the primary and original environment of the invaders, and 
it still remains to be considered whether the trout was originally a freshwater or a salt-water species.

The question which exercised the minds of the Sophists, namely, whether eggs or birds were created first, seems to have been particularly fatuous in respect that the answer-whatever it might be-held out very little promise of practical utility. If our present question is a degree less futile than the classical conundrum, it can, for us at the moment, only be useful for such light as the inquiry may help to shed upon the question whether the migratory sea-trout is distinct from, or is of the same species, and even race, as the non-migratory trout. The inquiry can hardly hope to solve the deeper problem raised by the mysterious habits of the fish in migrating at all. Yet that problem is a most attractive one, and Mr. Regan supports the view which he takes of it thus :-

"The Salmonida," he writes, "are found in the Arctic and temperate regions of the Northern Hemisphere, and may be regarded as marine fishes which are establishing themselves in fresh water"; and again, "Some writers look upon the Salmon and its relatives as true fresh-water fishes which have acquired the habit of going to the sea for food, and which return to their original home to spawn. Against this it may be urged that whereas many marine fishes take to fresh water, the reverse is a rare phenomenon." Now I do not propose to quarrel with Mr. Regan over his view of this problem, which to me seems immaterial, but I suggest that the word "rare" implies that the phenomenon is not impossible, and it may be fairly argued, or arguable, that the facts equally point to fresh water as the original habitat of the Salmonide. In particular, the fact that in salt water the spawn of salmon and trout cannot come to fruition seems to me to be pertinent, for if one casts back in imagination to the time before the fish had acquired its migratory habit, it is easier to suppose that the eggs then too hatched in fresh water than that, from being able only to hatch in 
the sea, they gradually reached a stage when sea-water became a deadly poison to them. Whereas, if we imagine the original habitat to have been fresh water it is plain that the breed might easily be perpetuated throughout the ages, as in fact it has been.

It is unnecessary to prove why some fish adopted the migratory habit and not others of the same species, but at the same time it is plausible to suppose that pursuit of food was the determining factor. It is at any rate plain, if we suppose the trout to have had a fresh-water origin elsewhere than in Britain, and to have become migratory, that the migratory habit, having once become established, accounts for the trout's wide distribution throughout the Arctic and temperate regions. It was a simple matter then for it to spread from the river of its birth to any other river it might chance upon in the course of its wanderings in the sea. Indeed, in the passage quoted, Mr. Regan very convincingly shows that this is the method by which our British waters received their stock of trout. From the sea they came, doubtless, to our shores, but it is not unreasonable to assume that they came from rivers in other parts of the Continent of Europe, or rivers elsewhere, devoid of ice, where they had their origin. It seems to me, then, that equally with the trout being derived from a marine sea-trout, the facts point to the seatrout being a derivative of a fresh-water trout; or, in other words, the proposition may as fairly be stated that the migratory sea-trout is a trout, as that the trout is a non-migratory sea-trout.

I understand that this is a question upon which science itself has come to no common agreement, although I am unaware of the precise weight of authority which may be ranged on either side. Mr. George A. Boulenger, F.R.S., the learned and courteous successor of Dr. Günther at the British Museum, thinks alike with Mr. Regan, who is his colleague and assistant. Dr. A. Noel Paton, as quoted by Mr. Calderwood, considers that "the Salmonide are originally fresh-water fish." Mr. Calderwood is himself for a marine origin, and I cannot do 
better than refer the reader to his clear discussion of the subject in the chapter on "Grilse" in his book "The Life of the Salmon." As Mr. Calderwood's point of view, in any debatable question, is ever that of the open-minded inquirer after truth, all the more weight may be allowed to his conclusion:- "In my view the prevailing characteristics of the group of fishes to which the Salmon belongs are those of marine fish of plastic nature, capable of much local variation both of appearance and habit, many of which enter fresh water freely." Dr. Day was of a like opinion.

Anglers would appear to prefer for the Salmonida a fresh-water origin. Sir Herbert Maxwell discusses the question in his book on "Salmon and Sea-Trout" (in "The Angler's Library" series), and arrives at a fresh-water conclusion; while the late Mr. Hamish Stuart in another connection recognised a fact which "seems to assign to the common ancestor of the Salmonida a fresh-water origin."

Presumably discovery made of the "common ancestor" and its habitat will finally settle this matter, but that discovery is not yet. That science is not without hopes may be inferred from this extract from a letter which Dr. A. Smith Woodward, Geologist in the British Museum, has written to my friend Dr. J. W. Gregory, Professor of Geology in the University of Glasgow, the purport of which has been kindly placed at my disposal. Dr. Smith Woodward writes:- "Practically nothing is known of the ancestry of the Salmonida. A few typical remains are found in the fresh water Tertiaries of the Continent (see references in Catal, Foss, Fishes, B.M., pt. iv), but they merely show how old is the family. Of all the modern fresh-water fishes we lack ancestors connecting them with the marine forms. We shall find them some day." I have no authority to rank Dr. Smith Woodward either as an exponent or as an opponent of the "marine origin" theory, but his letter suggests that something at least may be said for those who take the view of a fresh-water origin. 
As I have stated, the dispute, or rather discussion, is not very material to the purpose, the more so if we accept Mr. Regan's account of the manner in which our streams became peopled with trout, namely, through their having been invaded from the sea by trout which were de facto migratory, some of which gradually lost the extreme migratory habit. Such acquiescence in Mr. Regan's account would also involve acquiescence in the theory "that the migratory and non-migratory fish are not distinct species, nor even races," unless it be maintained that the invaders consisted of more than one species or race, or had since diverged into such, in my opinion an improbable development.

The reader who has been patient enough to follow the argument is as capable as I am of forming a judgment upon the problems which I have thus presented to him. But probably the first observation which occurs to him will be that, even accepting Mr. Regan's explanation of the original stocking of our waters with trout, he would like to have some clear proof that the interchange of habits and environment which Mr. Regan predicates actually takes place in our waters to-day. It is no reflection upon the general soundness of Mr. Regan's position that he cannot furnish such proof as would convince a British jury, but I think the theory which he expounds-for one hardly ventures to accept it as fact-is worthy of the most respectful consideration. There can be no doubt of this at least that the migratory and non-migratory trout are sometimes so alike that cases often occur where it is practically impossible to say definitely whether a particular fish is a sea-trout or a trout. In such cases the fish quite conceivably may be a trout which has taken on the colour of a salt-water environment or a sea-trout which has found congenial quarters in fresh-water.

The late Mr. H. Cholmondeley-Pennell, who, following Yarrell and others, made the very most of "distinctions" in "The AnglerNaturalist," said :- " The difference in colour between the two fish-the one being silver and the other golden-is uszally too obvious to admit 
of doubt; but it occasionally happens, especially when confined for a long time in a loch, that the Sea-trout acquires a colour not altogether unlike that of the Yellow Trout."

In "The Fishing Gazette" of September 6th, I9I3, to take a specific instance, I observed that a party of anglers fishing from a Donegal hotel had been divided in opinion on this question with respect to one of the fish caught. With commendable enterprise one of the party sent some of the scales of the fish for identification to Mr. R. B. Marston, who passed them on to Mr. J. Arthur Hutton, for his opinion. Mr. Hutton, disclaiming any expert knowledge of trout scales, "rather hesitated to express a decided opinion," but, arguing the case intelligently on the facts, came to this conclusion:- "I am inclined to think that your correspondent's fish was a sea-trout which had been a long time in fresh water." I may add that several similar cases of dubiety regarding trout from other waters were discussed in "The Field" in the autumn of 1913.

With regard to trout assuming the superficial appearance of seatrout, we have already noted that Mr. Calderwood found in the estuary of the Tay "large silvery common brown trout."

It is possible that the reader may seek to find some evidence of the theory here discussed in the waters with which he as an angler is familiar. I have myself sought for some such evidence, and it occurs to me that the theory may have some bearing upon the diversity of appearance which marks the trout in the area drained by the river Clyde, an area which, according to the Bathymetrical Survey, includes the Loch Lomond and Leven drainage area. The diversity is strongly marked between the trout which inhabit the river Clyde above the Falls of Clyde and those which one finds in the Loch Lomond basin which drains into the Clyde estuary.

Accepting Mr. Regan's proposition that our British trout, nonexistent during the Ice Agc, originally ascended from the sea, it is easy 
to explain the presence of trout above the Falls of Clyde by assuming that the stock ascended the river before subsequent elevation of the land and denudation combined slowly formed the now impassable barriers of Stonebyres, Corra Linn and Bonington Falls, and so isolated the trout of the upper waters. The trout above these falls are uniformly yellow, beautifully marked with brown spots and are, whether old or young, as unlike any fresh-run, silvery sea-trout in general superficial appearance as it is possible for any trout to be. On the other hand, for thousands of years migratory trout must have had free access to the Loch Lomond basin, which, in a comparatively recent geological period, has been a sea-loch, and is now only 26.9 feet above mean sea-level, being connected by the short even-flowing Leven with the Clyde estuary. But in contrast with the trout of the upper reaches of the Clyde, hardly any trout are so likely to be mistaken by the angler for sea-trout as are the trout of Loch Lomond. Indeed, in the later months, when sea-trout which have been in the loch for some weeks have lost their silvery sheen, they approximate in appearance so closely to the native non-migratory trout that it is difficult, even for experienced anglers, to distinguish between them. In spring it is a practical impossibility to distinguish young trout of two or three years old from sea-trout parr of equal age. I have been able to discover no features, beyond some small presumptive differences of colouration, by which one kind of fish can be distinguished from the other, and boatmen with life-long experience will seldom undertake to say with any assurance which is which.

The inference would seem to be legitimate that once the barrier on the Clyde reached a certain height, and trout, though many might descend, were barred from returning, the stock in the upper waters began to revert to the original type of fresh-water trout, or at least to develop along lines of colouration adapted to its isolated fresh-water environment, and has for centuries been so developing; while, as regards the 
Loch Lomond trout, there having been an uninterrupted coming and going for centuries from and to the sea, the stock has retained all the marked outward characteristics of the migratory fish. But so far as structure and outline are concerned the isolated trout from above the Falls of Clyde differ in no respect that I can discover from the trout or sea-trout below the Falls.

It may of course be objected that the strain of each distinct species in the loch (assuming for the sake of argument that the migratory and non-migratory fish are distinct species) has been affected by interbreeding over long ages, and that each has in consequence approached closely in its general characteristics to the other without wholly losing its proper individuality. But as to this matter of the crossing of breeds, in his great work "On the Origin of Species," Darwin makes this pregnant observation:- " The possibility of making distinct races by crossing has been greatly exaggerated . . . Certainly, a breed intermediate between two very distinct breeds could not be got without extreme care and long-continued selection; nor can I find a single case on record of a permanent race having been thus formed." He also states:- "It is difficult, perhaps impossible, to bring forward one case of the hybrid offspring of two animals clearly distinct being themselves perfectly fertile." We all know, moreover, his views as to the origin of our various breeds of pigeon:- "Great as the differences are between the breeds of pigeons, I am fully convinced that the common opinion of naturalists is correct, namely, that all have descended from the rockpigeon (Columba livia)," a passage which it is interesting to contrast with another written two hundred years earlier, to this effect :- "And you are to note, that there are several kinds of trouts: but these several kinds are not considered but by very few men; for they go under the general name of trouts: just as pigeons do, in most places." The reader may be referred, for the rest of the passage, to Izaak Walton, his book. On the whole, it would seem to be more in accordance with 
reason to adopt at once Mr. Regan's view that there is only one species of trout involved of which some unknown proportion in the Loch Lomond basin is migratory in its instincts and some unknown proportion non-migratory at any given point of time.

That the native trout of Loch Lomond descend to the Clyde estuary is proved by the fact already mentioned that they are sometimes caught in the estuary salmon nets, and I gave one instance of a trout taken in the loch which, having sca-lice on it, may be presumed to have so descended and then returned. If the objection is made that the mere fact of the migratory and non-migratory trout being distinguishable, even with difficulty, is an argument for, and not against, there being two distinct species or races involved, it may be answered that it has never been pretended that trout habituated to a salt-water environment do not differ greatly from trout habituated to a fresh-water environment in their exterior aspect.

But it may be said that, after all, it is not enough to prove that one sea-trout ceased to migrate and that one trout acquired the habit of going to the sea; what has to be proved is that a particular nonmigratory trout at some time adopted the migratory habit which thereafter persisted in itself and its descendants, or, on the other hand, that any particular migratory trout ceased to migrate and thenceforth with its descendants remained satisfied with its fresh-water environment. Such proof would no doubt be final, but I do not think that Mr. Regan's six points of evidence are conclusive. It seems to me, however, that taken together they give grounds for a strong presumption that there is no real distinction in structure or other material respect between certain of the migratory and all of the non-migratory trout, and that some of the offspring of any pair of either class may at any time develop the migratory instinct in an extreme degree while the rest may remain content with their environment. In the chapters which follow I think 
I shall be able to submit facts which at least suggest that such variation of habit is by no means impossible or even improbable.

This introductory chapter has already grown to an unconscionable length, but there is one other vexed question upon which some general comment must be made, and I crave the reader's patience.

Mr. Regan's dismissal of the migratory habit as an indication of species, or even race, leads him to the conclusion that the trout is a sea-trout. I have for my part suggested that certain sea-trout may just as probably be trout, but whichever view is taken will not affect the discussion which follows.

Mr. Regan states:- "Two races of Sea-trout may be recognised, although in many cases it is impossible to say to which race an individual may belong unless one knows beforehand where it comes from," about which statement there is a curiously Hibernian ring. "However," he continues, "the Sewen (S. cambricus) of Wales, Ireland, and our Western coasts often differ from the Sea-trout (S. albus) of the east coast, in having a longer head, a larger mouth with stronger jaws, the suboperculum projecting backwards beyond the operculum, and the fins somewhat larger, the lobes of the caudal especially being more produced. When typical examples of the two races, of the same size and sex, are compared, these differences may be seen, but they are slight, and not always apparent." And he elsewhere states:- "Some trout appear to go farther out to sea and to grow more quickly than others, and this is especially the case with the trout of certain rivers such as the Coquet and the Tweed; in the latter, sea-trout more than four feet in length and weighing nearly 50 lbs. have been captured."

Now Mr. Regan had no wish to detract from the weight of his main thesis, "that there is only one species of trout" in the British Isles, but he was puzzled to account for the "bull trout," and so he seems to ascribe it to a barely distinguishable race. Other systematists, in much the same way but more elaborately, have drawn a distinction between 
the broad type $S$. Irulla and a southern variety, S. Imutta (criox) for the migratory fish; and between $S$. fario (Gaimardi) and a southern variety, $S$. fario (Ausonii), for the non-migratory trout. But the "bull trout" is not yet, I think, thercby explained.

There is no reason to believe, nor is there any evidence, that since the prehistoric glacial cpoch changes have occurred in the types of migratory trout which became localised in British waters. As the types were then we may suppose them to be to-day. While it is no doubt true that there existed great river basins in the European plateau, whereof our islands are a fragment, and of which ancient rivers our greatest streams are, it is believed, but the surviving upper tributaries, or at least extensions of these tributaries, the plateau had a comparatively uniform sea-board on which the ancient rivers debouched. One need not therefore ascribe to each ancient river specific races of trout. But I think a fair analogy may be drawn between our modern trout and those prehistoric fish in this respect. Just as to-day there is great external difference between the trout of one locality and the trout of another locality, to such a degree that one can hardly allege the trout of one river area to be exactly like the trout of any other river area, so the trout of the ancient Rhine which flowed northwards over land which now forms the bed of the North Sea, the trout of the "Irish Channel River" which flowed southwards, and the trout of the "English Channel River" which flowed westwards, may quite well have had distinctive external characteristics. It is not a very extravagant speculation that some of the local characteristics of these prehistoric fish may survive to this day, and that, for instance, the trout of the Tweed and the Coquet, the Haddington Tyne and the Northumberland Tyne, the Forth and the Aln, all, we may suppose, connected with the ancient Rhine system, may still possess them.

But setting speculation aside for the moment, the best scientific opinion does not appear to concede the "bull trout's" claim to be a 
distinct species of trout. Dr. Günther, the great ichthyologist of the British Museum-I quote the Rev. W. Houghton, who published a book on "British Fresh-water Fishes" in 1879-wrote thus:- "No distinct species is designated by this name (Bull Trout); at all events the name is applied to different species at different localities, and by different persons. We have received numerous examples of 'Bull Trout,' each of them of a peculiar aspect, but without any characters by which the species could be determined. It would appear that many examples somewhat differing in general aspect from $S$. trutta are named Bull Trout."

In the year 1910 I had the honour of receiving a communication on this subject from Mr. Boulenger, already quoted in a former work of mine. " "I do not admit the 'bull trout' even to the rank of a variety," he wrote, "From a scientific view, the only one with which I have any right to speak, the designation 'bull trout 'should be entirely dropped." Dr. Day, in his "British and Irish Salmonida," had already negatived. the idea of any specific distinction. Mr. Calderwood, however, concedes the distinction of being at least a "variety" to the bull trout. In his book on "The Salmon Rivers and Lochs of Scotland," published in 1909, he incidentally remarks:- "The sea-trout of the Tweed is now almost exclusively the bull trout or round-tail, S. trutta var. eriox, the same fish as ascends the Coquet," and he had already, in a paper read before the Royal Society of Edinburgh given a more particular account of the fish. ${ }^{2}$

A great deal of confused and somewhat confusing "evidence" on this subject was listened to by the Royal Commissioners of I902, and is to be found scattered throughout the volume of evidence appended to their report. It is vague and contradictory in the extreme, and the reader who is curious enough to examine it will find some entertainment

1. "The Gentle Art" (1911). Chap. XVI. "Concerning Definitions," p. 295.

2. "The Bull Trout of the Tay and of Tweed." by W. I. Calderwood. Reprint from Proceed. ings of the Royal Society of Edinburgh, Session 1903.4, Vol. XXV, Part I (1904). 


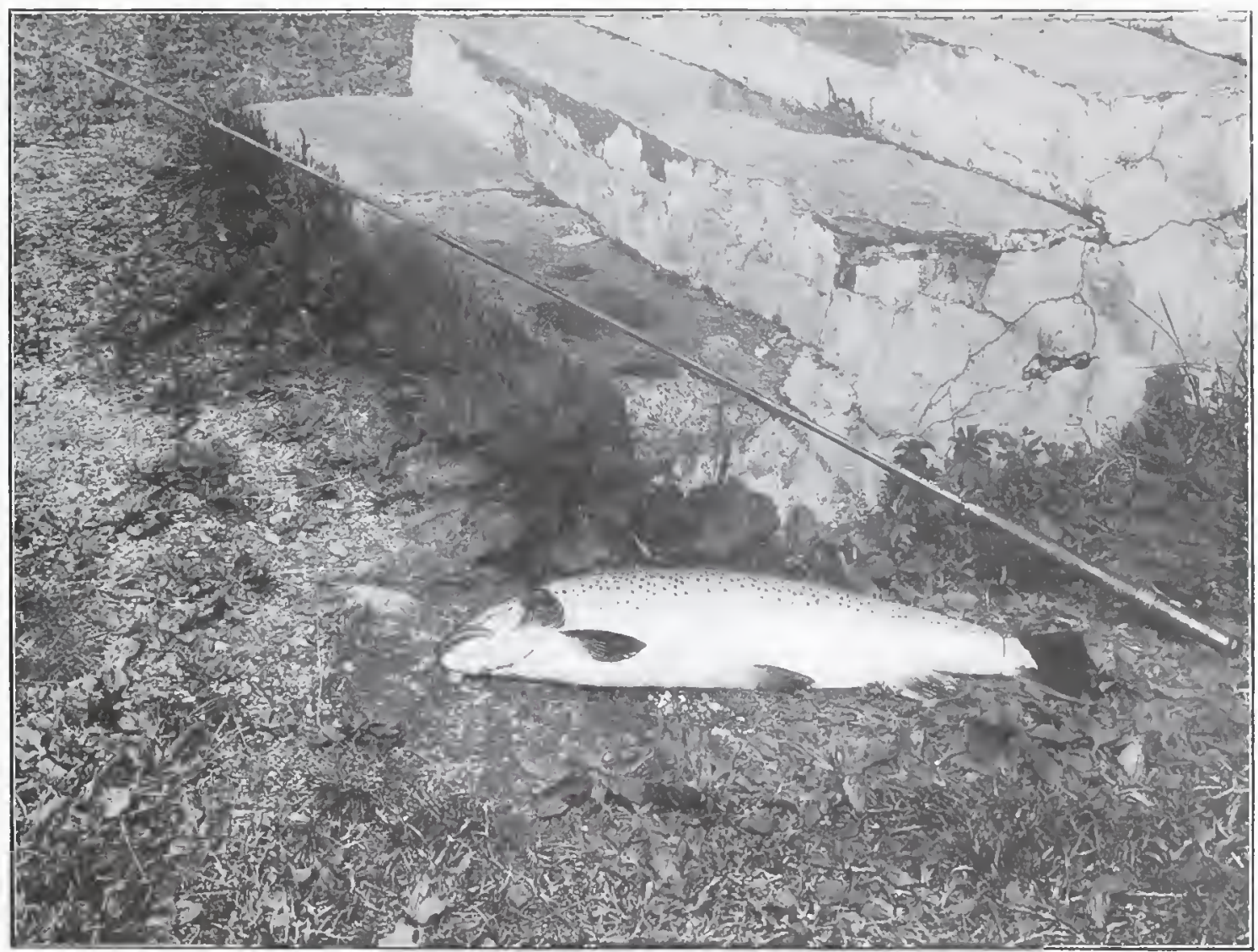

"Fresh Run from the Sea." 

in endeavouring to reconcile the statements of the different witnesses.

Perhaps the views of anglers should be received with caution, but I may submit this opinion concerning Tweed "bull trout" given me by an angler residing on Tweedside, who is himself a close student of fish and their habits and from whose pen any work on the Salmonida would be of great value. "I am afraid I am not an authority on the subject," he modestly wrote me, "but I hold that sea-trout, salmon-trout, and bull-trout are one and the same fish. They vary very much in size only-from $\frac{1}{2}$ lb. to, say, 25 lbs." So, too, Mr. John James Hardy, of Alnwick, wrote me when I inquired if he could furnish me with a characteristic photograph of an Aln or a Coquet "bull trout" :- "The trouble is that my opinion is that the Coquet so-called bull trout is only an overgrown sea-trout; that there is no difference between the bull trout and the sea-trout, and that Salmo criox exists only in imagination." It is difficult to get over the fact, however, that as far back as the time of Izaak Walton, the "bull trout" was a noticeable fish. "There is also," said his Piscator, "in Northumberland a trout called a bull trout, of a much greater length and bigness than any in the southern parts"; and Walton's detailed description of the "Fordidge" trout differs in no essentials from a modern description of the "bull trout," of which it may generally be said, if one be caught, that "that trout bit not for hunger but wantonness."

This subject is of course one which is frequently dealt with in current angling literature, and in the pages of "The Fishing Gazette" and "The Field" one finds constant references to the "bull trout." I have often curiously examined accounts of the fish to see if there is any recognisable distinction between them and sea-trout. but it is not easy to find anything in their habits that distinguishes "bull trout" from big sea-trout, and not much more in their appearance than a more pronounced convexity of tail.

It seems to me, therefore, admitting the characteristic of the "round 
tail" to be a more frequent feature of eastern sea-trout than western sea-trout, that there is no more warrant for claiming the "bull trout" as a separate species, or even race, on account of its round tail alone, than there is for making such a claim on behalf of the tailless trout of Loch-na-Maorachan, in Islay, or the "bull-nosed" trout of which some reservoirs can show a high percentage. Conclusive evidence of distinction must be sought along other lines.

I have, personally, an open mind on this really important subject, and would be glad if it could be scientifically settled once for all. It seems to me that careful scale examination may help to solve the difficulty, and later in these pages I shall give more precise reasons for so thinking. In the meantime it is enough to say that there may quite well be a distinct race, or even species, of sea-trout which has nothing in common with ordinary fario, except that, like the salmon, it spawns in very much the same way in our rivers, while at the same time there may be another race, or species of sea-trout, in reality ordinary fario, of which some individuals retain and some lose the migratory habit, its retention or loss being at any time entirely dependent upon the nature of the fish's environment. There is really nothing definite known of the matter, but I can easily imagine that naturalists might yet come to agree that there are suficiently distinctive points of difference to justify the grouping of three species, namely (I) the salmon ( $S$. salar), (2) the migratory true sea-trout (S. trutta) -in other words, the "bull trout"- and (3) the trout (S. fario), which last may be. indifferently migratory or non-migratory.

I may conclude the whole discussion with Dr. Day's remark:- "If, as seems probable, we merely possess one very plastic species subject to an almost unlimited amount of variation, that its largest race is found in the ocean, while in order to breed it ascends streams, but usually (to which there are many exceptions) not so far as the salmon, unless it permancntly takes up its abode in the fresh waters, we at once obtain a 


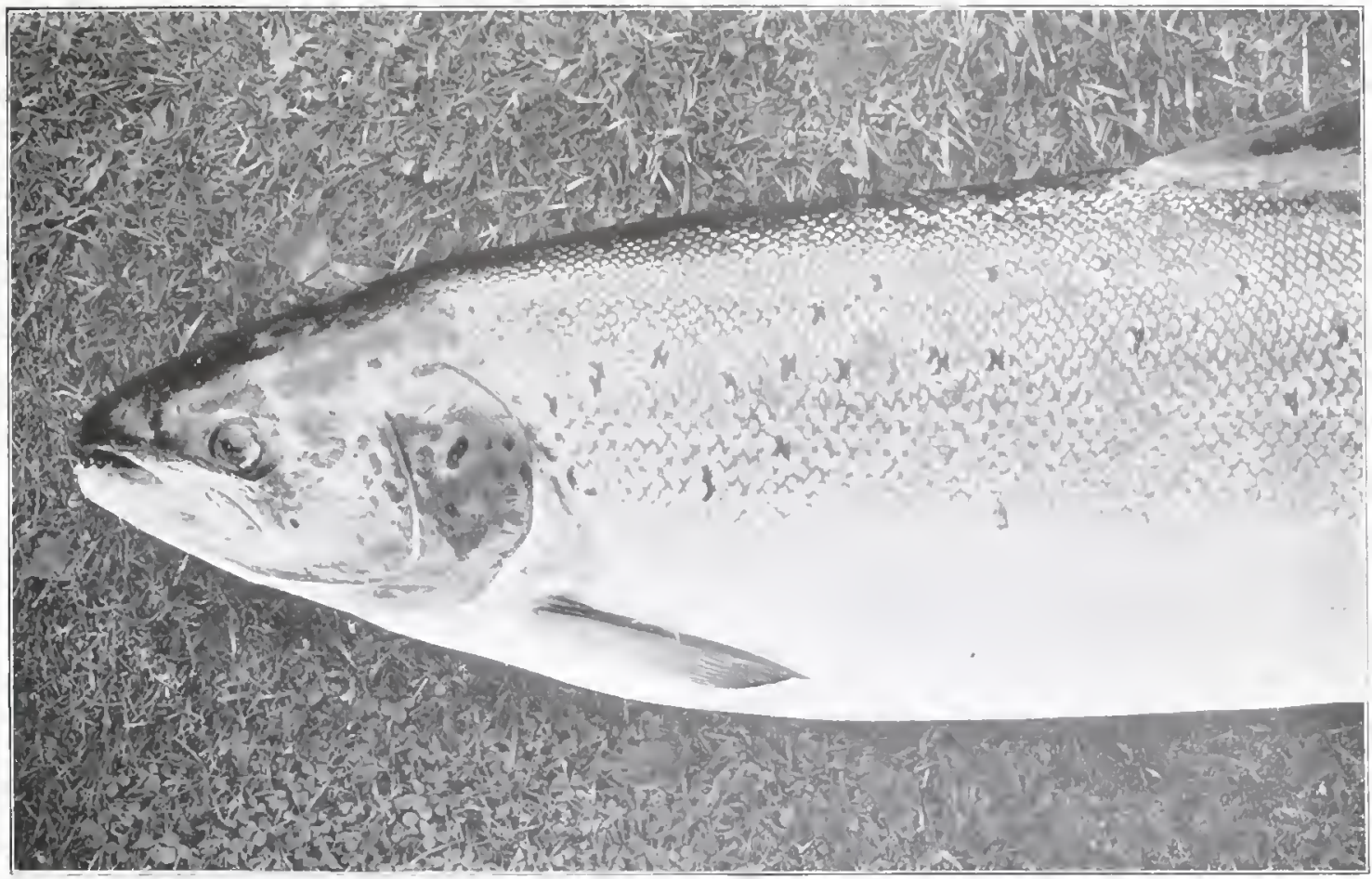

Fig. 1.-A Salmon, showing normal spots of the "maiden" lish.

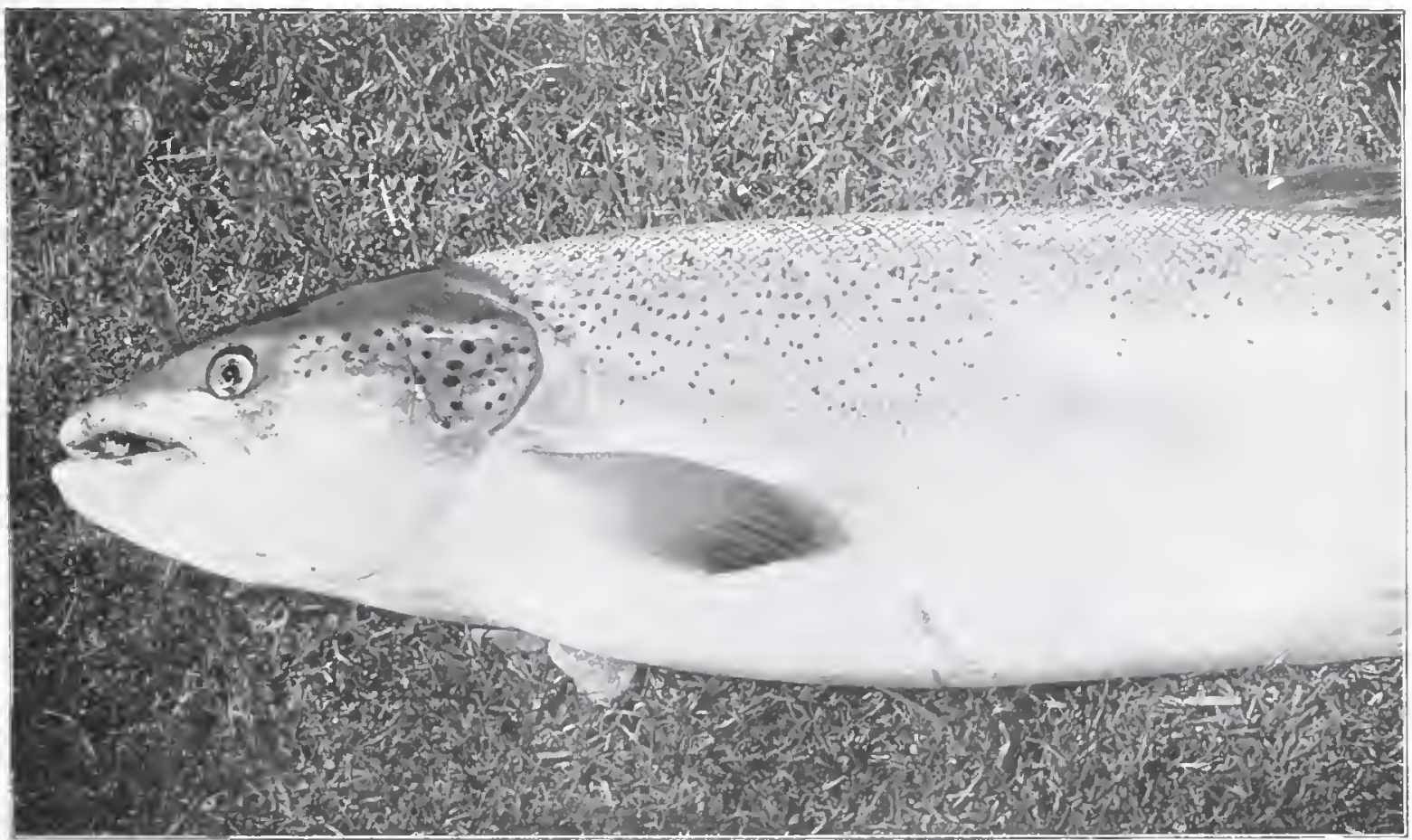

Fig. 2.- 1 Salmon, showing speckled appearance of a fish which has previously spawned. 

clue to the characters of the various so-called species, and relegate these different trout to a single form, in which numerous local races are to be found." This is, of course, a very easy way of evading all difficulties, but it does not dispose of them. I think the facts rather point to such a differentiation as I have suggested above.

What purpose would the solution of such problems as I have here considered serve? One never can tell of course in what direction definite knowledge may ultimately prove useful. Something at least is gained by the mere fact that the knowledge is definite. But there is this further consideration. It has for some years been apparent that the stock of sea-trout in once well-stocked waters has markedly declined. Even as long ago as I904 "The Spectator" feared that the fish was "doomed to a not very remote extinction"; and as recently as August 1914, there appeared in "The Salmon and Trout Magazine" a susc stive article on the decline of "White trout" fishing in Ireland from the pen of that well-known writer "Corrigeen." Mr. Calderwood also notes a general decline in the stock.

If there is anything at all in the theory that there is any one, or only one, species of trout in these islands whereof at any given point of time a certain proportion is migratory and a certain proportion non-migratory -the migratory habit per se in either case not being an indication of "species" or even of "race"- -then it necessarily follows that the innumerable causes which have brought about a depletion of the stock of trout in our once prolific rivers must be added to the many other causes which have made for depletion in the ranks of the sea-trout. If trout cease to exist in their pristine numbers in the main streams and upper tributaries, whence, it may be asked, are the ranks of the seatrout of the estuaries to be reinforced?

It is plain that such a question as this is far-reaching in its consequences, for it at once opens out the further question whether our fresh-water fishery laws dealing with trout have not been improperly 
divorced from the laws concerning the migratory fish embodied in the salmon fishery statutes; or, one might put it alternatively, whether the laws concerning the sea-trout are not too exclusively restricted to the region of salmon fishery legislation. I began with an examination of the legal view of the sea-trout and I find myself inevitably led back to it. The truth is that if any species of fish is to survive in these modern days, legislation concerning it must be based upon reason and a full understanding of the life-history and habits of the species.

I have in this introduction made free use of the views of Mr. Regan as set forth in his excellent book. I hope I have made it clear that I have not been influenced, in discussing these views, by any spirit of captious criticism. It will be quite apparent that I have no qualifications to criticise them beyond those which any thoughtful reader may possess. His book is the most recent work with which I am acquainted which can pretend to be of any scientific authority on the subject of British fresh-water fishes, and such observations as he makes upon the trout have been for me a convenient text upon which to discourse more particularly concerning the sea-trout.

To conclude-while one may very well accept the theories which guide scientists to the systematic classification of a species, there is no occasion to rest a description of that species on scientific classification alone. The angler will not perhaps concern himself overmuch whether the migratory and non-migratory trout constitute different species or no. He will concern himself chiefly with the appearance and habits of the sea-trout as a migratory fish so long as it retains such appearance and habits. These are in any case sufficiently marked to warrant a separate description being given of them. It is necessary to add that the description which I shall endeavour to give in the following chapters applies more particularly to the type of sea-trout which is commonly found in our Western waters rather than to the type which, as the "bull trout," has earned for itself a certain notoricty in our Eastern streams. 


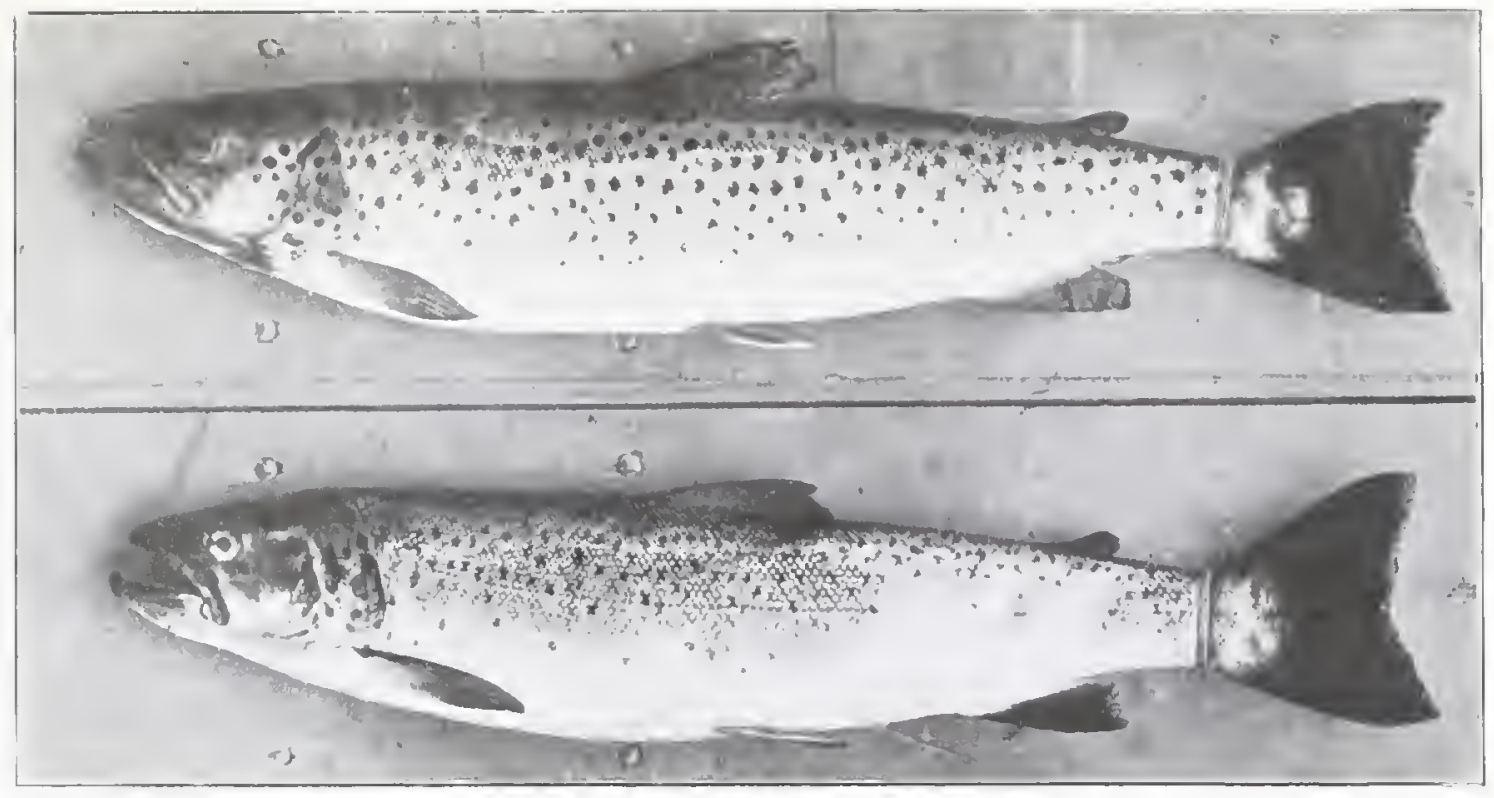

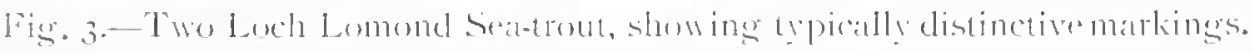

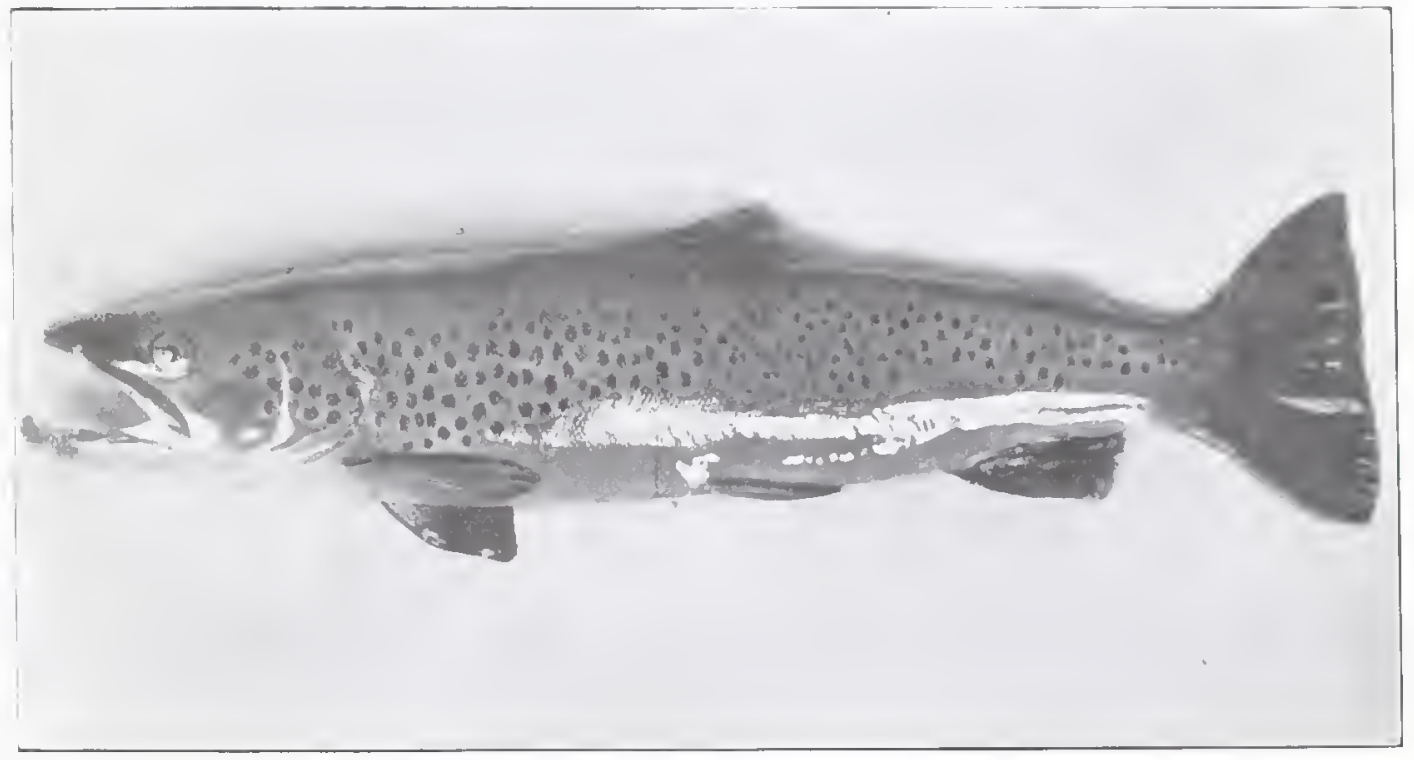

Fig. +. - I male Sut-trout at spawning time. 

The Sea-Trout 


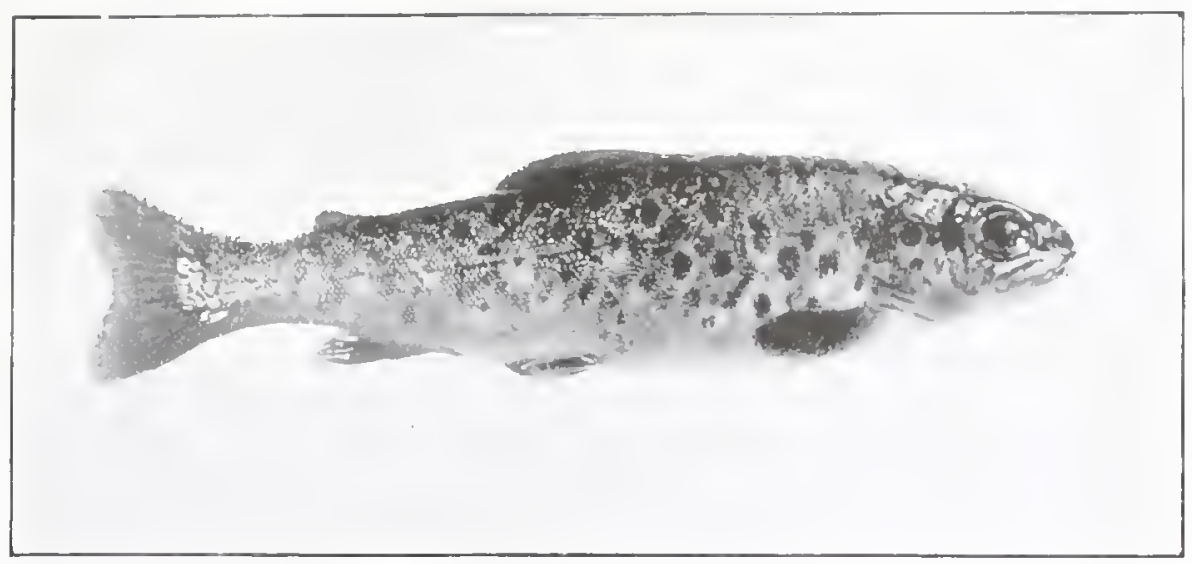

Fig. 5.-A " two year old " Trout (fario), with " hato" surrounding the spots strongly accentuated.

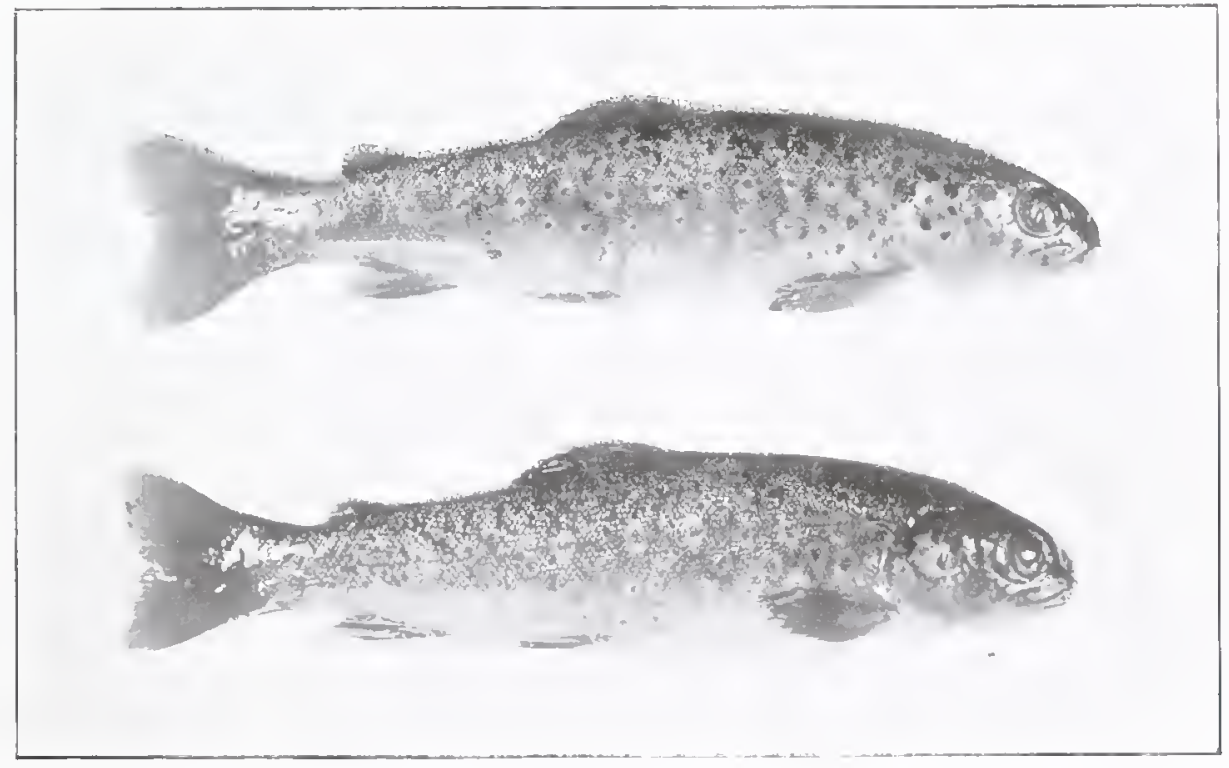

Fig. 6.-" Two year old" Trout (furio), showing normal markings. 


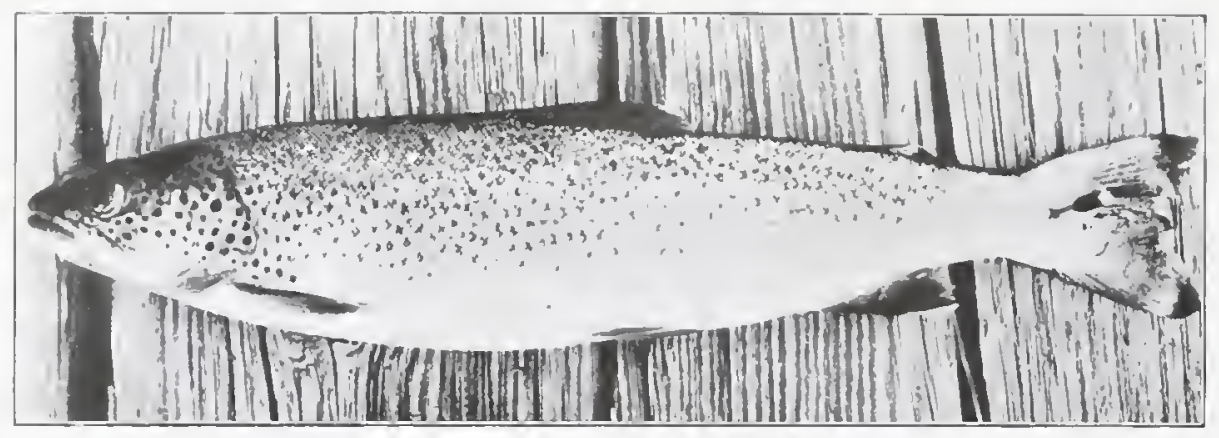

Fig. 7.-. I Vormegian rive Trout (jario).

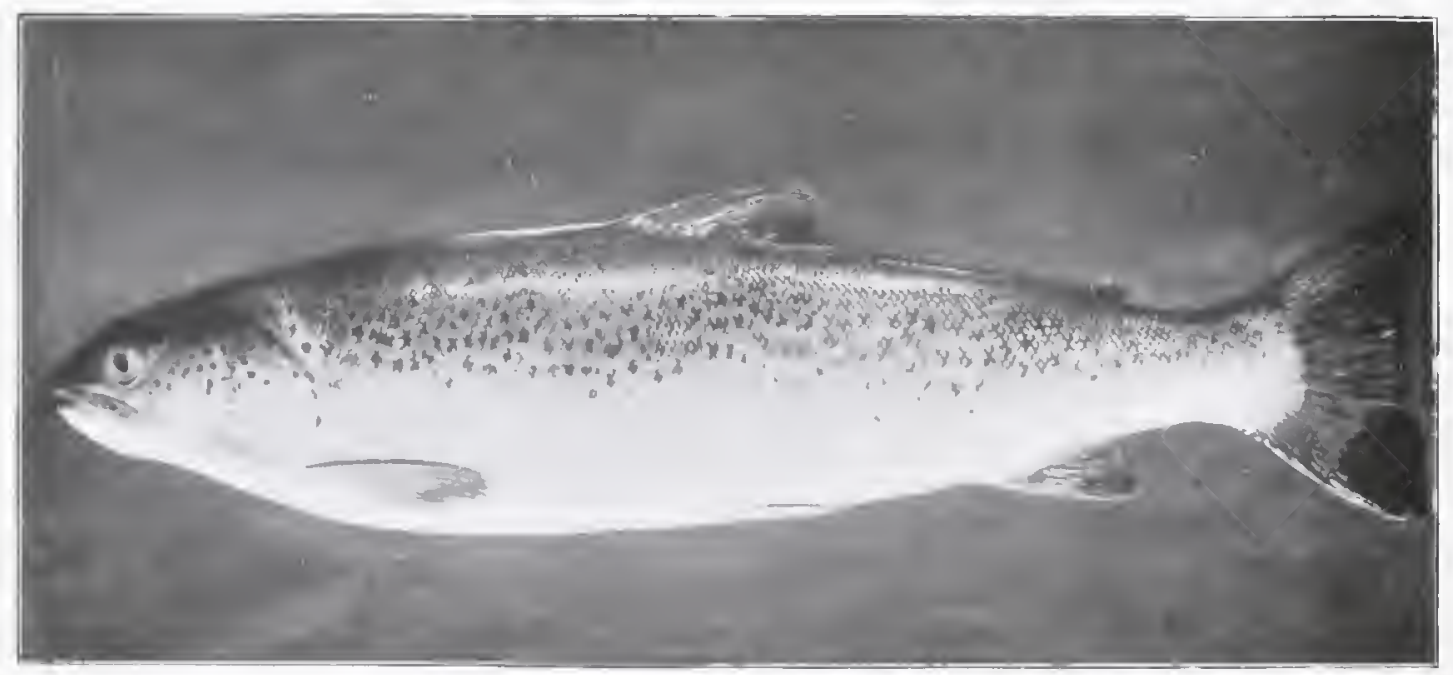

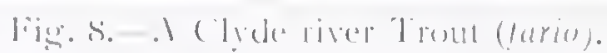




\section{CHAPTER II.}

\section{THE SEA-TROUT.}

"There are three beauties in death," runs the Gaelic saying, "a sea-trout, a blackcock and a young child." Of these, it will be observed, the sea-trout is ranked first, with how much of justice will be a matter of opinion. There can be no question, however, that an adult sea-trout of three or four pounds in weight, killed when fresh run from the sea, is one of the most beautiful objects in nature, suggesting, as it does, in its general outline and appearance, the perfect adaptation of physical form and harmonious colouring to habits and environment.

In beauty of shape alone the sea-trout perhaps stands midway between the salmon on the one hand and the trout on the other. The neater head and more slender tail of the salmon give to that fish a grace which the sea-trout with its more sturdy build cannot rival, and yet the latter as far excels most trout in its suggestion of compact elegance.

In colouration, too, while emulating each of the others, the sea-trout occupies a middle place, for, if it cannot vie with the splendour of the blue and silver mail of the salmon, it adds to its sheen the distinction of more characteristically varied markings. On the other hand, although few trout can approach the silvery brightness of the fresh-run sea-trout's scales, many of them far out-rival it in the colour and number and variety of their spots. On the whole it may be said that the seatrout successfully unites in its person the brilliance of the salmon and the more variegated beauty of the trout.

The sea-trout, like other members of the family Salmonida, is an inhabitant of the waters of the Arctic, sub-Arctic and Temperate zones of the Northern Hemisphere. Its exact range it would perhaps be not easy to define, but one might say generally that wherever there are trout 
found in the streams of those countries lying northwards of the Straits of Gibraltar, sea-trout will be found in their coastal waters also. But the success of modern experiments in the transplanting of trout ova has been so remarkable that the range of trout has been extended to the Antipodes, India and Africa, and in New Zealand at least a race of migratory trout has sprung from the transplanted stock which-as many of the facts noted in this book will suggest-is to all intents and purposes now a race of sea-trout.

In the British Islands, it is certain, the sea-trout is indigenous to all our coasts, and particularly it exists in enormous shoals on the western coasts of Ireland and round all the coasts of Scotland, both of the mainland and of the islands, wherever access can be gained from the sea or estuary to suitable inland spawning grounds. It is reasonable to assume that the absence from our rivers of impassable obstructions and serious pollutions is a condition necessary to the presence of seatrout in them and their estuaries. How far the destruction of trout in our streams from one cause or another will affect the stock of sea-trout is a problem which has already been touched upon.

It is not easy to state precisely what weight a sea-trout may attain to. The size of the fish appears to vary greatly according to the type of waters in which it has been bred and the type of coastal waters to which it may migrate. But the factors of fceding and spawning largely affect the rate of growth, and I think it would be difficult to discover any fixed rule. I have not the least doubt, too, that the problem of weight has been confused by some of those salmon which for brevity may be designated "Tay bull trout," having been recorded as sea-trout before their identity was so well cstablished as it is now. Further, the fish which has more claim to be called a "bull trout" grows to a considerable size, and it is not always easy to discover which class of sea-trout is in question when any record of weight is cited. Mr. Regan, discussing trout generally, refers th them as attaining a wcight of $40 \mathrm{lb}$., 

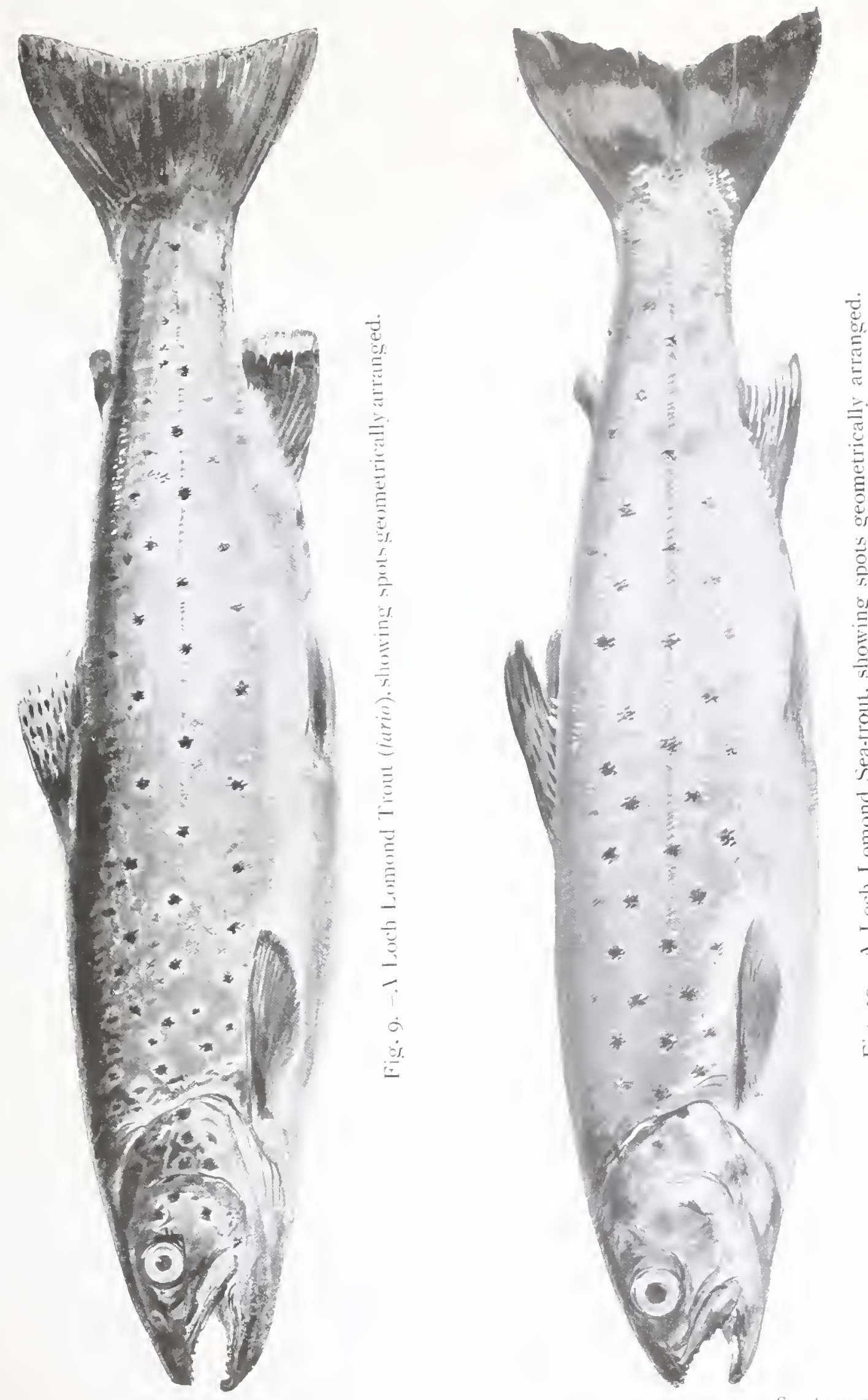
but no particulars of individual specimens are given by him. Then a Tweedside angler, who favoured me with his views on "bull trout," puts the limit of weight of these Tweed fish at $25 \mathrm{lb}$. Mr. Malloch usefully gives a photograph of a sea-trout of $19 \frac{1}{2} 1 \mathrm{~b}$., the "largest ever caught in the Tay." I have personally seen a sea-trout of ' $12 \mathrm{lb}$. which was caught with the rod in Loch Lomond, and specimens are sometimes taken in the Clyde estuary nets which weigh as much as $15 \mathrm{lb}$. But I do not know of any statistics which give reliably the weights of the heaviest specimens known to have been caught in British waters. ${ }^{1}$

The limit of age is even more difficult to arrive at. So far as I am aware there are no authentic records in the case of sea-trout. It will be seen that on a later page (page I43) I submit evidence from the scales of a Loch Lomond fish, which weighed only $2 \frac{1}{2} \mathrm{lb}$., that its age was actually as much as eleven years. The fixing of any definite limit of age with our present knowledge is probably yet a matter of pure surmise. Mr. J. A. Harvie-Brown speaks to having seen a trout nineteen years old. It had been kept in confinement for that time. ${ }^{2}$

There are some points of interest connected with the spots of salmon and sea-trout which I may here conveniently indicate. The dark spots of the salmon are, in fish which have not previously spawned _."maiden" fish as they are commonly called-few and irregular in shape. They are (Fig. I) on the body, mostly scattered above the lateral line with a few of intense black on the cheeks. In a fish which returns to spawn a second time the spots are now recognised to have undergone considerable change. They have become much more numerous (Fig. 2), and suggest the appearance of having been lightly sprinkled on the surface of the shoulders and sides. Until recent years these peculiarly speckled fish were thought to be a kind of "bull - trout," and, from the fact of their being frequently seen in that river, they were popularly known as "Tay bull trout." The Tay fish,

1. Day instances a Tweed male bull-tront of $44 \mathrm{lb}$. caught in 1868 .

2. "The Wonderful Tront" (1898). p. 16. 
weighing $42 \mathrm{lbs}$. and $40 \mathrm{lbs}$, referred to by Sir Herbert Maxwell on page 194 of his book on "Salmon and Sea Trout," and accepted by him as being "bull-trout," were no doubt really salmon of this class. Mr. H. W. Johnston, Mr. W. L. Calderwood, and Mr. P. D. Malloch have amongst them proved that these large speckled fish are true salmon which, having spawned in a former season, are now returning from the sea to spawn a second time. I have not observed that the spots of sea-trout undergo any similar modification consequent on spawning.

The variation of the sea-trout's markings, in the size and pattern of the spots, is endless. The two types shown in Fig. 3 are as distinct as well can be. They are both male fish, weighing $2 \frac{1}{2} \mathrm{lb}$. and $2 \frac{3}{4} \mathrm{lb}$. respectively, and were caught by two angling friends on the same day in Loch Lomond. The spots are generally, but not always, more numerous than those of the salmon, while the dorsal fin of the sea-trout is also commonly spotted, a distinction not shared by the salmon. I have even seen the upper lobe of the tail of a heavy male sea-trout spotted, but this was when it was in full spawning livery. At normal times the tail seems to be more generally fringed with a dark bar plainly noticeable in the swimming fish. The regularity of this bar was a feature of the fish which I used as a model for the frontispiece of this book (Plate I). The spots of a fresh run sea-trout are markedly cruciform, or X-shaped (Fig. 3 (2)), but not invariably so, and many occur below the lateral line, but as spawning time approaches, the spots tend to become blurred and, in the male fish especially, other spots not visible on the scales of the fresh run fish begin to show as the fish changes colour. (Compare Fig. 4 with Fig. 3(I)). This discoloration in the sea-trout, as in the case of the salmon, may perhaps begin before a late running fish leaves the estuary, but I have not personally proved the fact.

The spots of trout are cven more diversified than those of sea-trout, 
and almost every water boasts its own variety and sometimes several varieties, of size, shape and pattern. A peculiarity in trout spots often observable is that each spot has round it a pale purple-coloured halo, a feature only observable in sea-trout parr and in the mature fish after it has become discoloured by residence in fresh water. In small trout (fario) this halo is often very clearly marked (Fig. 5). The specimen figured is a "two year old" fario which Mr. Jas. A. Muirhead kindly sent me from the West of Scotland Fishery, at Bridge of Weir. It was so boldly spotted as to be rather a remarkable specimen. The two trout also figured (Fig. 6) show the more usual appearance of the "two year old." The Norwegian river trout of 6 in. in length (Fig. 7), whose photograph Mr. Abel Heywood, of Manchester, has kindly given me for reproduction, may be usefully compared with the river trout $13 \mathrm{in.}$ in length also shown (Fig. S), which was caught above the Falls of Clyde in waters wholly inaccessible to sea-trout. The markings of these fish are similar to and may be compared with those of the seatrout in Fig. 3 (I) and Fig. 4. As having a direct bearing upon much that is discussed here and elsewhere in this book I have inserted two plates reproducing coloured drawings of sea-trout, one fresh-run from the sea (frontispiece) and the other a fish on the eve of spawning (Plate IX). As a rule it may be said that superficial markings have but little scientific significance in determining species, though with reference to the sea-trout's external appearance one must take account of them in a general description. It has, however, sometimes occurred to me that a careful comparison made between the spots of the trout and sea-trout respectively of various waters might help to shed a sidelight upon the theory that there is only one species of trout in these islands.

It is generally supposed, and I think with justice, that the spots and markings of tront may be attributed to protective colouration. This will vary greatly with environment, although Dr. Ward in his interesting book on the "Marvels of Fish Life as revealed by the Camera" points 
out that "food is an equally important factor in bringing about colour changes," and I have no doubt that sexual selection temporarily affects colour also; but I think we may neglect these latter factors altogether here. The immediate point is that when the sea-trout is in the sea his best protection will clearly be the unbroken mirror-like surface of his body, but when he returns to fresh water a reversion to more troutlike colouration will be his best protection if it serve no other purpose. It may therefore be more than a mere coincidence that the trout-like aspect becomes most marked as spawning time approaches when the fish is in the smaller spawning tributaries. I have already shown in my introduction that it is when a sea-trout has been some time in fresh water that doubts arise in the angler's mind as to whether it is a seatrout or a trout.

I understand that the "spot" is caused by local concentration of the colour cells in the skin-and this may account for the almost colourless halo observable round the spots of trout-but such concentration will be less necessary to the sea-trout while it is in the sea than while it is in fresh water. As the spawning season approaches, the exterior parts of the scales of sea-trout, as of salmon, disintegrate considerably, especially in the case of male fish, while at the same time the skin thickens so much that the scales become almost wholly embedded in it. Therefore the spots are accentuated on the skin of the sea-trout at this period and stand out boldly as they permanently do in the case of the trout.

I now arrive at the point to which these observations have tended. One of the commonest "patterns" on Loch Lomond trout is a single spot surrounded by others arranged in an exact pentagonal or hexagonal diagram (Fig. 9), so exact that each might have been geometrically drawn. Yet that is precisely the pattern of spots that commonly appears on Loch Lomond sea-trout (Fig. IO), a pattern that appears even halo-surrounded like a trout's spots at spawning time. It would 
be very suggestive if the sea-trout of any other rivers were discovered in their spots to reproduce at spawning time the typical pattern of the spots of the non-migratory trout of the district. Such a fact, if established, would suggest that the variety of marking of the sea-trout is infinite just because the variety of marking of trout is infinite, or, in other words, that the fish are really one species whereof some are migratory and some non-migratory.

The sea-trout, in common with the salmon and trout, has what scientists call a fusiform body "moderately elongate and compressed," as Mr. Regan puts it, "deepest at or in advance of the middle of the length and tapering posteriorly." It possesses the same number of fins as salmon and trout do, and they are similarly placed in relation to each other (Fig. I I).

The first dorsal fin projects from the ridge of the back midway between head and tail. In direct line with it and midway towards the tail is the second dorsal fin, generally called the adipose fin, the distinctive badge of all the family Salmonide. The caudal fin, or tail fin, with practically equal lobes above and below the middle line, completes vertically the posterior extremity of the body. The anal fin projects vertically downwards and, in the sea-trout, backwards, immediately behind the vent. The pelvic fins, which used more commonly to be called the ventral fins-and perhaps might still be so called with advantage - are set midway on the belly, as a pair, immediately below the first dorsal fin, and springing beside each of these is a little rudimentary, or, it may be, an aborted fin, making four fins in this group. The pectoral fins, having their origin on each side of the gullet behind the gill-covers, complete the number of ten fins which salmon, sea-trout and trout possess in common.

One may revert to Mr. Regan's scheme of classification for such special structural features as characterise the genus Salmo; but in many matters of unscientific import salmon, sea-trout and trout bear so much 
of a general resemblance to one another that occasionally it happens that doubts arise as to the species of an individual. It may therefore be of some service to put on record here such marks of structural distinction between the species as have been found to be generally constant and more or less easily recognisable. To contrast, then, S. salar with $S$. trutta:-

"Of characters which distinguish Salmon from Trout," Mr. Regan says, differentiating broadly, it will be observed, between salar and trutta, "we may note that the dorsal fin has usually more rays (Io, exceptionally 9, to 12 branched rays in the Salmon, 8 to ro, exceptionally I I, in the Trout), and that the scales on the tail are larger, in an oblique series from the posterior edge of the adipose fin downwards and forwards to the lateral line numbering Io to 13 in the Salmon, I 3 (exceptionally I2) to 16 in the Trout." These figures, Mr. Regan explains, are based on an examination by him of more than a hundred examples of each species, and he states that these numerical differences are of special importance because they are not subject to change with the growth of the fish. It may occur to the reader that if the salmon's branched rays range between 9 and I 2 and the trout's between 8 and II, any fish that possesses Io may, for aught anybody can tell, be either a salmon or a trout, especially if it has at the same time 13 scales in the oblique line indicated, which, according to Mr. Regan, either species may have. But of course there are other features which help to supply corroborative evidence, in doubtful cases, for one opinion or the other.

"In a Salmon," continues Mr. Regan, "the tail is more constricted at the base of the caudal fin than in a Trout, and consequently the anterior caudal rays form more of a shoulder, so that a Salmon does not slip through the fingers when grasped round the caudal peduncle, but a Trout usually does; the caudal fin is more or less emarginate, or in large specimens truncate, or even rounded, but is usually more distinctly notched than in Trout of the same size." 


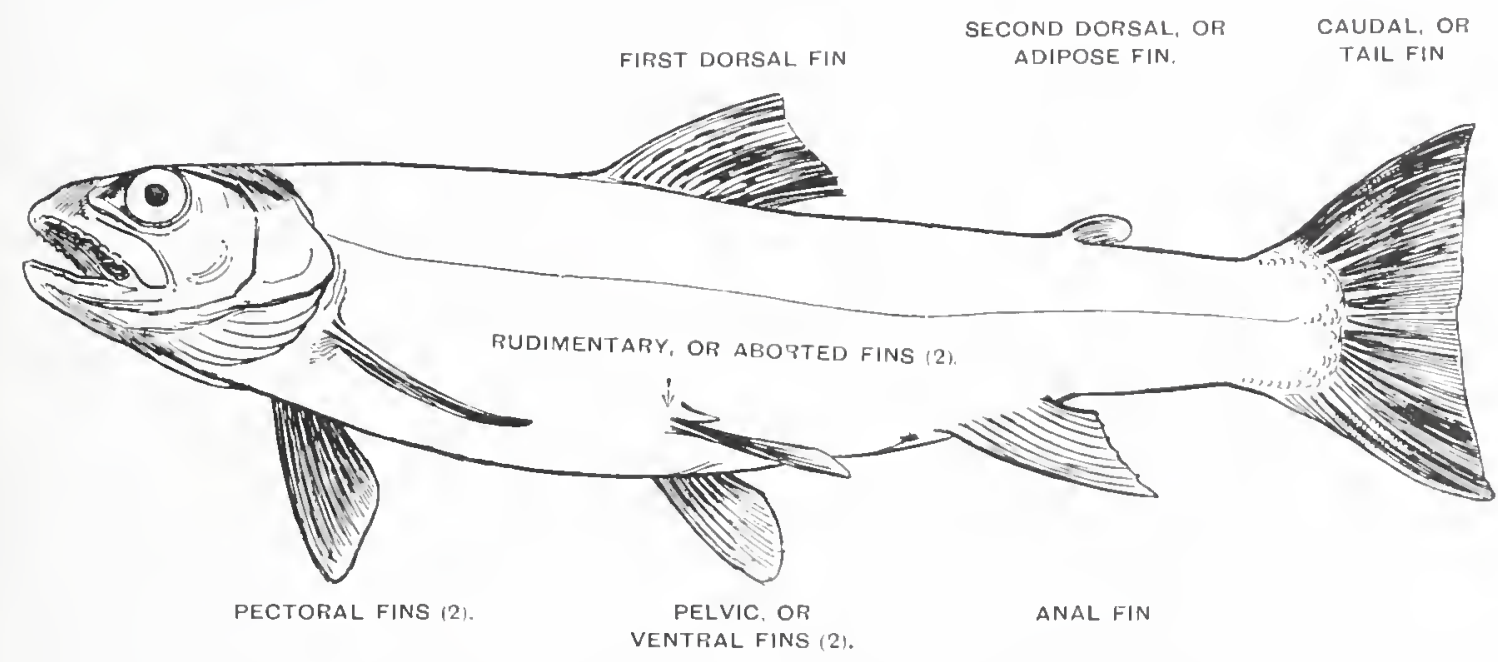

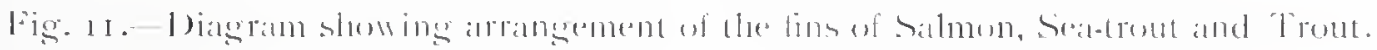




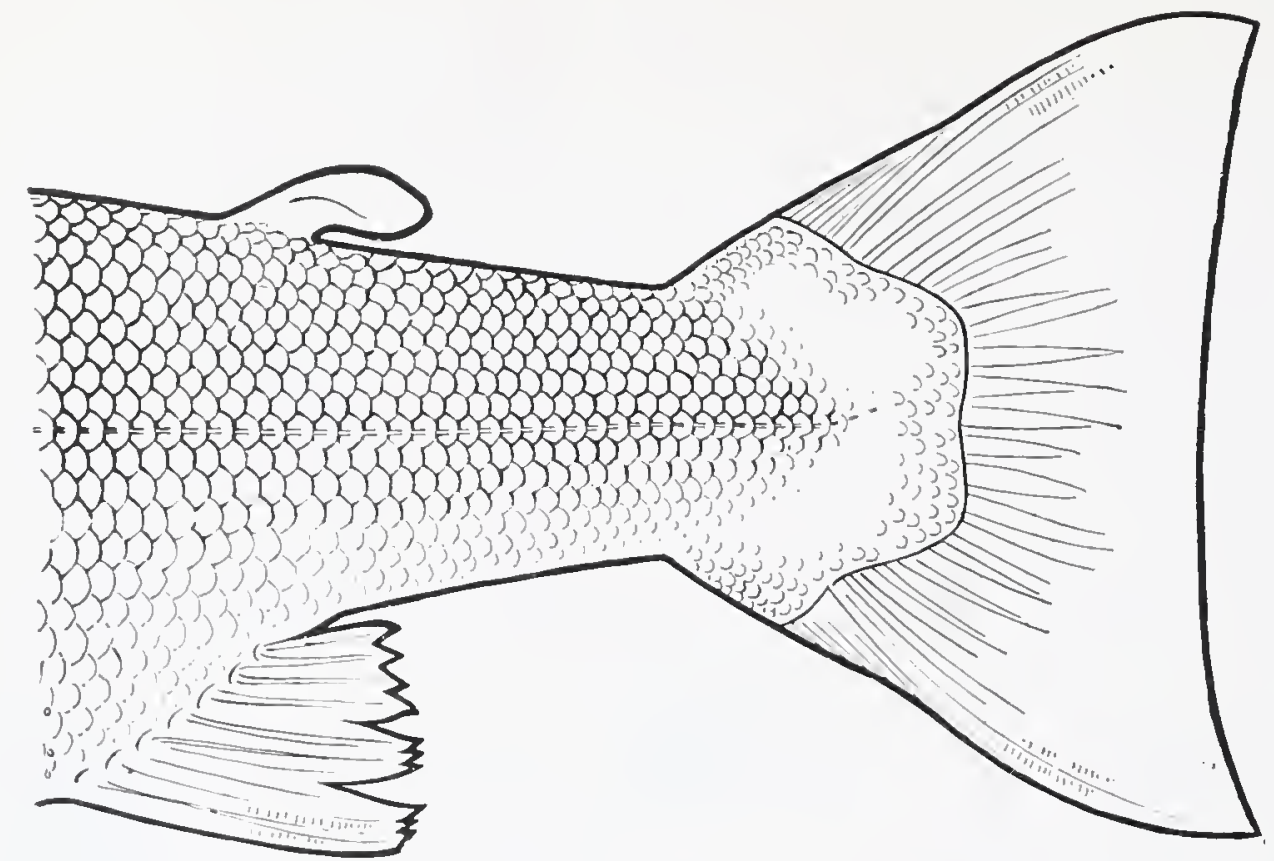

(1)

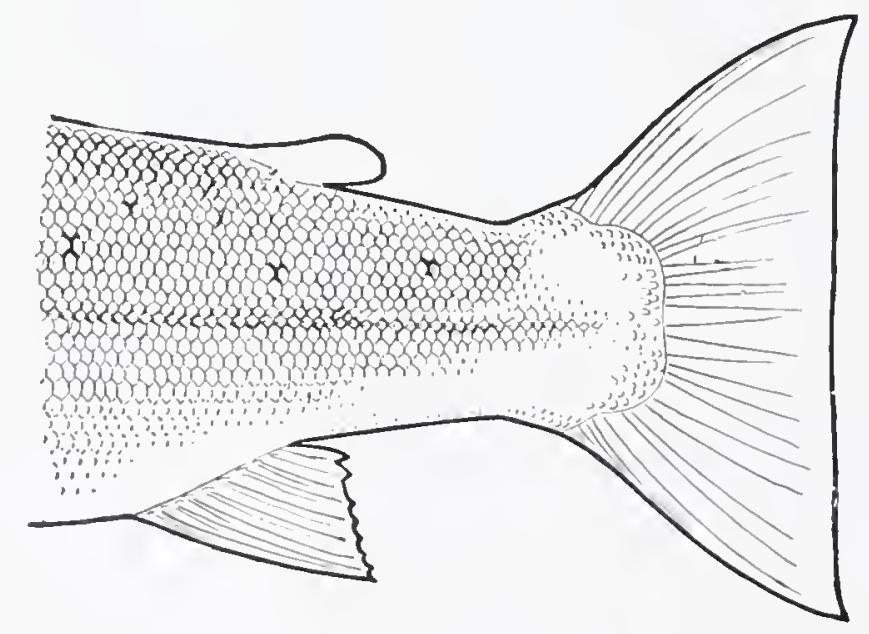

(2)

liig. 12. Diagram contrasting tails of Salmon and Seatroul.

1, Tail of Salmon.

2) Tail of Seca-Trout. 
Every angler will recognise in the first part of this description the "wrist" which, with the more spreading and fleshier lobes at the base of the tail (Fig. I2 (I)), enables one to hold a salmon with comparative ease. As to the marginal shape of the tail it is less easy to refer a particular salmon or sea-trout, for purposes of identification, to any constant abstract standard. In the young of both species the tail is markedly forked or notched, and as both fish grow to maturity the notch fills up till the margin of the tail in each becomes perfectly straight. In old fish, in both cases, the tail tends to become even round in outline. It is not probable that both fish would of ten tally weight for weight and age for age at the same time, but in a case where a grilse of $4 \mathrm{lb}$. weight and a sea-trout of equal weight were in contrast, the tail of the grilse would still be forked while that of the sea-trout would be perfectly straight or even rounded, in its outline.

Dealing with the fins Mr. Regan also points out that "In adult Salmon the anal fin is less pointed than in Trout, so that when it is laid back the last ray usually extends farther than the longest, the reverse obtaining in the Trout." A reference to the fish themselves will clearly show the distinction indicated. I have endeavoured in the diagram (Fig. I2) to show the main distinctions between the tails and anal fins of salmon and sea-trout and to contrast their scales.

Lastly Mr. Regan points out that "The maxillary extends to (in Grilse or small Salmon) or a little beyond (in large fish) the vertical from the posterior margin of the eye, being shorter than in the Trout." Put rather more crudely the trout has a longer jaw and consequently a relatively bigger mouth than the salmon (Figs. I 3 and 14 ).

I make no apology for thus stating Mr. Regan's distinctions in his own words. I myself profess to have no scientific knowledge, and in this matter prefer to offer the reader the safe guidance of his expert authority.

It is interesting that $\mathrm{Mr}$. Malloch makes no allowance for variation 
in the number of scales in the oblique line mentioned by Mr. Regan. There are I4, he states, "from the adipose or dead fin to the lateral line" in the sea-trout, Io in the salmon; but he does not indicate, as Mr. Regan properly does, which line of scales should be counted. As to another structural distinction, in a letter to "The Fishing Gazette" of Io May, I913, Mr. Malloch wrote:--" The quickest way to tell a sea-trout from a salmon is to lay a pencil along the upper jaw past the eye. If the eye is all above the pencil it is a sea-trout. If the pencil line is through the centre of the eye it is a salmon. The difference is so great one can teil at a glance without the pencil. The same with the smolts of the salmon and sea-trout." An illustration of using the pencil is given in the second edition of his book. It may be remarked that the late Mr. Cholmondeley-Pennell, in "The Angler Naturalist," also drew attention to this distinction, and it is possible that both observers were in this matter under obligation to Yarrell. In "A History of British Fishes" at any rate one finds that Yarrell gives contrasted diagrams of the gill-covers of the salmon, grey trout and salmon trout, and states that "looking at the form of the three gillcovers, it will be obvious that a line drawn from the front teeth of the upper jaw to the longest backward projecting portion of the gill-cover, in either species, will occupy a different situation in respect of the eye; that the line will fall nearest the centre of the eye in the first, that of the Salmon, and farthest below it in the second, that of the Grey Trout." I reproduce here, roughly, for reference (Fig. I5), Yarrell's diagram of the three gill-covers reversed.

Yarrell, of course, accepted the grey trout, or "bull trout," as a distinct species, and so he attached considerable weight to distinctions in the form of the gill-covers, a distinction which some modern observers have not wholly ratified. But it is clear that the position of the eye seemed to him to be of importance in the distinguishing of the species, and a reference to several specimens of salmon and sea-trout will satisfy 
the reader that the point is in fact material as a mark of distinction, at any rate between salmon and trout.

Such bearing as the gill-covers have upon the matter in hand may best be explained by reference to the diagrams of the heads of salmon and sea-trout (Figs. 13 and 14) here given.

In the salmon, as Yarrell noted, the posterior free edge of the gill-cover formed by the operculum, suboperculum and interoperculum is almost invariably of so true a curve as to form part of a circle. In the sea-trout, and, one may say, in the trout also, the free edge, where the junction of the operculum with the suboperculum occurs, projects backwards as a rule beyond the line of the curve of a true circle. One cannot say that the distinction is absolute or constant, for the curve in each species may approximate sometimes so closely as to be indistinguishable; but in most cases the true curve of the gill-cover of the salmon will be easily marked off from the more projecting curve of the gill-cover of the sea-trout.

Something also falls to be stated regarding the teeth in this connection because, although the young salmon, sea-trout and trout, begin life with equally well-armed jaws, most of the teeth of the salmon disappear as the fish attains maturity. As a distinction in mature fish of the two species we are considering the teeth therefore are of some importance. Yarrell here again puts the matter very clearly. "I have observed," he says, "that some specimens of the migratory or Sea Trout carry their vomerine teeth longer than the Salmon; and the Trout which do not migrate appear to carry their vomerine teeth longer than those which do migrate." He remarks that the salmon loses a portion of the vomerine teeth during the first visit to salt water, and states further:"The teeth on the vomer of the Salmon, when the fish is old, seldom exceed two or three in number, sometimes only one, and that placed on the most anterior part." It may thus be inferred that any large fish which discloses a fairly complete set of teeth on tongue, jaw and vomer is not a salmon. 
I may add as a further structural distinction, on the suggestion of Mr. J. Arthur Hutton, that microscopic examination of the scales shows, in most cases where the "bull trout" is not involved, whether the fish in question is a salmon or a sea-trout, for, weight for weight, the salmon almost invariably is the younger fish. For purposes of comparison I am able, through the kindness of Mr. Hutton, to show in one plate (Fig. 16) the contrast between the scales of a grilse and those of a sea-trout each of which fish weighed $4 \frac{1}{2} \mathrm{lb}$. The scales respectively indicate that the grilse is three and a half, and the sea-trout seven and a half years old. It is possible, as I have elsewhere shown, that the scales of the "bull trout" approximate closely to those of the salmon in its various stages.

Subject to the foregoing remarks it may perhaps be convenient to tabulate thus:-

\section{The Distinctions between Salmon and Sea-trout.}

I. Weight for weight, the sea-trout is generally shorter and of more sturdy build than the salmon.

2. The gill-covers of the salmon form a true curve, those of the sea-trout project backwards more or less to an apex.

3. The eye of the salmon is set nearly in the medial line of head and body, that of the sea-trout markedly above it. The pupil of the salmon's eye is curiously pear-shaped.

4. The mouth of the sea-trout is larger than that of the salmon, extending backwards beyond the eye. Relatively, the maxillary bone is longer than in the salmon.

5. The salmon has generally more branched rays in the dorsal fin than the sea-trout.

6. The postcrior margin of the anal fin in the salmon tends to convexity while in the sea-trout it is rather concave and projects towards the tail.

7. The tail rays of the salmon spring from a relatively broader base than in the sea-trout giving the former a "wrist" by which it can be securely grasped. 


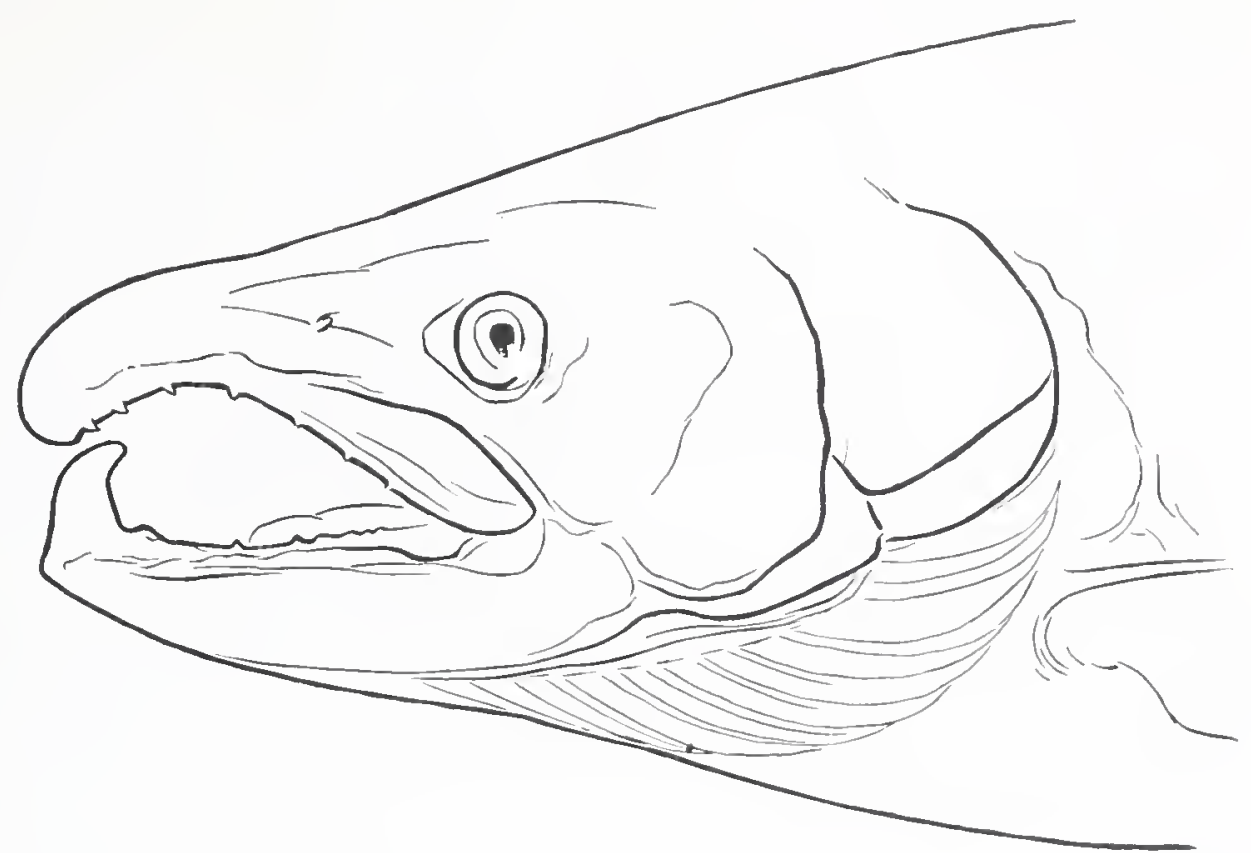

(I)

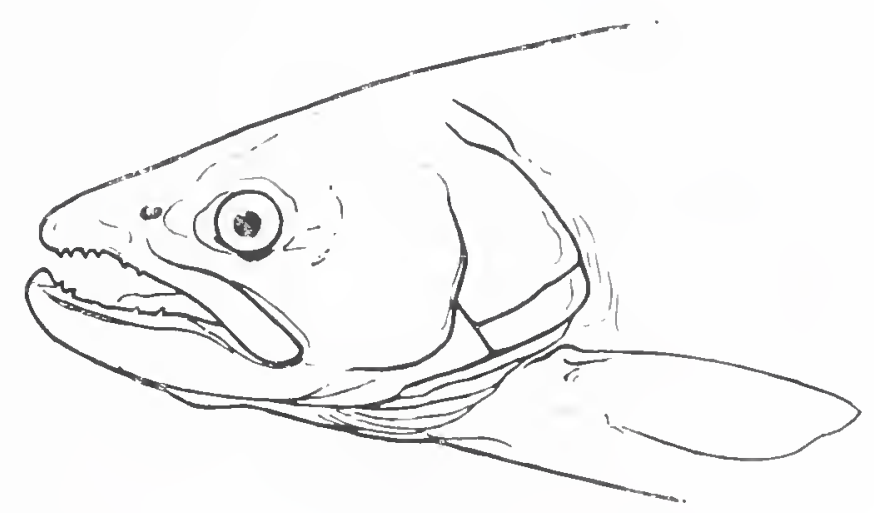

(2)

Fig. 13. Diagram contrasting heads of male Sitmon and Seatrout.

(1) Head of male sillmon.

(2) Head of male seit-lout. 


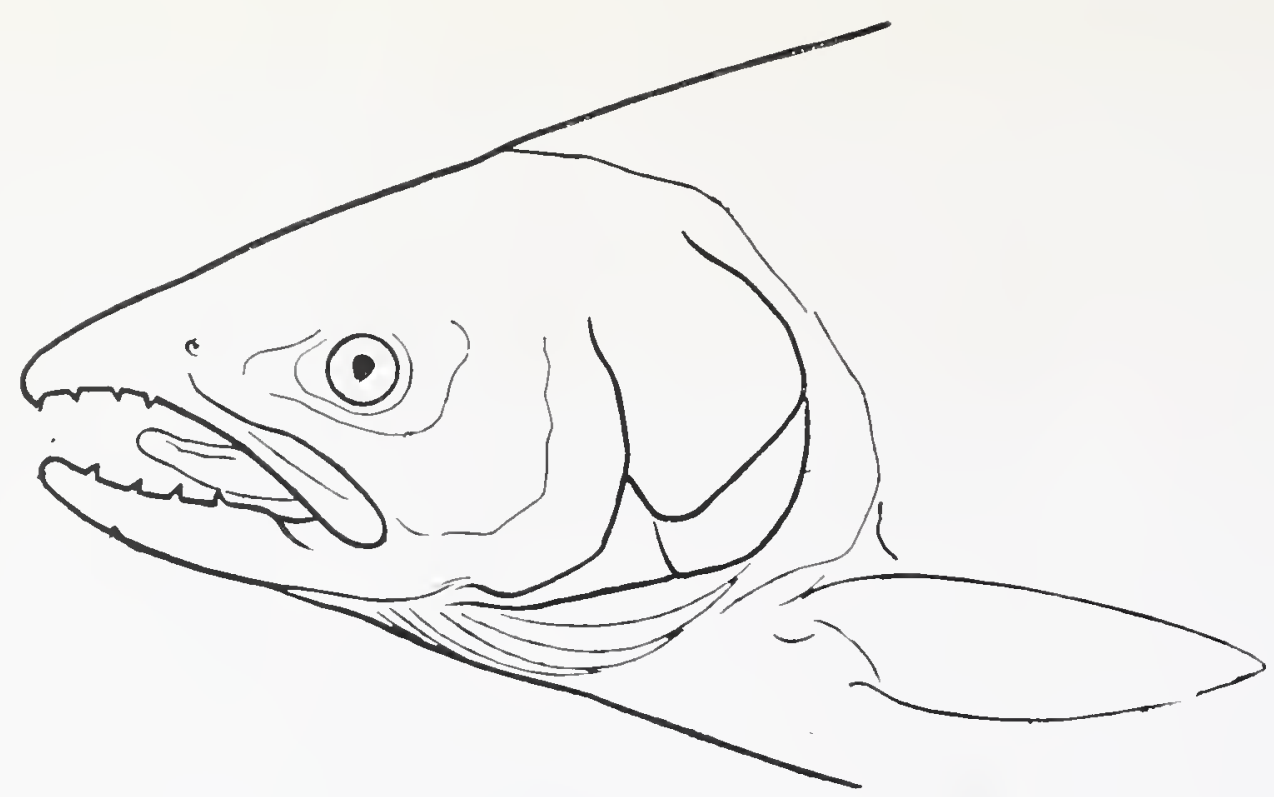

(I)

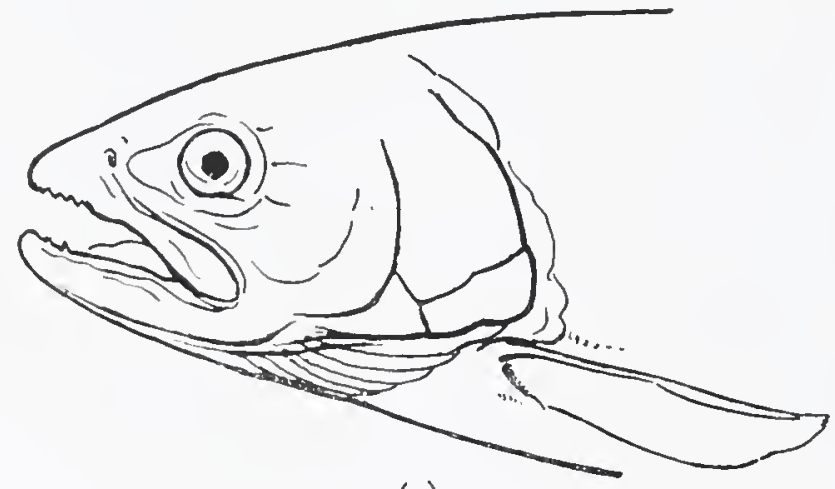

(2)

Fig. I4.- Diagram contrasting heads of female Salmon and Sea-trout.

(i) Head of female salmon.

(2) Head of female sea-trout.
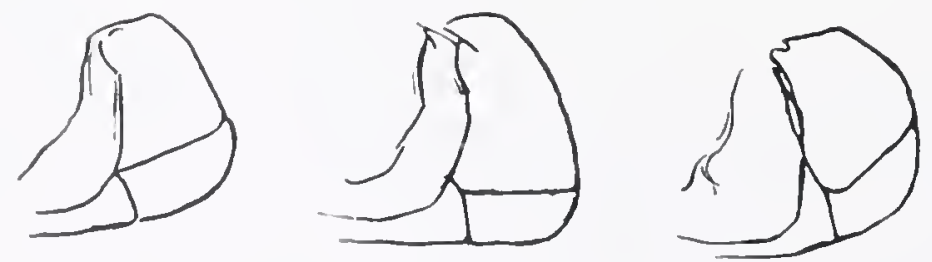

Fig. 15.-Diagram of gill-covers of Salmon-'Trout, Grey Trout, and Salmom.

(afler larrell, reversed). 
8. In fish of equal weight the margin of the sea-trout's tail is less forked than that of the grilse.

9. The scales of the salmon are generally actually, and always relatively, larger than those of the sea-trout.

IO. In the oblique line of scales traced forwards from the adipose fin to the lateral line, the salmon has, as a rulc, io scales, the sea-trout I 4 .

I I. The rings of annual growth shown on the scales of salmon and sea-trout widely differ, those of the sea-trout, weight for weight, generally indicating greater age.

We may now turn to the question whether there are any structural differences between sea-trout and trout, a question which I have warned the reader would crop up again and again throughout these pages. For the scientific answer we are forced back upon Mr. Regan's dictum that "there are no structural differences."

I have already stated that, failing proof to the contrary, Mr. Regan's dictum must be accepted, and I for one have no conclusive rebutting evidence to offer. I may say indeed that I have again and again, with sea-trout and trout of equal weights before me, examined them minutely to see whether I could detect any particular part, or even outline, which could fairly be held to differentiate the one fish from the other. Hitherto (with the doubtful exception of a different rate of scale growth) I have been unable to do so. It must be said, however, that in general outline the trout of some rivers have a clumsier appearance than the sea-trout caught in the same stream, while fin and tail have the appearance of being coarser in texture. But on the other hand river trout differ as greatly from the better proportioned trout which can be caught in almost any lake.

In the general case it will be found that with equally wellproportioned fish it is the colouration alone that enables one to distinguish whether a particular fish is a migratory or a non-migratory trout. 
I may now state more precisely wherein the teeth of trout differ from those of sea-trout. There are always, I think, two rows of teeth on the vomer in the case of both fish in their earlier stages of growth, but as the fish get older the teeth are more or less freely shed and they disappear the more rapidly as the fish adapts itself to a salt-water environment. As to this matter Dr. Day, I think, writes with considerable weight of authority. "However," he states, "the dentition varies excessively, while we find examples possessing the colours, form, etc., of the brook trout resident in brackish waters or even the sea, but mostly, not invariably, possessing the limited number of vomerine teeth of the anadromous forms. On the other hand there are anadromous forms (in colour) in fresh water, with the teeth assuming that present in the brook trout or retaining the par dentition. It has been asserted and reasserted that brook trout invariably have a double row of teeth along the body of the vomer, and some authors have gone so far as to insist that these teeth are not deciduous. Doubtless it is not uncommon to find trout, even up to $2 \mathrm{lb}$. weight or even more, with all the vomerine teeth thus remaining intact when a double row is present, but it is by no means rare to see only one irregularly placed row. While in very large specimens these teeth (unless they have entirely disappeared) are always in a single row, and the vomer may be found even toothless or with one or two teeth at the hind edge of the head of that bone. Equally incorrect is the statement that the teeth disappear differently in different forms, for in all they first assume a single row and then fall out, first commencing from behind. But in the rapidly growing sea-trout the vomerine teeth are shed sooner than in the brook trout." In illustration of this passage from Dr. Day's work the reader may refer to the drawing which I give of the vomer of a trout weighing I 3 oz., taken from above the Fills of Clyde (Fig. 17). The spaces which the shed tecth occupied are distinctly scen. and the double row of tecth is clearly in process of becoming a single row. The diagram (Fig. 18) shows the dentition of a sea-trout of $2 \frac{1}{4} \mathrm{lb}$. 
Nor can it be said that the test of the scales will prove final as a distinction between sea-trout and trout, for the concentric rings of growth are added to the scales of the sea-trout exactly in the same way as in the case of the trout, while both fish remain in their earlier stages of growth in fresh water. No doubt an immediate distinction takes place as to the scales of the sea-trout when that fish migrates to the sea, the rings of growth which are then added being comparatively wide apart, so that the salt-water series of rings contrasts strongly with the fresh-water series. But the same kind of distinction immediately occurs in the rings of growth of the scale of a trout when by chance it happens to change its quarters from an ill-provided and circumscribed hill stream or tarn to a rich and extensive lake.

I am far from wishing to appear dogmatic on this still somewhat theoretical question of the identity of the sea-trout and trout-or, I should perhaps put it, certain sea-trout and trout-but the fact has apparently to be faced that it is not very easy to discover any such characteristic structural differences between the fish as would warrant their systematic classification in distinct groups.

Turning now to another matter, it is not always easy, with fresh-run sea-trout, to distinguish the male from the female. The distinction becomes more marked as the spawning season approaches, for then the male fish becomes reddish coloured and the female, as a rule, a dingy grey. But if, on firmly closing the mouth of any sea-trout, it is found that the under jaw closes well within the upper, the fish may be pronounced a female. If not, it is more probably a male, and at spawning time, or, in the case of old fish, at any time, a more or less well developed "hook" will be found on the lower jaw (see Figs. I3 and I4) which emphasises its length relatively to the upper. An autopsy will, of course, always disclose the sex.

There is still the question to be considered whether, in respect of the migratory trout, there is sufficient warrant for making a distinction 
between the sea-trout proper and the alleged "bull trout." I have already considered the matter at some length in my introductory chapter and there is the less occasion to labour the subject here. Two points, however, may be referred to.

We have seen that Mr. Regan agreed that a slight difference might sometimes be recognisable between western and eastern sea-trout. In his own words, "the Sewen (S. cambricus) of Wales, Ireland, and our Western coasts often differ from the Sea-trout (S. albus) of the east coast, in having a longer head, a larger mouth with stronger jaws, the suboperculum projecting backwards beyond the operculum, and the fins somewhat larger, the lobes of the caudal especially being more produced." Now it was partially in respect of the shape of the gill-covers that Yarrell distinguished between the "grey trout" of the Tweed, and other rivers, notably those of South WVales, "where it is called the Sewin," and other sea-trout. He found that "The operculum is larger; the free vertical margin much more straight; the inferior posterior angle more elongated backwards; the line of union with the suboperculum not so oblique, but ncarly parallel with the axis of the body of the fish; the inferior edge of the suboperculum parallel to the line of union with the operculum; the interoperculum much deeper vertically; the vertical edge of the preoperculum more sinuous." The reader who admires the zealous cxactness of this description may trace its various parts with reference to the diagram (Fig. I 5) given at page 56. I shall merely note that Mr. Regan's observation of "the suboperculum projecting backwards beyond the operculum" and Yarrell's of the opcrculum having its "inferior posterior" angle more elongated backwards" both help to describe the fact that nearly always the gill-covers of sea-trout, unlike those of salmon, project backwards in a curve considerably more abrupt than the circumference of a true circle, the free edge of the suboperculum almost invariably projecting beyond the edge of the opcrculum. That there is any distinction in 

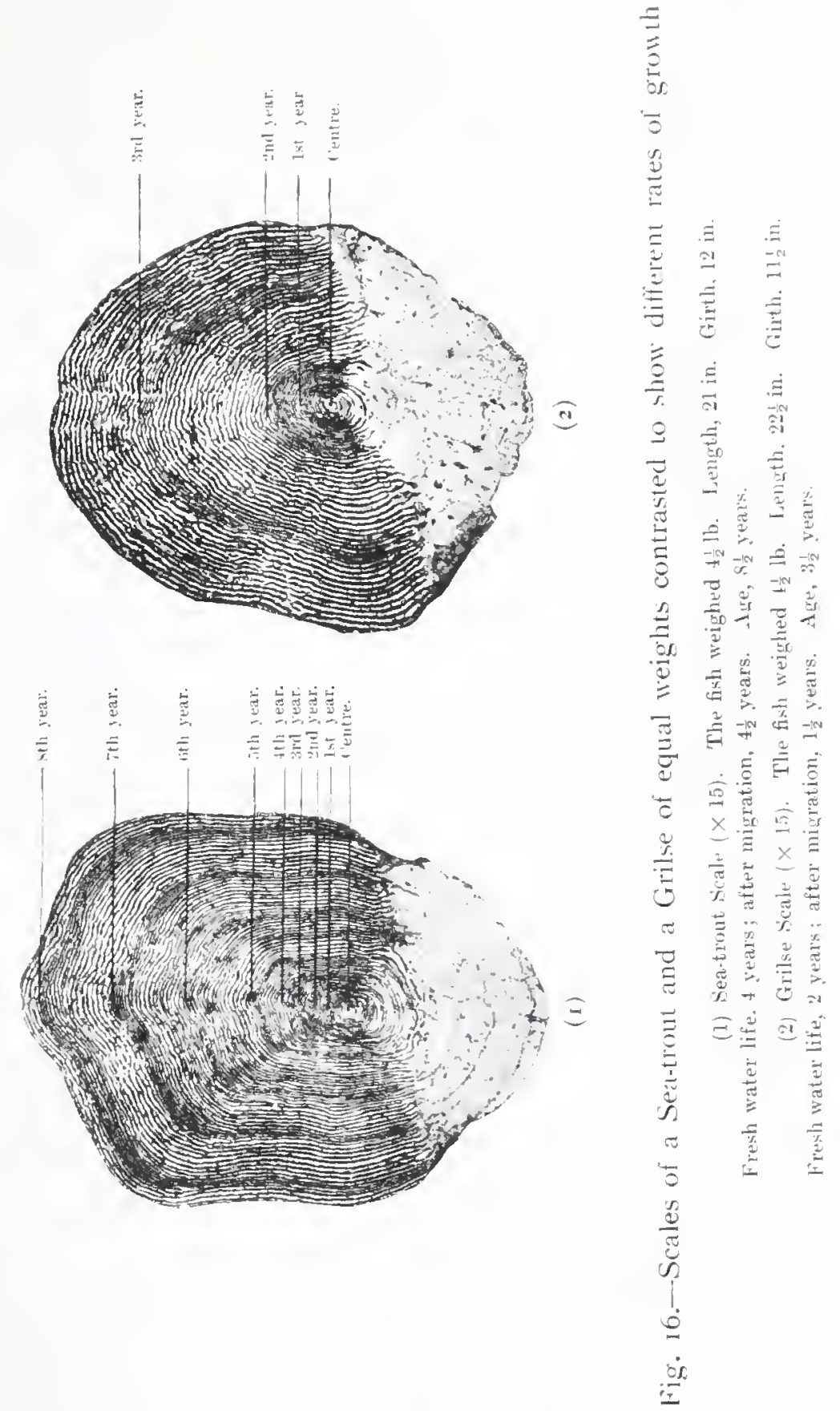

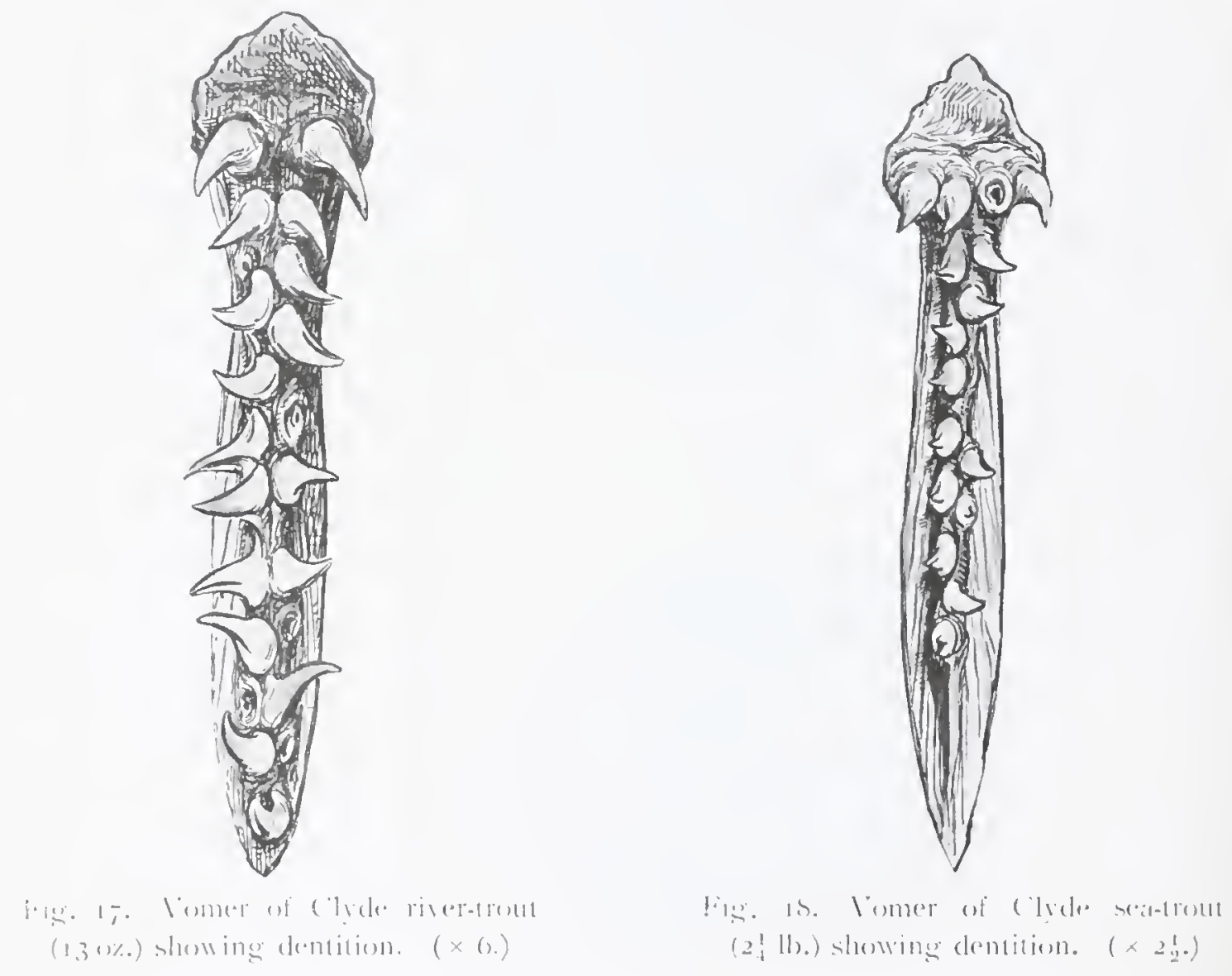
this respect between the sea-trout of different rivers sufficiently constant or pronounced to warrant them being classed as separate species, or even races, neither Dr. Günther nor his successor, Mr. George A. Boulenger, would agree, and I see no good reason to differ from their opinion. The fact, however, may have cumulative weight.

As with the head so with the tail. I have already shown that, as the sea-trout becomes older, the posterior margin of its tail tends to become convex in outline, or, in other words, the hitherto square-ended tail becomes round. The more pronounced tendency in this direction in the sea-trout of the Tweed and some other East Coast rivers, and the fact that such sea-trout are in general of a larger average size than those of other districts, might point to the conclusion that they are older fish, the roundness of the tail in the larger specimens having had longer time to become accentuated. Careful examination of scales will settle the question of age. Also one might infer that these so-called "bull trout" are old fish, or at least that they have very frequently spawned, from the fact that their flesh is always poor and white and very unlike the rich condition of the flesh of the smaller and presumably younger specimens. Scale examination will settle this point also.

In this connection I am able to give, for purposes of comparison, the diagrammatic outline of the tail of a $3 \frac{1}{2} \mathrm{lb}$. male sea-trout caught at Luss in November, 1914, and of the tail of a $7 \frac{1}{4} \mathrm{lb}$. male "bull trout" caught in the Tweed in the same spawning season (Fig. 19). The first outline I took myself, and the second was kindly taken for me by a member of the watching staff of the Tweed. One must admit that, even taking account of the relative weights of these fish, there is an essential difference in the outlines of the tails. Possibly, in the case of each district, larger fish would show even more definite variation.

I am not contending either way for differences discoverable between these "bull-trout" of the Tweed and other rivers and the sea-trout of other districts. But the facts point to differences 
superficially apparent, though it is doubtful if they are a structural difference warranting special classification. In the matter of size, for example-because it must be admitted that these East Coast sea-trout attain a large average size-there may be an augmentation of growth through the fish ranging further afield in the North Sea. Hardly any of the East Coast rivers in which these "bull trout" are said to be numerous have any estuary. The Scottish Tyne, the Tweed, the Northumberland Aln and Coquet, and the English Tyne have none of them, except the last, a distinctive and extensive estuary, and the local sea-trout may possibly have acquired habits like those of the salmon of ranging far afield in the ocean, with a proportionate effect upon their growth. In the regions of pure surmise also it might be argued that they go far afield because they are descendants of fish which in earlier geological times had to traverse great river-channels long since submerged in the waters of the North Sea. Such speculations have a certain attraction. But there may be this prosaic explanation of the size to which these sea-trout attain that, as they run in greatest numbers after the netting close-time has begun, there is very little toll taken of the stock and that therefore a higher percentage, or a greater proportion, of the older and larger fish survives. However this be, I think that Mr. Regan, apart from his theory that there is only one species of trout in these islands, has not conclusively established that there are sufficient grounds for recognising either two species, or two races, in the sea-trout, although the cumulative effect of the facts may help to establish that there are two types of sea-trout, and, I believe, two species.

This is clearly one of the points connected with the sca-trout and its life-history in regard to which more definite information is required, and I think that scale reading, if systematically undertaken, will help to throw considerable light on the subject.

I have not myself, I regret to say, had the opportunity yet to make such a systematic examination of the scales of East Coast fish, 


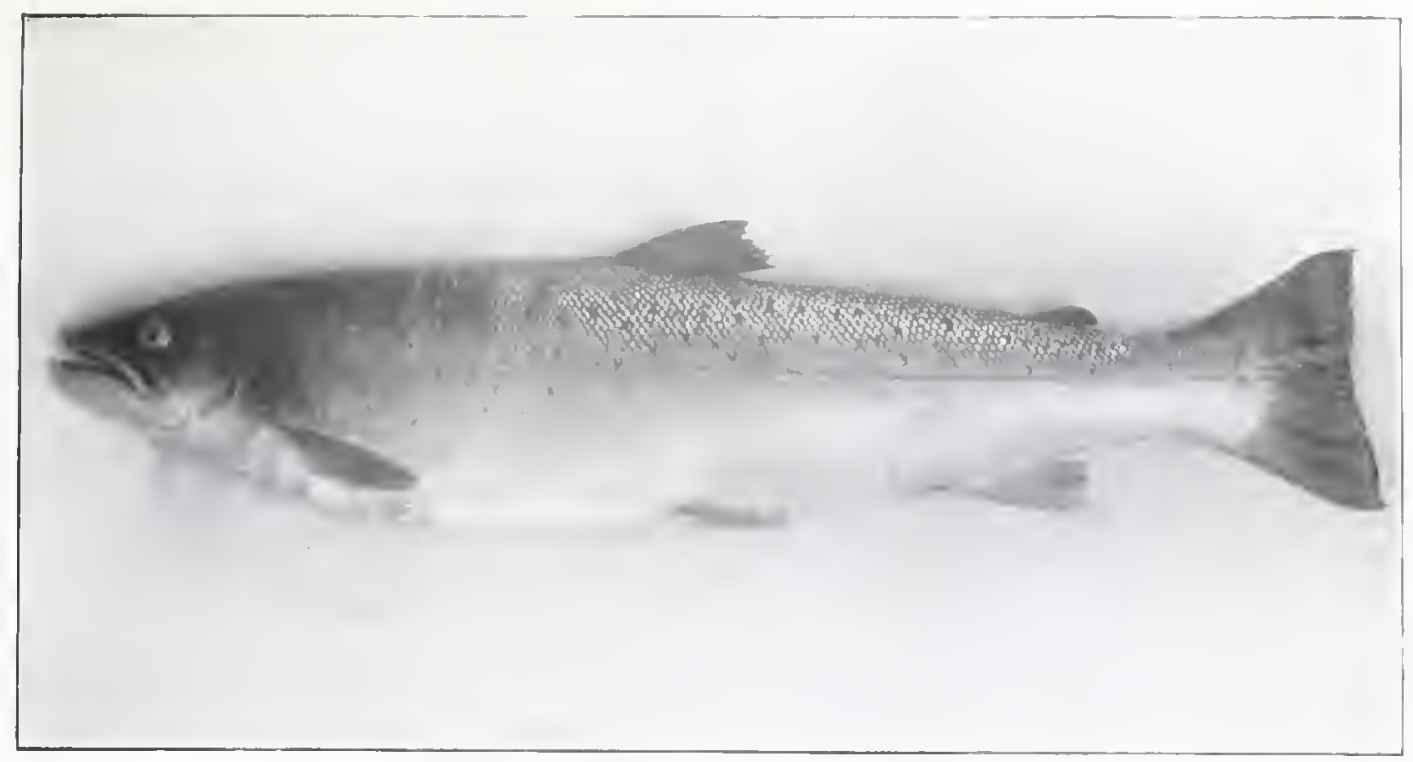

livg. 20.-." bull Trout" ( $3 \frac{1}{4} \mathrm{lb}$, from the River Aln.

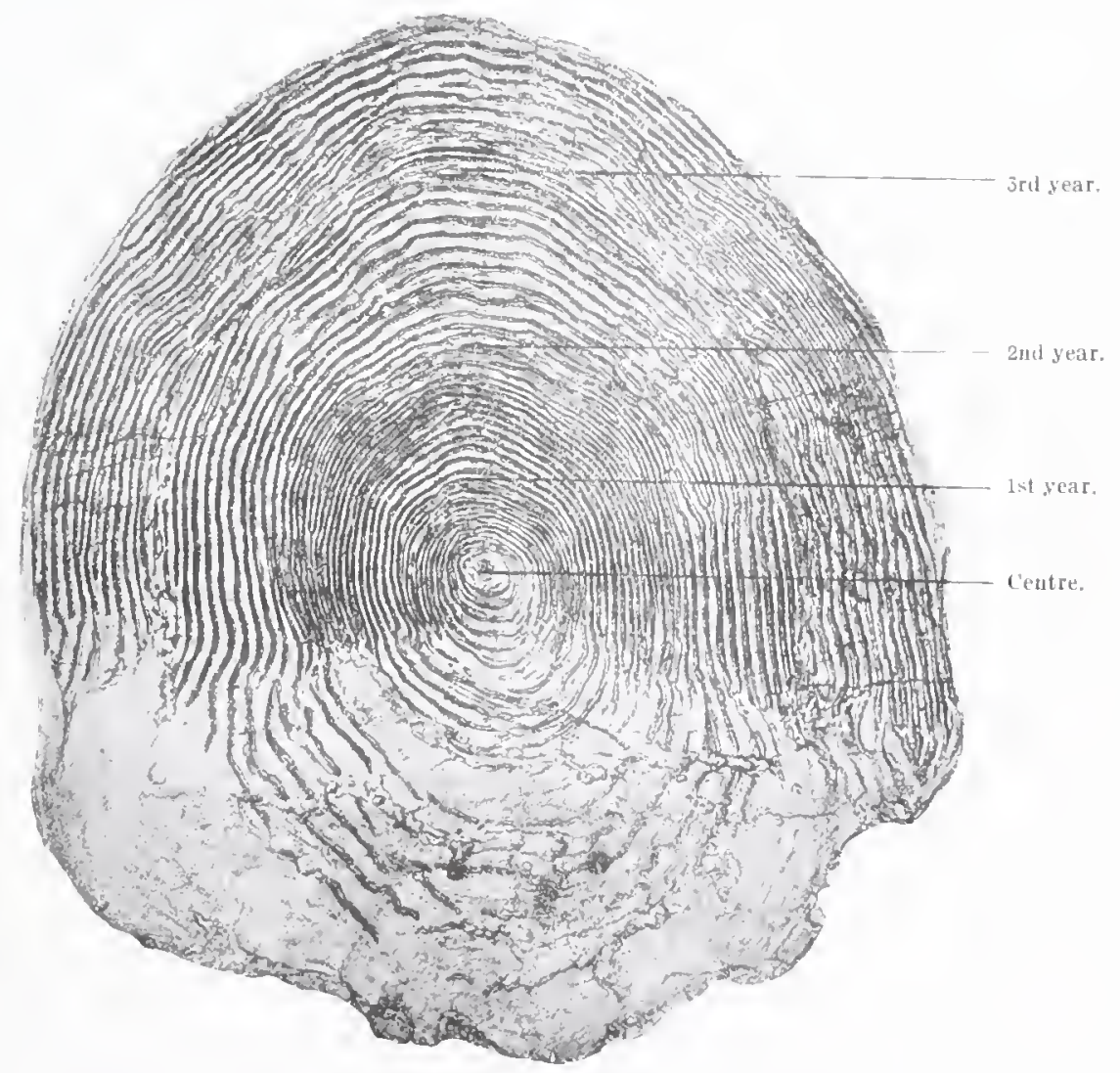

Fig. 21.- Scale of River Aln "Bull trout" (3la lb.) indicating growth similar to that of a salmon grilse.

Fresh water lifte, 2 years; after migration, $1 \frac{1}{2}$ years. Ige, $3 \frac{1}{2}$ years. ( $\times 32$ ). 

but I am able to give a reproduction (Fig. 20) of a photograph of a seatrout which was caught in the coastal nets off the mouth of the river Aln on 27 th July, 1915. The fish, a male, weighed $3 \frac{1}{4} \mathrm{lb}$., and there is, so far as I can see, nothing very distinctive in its appearance. Mr. J. J. Hardy, of Alnwick, who kindly sent me the photograph, states that "it is quite a typical fish for the Aln and Coquet." There is something to be said about the scales, however, and their appearance must give one pause. They are far more like the scales of a grilse than one would expect to see in a sea-trout weighing as much as $3 \frac{1}{4} \mathrm{lb}$. The reproduction of one of the scales here given (Fig. $2 \mathrm{I}$ ) clearly indicates, I think, that the fish spent two years' residence in fresh water before its descent to the sea as a smolt; thereafter it spent its third year in the sea, and was apparently caught when making its first return to fresh water to spawn in its fourth year. Now this would be exactly the life-story of a grilse if the fish belonged to the species Salmo salar. It is, however, undoubtedly a sea-trout, and the scales point to its being a maiden fish in its fourth year; but, if so, one would in ordinary circumstances expect it to weigh hardly more than at most $\mathrm{I}_{2} \mathrm{l} \mathrm{lb}$., equivalent to the weight which one is accustomed to recognise in those sea-trout which, failing to ascend the river as whitling, ascend in the following year as maiden fish. But this fish weighed $3 \frac{1}{4} \mathrm{lb}$.

Now, if one is to accept the foregoing scale reading as correct-and there seems to me no good reason why one should not do so-some interesting speculations suggest themselves. The fish may be an ordinary sea-trout whose rate of growth has been abnormal, which is unlikely. East Coast sea-trout, again, may all show an equally rapid growth, which, in view of the data given by Mr. Malloch of Tay fish, seems also unlikely. Finally it may, after all, be that the "bull trout" is a distinct species, or race, whose rate of growth in the earlier stages is practically equivalent to the rate of growth of the salmon grilse.

I also reproduce here (Fig. 22) another sea-trout, weighing $8 \mathrm{lb}$., 
which was caught at Alnmouth on 6th September, 1915, and show (Fig. 23) an enlargement of one of its scales. Attributing to this fish two years of fresh-water residence, it is quite plain that it spent two further consecutive years in the sea without spawning, and was, when caught, presumably making for the river to spawn in its fifth year. Now if the fish shown in Fig. 20 discloses a life-history corresponding to that of a salmon grilse, the life-history of this second fish bears exact resemblance to that of a small summer salmon. Yet it is indubitably a sea-trout, and, as sea-trout go, a large one; but-and this is the point-an unexpectedly young one. The question therefore arises whether these two fish do not, after all, represent a distinct species, or race, of sea-trout, which in rate of growth and possibly wide range (evidence of which may be found in the late seasonal ascent of the fish) approximates more closely to the salmon than to the trout. I concede at once that no conclusions of value can be drawn from the examination of the scales of only two specimens. But I give my observations upon them simply to show in what directions a careful and extended examination of the scales of East Coast fish may be fruitful of interesting and definite results in a matter as to which, frankly speaking, nothing at all is known.

It is of considerable interest that in Norway also the "bull trout" is recognised as a distinctive type of sea-trout. My friend, Mr. G. H. Ramsbottom, of Alderley Edge, informs me that when fishing the Gloppen River, Nordfjord, in 1913 , he caught with fly a fine specimen of the type which weighed $8 \frac{1}{2} \mathrm{lb}$. Local people actually used the term "bull trout" to describe the fish, but the term was doubtless borrowed from some British angler. Be that as it may, the important point is that apparently the two types of fish are easily distinguishable. It was further said that the "bull trout" of the Gloppen River occupicd a certain tributary stream at spawning time to the total exclusion of the other and commoner type of sea-trout. I am able to give a reproduc- 


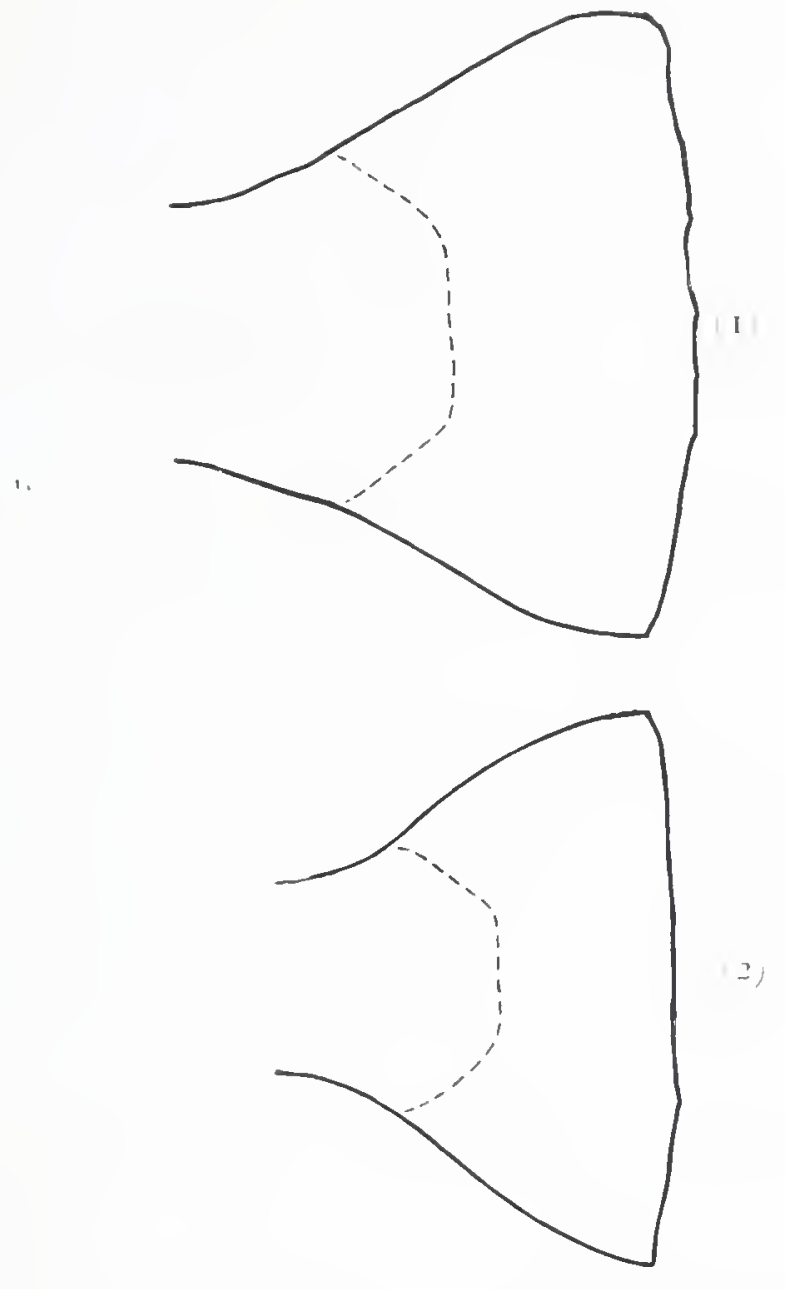

Fig. I9.-Diagram contrasting unlines of tail of a Tweed "Bull Trout "and of a boch Lomond Sea-trout.

(I) Tail of Tweed "bull trout" ( $/ \frac{1}{4} 1 \mathrm{~b}$.).

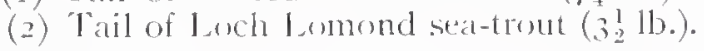



tion of a photograph of Mir. Ramsbottom's fish (Fig. 24), but unfortunately no scales of the fish were taken for examination.

As it may be necessary from time to time to refer to points of law in relation to my subject it seems appropriate here to remind the reader, while we are at any rate considering distinctions, that, according to Scottish statutory law, no distinction exists between a salmon and a sea-trout, as the definition given in the Acts of the former expressly includes the latter.' Hence every statutory prohibition or provision which affects the salmon and its young applies with equal force in Scotland to the sea-trout and its young, a fact which it is very necessary that the angler should know. I understand that the law of England is substantially to the same effect. The law which applies to trout and trout fishing depends upon an entirely different set of statutes and legal principles.

The life-history of the sea-trout, to which it is time now to turn, will perhaps be brought most clearly into focus for the reader if the description proceeds $a b$ ovo. This will give an opportunity of discussing in proper sequence the various stages of development in the growth of the fish and the various important questions connected with each.

1. "Salmon" shall mean and include salmon, grilse, sea-trout, bull trout, smolts, parr, and other migratory fish of the salmon kind." Salmon Fisheries (Scotland) Act, 1862, 25 and 26 Vict. c. 97 , Sec. II. 



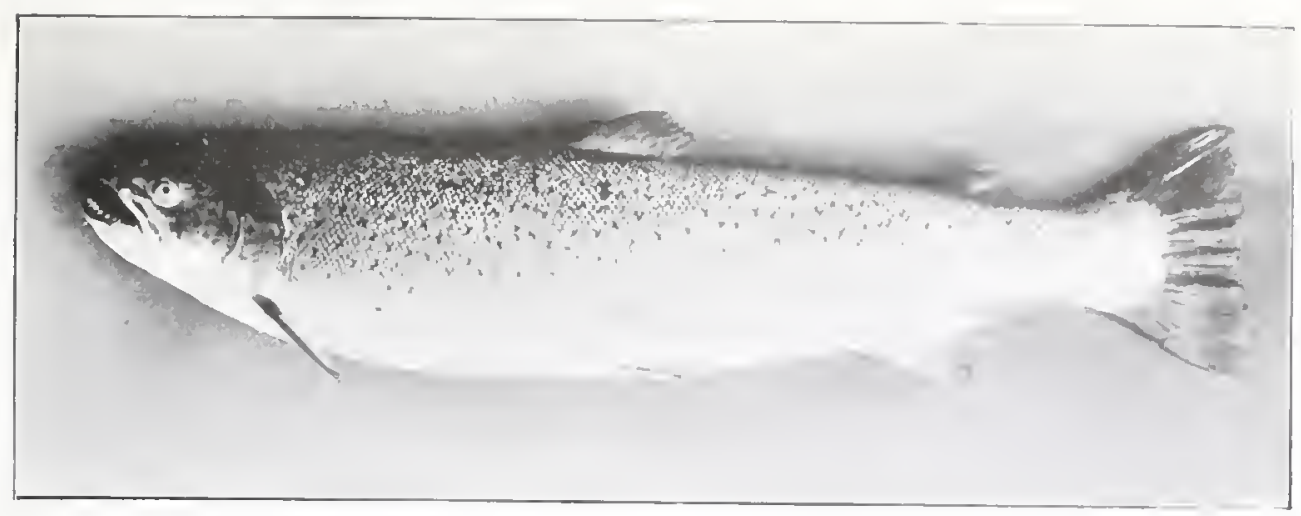

lig. 22.- "Bull Trout" (s lb.) from the liver Mn.

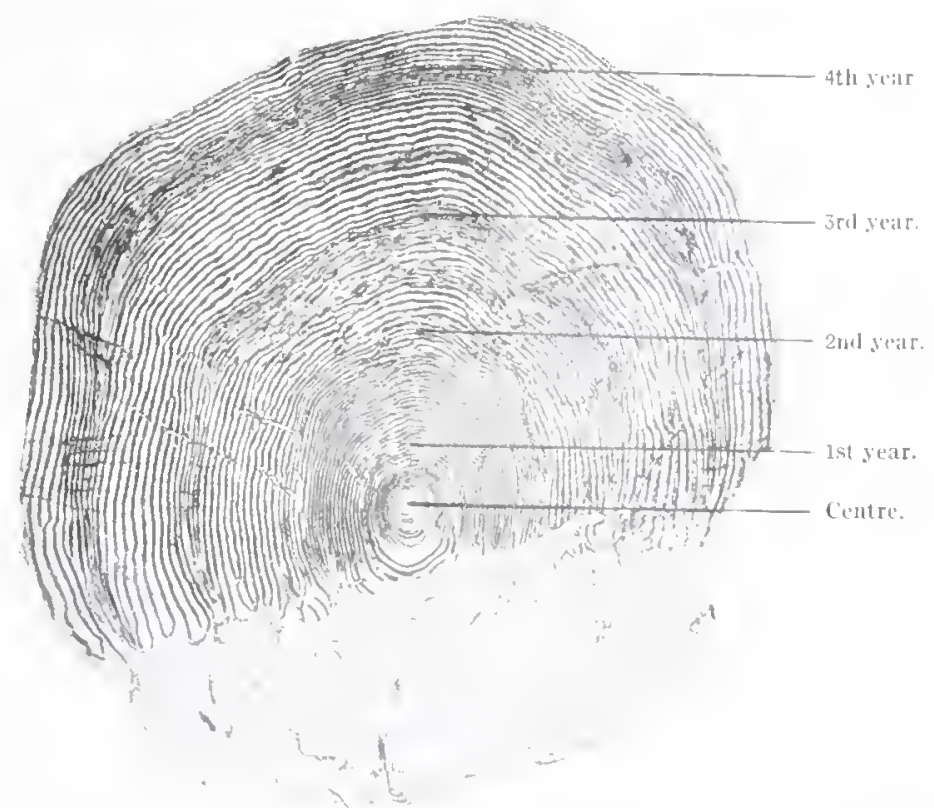

Fig. 23. Scale of River $\mathrm{H}_{\mathrm{n}}$ "Bull trout" (SH).), indicating growth similar to that of a small summer silmon. ( $x$ wo.)

Fresl water life, 2 years; after migration, $\frac{01}{2}$ years. Ape, $f_{2}^{\prime}$ years.

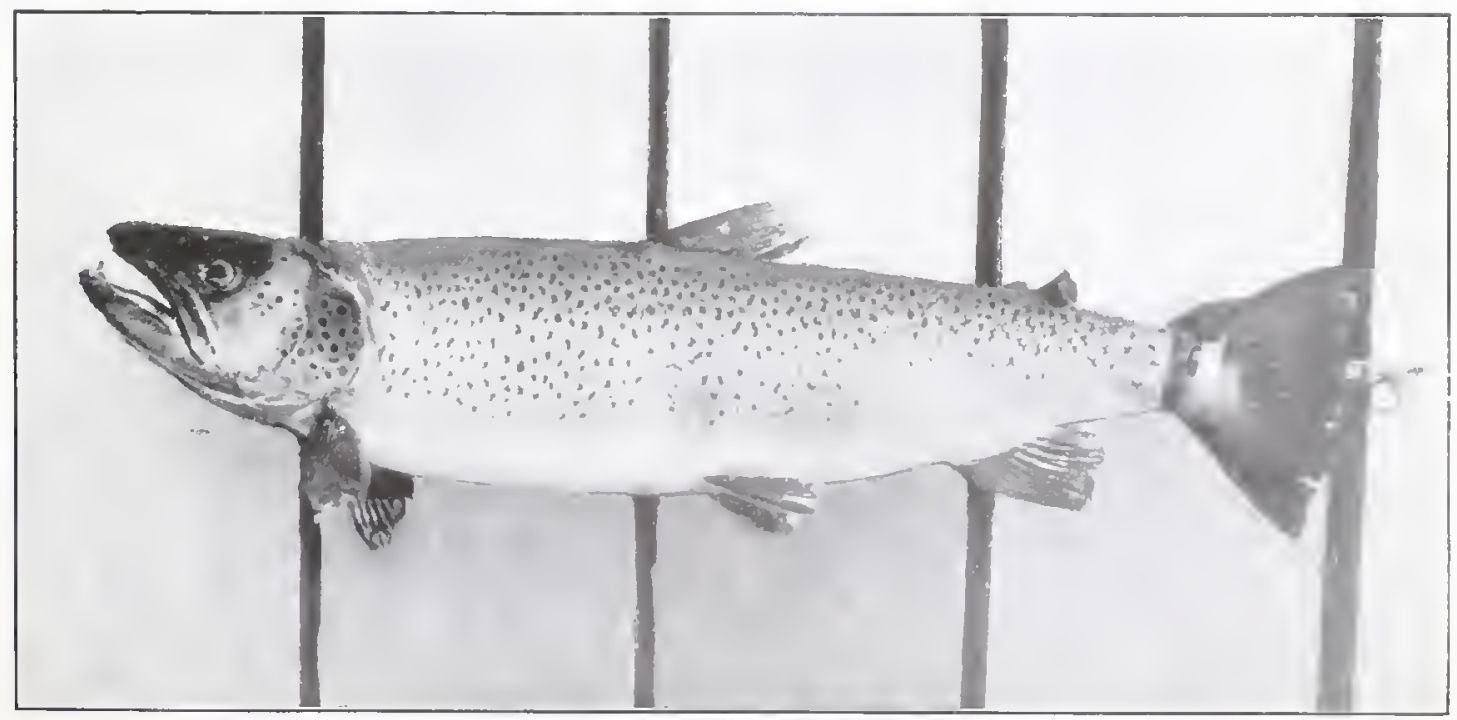

Fig. 24.-. I Norwegian "liull Trout" ( $8 \frac{1}{2}$ lb.). 

Eggs and Alevins 



\section{CHAPTER III.}

\section{EGGS AND ALEVINS.}

Sea-trout eggs and salmon eggs are so like each other in point of size and colour that they cannot readily, if at all, be distinguished at a glance. As it is the size of the individual specimen rather than the species which, with these closely-related fish, determines the size of the egg, the sea-trout eggs, like the sea-trout themselves, are generally but not invariably the smaller. The same determining cause holding good, it will be found that trout eggs in general are smaller than seatrout eggs. As a rough indication of size it may be said that four salmon eggs placed in a row almost exactly occupy the space of one inch, sea-trout eggs on the average rather less, and trout eggs again less, although five of either of the latter will generally exceed the inch.

I have found that twenty-six salmon eggs laid in line occupy exactly the space of six inches, but I have seen an equal space occupied by the same number of eggs of a well-developed sea-trout of only $2 \frac{1}{4} \mathrm{lb}$. weight. It has been said, though I can neither confirm nor disprove the statement, that the eggs of spring salmon are larger at spawning time than those of autumn fish. The point does not seem to be material with respect to sea-trout eggs.

The colour of the eggs of salmon, and of most sea-trout, when they are first shed, is a rich salmon pink, but on fertilisation they become immediately slightly paler and more opalescent. In one respect salmon eggs differ wholly from those of sea-trout and trout. The colour of the former does not seem to vary at all according to locality or the breed of the parents, but there is a wide range of distinctive colouration in the eggs of sea-trout and trout. They may vary from a pale yellow to a dark rich pink according to the locality of the breeding 
stock and the age of the parent fish. It is probable that the feeding of the parents accounts largely for this uniformity in the case of the salmon and variation in the case of trout, because, while the feeding of salmon in the sea all round our coasts is comparatively of a fairly uniform degree of richness, it is common knowledge that the fresh water and estuarial feeding of trout and sea-trout varies both in quality and quantity to an extraordinary extent in different localities. But while feeding conditions undoubtedly affect the colour of sea-trout eggs to some extent, the age of the fish, most probably on account of the frequency with which it has formerly spawned which age implies, affects it more. The older a fish is, the paler are its eggs. They approximate nearly to the generally paler colour of the flesh. The vast majority of salmon caught are " maiden " fish; all large, or at least old, sea-trout, as will be shown, have previously spawned.

It may be worth noticing that salmon eggs are uniformly round, while the eggs of sea-trout and trout are very irregular in contour. In Plate II I have endeavoured to show the development of the salmon from the egg to the smolt stage, and in Plate III the parallel development of the sea-trout. I need not, I think, refer to these plates specifically in connection with each point hereafter discussed. The reader will perhaps bear this general reference in mind and turn to the plates for any point which, up to the smolt stage, is mentioned in the text.

As to the number of eggs which each species may shed, hatchery operators are inclined to calculate the yield of salmon ova relative to the weight per pound of the parent fish at about 850 ; sea-trout ova at about 800; and trout ova at about 750 .

Inspired by the example of Frank Buckland I once amused myself by counting the eggs of a salmon, a well-shaped fish of $9 \frac{3}{4} \mathrm{lb}$. weight. I counted individually I,Ooo eggs, and weighed the remainder against them, finding the total to be 9,000 less 234 eggs, leaving a balance of 

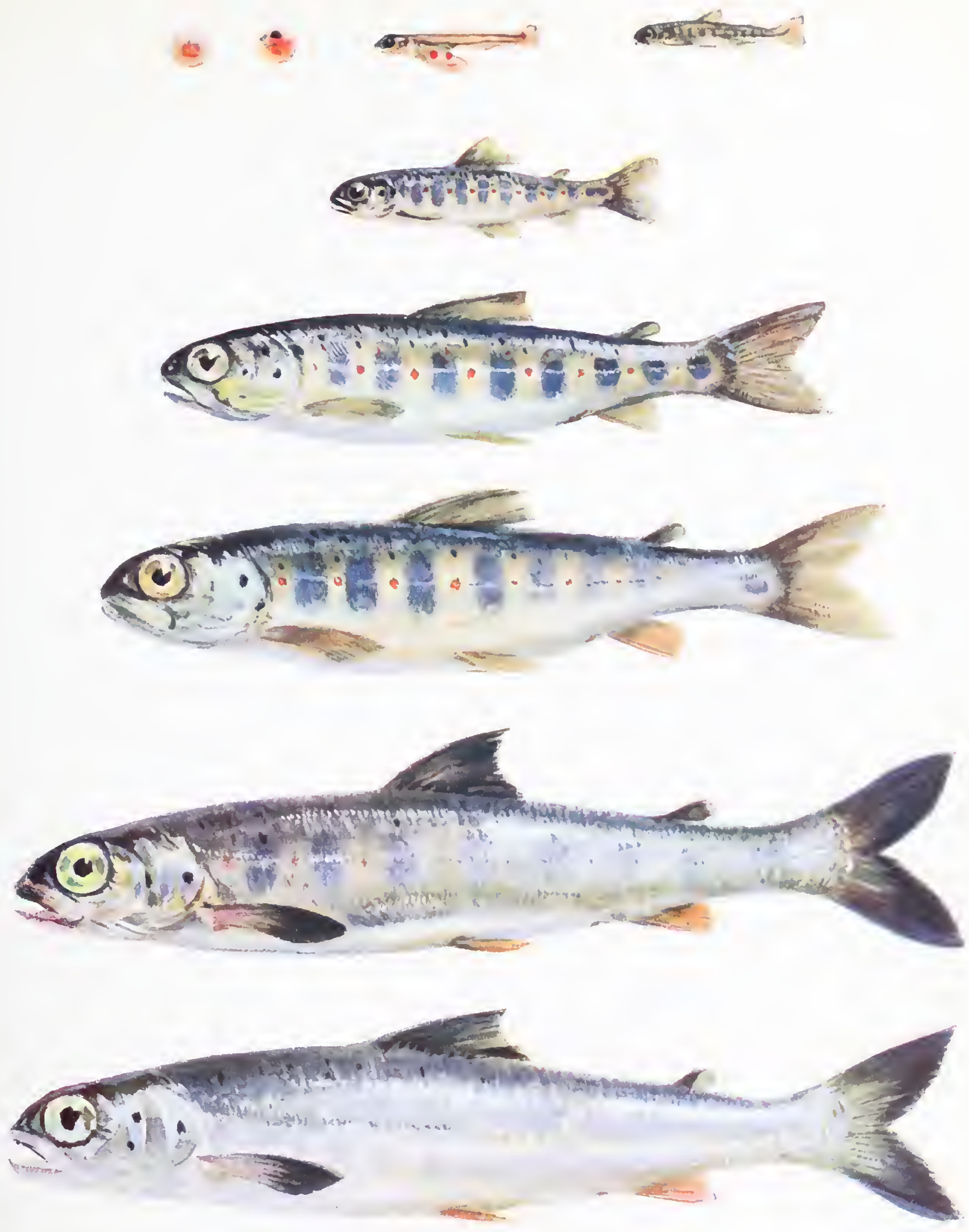

8,766 . There may have been a loss of, say, 34 in handling the fish and detaching the ovaries, which would make the exact total of eggs 8,800 , equivalent to almost exactly 900 eggs per pound weight of fish.

Making the calculation another way I found that 260 counted eggs weighed exactly I oz., so that a pound weight of ova would contain $4, \mathrm{I} 60$ eggs. As the mass of ova yielded by this fish weighed actually $2 \mathrm{lb} .2 \mathrm{oz}$. presumably the eggs it contained numbered 8,840, equivalent almost to the first result. But 900 eggs per pound weight of fish is slightly in excess of the usual hatchery allowance of 850 , which figure may, however, represent a fair average.

It is not so simple a matter to calculate the number of sea-trout eggs. One can never be certain that the female fish has not already shed some eggs, and the number of eggs varies greatly in different females according to the condition of the fish. Females out of condition, obviously ill-nourished, contain few eggs, and old fish contain relatively fewer eggs than young fish. Possibly 800 per pound weight of fish is a generous average allowance.

On I 2th November, 1914, when collecting sea-trout ova for Luss Hatchery, I looked out for an opportunity of getting a perfectly shaped unspawned female in order that I might count the exact number of eggs she contained. In the afternoon I got such a fish which had apparently just arrived to spawn in a small tributary of Luss Water. It was a beautifully shaped and prettily marked fish of exactly $2 \frac{1}{4} \mathrm{lb}$. in weight. We stripped her of her eggs and fertilised them with the milt of a male in a special basin. On arriving at the hatchery the eggs were arranged by themselves on the glass grilles of one hatching box. They were full-sized eggs, as large as average-sized salmon eggs and very rich in colour. As is stated later in the chapter devoted to "Artificial Propagation," each glass tube in Luss Hatchery is a shade over six inches in length and each row of the grille contains comfortably 26 eggs, a fact which I verified in this instance by counting the eggs of 
several rows here and there. As the eggs occupied 78 rows of the 90 in the grille, there were apparently altogether 2,028 , but allowing $5^{2}$ for any possibly unshed and for loose eggs here and there on the grille, we get a total of 2,080 eggs for this fish of $2 \frac{1}{4} \mathrm{lb}$. in weight. This gives us (with one egg out) exactly 924 eggs per pound weight of parent.

Assuming that these eggs, as in the case of the salmon eggs mentioned above, weighed 260 to the ounce, the mass of eggs in this seatrout weighed exactly half-a-pound. Of course 924 eggs is greatly in excess of the usual allowance of 800 , but this was an exceptionally fine specimen fish, caught too before a single egg had been extruded.

Most of our knowledge regarding the development of the eggs of salmon, sea-trout and trout has been acquired in hatcheries, but there is no reason to assume that such development differs in any important respect from the development of the ova under natural conditions. Perhaps hatchery conditions may accelerate matters to some little extent because in nature development is often retarded by recurring periods of low temperature, a disadvantage which the hatchery eggs escape as the temperature within doors is kept at a uniform level. But any difference is immaterial to the present purpose.

One can imagine, then, that in the fertilised egg, hidden away in some dark recess of the gravel, with the temperature of the water varying between $40^{\circ}$ and $45^{\circ} \mathrm{F}$, the embryo fish will, after thirty days or so, have so far developed that its eyes will have become visible as two little dark specks through the semi-transparent covering of the egg. At this stage, when the eggs are technically called "eyed ova," they may with impunity be subjected to a good deal of handling and disturbance, and it is when in this state that the eggs of trout are usually transferred from hatcheries to purchasers for the purpose of stocking and re-stocking waters.

With things going propitiously, in other 60 days, or in about 90 days altogether (trout taking a total of 7o days and salmon 120 days) 


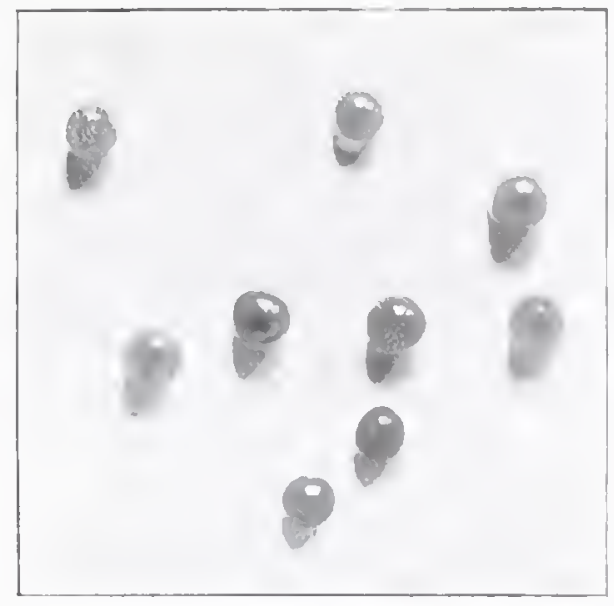

Fig. 25.-Sea-trout eggs.

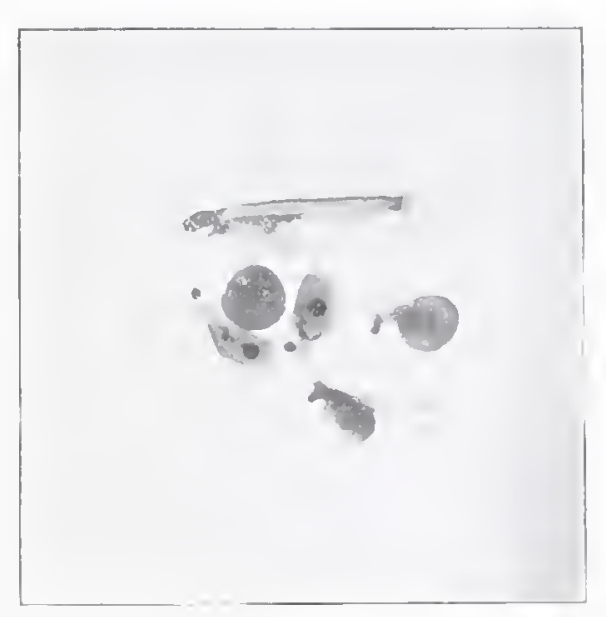

liis. 27.- Sea-trout alevins hatching out.

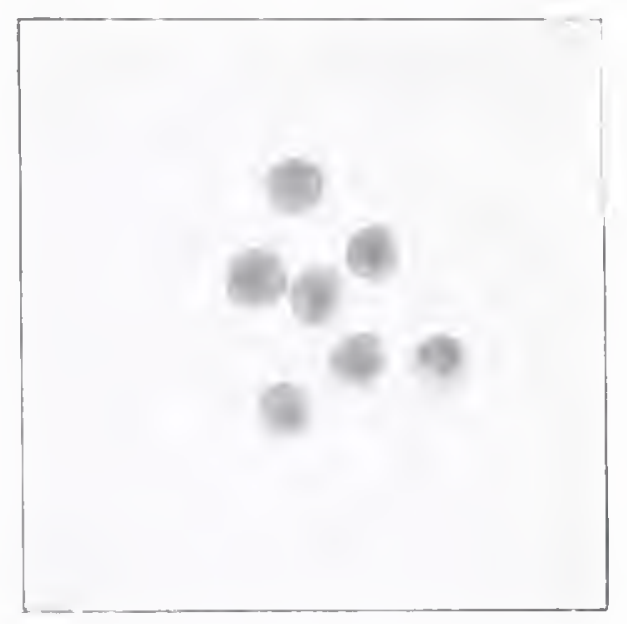

Fig. 20.-Sea-trout "eged uva."

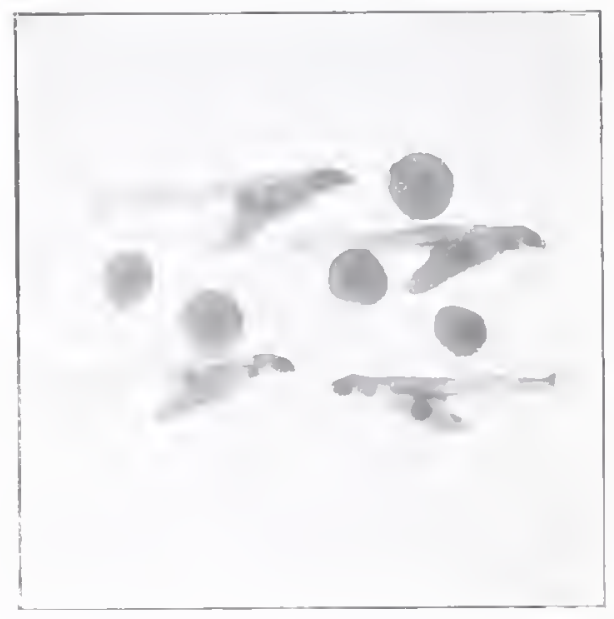

Fign. 28. - Late exas and early alevins. 

the sea-trout eggs will begin to hatch out through the imprisoned embryo having become strong enough to burst its containing envelope. The shorter time taken to hatch out of sea-trout and trout eggs respectively may possibly be due to the higher temperature of the water when the eggs are shed and during the earlier stages of incubation; at any rate, in all cases, cold weather greatly retards the hatching process.

Most of the little fish, which when clear of the shell are known as "alevins," hatch out tail first, and easily succeed in detaching themselves from the shell. Some few, however, but in what proportion is not known, hatch out head first and these, unless released forthwith, generally perish, but whether by strangulation or through some inherent lack of vitality in the embryo I am unable to say. In Figs. 25, 26, 27 and 28 will be seen reproductions of several photographs of eggs and alevins, in one instance (Fig. 27) of the alevins actually in the process of hatching out.

The little alevin is very unlike a fish. It is barely an inch in length, and has a blunt head of which the prominent black eyes are the most striking feature. The body is transparent and through it the rudimentary organs are clearly seen. The pectoral fins are separate and keep up a constant fanning movement, but the other fins yet consist of a continuous fringe round the margin of the body, a fringe that will not evolve into the permanent fins for several weeks.

But the most remarkable peculiarity of the alevin is a curious transparent appendage called the umbilical sac, or yolk-sac, which hangs between throat and vent, at first equal in bulk to the true body of the fish. This sac, in which little drops of oil may be seen, gives nourishment to the alevin during such period as it is unable either to swim about or to feed in a natural manner. In fact, the alevin shuns the light and wriggles into the deepest crevices it can find, prompted doubtless by the instinct of self-preservation. But the umbilical sac becomes gradually absorbed, the fish becomes bolder, and in about 50 
days, the sac being wholly absorbed, the little fish, perfect in shape, may be seen darting about amongst the gravel. This is the "sea-trout fry."

It may be convenient here (reverting to Mr. Regan's dictum already quoted) to consider in one view various differences, no doubt more or less superficial, which I have noted as occurring between "the young" of salmon, sea-trout and trout.

I. Salmon eggs are uniformly round in shape while those of seatrout and trout are very irregular.

2. The eggs of salmon are practically uniform in colour; those of sea-trout and trout vary considerably.

3. Salmon eggs take longer to hatch out than sea-trout eggs and still longer than trout eggs.

4. The colour of the respective alevins differs materially and does not seem to be necessarily dependent on the colour of the respective eggs. The salmon alevin is always pale flesh coloured-c "like finely chopped carrot" as it was once expressed to me; the sea-trout alevin is at first crimson-red in tinge and rapidly develops a dark brown colour on the back. Trout alevins are much greyer than the other two all the time they are alevins.

5. The salmon alevin is appreciably larger than the other two on hatching, its body being markedly longer, while the greatest development of the umbilical sac appears to be midway in the body rather than near the throat as in the case of sea-trout and trout.

6. On being hatched, salmon alevins lie, as it were, dormant for about eight days, the same period of inertia with sca-trout lasting only two days.

7. The eye of the salmon fry is appreciably larger than that of the sea-trout or trout fry.

8. At the earliest stage, parr marks are most sharply defined on the salmon, less so on the trout, and least on the sea-trout. 


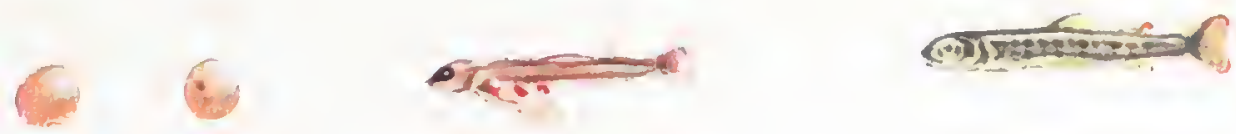
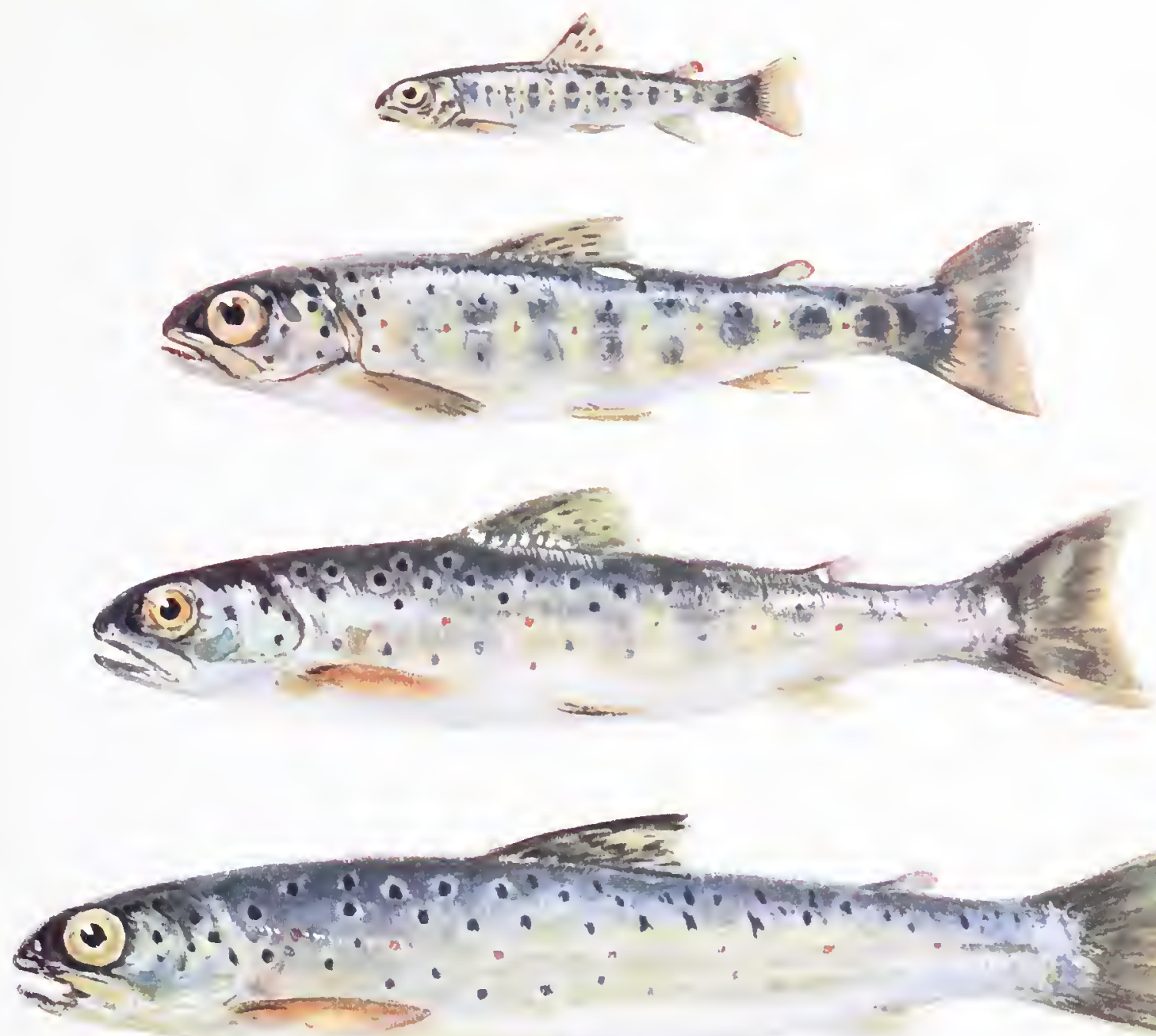

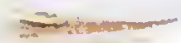

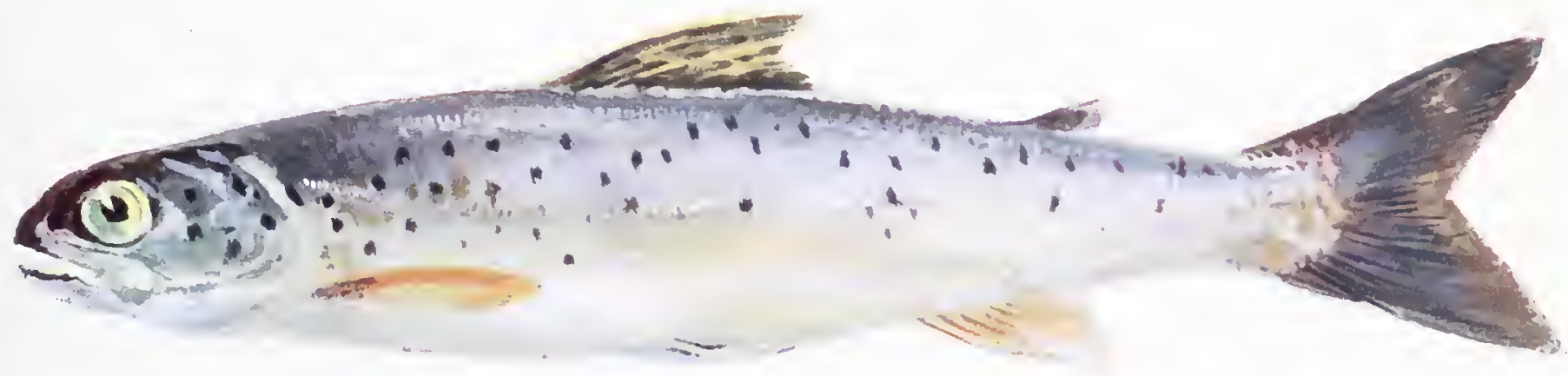



I do not say that these "differences" will be found of constant occurrence, but they are worth noticing. At Luss I have had the advantage of studying the ova of fish from commercial hatcheries as well as of fish native to the district, ard upon the eggs and the resultant alevins and fry I have made notes at various times.

I think that the facts noted regarding the earliest stages in their respective careers point to a marked distinction between $S$. salar and $S$. trutta, and to a considerable variation between the various breeds of trout irrespective of whether they happen to be migratory or nonmigratory.

Distinctions between the fish at later stages of growth will be pointed out as these stages are being considered.

A considerable number of "monsters," or deformed alevins, is always discovered amongst sea-trout hatched under artificial conditions, although oddly enough few are ever found in the salmon boxes. No very accurate estimates have been made by which it can be deduced that the number of monsters is variable or fairly constant. In all probability much the same number appears amongst naturally hatched fish, but under natural conditions few deformities have any great chance of being seen, and doubtless few survive to be seen. Some interesting notes on this point are given in a work on "The Teratology of Fishes" by my friend Dr. James F. Gemmill, Lecturer on Embryology at Glasgow University. He states that the following figures have been found to apply to deformities amongst the Salmonida:-I in 50, and I in 280 (Rauber); I in 600, none in 600, and 68 in 900 (Schmitt); I in 200 , and I in 350 (Gemmill); over Ioo in 400,000 (Coste). He adds this interesting statement:- "It is worthy of note that the frequency with which double monstrosity appears in the eggs of fishes is not far from corresponding with its frequency in those of the fowl."

Sometimes sea-trout with truncated snouts, spinal curvature, or stunted tails are caught, the largest "deformity" I have seen being 
one-an extreme case of spinal curvature-where the fish weighed about $3 \mathrm{lb}$. It is often thought by anglers who catch these fish that some early injury may have been the cause of the deformity, but apparently the origin goes back to the unhatched embryo. Dr. Gemmill's view seems to be that the actual causation has not yet been definitely ascertained.

But the most curious "monsters" found in the hatching boxes are those of the Siamese Twin type (Fig. 29), where the "twins" may be attached to each other in a variety of ways, the result being doubleheaded fish, double-tailed fish, or even double-bodied fish, in which extreme case the umbilical sac forms the connecting link. But of this type of "monster" it is safe to say hardly any survives the alevin stage. The late Mr. Cholmondeley-Pennell, however, in "The Angler-Naturalist," states that, "In the river Towey, Carmarthenshire, a fine fish of the Salmon or Trout species was caught, with the net, which had two heads and two tails-the heads being joined on to one neck, and the tails meeting about the centre. The fish was preserved for some time in a small pool at Llangattock, for the inspection of visitors." But the facts thus given concerning this fish are vague enough. The author merely paraphrases those stated by Yarrell, who adduces some evidence, with the date I829.

It is often asked, as a matter of interest, what proportion of eggs deposited reach the fry stage; and sometimes the question is put thus, how many eggs are required to produce one mature sea-trout? Conservators of fisheries would be only too glad to discover the answer. Taking one year with another the proportion is doubtless fairly constant and in the chapter on "Artificial Propagation" which follows I give Mr. J. J. Armistead's estimate regarding trout. But unfortunately there are no means of making even the roughest computation, and hatchery work throws but little light on nature's operations in this matter. 


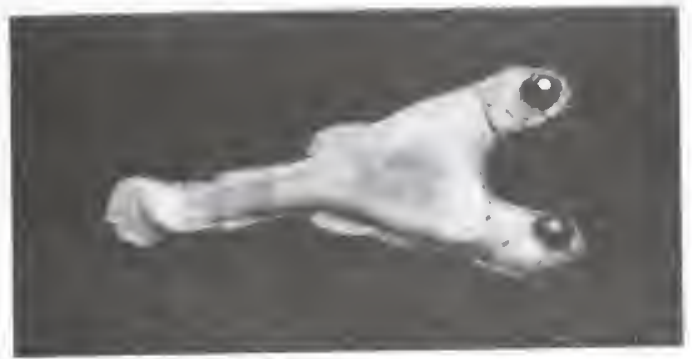

( I)

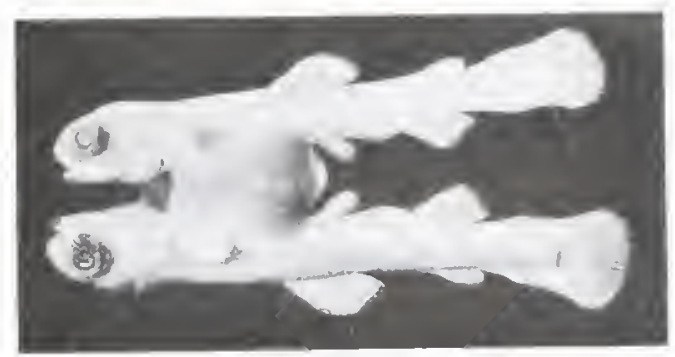

(2)

Fig. 29.-Sea-troul "monstrusities."

(after (iemmill.)

(1) I double-headed alevin.

(2) In alevin of the Siamese-min type. 

It is easy enough to assign such loss as must occur in nature to its various causes. Amongst these must be reckoned original want of fertilisation of a proportion of the ova shed and the immediate devouring of some of it by predatory fish in attendance on the spawners. Then the vicissitudes of the weather must be reckoned with, for an excessive drought may lay bare the shingle in which the eggs are deposited and exceptional floods may sweep the gravel beds wholly away. Then there is a host of creatures-larvæ, beetles, fish, and birds-which levy a constant toll upon the eggs and alevins. Finally, it has been discovered through hatchery work that a heavy death-rate occurs amongst the alevins, due perhaps, as it has been said, to an inflammation of the gills at the stage when the umbilical sac has become almost absorbed and the little fry begin to forage for food. I have suggested elsewhere that probably this particular mortality is increased by artificial rearing, especially where hand feeding is resorted to. But in any case it requires no great stretch of the imagination to assume a considerable mortality at this critical transitional period even with fish in their natural environment.

All that human ingenuity can do to mitigate loss, without resorting to hatchery operations, is to secure that as large a stock as possible of healthy fish deposit their spawn in peace, and that the eggs and alevins are protected as far as may be from predatory enemies.

It is hardly worth while to quote such estimates as have been made of the wastage that occurs, but Dr. Francis Ward, in his "Marvels of Fish Life," remarks that "in nature only a small percentage of the eggs deposited result in the birth of an alevin." If this is so, how few of the eggs hatched must produce a fish destined to reach maturity. Yet the numbers of sea-trout, in some seasons, are in fact enormous.

I have postponed till later consideration of the actual process of spawning and the periods of spawning, but, to summarise here what is contained in the foregoing pages, we may assume the sea-trout ova to 
have been deposited on November 15; and we may tabulate the various stages of development of the little fish up to the fry stage thus:-

Ova deposited (say) $\quad \ldots \quad \ldots \quad \ldots \quad$ November 15

Ova eyed, 30 days $\quad \ldots \quad \ldots \quad \ldots \quad$ December 15

Alevin hatched, 6o days $\quad \ldots \quad \ldots$ February 15

Perfect fry, 50 days $\ldots \quad \ldots \quad \ldots$ April 5

Altogether 140 days, or nearly five months, have elapsed since the shedding of the ova. It is a fact, worthy I think of special observation, that nature has arranged that the little fish have become best able to fend for themselves just at the time when the stream in which they were hatched is likely to afford a sufficiency of food for their subsistence 
The Fry Stage 



\section{CHAPTER IV.}

\section{THE FRY STAGE.}

By the time the umbilical sac has entirely disappeared the young sea-trout has already learned to quest for food. It is interesting to see that these little fish, even at this early stage, have inherited all the graceful activity of their parents, as well as their graceful form. The fry are pretty little things, about an inch and a quarter in length, which boldly enough forage amongst the gravel of the shallower water and even "rise" to floating objects, but at any sudden alarm they take cover with surprising quickness. At one moment a shallow stream may be seen to be alive with them and at the next may seem barren of all life whatever, so completely has each concealed itself in the gravel.

The body of the fry is at first still almost transparent, but it is already delicately spotted and the transverse bars, or "parr marks," on the sides, which characterise alike the young of salmon, sea-trout and trout, have already appeared. Eight or more of these may be counted on each side of the young sea-trout or salmon and indeed of the trout too. There is apparently no constancy in this matter as regards any of the fish.

Once the fry have begun to feed in the open their growth is fairly rapid for their appetite is insatiable and very little that is edible and of a convenient size escapes them. From this point of time the rivalry between the sea-trout and salmon fry and the young native nonmigratory trout of the stream becomes acute. There is of course only a certain amount of food available for all, and of that quantity the young sea-trout from their greater activity and strength secure the lion's share. Here is a vital handicap against the trout in the struggle for existence, and it may easily be understood that when fry and parr of both sea-trout and salmon throng any of our streams, the native 
trout have small opportunity of being over-fed. As a matter of fact in such circumstances they remain undersized and are of the poorest quality. This is a matter of great practical importance in the proper maintenance of trout waters, and I shall have occasion to refer later to other handicaps against the trout and in favour of the sea-trout. It is my opinion that the cumulative effect of these is to reduce the value, as trout fishing waters, of all waters to which sea-trout have access. From another standpoint it is possibly a mistake to endeavour to encourage trout in salmon and sea-trout waters. One might perhaps even go further, and, having the history of the river Coquet more particularly in view, argue that sea-tront are not fish to be whole-heartedly welcomed in salmon rivers. In my introductory chapter I pointed out that the broad theory of there being only one species of trout in these islands would meet us at every turn in the life-history of the sea-trout. We touched upon it in the case of the spots; we now come more closely upon it. The question arises how far sea-trout may communicate their pronounced migratory habit to the native non-migratory trout of any stream. No one can really tell, but it seems to me that it is not an unreasonable speculation to imagine that they do so to a greater or less extent, and that, under special circumstances where, for instance, the spawning grounds are limited in extent, all the trout of a stream may become fish of pronounced migratory habit, while in other streams, the bolder and stronger fish becoming migratory, the non-migratory specimens left behind to people the stream-as, it may be said, "native" trout-will be trout of poor quality.

It is noticeable that the young fish of any brood of sea-trout keep together and feed as a shoal, far more so than is the case with either salmon or the non-migratory trout, and, indeed, my belief is that this habit persists to a certain extent all through life so long as any individuals of the shoal survive. It might be going too far to say that the brood of each female forms an independent and distinctive shoal, 
but I think that the young fish which have hatched out together in neighbouring redds in the one little spawning tributary tend to remain together. I would wish to make my meaning perfectly clear in regard to this matter. I do not of course pretend that the sea-trout fry are gregarious, as a shoal of minnows which cruises up and down the still waters of a pool is gregarious, each individual minnow conforming in its movements to the general movements of the shoal. All I suggest is that the sea-trout fry hatched out in any stretch of shingle remain together in that stretch of shingle, until the necessity of seeking other quarters where richer feeding may be obtained arises. When the necessity arises I am inclined to think that all the fish hatched out together seek the richer feeding grounds in a body, dropping down stream to the main river, or to a loch, if such is within immediate reach.

The Loch Lomond district, with its numberless little streams, many of which have perhaps no more than a dozen yards or so of spawning ground, offers peculiar opportunity for observation. Where one of these streams is so small as to be obviously incapable of providing food for the growing fry in it, these are known to desert the stream and seek sustenance in the loch where the shoal can be seen on a calm day cruising along the shore. I believe, further, that sooner or later shoals of these young fish even cross deep water to the feeding banks of the numerous islands where these are near the parent stream. The shoals which thus take up their feeding ground spread over the banks as the growth of each young fish demands for it a wider range.

But doubtless every district has its own type of feeding ground, in river, loch or even brackish water, and such fry as are not driven by force of bare necessity to seek a livelihood elsewhere scatter themselves over the shallows in the neighbourhood of the redds in which they were spawned, redds which are almost always in some inconsiderable tributary of a greater stream. Here they spend an active existence in summer in pursuit of food and in evading their natural enemies. By 
the autumn they will have obtained a length of two or three inches. As the temperature of the water falls and food grows scarce they retire, like Cæsar, into winter quarters, and, seeking a safe shelter below some stone, they practically hibernate until the following spring when they again emerge for another active summer of fresh-water sojourn. With numerous opportunities for observation, I have never seen the young sea-trout "feeding" in a stream in mid-winter, but I have disturbed them under the ice of a frozen river.

Mr. Malloch has happily described this habit of the parr of salmon, and I take it that the habits of the young sea-trout, at least of such of them as have not sought sanctuary in a loch, are not materially different. "Very little feeding," Mr. Malloch writes, " takes place after the end of September, and when the cold weather sets in, the parr leave the shallow water to take up their abode under stones, where they remain till March or April, and almost entirely cease to feed. During their stay in winter quarters they become very black and fall off in condition. Often, when collecting larvæ, I have lifted a flat stone quietly and disclosed to view three or four parr. These did not swim away at first, but remained motionless for some time, apparently in a dazed, sleepy condition. When the water becomes warmer their winter abode is forsaken for the quieter pools." Mr. Malloch adds a curious statement difficult, one would think, to substantiate. "Strange to say," he writes, "they are now smaller than they were during the autumn." I think it is possible that, taking into consideration the wide distribution of salmon and sea-trout in our islands, Mr. Malloch's periods of feeding may be somewhat over-definitely stated. In southern rivers, at any rate, with warm weather and in low water, salmon parr may be observed feeding freely during the first half of October and possibly earlier than even March. I fancy that young sea-trout in this respect approximate most closely to trout, which feed more or less freely as weather conditions give them the opportunity, and that it is only during the 
coldest period of mid-winter that there will be any prolonged cessation from feeding. At any rate, the fish in the streams feed less because there is less to feed on. Here, perhaps, the "reading" of a scale, as it is technically called, may serve to confirm what is stated in the text as the result of more general observation. The nucleus of the scale becomes first visible to the eye some little time after the alevin has wholly absorbed the umbilical sac. It is now of course generally known that the scales are not annually shed, but that, growing with the growth of the fish, they-besides other changes - add each season a series of rings to their circumference. It will be necessary to point to the condition of the scales at various stages in the sea-trout's growth, and here it is appropriate to state that the rings of growth acquired during the winter between the first summer and the second summer of the fish's life are set more closely together than the rings acquired during each successive summer with the effect of forming a sort of band, or ring, of demarcation. This points to the two inferences that the salmon parr feeds hardly at all in winter and that it practically ceases to grow during the winter months, but it hardly bears out Mr. Malloch's statement that the fish grows "smaller," else there would be no "band" or series of winter rings, but only one ring marking shrinkage of the body and disintegration of the scale. But when it is pointed out that the winter band in the sea-trout scale (and in the trout scale also) is seldom so clearly defined as in the salmon scale, one may infer that sea-trout parr tend to feed with more freedom during the winter months than salmon parr, a fact which helps to account for the sea-trout's proportionately quicker growth than the salmon during the period of residence of both fish in fresh water.

It is worth while noticing these facts as to the sea-trout scales now, at their earliest manifestation, because throughout the life of the fish the scale rings of summer and winter growth may, as in the salmon scale, be differentiated and distinguished.

It is not my purpose here to describe the general theory and practical 
application of scale reading, but only to refer to the subject in so far as in my opinion it helps to shed light upon the life-history of the seatrout. For an introduction to the subject I need only refer the reader to certain very clear and admirable works which have already been written with reference to the scales of salmon by both English and Scottish authorities. 
Parr and Smolts 



\section{CHAPTER V.}

\section{PARR AND SMOLTS.}

With the advent of the warmer weather of spring the shallower waters of the streams become again peopled with the active fry, which, it will be observed, by the beginning of April have now lived through twelve months since ceasing to be alevins. They are in fact "yearlings," and having survived the fry stage are beginning now, as "sea-trout parr," their second year's residence in fresh water. How long they may remain parr I will discuss immediately.

These sea-trout parr are as active as ever the fry were in pursuit of food and they are bottom feeders, mid-water feeders and surface feeders indiscriminately as each particular kind of food is in evidence. They are, like salmon parr, troublesome to the angler, for they take his fly and worm with avidity and will even boldly attack an artificial minnow. If they are thus noticeable in the river they are equally so in a loch, for fishing with fly inshore on the feeding banks the angler will raise and hook numbers of them. It is clear that these, as I noticed happened in the case of some of the Loch Lomond streams, are fry which have left the parent stream for the loch and, having occupied a convenient feeding bank there, have not since changed their quarters. Nor will they do so, I think, till they are disposed to descend to salt water as smolts.

In any case, whether in river or loch, the sea-trout parr grow apace, outstripping in this respect the salmon parr of which at hatching, however, it must be remembered they had fully a month's start in life. When they go into winter quarters for the second time they will measure from four to as much as eight inches in length according to the quantity and quality of the food they have been able to obtain. There is a marked difference, at any rate, in the general condition of the sea-trout 
parr of a stream flowing gently through rich agricultural land and of those of a rocky barren stream which hurries tumultuously down a Highland glen. This initial difference persists through life and marks the well-conditioned or ill-conditioned types of sea-trout characteristic of the respective types of stream.

On this subject of the relative growth of salmon, sea-trout and trout, Mr. Knut Dahl has much that is interesting and suggestive to say regarding Norwegian fish, ${ }^{1}$ and I cannot conceive that, were equally full investigation to be made regarding British fish, any great discrepancy would be discovered between the results obtained in Scotland and those obtained by him in Norway.

In Scotland, as every angler is aware, it is illegal to take salmon parr, or, as the Act expresses it, "any smolt or salmon fry," and as sea-trout are "salmon" in the sense of the Salmon Acts, the provisions on this head apply to them also. The section of the particular Statute which deals with this offence relates also to offences concerning spawn and spawning fish, and therefore $I$ insert it fully here in the accompanying note. ${ }^{2}$

While it is thus illegal to take sea-trout parr the difficulty that meets the angler everywhere and at all times is to distinguish young salmon and sea-trout from the young of common trout, because, as there is no law yet in Scotland prohibiting the capture of trout however small, the

1. "The Age and Growth of Salmon and Trout in Norway as shown by their Scales," Knut Dahl (1910). Trans. by Ian Baillie. Ed. by J. Arthur Hutton and H. T. Sheringham for the Salmon and Trout Association.

2. "Every person who shall wilfully take or destroy any smolt or salmon fry, or shall buy, sell, or expose for sale, or have in his possession, the same, or shall place any device or engine for the purpose of obstructing the passage of the same, or shall wilfully injure the same, or shall wilfully injure or disturb any salnon spawn, or disturb any spawning bed, or any bank or shallow in which the spawn of salmon may be, or during the annual close time slaall obstruct or impede Ralmon in their nassage to any such bed, bank, or shallow, shall be liable to a penalty not exceeding five pounds for cvery such offence, and sluall forfeit cvery rod, line, net, device, or encine used in committing any such offence, and shall forfeit any smolt or salmon firy that may be found in his possession; but nothing berein contained shall apply to acts done for the purpose of artificial propigation of salmon or other scientific purnose, or in tho course of cleaning or repairing any dam or mill lade, or in the conrse of the exercise of rights of property in the bed of any river or stream: l'rovided also, that the district hoard may, with the consent of all the proprictors of salmon fisheries in any river or estuary, adopt sucli means as they think fit for preventing the ingress of salmon into narrow streams in which they or the spawning beds are from the nature of the channcl liable to be destroyed, but always so that no water rights used or enjoyed for the purposes of manufactures, or agricultural purposes or drainage, shall be interfered with thereby. Salmon Fisheries (Scotland) Act, 1868, 31 and 32 Vict. c. 123, Sec, XIX. 

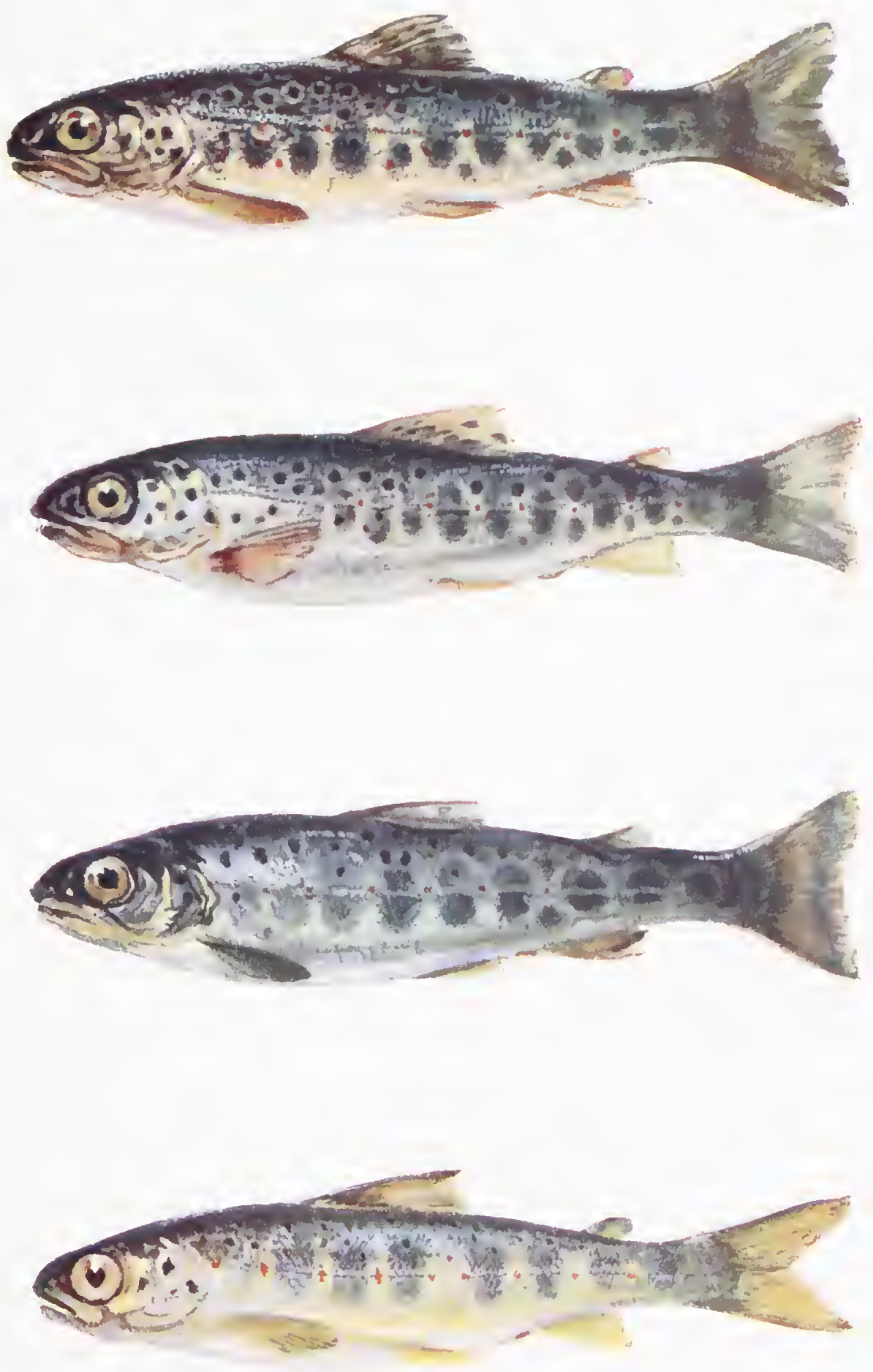

1. A TROUT, 2. A LOCH LEVEN TROUT, 3. A SEA.TROUT, AND 4. A SALMON. AS "YEARLINGS." 

angler may-quite innocently mistaking one kind for the other-incur the considerable odium of a conviction. There are those who may contend that he deserves to be punished for taking even trout of the size of salmon parr and smolts, but there is in many districts no discredit in taking trout of nine or ten inches in length, and I have seen sea-trout parr and smolts of that size quite innocently, if unlawfully, captured by anglers and put in the basket. Anything that will help to guide the angler to a safe decision in cases of doubt will consequently be of advantage.

I am not sure that any author in this country has dealt very satisfactorily with this matter, although a Norwegian author, Mr. Hartig Hüitfeldt-Kaas, has tabulated certain more or less constant distinctions between the young of salmon and trout. To tell the truth, it is by no means easy to give a verbal description of such differences as may be recognised between the several fish at their various stages of growth. For convenience of reference I insert here a plate showing approximately the colouring and markings, when the fish are yearlings, $4 \frac{3}{4}$ inches in length, of (I) a trout, (2) a Loch Leven trout, (3) a sea-trout, and (4) a salmon (Plate IV). As a first step, I shall try to indicate some distinctions between a salmon parr and a young trout.

One may start from the broad principle that if the angler is fishing in waters which he knows contain salmon he is bound to be upon his guard against taking their young. If he has any conscience at all in the matter he will, after catching one or two of the smaller fish, be able quite easily to detect that some of those he catches differ materially from others. He may not be able to say at once wherein the difference lies but he will be quite conscious that there is a difference. It will be found, I think, to be one of colour.

Young salmon, when held slanting to the light, have very obviously a general bluish tinge; young trout, when similarly held, appear to be of a yellowish-brown colour. This difference is so marked that I 
imagine the colouring of "blue and silver" and "brown and gold" phantom minnows is intended to give effect to it.

If then, having perceived this contrast, the angler now compares the two kinds of fish more minutely, still dealing with the superficial colouring and markings, he will see that the salmon parr is somewhat differently marked from the young trout. Both kinds of fish for at least the first year have a distinct series of dark slate-coloured oval marks along their sides, the ovals being bisected by the lateral line. They are variously referred to as "bands," or "arches" or "finger marks," but the term "parr marks" describes them sufficiently.

The parr marks are not, in either the young salmon or trout, of uniform number, but generally there are from eight to ten distinct ovals along the side of the salmon parr; but a curious break, as if an oval were missing or not fully formed, sometimes occurs in the middle of the series. The "parr marks" of the young trout are not only more numerous and less regular in their oval shape but the curious breaks referred to occur with more frequency in the series as if some of the ovals had been broken into upper and lower portions by the lateral line. The parr marks persist in the young salmon in definite outline until the fish is on the eve of migration when the silvery smolt scales effectually conceal them, yet on the scales being removed they may still be distinctly seen. The parr marks of the trout usually become irregular in shape and indistinct in outline in the second year, and appear then rather as darker patches of the body colour. I have said "usually," because in some instances, notably in Loch Freisa in Mull-and I may instance also Loch Tay and Loch Lomond-the trout retain their parr marks until they are fish of nearly a pound in weight. But in the general case, when a trout is about seven inches in length, the marks have become so indeterminate as to enable the fish to be easily picked out from a number of salmon parr on this account alone. In order that the reader may have an idea of the contrast between ycarling and two-year old fish, I 

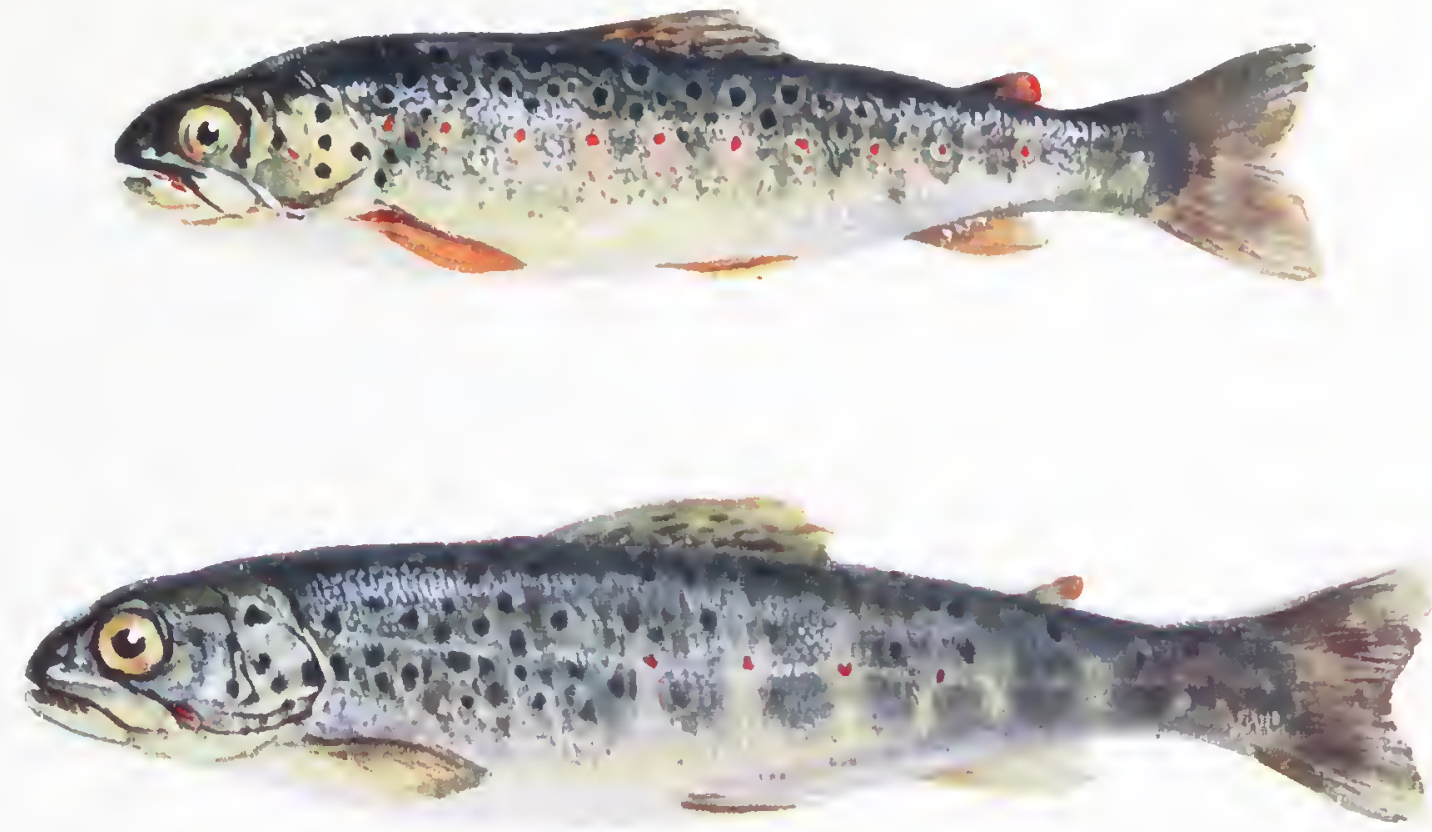
$($ (c)

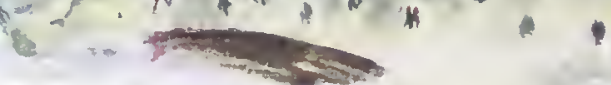

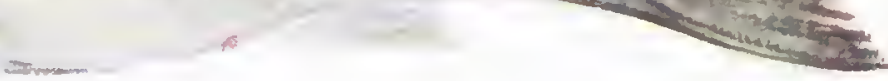

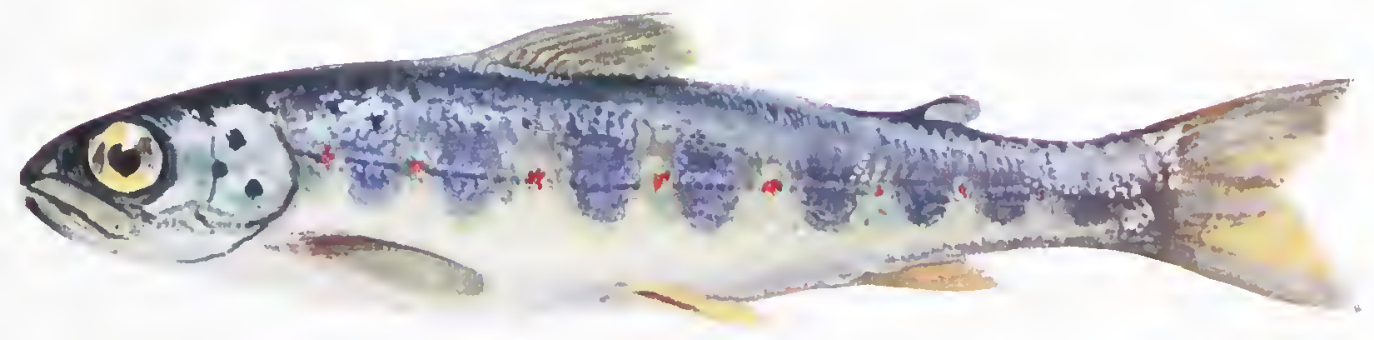

A TROUT, 2. A LOCH LEVEN TROUT, 3. A SEA.TROUT 

insert here a plate indicating in colour the general appearance and markings of (1) a trout, (2) a Loch Leven trout, (3) a sea-trout, and (4) a salmon, when at the "two year old" stage of growth (Plate V).

Young salmon and trout are both freely speckled with dark and crimson spots, and as to these something may be said. The dark spots of the salmon parr are small and occur only above the lateral line, while those of the young trout are generally bolder and are often numerous below the lateral line as well as on the back and shoulders. Each spot of the trout, too, as I have noted elsewhere, is usually surrounded by a ring or halo paler in hue than the general body colour. But a very distinctive feature of the salmon parr which one clearly recognises when attention is drawn to it is the intense black of the spots, generally one, two or three in number, on the operculum, that is, on the cheek. It may be noted too that the dorsal fin of the salmon parr is never very boldly spotted, while that of the trout alnost invariably is.

Dealing with the colouring of the fins, never a very certain feature, it may be stated that the pectoral fins of the salmon parr appear of a watery paleness compared with the rich yellowish-brown of those of the trout. So too the adipose fin of the young trout has nearly always, but I think not always, a reddish fringe, that of the salmon parr being in colour merely a dark continuation of the dark blue back.

Again viewing both fish broadly, but now in regard to shape, it will be seen that the salmon parr has a more graceful outline and a general air of greater delicacy than the young trout. Coming to details, its head is neater and its mouth relatively smaller than that of the trout, for, while the jaw of the salmon parr reaches back to a level with the middle of the eye, that of the trout extends as far as, or even beyond, the posterior margin of the fisl's eyeball. The eye of the salmon parr is also relatively larger than that of the trout, and, as already noted, is set more nearly in the middle line of the head when viewed in profile, that of the trout being set rather above the middle line. 
The pectoral fins and tail of the salmon parr are more delicate and pointed than the rounder and coarser fins of the trout, and the deeply forked tail of the salmon parr is a very distinctive feature.

It may be repeated that the numerical difference in the scales formerly noted also holds good with both fish in the parr stage.

So much for colouring and structure, but I may add the curious fact noted by Mr. A. H. Chaytor in his excellent "Letters to a Salmon Fisher's Sons" that "A young salmon or a parr or smolt of any other kind, when lifted out of the water, kicks and wriggles vigorously until actually secured by the hand, whereas a small trout lifted out on the line almost always hangs quietly or at most gives a few kicks," and he adds, "it is an absolutely certain way of knowing a young trout from a parr or from a smolt."

Altogether, it will be seen that there are a good many points which differentiate the salmon parr from the young trout.

I have thus contrasted first the salmon parr with the young trout to save complication of description as far as may be, and I shall now try to point out wherein specially the salmon parr differs from the sea-trout parr.

Perhaps, first, it should be said that in respect of size the two fish differ greatly. The Royal Commissioners of 1902 found that about 90 per cent. of the salmon smolts, as seen at Fochabers on the Spey, "were about 7 inches in length, and weighed a little over 3 ounces." Hence it may be taken that a salmon parr in its third year seldom exceeds seven inches in length. On the other hand sea-trout parr may actually grow to nine or ten inches in length before becoming smolts.

In respect of general colour the sea-trout parr approximates more closely to the young salmon than to the young trout, and curiously enough this is characteristic of the Loch Leven "parr" too, the marked bluish tinge in it also predominating.

As to the "parr marks," I have elsewhere noted that in the early 
fry stage the sea-trout has these less clearly defined in outline than either the salmon or the trout. The parr marks of the young sea-trout hardly remain visible after the first year, but they always appear with more or less definiteness upon the skin when the scales are scraped off, even after the fish has become a smolt.

The sea-trout parr has also both crimson and dark spots, but the dark spots vary greatly in number and appearance, and are far more like those of young trout than those of young salmon. The sea-trout's greenish-yellow tinted dorsal fin is usually boldly spotted.

The colouring of the fins of the sea-trout varies very much but generally the pectorals are yellow, tending sometimes to reddish-orange. Sometimes they are quite dark and of a greenish-grey.

Structurally, as regards head and jaw, the sea-trout parr differs from the salmon parr just as the young trout differs from it, and both as regards the lesser size and higher set position of the eye the sea-trout parr and the young trout are alike in differing from the salmon parr. So too the fins and tail of the sea-trout parr are more akin to those of the young trout, but perhaps as a rule the tail of the former is the more forked.

Again, counting in the oblique line of scales formerly mentioned the "I 4 -scale formula" obtains in the young sea-trout in contrast with the "Io-scale formula" of the salmon.

On the whole it will be recognised that while the salmon parr and sea-trout parr have something in common, in detail the sea-trout parr approximates perhaps more closely to the young trout.

As to any differentiation between sea-trout parr and young trout, account must be taken of Mr. Regan's dictum that "there are no structural differences, and the young are indistinguishable." But that there are some superficial distinctions there can be no question, although these are never very constant in consequence of the endless variety of marking and colouring that characterises both kinds of fish. 
Although not strikingly blue in the general tint of the body colour as the salmon parr is, the sea-trout parr has a tinge of blue in its colouring which, with the troutish yellow or brown that also enters into its composition, results in a greenish-blue, or at least a hue that marks it off from the purer yellow or brown of the trout. The distinction becomes more apparent after the fish have been dead for some hours and when the skin has dried.

I have never been able to detect in the spots a characteristic difference between a young sea-trout and a young trout; nor is the colouring of the fins in either fish always constant or distinctive.

As to structure, the sea-trout parr seems to retain longer than the trout an immature appearance of slender delicacy. With two fish each of eight or nine inches in length the trout will seem of more robust build, and its pectoral fins and tail will appear stronger and less delicate than those of the sea-trout parr. The tail of the latter certainly retains its forked shape much longer than does that of the trout.

It has puzzled me not a little to compress within small compass, for convenience of comparison and reference, these various distinctions, but the following table may-subject to what has been written aboveserve the purpose:- - 


\section{Distinctions between Salmon Parr, Sea-trout Parr and Young TROUT.}

\begin{tabular}{|c|c|c|c|}
\hline & Salmon Parr. & Sea-trout Parr. & Young Trout. \\
\hline LIMIT OF SIZE. & Seren inches. & Possibly ten inches. & No criterion. \\
\hline BODY COLOUR. & Blue. & Greenish-blue. & Yellowislı-brown. \\
\hline PARR MARKS. & Very distinct. & Less distinct. & $\begin{array}{l}\text { Very distinct when year- } \\
\text { ling. Traces only later. }\end{array}$ \\
\hline BLACK SPOTS. & $\begin{array}{l}\text { One or two very intense on } \\
\text { cheek, small and few on } \\
\text { body above lateral line. } \\
\text { No halo. }\end{array}$ & $\begin{array}{l}\text { Various and more or less } \\
\text { numerous. Halo not con- } \\
\text { stant. }\end{array}$ & $\begin{array}{l}\text { Various and more or less } \\
\text { numerous. Halo usually } \\
\text { constant. }\end{array}$ \\
\hline RED SPOTS. & Not distinctive. & Not distinctive. & Not distinctive. \\
\hline PECTORALS. & Dusky pale. & Pale to yellow or dark. & Vellowish-brown. \\
\hline ADIPOSE FIN. & Dark. & $\begin{array}{l}\text { Dark. Frequent reddish } \\
\text { fringe. }\end{array}$ & Reddish fringe. \\
\hline SHAPE. & Slender. & Slender. & Robust. \\
\hline HEAD. & Small, neat. & Longer. & Larger and blunter. \\
\hline MOUTH. & Small. & Large relatively. & Large relatively. \\
\hline TEETH. & Not distinctive. & Not distinctive. & Not distinctive. \\
\hline EYE. & Large, and set low in head. & $\begin{array}{l}\text { Relatively smaller, and set } \\
\text { ligher in liead. }\end{array}$ & $\begin{array}{l}\text { Relatively smaller, and set } \\
\text { ligher in head. }\end{array}$ \\
\hline FINS. & Delicate and pointed. & $\begin{array}{l}\text { Less delicate and more } \\
\text { pointed. }\end{array}$ & Stronger and more rounded \\
\hline TAIL. & Forked. & Less forked. & $\begin{array}{l}\text { Less forked, and more } \\
\text { rounded in outline. }\end{array}$ \\
\hline SCALES. & "Io-scale formula." & "r4-scale formula." & "x4-scale formula." \\
\hline $\begin{array}{l}\text { ACTION } \\
\text { (Chaytor). }\end{array}$ & Agile on capture. & Agile on capture. & Quickly inett. \\
\hline
\end{tabular}


It is probable that some one or other of the distinctions thus tabulated will help the reader to discriminate in most waters between salmon, sea-trout and trout when in the "parr" stage of growth. It remains to point out the special characteristics of the smolts of salmon and sea-trout.

One cannot well speak of the smolt of the common trout because, while individuals of the type known as Salmo fario seek the sea and in doing so assume a silveriness of scale beyond the normal, their migration is never so marked or so periodic as to constitute a feature of their career. But it is curious to note that trout are commonly more silvery in spring than at other seasons of the year. How far this may suggest preparation for a possible migration, and how often that migration may actually be effected it is not very easy to decide. In circumstances where environment specially favours migration it may, as we shall see, very commonly occur. I apprehend that if and when such a descent does occur the descending trout will be indistinguishable from descending sea-trout smolts. In this connection I submit a plate of a Loch Lomond trout (Plate VI) in which the first figure shows the complete silvery dress while the second figure (of the same fish) shows the silvery scales partially removed. The scales of this fish, which was caught towards the end of May I9 I5, showed that it had just commenced feeding freely in its third year. Assuming my drawing to be approximately accurate it may readily be conceived that the difficulty of distinguishing a Loch Lomond trout from a sea-trout is extreme, but my own opinion, based very much upon the appearance of the exposed skin surface that this fish was actually a trout, was confirmed at the time by the opinion of several of the most experienced Luss boatmen, and of the manager of Luss Hatchery.

The salmon smolt can hardly be mistaken. It is seldom less than six and a half-inches in length and seldom more than seven and a half inches. It is of the most brilliant silvery sheen, the general body colour 


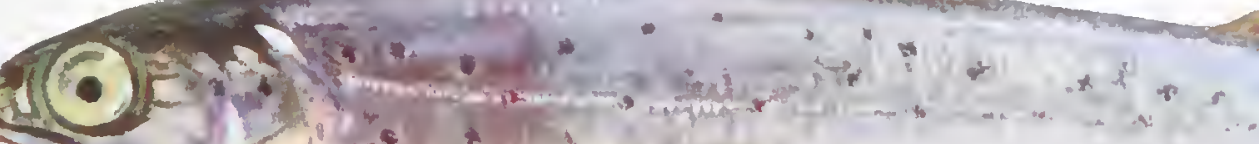

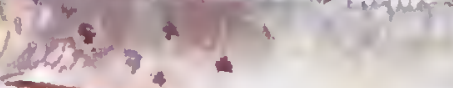

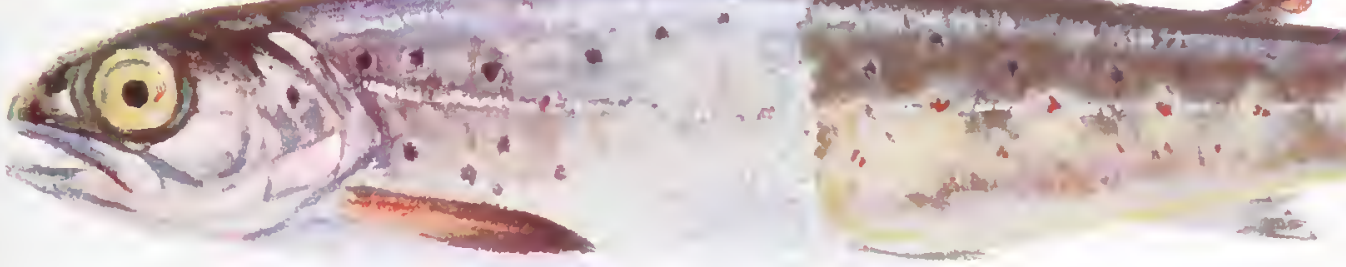





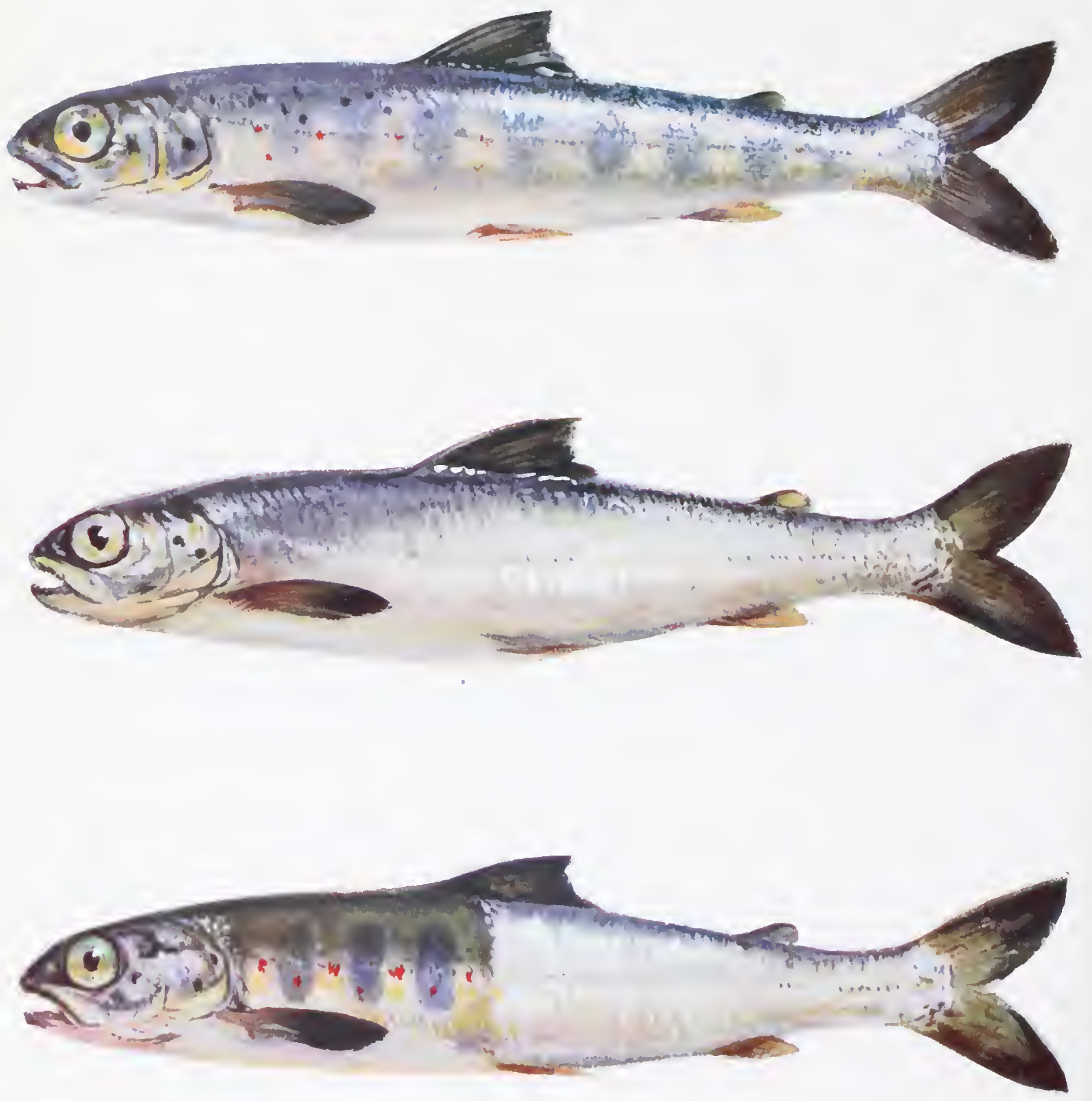
being of a pronounced blue on the back shading to pure white on the under parts. The scales come off very freely and adhere to the hand when the fish is grasped. The fins are delicate and the tail is deeply forked. The tail is of a peculiarly rich black, the pectorals are a dusky grey colour, and the dorsal fin is unspotted. The black spots on the body are hardly discernible, but the distinctive spots on the cheeks remain. The crimson spots may sometimes still be seen here and there along the lateral line. Otherwise all the parr markings are concealed beneath the smolt dress of silver.

The sea-trout smolt in the main resembles the salmon smolt, being like it in general colour, blue-backed and white-bellied, with the same glistening silvery scales easily detachable. The distinctions between the two fish chiefly lie, first, in the relative size which in the sea-trout may be as much as ten inches; second, in the colour of the sea-trout's fins-especially the pectorals - which are often of a rich yellow; thirdly, its dorsal fin is usually spotted, and, fourthly, the black spots of the body, and sometimes the red spots along the lateral line, are more conspicuous than in the salmon smolt.

When the silvery scales are scraped off the distinctive parr markings of both fish are clearly seen on the skin beneath. It may interest the reader to see a coloured presentment, as I give it in Plate VII, of (I) a young salmon in the transition stage between the parr and the smolt, (2) the smolt in full sea-going dress, and (3) a smolt with the silvery scales partially removed. The idea of this drawing is of course not original. In Scrope's "Days and Nights of Salmon Fishing in the Tweed" ("The Sportsman's Library," edited by the Right Hon. Sir Herbert Maxwell, Bart., I 898), there is a coloured frontispiece of a salmon smolt with the silvery scales partially removed to disclose the parr marks. Mr. Malloch, too, has adopted this method of showing the smolt dress in some of his excellent photographic illustrations.

I think it is of interest to note that the more prominent of the black r 
spots on the skin of the sea-trout parr are repeated on the silvery surface of the sea-trout smolt as if they were endeavouring to shine through, but they are not now so conspicuous because they have already begun to be broken up into the $\mathrm{X}$-shape which so often characterises the spots of the mature fish.

In supplement of the foregoing notes upon the various distinctions which characterise the young of salmon, sea-trout and trout, I may add a table of the distinctions which have been noted by a Norwegian observer, Mr. Hartig Hüitfeldt-Kaas, as occurring between the parr and smolts of salmon and trout, i.e., sea-trout. The following rough translation has been kindly made for me by Mr. Hutton :-

SALMON.

The body is comparatively more delicately and more pointedly shaped with a long and slender tail.

The head is set lower on the body and more finely shaped. At the first glance the head seems to be exceptionally long, but this is due to the fact that the front portion (viz., the nose and mouth) is distinctly shorter than the trout's, so that the gill-covers are longer in proportion.

The eye is comparatively large and is placed well forward in the head. A perpendicular line drawn downwards from the posterior margin of the pupil will as a rule not touch the posterior end of the maxillary bone.

The mouth is comparatively small, and the length (measured to the posterior edge of the maxillary bone) is equal to about $1 \frac{2}{3}$ diameters of the eye.

All the fins (with the exception of the adipose fin) are longer than the trout's.

The tail fin is distinctly V-shaped, and the extremities of each lobe are either pointed or very slightly rounded.
Trout.

The body is comparatively clumsy with a short thick tail.

The head is comparatively larger and more clumsily shaped than the parr's. The front part is much longer, and the nose is longer and deeper, and the lower jaw heavier. Consequently the mouth is larger, and therefore the maxillary bone is distinctly longer than the parr's.

The eye is distinctly smaller. Although it is set further back in the head, a perpendicular line drawn downwards from the posterior edge of the pupil will either cut or touch the maxillary bone.

The mouth is large, and the length (measured to the posterior edge of the maxillary bone) is about $2 \frac{1}{2}$ to 3 times the diameter of the eye.

All the fins (with the exception of the adipose fin) are shorter than the parr's.

The back of the tail fin when stretched out forms either a straight line or is only slightly concave, and the lobes are broader and more rounded. 


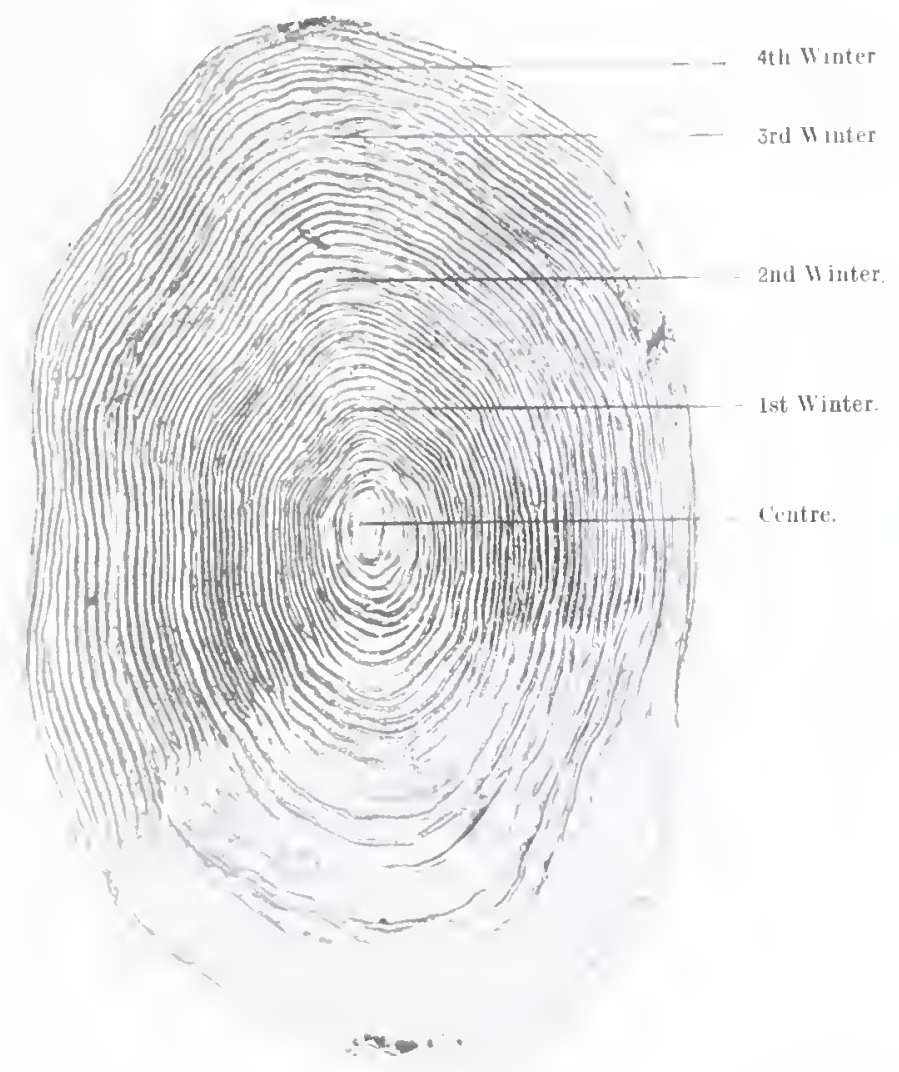

Fig. 30. - honle of a hate-descending Sea-trout Smolt. ( $x$ fo.)

The fish had spent four whiters in fresh water. It was canght in Lorh Lomond on 13 ht August, 1914 . Weight, $\frac{1}{4} \mathrm{lb}$. Length, $9 \frac{1}{4}$ in. Age, over 1 years. 

SALMON.

The extremity of the pectoral fin when stretched flat against the side will reach a line drawn from the anterior edge of the dorsal fin.

The adipose fin has no red colour.

The scales are larger and less in number than in the case of the trout. In a slanting line between the posterior edge of the adipose fin and the medial line there are usually 1 I-I 2

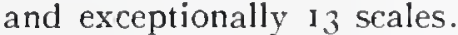

Before the migratory colouring is assumed, the colouring of the parr is similar to that of small beck trout, with one row of large, distinctly red spots along the medial line, and of ten with some smaller red spots above and below this line. There are also a number of small dark spots spread over the whole body above the medial line, with a lesser number below.

What is especially characteristic of the parr is the regular row of large blue-grey blotches, even in breadth, about $8-I_{3}$ in number, and about 1 to 2 diameters of the eye wide, which contrast remarkably with the white colour of the under portion of the body. They resemble the smudges which would be made by fingers smeared with blue-grey paint.

The smolt dress differs from the parr colouring only in the fact that a silvery sheen covers over the original colouring, which latter shows through the semi-transparent silvery coat, and little by little the original colouring is less and less visible, but so long as the smolt remains in fresh water the parr colouring can still be distinguished, and especially in certain angles of light.

There are usually from 2 to 4 black spots on the gill-covers.
TROUT.

The pectoral fins when stretched out will not reach a perpendicular line drawn downwards from the anterior edge of the dorsal fin.

The end of the adipose fin is usually tinged with red or orange.

The scales are smaller and more numerous. In a slanting line drawn between the posterior edge of the adipose fin and the medial line there are usually 14-16 scales and occasionally more.

The colouring before the migratory dress is assumed is more variable than with the parr. In addition to the red spots on the sides, which are usually in three rows, one generally finds a large number (exceptionally a few) small dark spots scattered over the back and sides of the fish, with a relatively large number below the medial line.

In place of the characteristic "finger marks" of the parr, on the trout there are fewer blotches and they are much more irregular in shape.

As far as the migratory dress is concerned (in which condition sea trout are to be found in large numbers and of the same size as salmon smolts) the trout is of a silvery white colour, hut it retains unchanged all the small black spots both above and below the medial line, but not the red spots. This is the most distinctive difference between salmon and sea trout in the smolt stage.

The black spots on the gill-covers are usually more than 4 in number.

The following points should be specially noticed: the shape of the head, the size of the eye and the mouth in comparison with one another, the number 
of scales, the shape of the tail, and the number and arrangement of the small black spots : it is most exceptional to find on salmon any black spots below the medial line behind the posterior edge of the back fin. ${ }^{1}$

The actual description of a sea-trout smolt which was taken from the river Leven on ist March, I9I3, is as follows:-Length, over all, $9 \frac{1}{2}$ inches, of which the head occupied 2 inches and the caudal rays $\mathrm{I} \frac{1}{4}$ inches; girth, at dorsal fin, $4 \frac{1}{4}$ inches; weight 6 ounces. Body colour, a pronounced blue on the back shading towards the lateral line to a pale blue and thence to clear white on the under parts. Dark cruciform spots closely speckled on the skin both above and below the lateral line. The silvery scales, counted in the oblique line formerly described, clearly numbered I4. The scales were easily removed and beneath them 9 parr marks were faintly seen on each side of the fish. The fins shaded from a pale yellow in the pectorals to a still paler yellow in the ventral and anal fins. The dorsal fin was a dusky yellow closely spotted with dark spots, and the dusky adipose fin had a reddish tinge on its margin. The dusky tail was deeply forked. I am able to give a coloured drawing (Plate VIII) of one of these exceptionally big smolts. The specimen figured measured 9 inches in length.

I have seen in other districts ascending whitling which were scarcely larger than the smolt figured, but Loch Lomond whitling, which are noted for their exceptional size and quality could hardly be so small. The fish was unmistakably a sea-trout smolt engaged in a leisurely descent to the Clyde estuary.

The "run," as it is called, of descending smolts begins intermittently as early as February-in the Leven a sea-trout smolt has actually been got as early as January--and gradually increases during March, the main body descending towards the end of April, after which the run again becomes intermittent in May and practically ceases in June. But I have evidence that smolts may descend very much later in the 1. From "Huorledes adskilles lakse-örret-os roieyngel fra |hinanden," [by IIartig Huitfeldt-
Kats, Clıristiania (1905). 


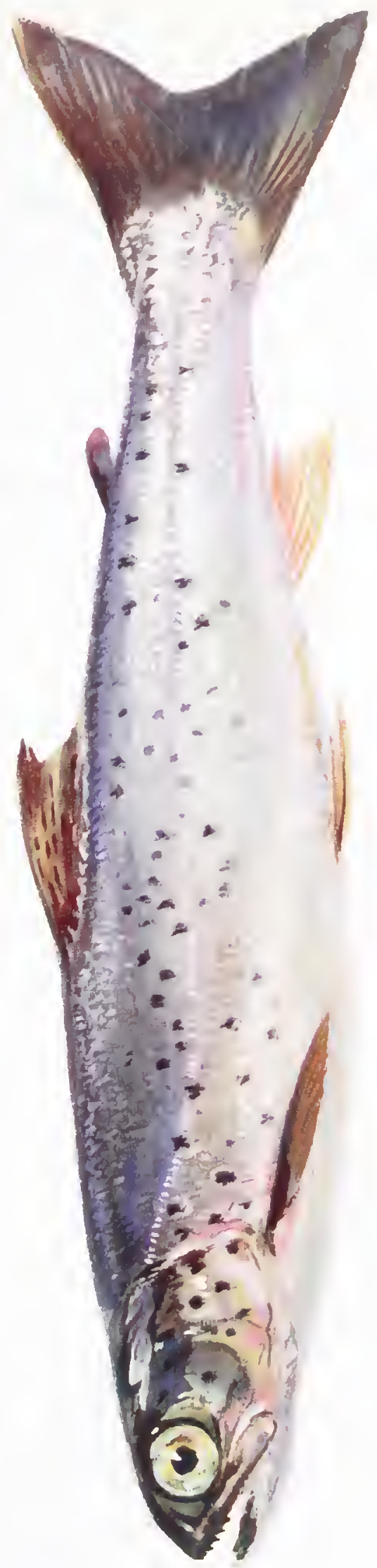



season. On August 13, 1914, I caught in Loch Lomond a fish which was clearly a sea-trout smolt on its way to the estuary. It measured $9 \frac{1}{4}$ inches in length, was $4 \frac{1}{2}$ inches in girth, and its scales came off freely in handling. When sending some of the scales for examination to Mr. Hutton I noted briefly:- "A very interesting fish as being apparently a very late-running smolt. Four parr marks still visible towards the tail on the scales being removed." I reproduce a photograph of one of the scales (Fig. 30), which indicates that the fish had completed four ' winters' residence in fresh water before the migratory instinct asserted itself in its fifth year. ${ }^{1}$

Weather conditions affect considerably the time of descent of the main body, and where the stock is large and distributed throughout a great stretch of country inland, the run will be proportionately prolonged. It is, I think, always prolonged where an extensive estuary receives the inland waters through long tidal reaches. The descent under these circumstances is a very leisurely affair, or it might be said that once in brackish water the smolt is in no haste to go further afield.

It is a curious fact, worthy of spesial observation, that the descent of the main body of sea-trout smolts in the river Leven always precedes the main descent of the salmon smolts by about a fortnight, and I understand, for I have made inquiry, that this order of progression to the sea obtains elsewhere.

So far as I am aware, no investigations equivalent to those undertaken by Mr. Knut Dahl in Norway have been attempted in Britain with a view to determining when the young sea-trout first migrate to salt water as sea-trout smolts, whether in the first, second, third, or even some subsequent year of their existence. This appears to me to be a vital question in the life-history of the fish and one deserving of the fullest and most careful investigation in many rivers. I have not myself made any such extensive investigation, and can only submit

1. See later as to this subject, page 110. 
such very imperfect data as I possess bearing upon the point-imperfect as being gathered in a restricted field. But my data, so far as they go, suggest speculations which seem to me to be reasonable, though not a little surprising, and all the more interesting that they once more bring us into touch with the theory that there is only one species of trout in the British Isles.

I think, then, that it is very improbable that any young sea-trout will in its first year-that is, during the year in which it is a "sea-trout fry"descend to the estuary or the sea, nor is proof of such a descent anywhere to be found.

It is quite possible, however, in such rivers as the Tay, the Tweed and the Leven, where the tidal influence is felt for a considerable distance above the actual mouths of the rivers, and in waters such as are found in the Orkneys and the Hebrides, which are hardly distinguishable as salt or fresh, that some of the young fish may, in their second year-that is, as "sea-trout parr"--drop down towards salt water though never adventuring, as true "sea-trout smolts," that year into water which is markedly salt. Mr. Calderwood, in one passage in "The Life of the Salmon," makes a suggestive remark in this connection besides incidentally showing that he has some belief in the "shoal theory," which I have already propounded. As to some small salmon fry being found near salt water in the lower reaches of the Tay he hazards this explanation:- "It seems probable, however, that other young fry, following the instinct to form into shoals which we know parr possess, have joined themselves to companies of larger parr, or it may be have been to some extent washed down by floods." Much more is this descent probable in the case of the sea-trout, a more characteristically estuarial fish than the salmon; but here again I can give no proof of such a descent in the second year.

The earliest marked descent of the sea-trout smolt occurs in its third year, that is, after it has spent two winters in fresh water After 

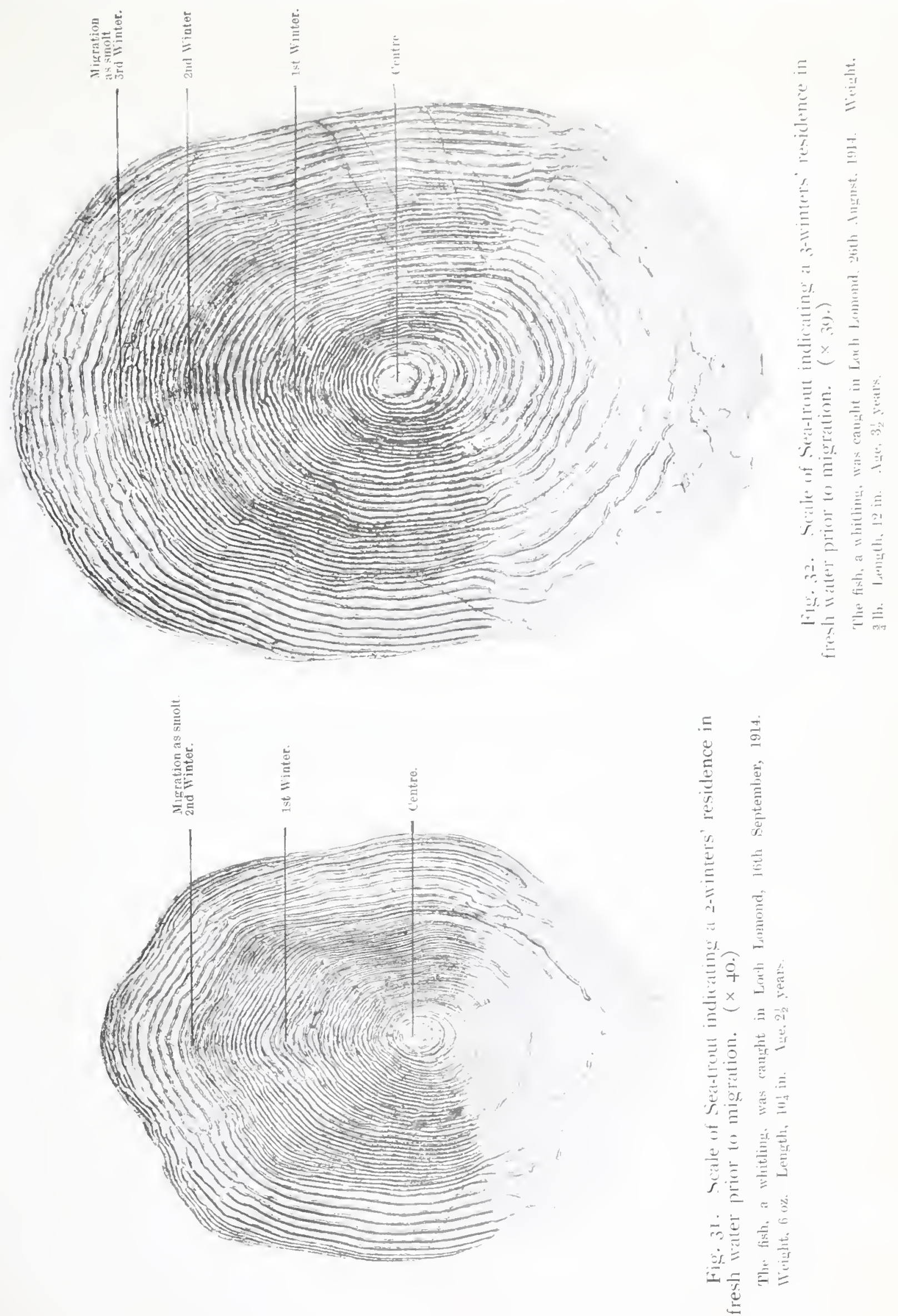

the turn of the year, then, and, if the winter has been mild and open, all the sooner, the various shoals up-stream begin to pack in earnest and work down towards estuary or sea. By April of this year the youngest of these fish will have had two full years of life since ceasing to be alevins. In hatchery parlance they are "two year olds," and it is at this age the earliest true descent is made. In any event, it is only on the fish assuming the sea-going silvery scales prior to its descent, whensoever that descent may take place, that the young fish should properly be designated a "sea-trout smolt." That the period when the young sea-trout thus becomes a smolt varies considerably I shall now proceed to show.

I may make first this general observation that, with the Salmonida, size has very little co-relationship with age. One is apt unthinkingly to take it very much for granted that a large salmon, for instance, is an old salmon and that a small trout is a young trout. How far this is erroneous may be seen when we consider that a Tay salmon weighing over $50 \mathrm{lb}$. may be only six years old, while an Add fish of Io lb. may quite well be two years older. Even more strikingly, a young salmon may be larger than an older salmon taken from the same river owing to the latter having been handicapped in its growth by having visited fresh water more frequently for the purpose of spawning. Similarly with regard to trout, the stunted little occupant of the moorland burn or hill loch weighing but a few ounces may very well be an older fish than the pampered occupant of some rich reservoir weighing as many pounds. One has therefore no real warrant for supposing that the sea-trout smolt which is seen descending a river at any time is only as old as it looks. On the contrary there are reasonable grounds for the belief that it may very well be much older. Even allowing that sea-trout parr, as has been noted, grow proportionately quicker than salmon parr, I had often puzzled myself to account for the remarkable size attained by some of the Loch Lomond and Leven sea-trout parr, specimens of 
which I have seen measuring $10 \frac{1}{2}$ inches in length. In the same way some of the Loch Lomond whitling appeared to me to attain exceptional growth. It had occurred to me that the question of age, as well as questions of diet, might have some bearing upon the matter, but it was not till the autumn of 1914 that the matter was made fairly clear.

Early in $1914 \mathrm{Mr}$. J. Arthur Hutton was kind enough to say that if I would collect for him a series of scales taken from Loch Lomond sea-trout he would devote some of his leisure to making a special study of them, as the facts derived from such a study might help to throw some light upon the various problems which would certainly arise in course of the inquiry which I was undertaking. I need hardly say how valuable such an offer in the circumstances appeared to me to be and I gratefully availed myself of it, collecting as I did for Mr. Hutton during the season of 1914 a series of scales taken from 45 sea-trout in various stages of growth and in different states of physical condition. Mr. Hutton was further so kind as to place at my disposal such data on this subject as could be gleaned from other sets of sea-trout scales in his possession. Notwithstanding that he has cautioned me against rating his experience of the reading of sea-trout scales too highly, I myself have no real doubts as to the substantial accuracy of his scale interpretations, more especially as these are borne out by the results obtained by Mr. Knut Dahl with respect to Norwegian fish.

On the particular point, then, as to the time of descent of the seatrout smolts as indicated by the scales, Mr. Hutton finds-and in his company I have confirmed his "readings"- that of the 45 Loch Lomond fish none descended after only one winter spent in fresh water. Mr. Hutton further informs me that of all the sea-trout scales he has examined, including scales of fish from several rivers in Norway, from the Wye, and from South Uist, he has not come upon a single instance of a sea-trout having migrated to the sea after only one year's freshwater life. The periods of actual descent, following Mr. Knut Dahl's method of tabulating the facts, may be shown thus:- 
Scotland.

\begin{tabular}{c|c|c|c|c|c}
\hline \multirow{2}{*}{$\begin{array}{c}\text { Loch Lomond Fish } \\
\text { Examined }\end{array}$} & \multicolumn{4}{|c}{ Of these the Following had Completed previous to Migration } \\
\cline { 2 - 5 } & 2 Winters & 3 Winters & 4 Winters & 5 Winters & 6 Winters \\
\hline 45 & 7 & 30 & 7 & 1 & 0 \\
\hline
\end{tabular}

Tabulating now in the same way the data drawn from Mr. Hutton's collection of sea-trout scales on this particular point, the results are :Scotland.

\begin{tabular}{c|c|c|c|c|c}
\hline \multirow{2}{*}{$\begin{array}{c}\text { Sonth Uist Fish } \\
\text { Examined }\end{array}$} & \multicolumn{4}{|c}{ Of these the Following had Completed previous to Migration } \\
\cline { 2 - 4 } & 2 Winters & 3 Winters & 4 Winters & 5 Winters & 6 Winters \\
\hline 6 & I & 5 & 0 & 0 & 0 \\
\hline
\end{tabular}

\section{EngLand.}

\begin{tabular}{c|c|c|c|c|c}
\hline \multirow{2}{*}{$\begin{array}{c}\text { River Wye Fish } \\
\text { Examined }\end{array}$} & \multicolumn{4}{|c}{ Of these the Following had Completed previous to Migration } \\
\cline { 2 - 5 } & 2 Winters & 3 Winters & 4 Winters & 5 Winters & 6 Winters \\
\hline I7 & 7 & so & 0 & 0 & 0 \\
\hline
\end{tabular}

NORWAy.

\begin{tabular}{c|c|c|c|c|c}
\hline \multirow{2}{*}{$\begin{array}{c}\text { River Aa Fish } \\
\text { Examined }\end{array}$} & \multicolumn{4}{|c|}{ Of these the Following had Completed previous to Migration } \\
\cline { 2 - 6 } & 2 Winters & 3 Winters & 4 Winters & 5 Winters & 6 Winters \\
\hline 22 & 5 & 17 & 0 & 0 & 0 \\
\hline $\begin{array}{c}\text { River Osen Fish } \\
\text { Examined }\end{array}$ & 2 Winters & 3 Winters & 4 Winters & 5 Winters & 6 Winters \\
\hline \multirow{2}{*}{25} & Of these the Following had Completed previous to Migration & I & O \\
\hline
\end{tabular}


Before making further comments upon these results I venture to submit for purposes of comparison with every proper acknowledgment, the results obtained by Mr. Knut Dahl in Norwegian waters :-

Norway.

\begin{tabular}{c|c|c|c|c|c}
\hline \multirow{2}{*}{$\begin{array}{c}\text { Norwegian Fish } \\
\text { Examined }\end{array}$} & \multicolumn{3}{|c}{ Of these the Following had Completed previous to Migration } \\
\cline { 2 - 4 } & 2 Winters & 3 Winters & 4 Winters & 5 Winters & 6 Winters \\
\hline 192 & 25 & 78 & 67 & 21 & 1 \\
\hline
\end{tabular}

Accumulating all these results, as I think may instructively be done, we obtain the following data:-

\begin{tabular}{l|c|c|c|c|c}
\hline \multirow{2}{*}{$\begin{array}{c}\text { Fish } \\
\text { Examined }\end{array}$} & \multicolumn{4}{|c}{ Of these the Following had Completed previous to Migration } \\
\cline { 2 - 5 } & 2 Winters & 3 Winters & 4 Winters & 5 Winters & 6 Winters \\
\hline 307 & 46 & 159 & 78 & 23 & 1 \\
\hline
\end{tabular}

In order that the reader may judge for himself of the value of this evidence drawn from scale reading, I submit reproductions of photographs taken by Mr. Hutton of (I) scales of Loch Lomond sea-trout indicating $(a)$ a 2 winters', (b) a 3 winters', $(c)$ a 4 winters', and $(d)$ a 5 winters' residence in fresh water, and (2) to compare with the last of these, because the reading is doubtful, the scale of a Norwegian seatrout indicating a 5 winters' residence in fresh water, prior to the migration of these fish to the sea as sea-trout smolts (Figs. 31, 32, 33, 35 and 36 ).

In this connection I may be allowed to repeat the scale of the descending smolt (Fig. 34) described on page 105, which shows a 4 winters' residence of the fish in fresh water prior to its descent to the sea in its fifth year, in order that the reader may compare it with the scale of the whitling (Fig. 33) which had spent 4 winters in fresh water 

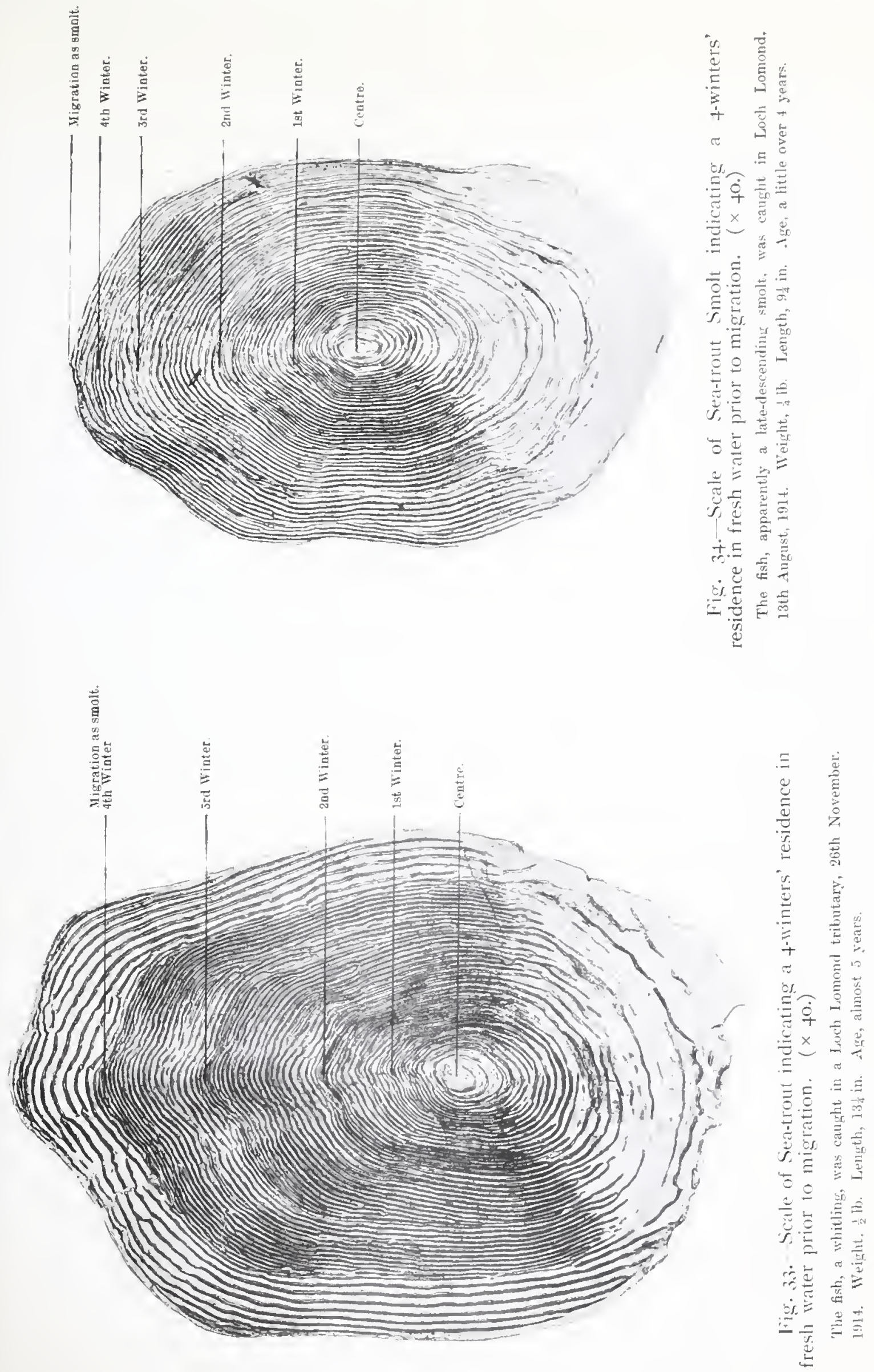

before it descended as a smolt. The two scales are shown side by side for convenience of reference.

Now it has to be admitted that the British data are too limited in extent for any certain principles to be deduced from them, but I think they prove conclusively that there is considerable variation of the time of descent of the sea-trout smolts even in any one particular district or river. They also suggest, if they do not actually prove, that the period of descent of the majority of the smolts, in Scotland and England as well as in Norway, is after three winters' residence in fresh water. One Loch Lomond instance also proves that a sea-trout may voluntarily delay its descent till after its fifth winter spent in fresh water, while a single instance given by Mr. Dahl also proves that in Norway the delay may be protracted even for another year. There can be no question, however, that the general principle is established from these data that one has no right to assume as regards any river that all the sea-trout smolts which descend to the sea in any particular year are the produce of any one particular preceding spawning season.

It is an interesting speculation-and I think a legitimate speculation-that the occurrence of a lake in any river system may encourage the young fish to protract their stay in fresh water. The data concerning Loch Lomond fish are at least not adverse to that assumption, and I am informed by Mr. Hutton that two considerable lakes interrupt the uniform channel of the Osen river in Norway. A wider investigation may establish this theory which on the face of it does not seem to me to be unreasonable. I shall return to this point later. ${ }^{1}$

Some connection with what I have called Mr. Regan's theorythough of course it is not alone his-may, to speculate further on these data, be traced in this way.

"If salmon smolts," writes Mr. Calderwood, "are retained in fresh water beyond their natural time of descent to the sea, they assume again the trout-like appearance of the juvenile." This "natural time of 1. See post, page 144 . 
descent" of the salmon smolt, though not absolutely constant, is, in Scotland, in the great majority of instances in the spring months after two full years' residence in fresh water. But if the young sea-trout voluntarily remains in fresh water, as the scales seem to indicate, for three, four, five, or (in Norway) actually six years, how much more will it be likely to retain a "trout-like appearance"? To all seeming it is quite content to remain a trout for an indefinite period, or, to put it another way, the migratory habit takes a somewhat indefinite number of years to declare itself. While this instinct or habit remains dormant, the sea-trout is to all intents and purposes rather a miserable specimen of a trout which will not develop generous proportions till it gains the richer feeding grounds and more extended range of the sea or estuary, just as the puny occupant of a mountain tarn will never develop in such a habitat, but will, if removed to richer feeding grounds in a wider range of water, at once begin to gain in bulk and appearance. Most readers will be aware of some instance where such a result has followed upon the transplanting of trout. For a curious example noted by $\mathrm{Mr}$. Knut Dahl I may refer the reader to pp. 77 and 78 and Fig. 33 (Plate $\mathrm{X}$ ) of his work already noticed.

In this connection I think that the Howietoun experiments described in my introductory chapter have some relevancy, and I would ask the reader again to study the account given of them with some care. The points material to the history of the sea-trout-and to Mr. Regan's theory-may for convenience be here again noted :-

I. That the Howietoun sea-trout parr lived in fresh-water quarters for four years without any apparent discomfort;

2. That in their third year critical observers could not distinguish them from common trout;

3. That in their fourth year the females inter-bred with Loch Leven males; 
4. That the resulting "cross" breed became indistinguishable from other trout fry; and

5. That the parent true sea-trout brood survived in a reservoir even if they did not attain any great size.

I think on the whole it is a fair and reasonable conclusion to draw from the facts of the foregoing experiments, supplemented as these are by the evidence of the scales of wild fish which I have just submitted, that the young of the sea-trout may without discomfort postpone their descent to the sea for a period of years more or less prolonged according to the nature and circumstances of their freshwater environment. To carry the matter still further, it does not seem to me to be extravagant to imagine, if indeed it is the case that the sea-trout brood is ever indistinguishable from the brood of the common trout of the district, that some of the young fish never develop the migratory habit at all, or, in other words, that they remain trout.

With the approach of the sea-trout smolt to the whitling stage the facts definitely known about the fish become even less well defined. No systematic examination of scales, or marking of sea-trout, have to my knowledge yet been carried out, as they have been in the case of the salmon, and there is no reason to believe that when they are so any less interesting facts will be discovered than have been discovered with reference to the life-history of the salmon.

I have already referred to the fry and parr of sea-trout maintaining an original shoal formation, and I am inclined to think that, as these shoals descend from the upper waters, whether they have packed together in one great body or not, they still maintain their separate individuality, just as at a review of troops battalions, companies and platoons may mass together at one time and separate at another. It might perhaps be difficult to adduce direct evidence of this, but if one accepts the theory of shoal feeding at all, there seems no very good reason why the shoal which foraged for food in the fry and parr stages 
of the fish's existence should not continue its foraging in the sea or estuary when the fish have become smolts and indeed thenceforward, at least, as I shall suggest, until they have become whitling.

On reaching the brackish water of an estuary the sea-trout smolts show no great anxiety to push far afield. In this way they differ essentially from the salmon smolts which, it must be remembered, are descending towards salt water at and about the same time, many of each kind being actually in company. Mr. Calderwood and Mr. Knut Dahl have, with some degree of definiteness, proved that, estuary or no estuary, the salmon smolt makes directly for the sea and does not linger for any length of time in brackish water-it makes a bolt for the blue. I shall venture to state here what Mr. Calderwood discovered concerning salmon smolts in course of a special netting expedition which he conducted in the Tay in I903, for some valuable facts regarding sea-trout were ascertained at the same time. The object of the expedition was to trace the descent of salmon smolts down the estuary.

"From the time we left the neighbourhood of Kinfauns," Mr. Calderwood writes-the passage is from his valuable work on "The Life of the Salmon "- "the smolts became fewer, and when we had descended about two miles and a half, and had reached a point a short distance below the mouth of the river Earn, where sea-weed begins to make its appearance upon the shore, smolts could not be found at all. We proceeded down the estuary, however, and, thanks to the courtesy of the Tay Fisheries Company, who granted the use of their steam yacht, completed a survey of all available fishing places, both on the shores of the lower estuary and on the shallow banks in mid-stream near the Tay Bridge, till eventually we reached Budden Ness and the open sea, some twenty miles below our starting point. Not another salmon smolt did we catch, however, although sea-trout smolts were everywhere in evidence, as well as brown trout, herrings, flounders, a 

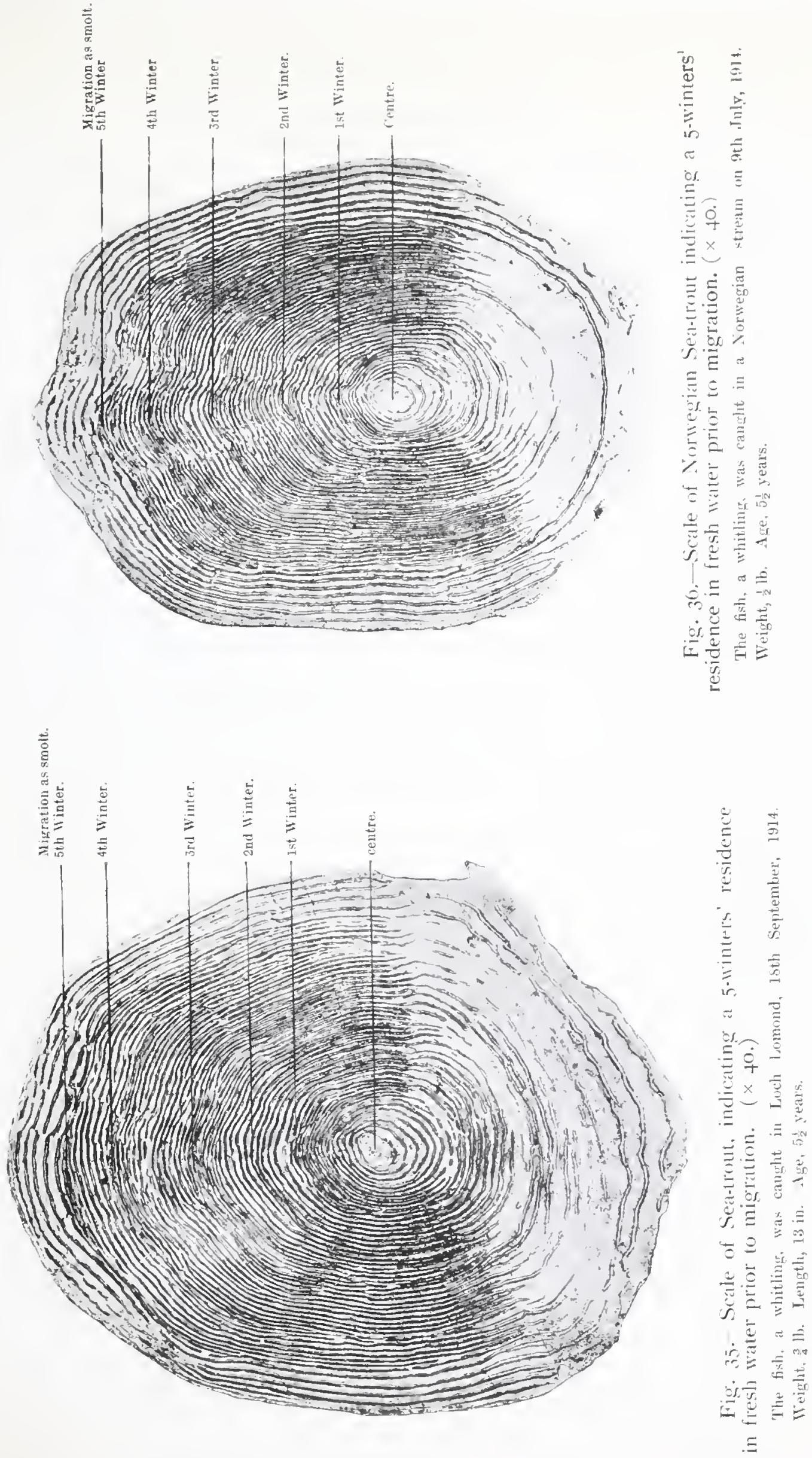

young turbot, sand eels, pipe fish, and various marine shore forms. In this we repeated the experience of Mr. Dahl in his attempts to follow salmon smolts from the rivers of Norway down the fjords." Then in course of renewed operations with a boom-net in the following year, Mr. Calderwood made further discoveries of which one in particular is relevant to the present subject, namely: "All salmon smolts captured were taken when the net was set so as to fish the ebbing tide. When the net was set so as to fish the flood tide or incoming current sea-trout were alone taken, and many of these were nearly twice the size of the salmon smolts. Sea-trout were also taken during ebb tide."

The relatively larger size of the sea-trout was illustrated in my description of a Leven smolt given on a previous page. But the main point which Mr. Calderwood's investigation brings out is that the seatrout is essentially an estuary fish. It may be presumed, therefore, that in such great estuaries as those of the Tay and the Clyde there is no occasion for the sea-trout to leave even the narrower waters of the estuary in its transitional stage between the smolt and the whitling, nor in such environment does the whitling do so before it again ascends to fresh water, as one finds them there in all stages of the transition.

But there are few estuaries so extensive and so rich in feeding grounds as those of Tay and Clyde. Many sea-trout streams have practically no estuary at all, and between both types the variety of river formation in Scotland is endless. On the type of estuary, then, and the feeding grounds afforded by it, and where there is barely an estuary or none, then on the available feeding grounds in the sea in the vicinity, will, I think, depend in great measure the habits of the local sea-trout. For this reason alone I think it would be unwarrantable to lay down any scheme of definite uniformity in the habits of the fish although most of these habits, I imagine, will be found to be not inconsistent with certain broad general principles. 
1 
Whitling 



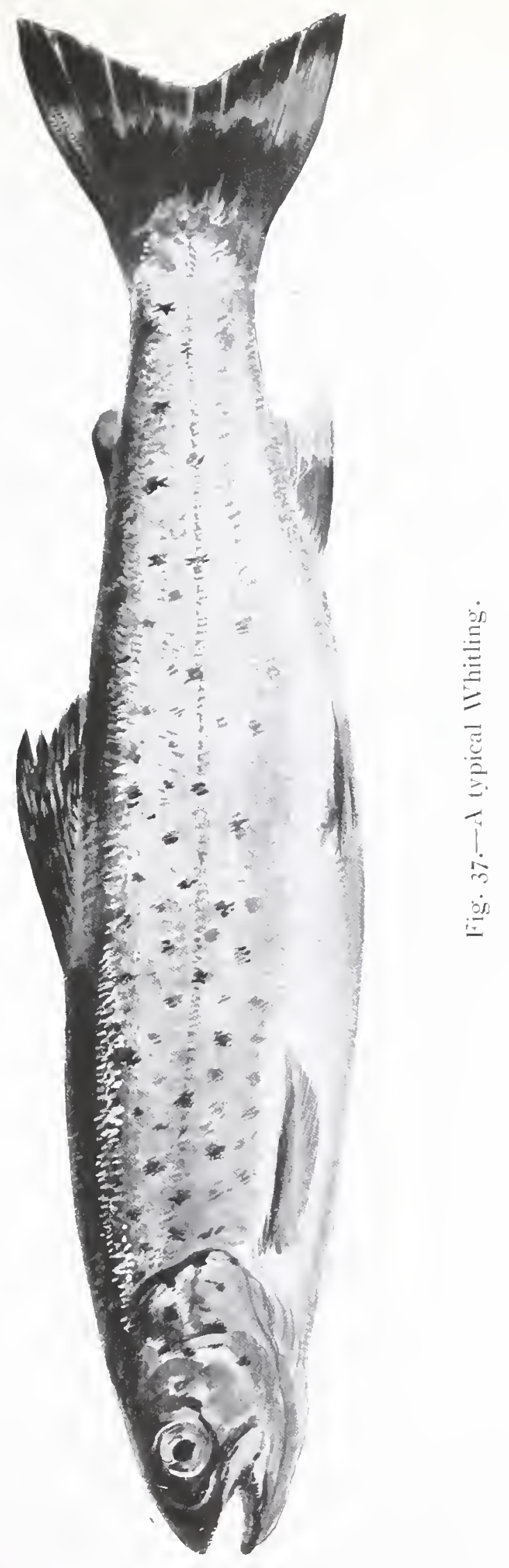





\section{CHAPTER VI.}

\section{WHITLING.}

In brackish or salt water, then, the young fish, once they have descended as smolts, whenever that may be, continue their existence. While merging insensibly from smolts to whitling they finally lose all traces of the parr state, their scales become more firmly set-but not so much so as in the mature state-and, if the scales are now removed, no parr marks will remain visible on the skin. The fins and tail become stronger and the colouring of the upper body of the fish becomes much darker - the small dark head giving origin to the Loch Lomond name of "black-neb" (i.e., black nose) for the fish at this stage. I insert a drawing of a typical whitling (Fig. 37) which I caught at Luss on 2oth September, 1915. The fish weighed $\frac{3}{4} \mathrm{lb}$. and was $12 \frac{1}{2}$ ins. long, and $6 \frac{1}{4}$ ins. in girth.

The richer quality of marine feeding makes for rapid growth and the smolt of seven, eight or nine inches in length in about three months becomes a whitling measuring twelve, thirteen or fourteen inches. In three months, at least, they are ready to undertake their first return to fresh water. One can fix this period of three months with exactitude, for, just as the main body of smolts practically everywhere descends in April and May, so the main body of whitlings in most rivers ascends in July and August. So general is their habit in this respect that the sea-trout of this small class are popularly called Lammas trout.

Confirmation of the time of return is also obtained from the scales, and I could show several scales of whitling clearly illustrating it. But I shall content myself with giving the reproduction (Fig. 38) of a scale of a fish weighing $I_{4}^{1} \mathrm{lb}$. which I caught in Loch Lomond on $4^{\text {th }}$ September, I914. I had noted it at the time of capture as "a beautiful clean whitling." The fresh-water residence in this instance is almost 
perfectly contrasted with the marine residence, while towards the margin of the scale will be seen the closing in of the rings of growth representing the beginning of what is termed the winter band. These are the more apparent that the fish had ascended comparatively late in the year, a fact which its considerable weight of $1 \frac{1}{4} \mathrm{lb}$. helps to establish.

But just as some shoals of smolts descend earlier and later than the main body in even normal seasons so some of the whitling return to fresh water earlier and later than the main run. The run of the main body itself varies in different localities. In the Solway rivers, such as the Nith and Annan, it is a comparatively late run; in Loch Lomond one expects the main run to occur by the second week of August; and in the Tay, Mr. Malloch puts it as "about the end of June." As he writes somewhat confusedly on this matter it is necessary to quote what he says. "I am of opinion," he writes, "that the yellow-fins do not go far to sea before returning as whitling about the end of June," and then immediately after:- "The yellow-fins, then, which return about the end of June, have only been three months in the sea." Now what are we to understand by "yellow-fins" and what by "whitling"?

I have taken pains in tracing the life-history of the sea-trout up to the present point to use such nomenclature that no confusion need arise in the reader's mind at any moment as to what stage in the life of the fish is being dealt with. Mr. Malloch, too, refers to the confusion that may be caused through the fish being known under different names at the various stages of its existence, but I cannot commend his own practice or the recommendations which he makes in the interests of uniformity. "It would be a very simple matter," he writes, "to call them sea-trout, in the grilse stage whitling, and in the smolt stage yellow-fin," and elsewhere he amplifies this thus:- "Salmo salar should be called try, parr, smolt, salmon; foul salmon in the spawning season, and kelt salmon after spawning. Salmo trutta should be called fry, parr, yellow-fin, sea-trout; and if a further distinction is wished, grilse 
could be called young salmon and whilling young sea-lroul." But apart from the curious inversion which I have ventured to italicise, and his confusion between "yellow-fin" and "whitling" noted above, it will be observed that he gives no distinctive name to the sea-trout earlier than "yellow-fin," so that he is driven to use such a cumbrous phrase as "parr of the yellow-fin" to denote a "sea-trout parr." Not only so, but "yellow-fin" seems to be a futile term, for he himself says:- "although yellow-fin is the name applied to the smolt stage of the sea-trout, it must not be understood all have yellow fins, for many have their fins of quite as dark a colour as those of a salmon smolt."

In my opinion the proper nomenclature for the sea-trout, from the time of hatching, is:-_ "sea-trout alevin," until the umbilical sac is absorbed; thereafter, "sea-trout fry," during the first year of residence in fresh water; "sea-trout parr," during the second, or it may be third, or even fourth year of residence in fresh water; and "sea-trout smolt," when the silvery scales are actually assumed in descent to the sea. "Whitling" conveniently identifies the fish on its earliest return to fresh water, and "sea-trout" imports a fish that has reached maturity. For the continued use of "yellow-fin" there is neither necessity nor authority.

The terms "fry," "parr," and "smolt" are used specifically in the Salmon Acts, and as "whitling" was also so used at one time I would retain that term in preference to "sea-trout grilse," or to such local terms as "herling," used in the Solway district; "finnock" or "phinock," used on Speyside; and "black-neb," used at Loch Lomond. For want of some precision in this matter long and acrimonious discussion has persisted in many districts regarding the identity of the sea-trout in its different stages, even after test decisions have been pronounced in the law courts; so the matter is more important than the casual reader might think.

The whitling of different localities vary in average size to a 
remarkable extent by the time they are ready to ascend to fresh water. In some districts they are barely more than quarter of a pound in weight, in others they weigh more than a pound, and I think this variation is due rather to the quality of feeding they have formerly experienced in fresh water as fry and parr than to their subsequent feeding in the sea or estuary. Clearly also it may be due, as we have seen, to some fish being in fact older than others. As going to show how extremely small some whitling may be I show (Fig. 39) the scale of one which was caught in the Little Osen, Hoidalsfjord, by Mr. Hutton. It weighed only I ounce. Yet this fish was a shade over three years old. The reader may check the interpretation of this scale from the scale of another Norwegian whitling here shown (Fig. 40). The first of the three years' residence in fresh water in this case is clearly indicated by the rings of growth subsequently acquired being disconform to those of the first year. This fish weighed 4 ounces. I have heard of no Scottish whitling which weighed so little as the Norwegian fish first here noted.

What instinct is it, one may ask, which induces the whitling to run at all? The question, I believe, has never been satisfactorily answered. Size alone appears to have very little to do with it, for in the same district those that are late runners are generally, as one would expect, rather larger than the early runners, but many of the last to ascend are extremely small. Nor, apparently, has their condition of nourishment much influence in the matter, for I have seen them ascend while in the poorest condition. Nor can it be that they are following some special prey up the river else that would easily be ascertained. Finally, their ascent cannot be due to the spawning instinct, as it almost certainly is in the case of grilse of salmon, for, as few out of the large numbers of whitling that ascend can be seen spawning, it is ocularly demonstrable that all whitling do not spawn on their first ascent as salmon grilse do. The two cases are hardly parallel, however, for, while some whitling 


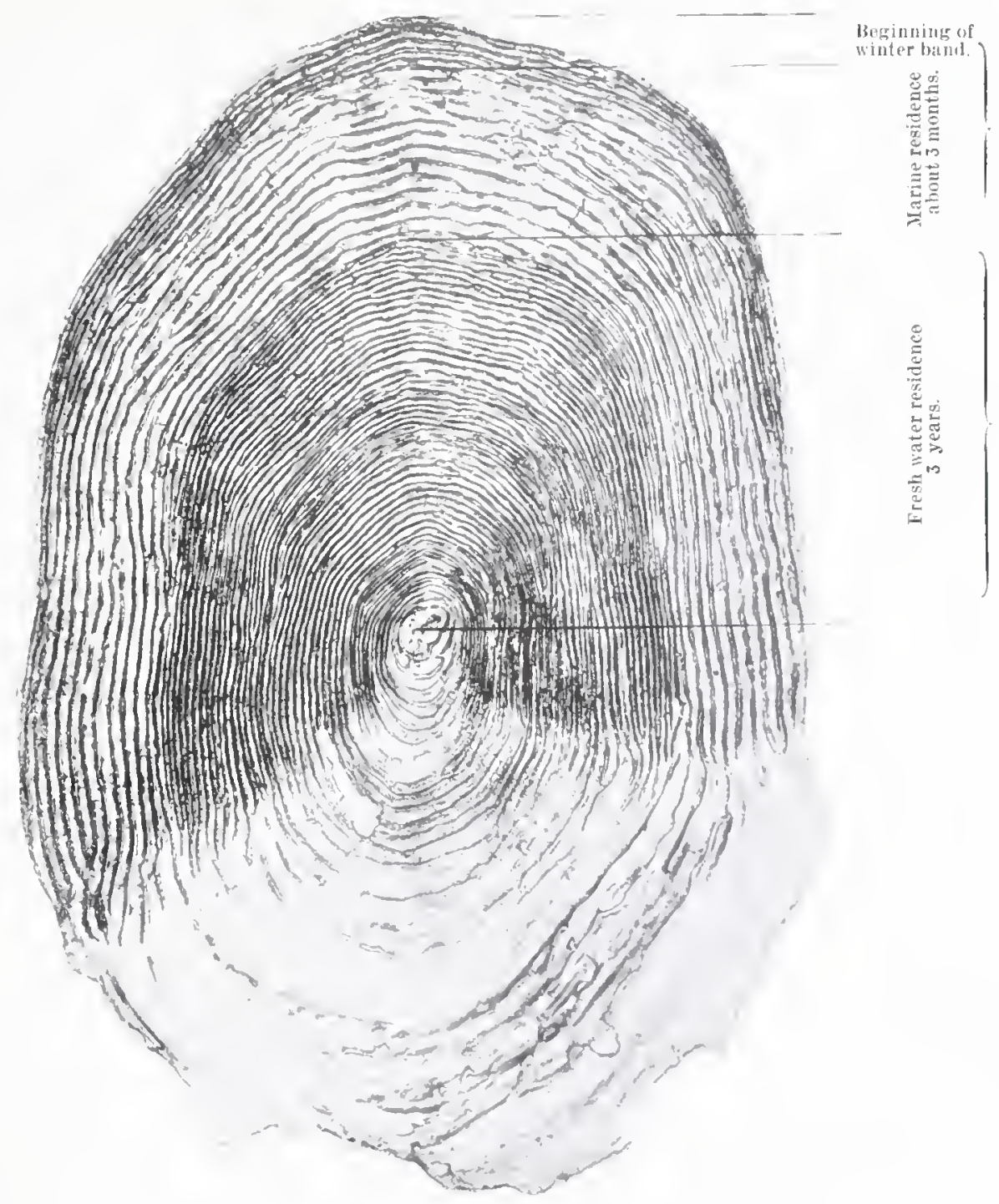

Fig. 38.- Scale of Seatrout, illustruting period spent in the seat after descent as a smolt and prior to return as a whitling. $(\times 39$.

The fish, a whitling, was caught in Loch Lomond on 4th September; 1:11.

Weight, $1 \frac{1}{4}$ lb. Length, $14 \frac{1}{2} \mathrm{~m}$. I ge, $3 \frac{1}{2}$ years. The fish probably descended as a smolt in late May, had spent June, July and Lugust in salt water'; and retumed early in sepitember. 

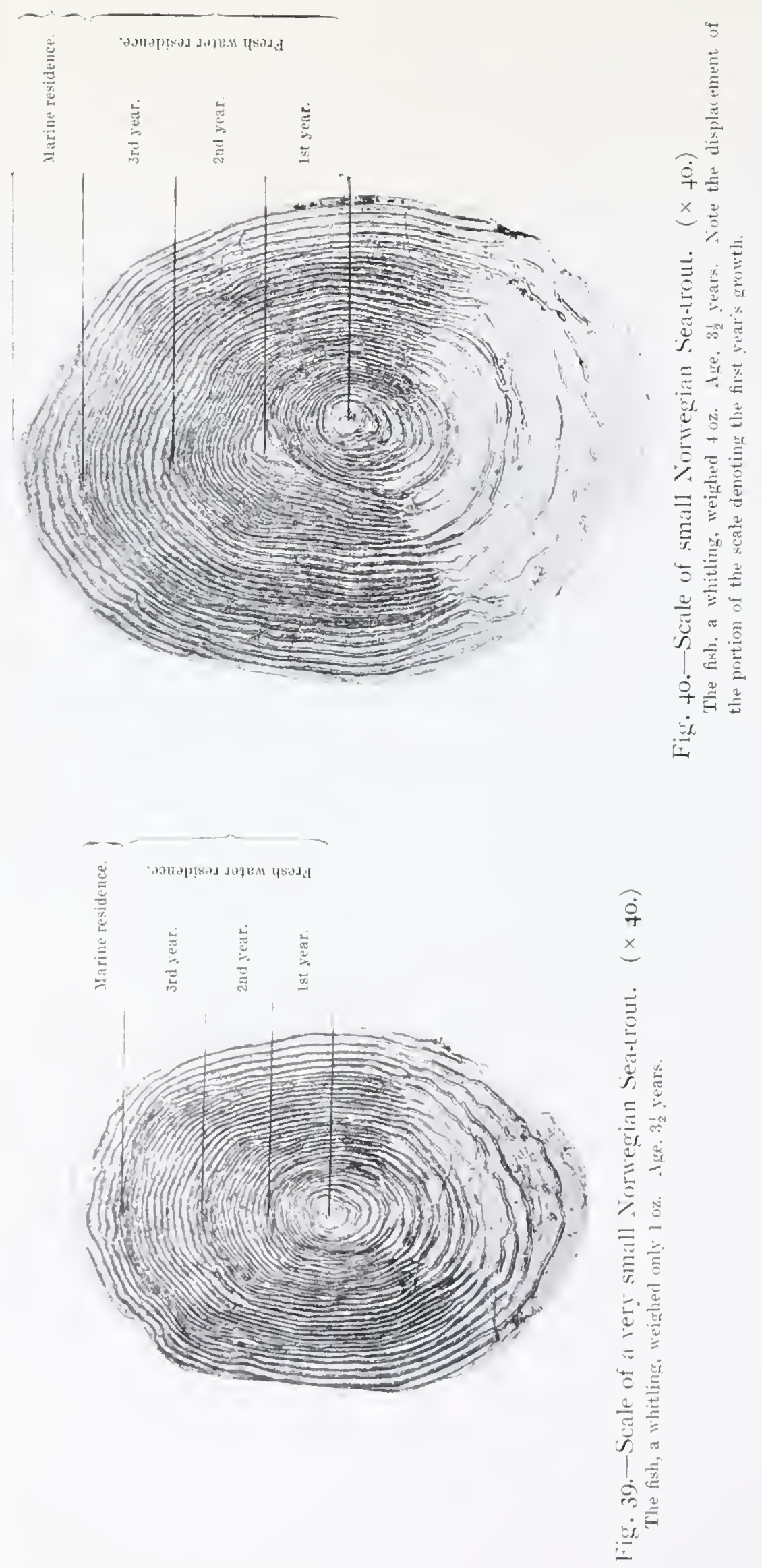

Sec page 122. 
return in the same year as their descent-within three months in factgrilse do not return until they have spent in addition a full autumn, winter and spring in the sea." To describe the whitling as the "grilse" of the sea-trout is thus a little misleading.

I can hazard no more plausible conjecture for the ascent than this, that the sea-trout being of marked estuarial habits, the shoals of young fish count it immaterial for their winter residence whether they range upwards wholly into fresh water, in which to tell the truth they never range very far, or downwards wholly into salt water, or remain hanging about in the brackish water between the two, their preference being determined at any time by the conditions which prevail in regard to temperature and the volume of fresh water, perhaps, that affects these conditions. It may also be, as Mr. Calderwood surmised, that the younger fish in this matter simply follow the leadership of the maturer shoals which are running up about the same time. It is seldom that the whitling run anywhere in numbers until the Lammas floods have broken.

Another question now presents itself. Do all the whitling of any year so ascend to fresh water? I cannot believe that they do. I have already suggested that from the time of hatching the tendency of the young sea-trout is to remain together in shoal formation and that they so remain together in the estuary. I would now carry this further and suggest that the shoal still retains its identity in ascending the river, but no longer the shoal in its entirety. Part only ascend, I think, and part remain behind.

It has been proved to demonstration by $\mathrm{Mr}$. Calderwood, who in this matter confirms the views of Mr. H. W. Johnston, that the salmon smolts which descend in any particular year do not return all together to spawn as grilse, but that only a proportion does so, the rest remaining

1. There are a few isolated instances of salmon returning to fresh water in the same year as their descent as smolts. Cf. Fishery Board for Scotland-Fisheries, Scotland, Salmon Fish., 1914, III. and IV. (April, 1915). 
in the sea over winter to return, some of them, as maiden spring fish in the following year. In pursuing further the same line of inquiry, Mr. Johnston held, and Mr. Calderwood confirmed the fact, that, not only do the lingerers not all return as maiden fish in the year subsequent to that autumn in which the grilse spawned, but many of them delay their return actually for four or five years, a proportion only of the original run of smolts returning each season as maiden salmon for the first time.

Whatever be the real import of this provision of nature-of its practical advantages to man there can be no question-it seems to me to suggest the possibility of at least a partially similar habit in the sea-trout. To be more precise, I think that the habit manifests itself at this whitling stage, and that now a first great division of the shoal occurs. In other words I think that a proportion only of each shoal of smolts returns as whitling in the year of descent, though for some reason not definitely known, or at least not definitely known to me, the proportion varies from year to year in an extraordinary degree. It is common to hear it said in a district that when any particular year is a poor whitling year the next year will in consequence be a poor sea-trout year. In my experience no reasoning can be more fallacious, for no account is taken of the numbers of whitling which may have remained over winter in the sea. In illustration I may point to the phenomenally dry season of I9I I when, at Loch Lomond, there was an exceptionally poor run of whitling. Yet in the more normal season of 1912 there was a remarkably heavy run of sea-trout, and shoal after shoal of them, fish of from $1 \frac{1}{2} \mathrm{lb}$. to $2 \frac{1}{2} \mathrm{lb}$. in weight, had all the appearance of the missing whitling of I 1 I n now returned to fresh water for the first time as mature sea-trout. I shall at a later stage show that scale examination throws some light upon this question of the divided run.

As for my suggestion that the constituent members of the proportion of the shoal which ascends remain together, I shall with great 
diffidence give my reasons for making it, and to elucidate these reasons I would make the further suggestion that not only do sea-trout return to their parent river but that the shoals which have been reared in Loch Lomond and its spawning streams, and in similar waters in Scotland, actually return to their special haunts where they were reared and fed as fry and parr.

In Loch Lomond, then, one can trace the shoal of travelling whitling by seeing individuals of the shoal leaping. They appear to head directly for some particular spot on the shores of an island or the mainland, and one's inference is always later confirmed by finding that spot, which had hitherto yielded no sport to the rod, now alive with fish. Further, in comparing notes of an evening when the whitling are entering the loch, the boatmen may find that banks widely separated are thronged while intermediate and equally good ground is barren. The local shoals have reached the first, but have not yet arrived at the other ground. Yet in a day or two the intermediate ground has received its local stock. It seems improbable that the fish, entering so vast a sheet of water as Loch Lomond is, would make directly for a particular quarter of it unless they had that quarter particularly in view. This is more or less surmise in the case of the whitling, but I shall submit at this stage instances of mature marked fish having returned to the same trifling spawning burn. I discuss these instances later in another connection, but meantime I may tabulate the returns of marked seatrout, to show their homing propensities, thus :-

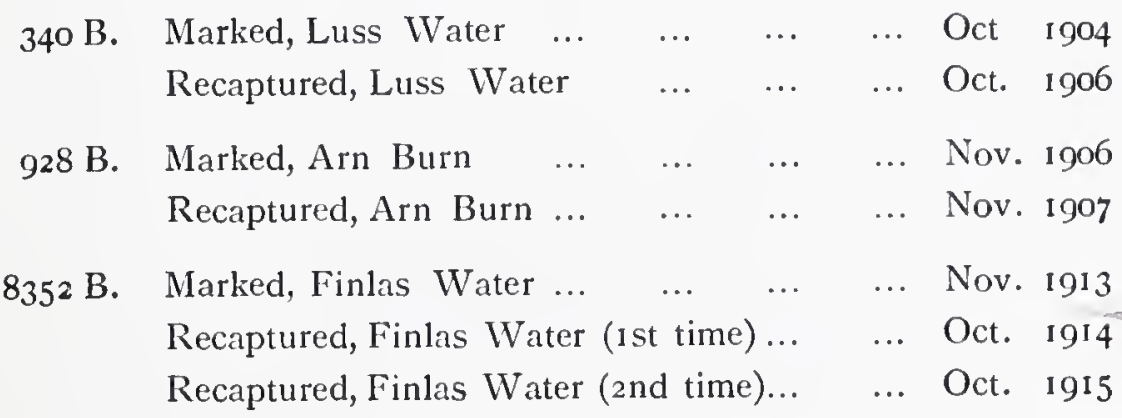


9331 B. Marked, Altnagairoch Burn ... ... ... Nov. 1913 Recaptured, Altnagairoch Burn _.. ... Nov. 1914

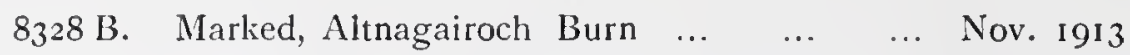
Recaptured, Altnagairoch Burn (Ist time) ... Nov. 1914 Recaptured, Altnagairoch Burn (2nd time) ... Nov. I9I5

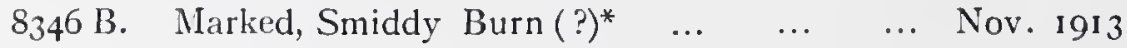
Recaptured, Altnagairoch Burn (?)* ... ... Nov. 1914

8347 B. Marked, Smiddy Burn ... $\quad \ldots \quad \ldots \quad \ldots$... Nov. 1913 Recaptured, Smiddy Burn $\quad \ldots \quad \ldots \quad \ldots \quad$ Nov. 1914

* There may easily be an error here in confusing the place of marking or recapture, as fish taken in both burns are often carried from one to the other by the hatchery men. The two burns enter Luss Water within a stone's throw of each other.

In addition, two marked Loch Lomond fish have been recaptured in nets in the Clyde estuary near the Leven mouth, which suggests that the fish were "homing" towards Loch Lomond; and another (besides 928 B) previously marked in the Arn Burn, was caught two years later by an angler in the loch in the immediate vicinity of that burn. It should be stated that no fish marked in one tributary (with the doubtful exception noted above) has been recaptured in any other tributary.

If it be thus proved, then, that mature sea-trout return to Loch Lomond in two consecutive years and even in three consecutive years, and not only so but are found again in the same trifling tributaries (the Altnagairoch, Smiddy and Arn Burns), as well as in the larger streams (Luss and Finlas) in which they were marked, there is surely nothing surprising in the fact that the shoals of ascending whitling should return to the locality whence they descended as smolts. That each shoal is actuated by an impulse to travel in the one direction convinces me that it is one shoal returning to known ground and not a fortuitous gathering of individuals travelling at haphazard towards the unknown.

Another thing which led me to form the conclusion that particular shoals of sea-trout retain cohesion was this. At one time the river 


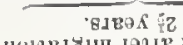

"s.uas

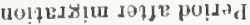

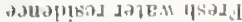

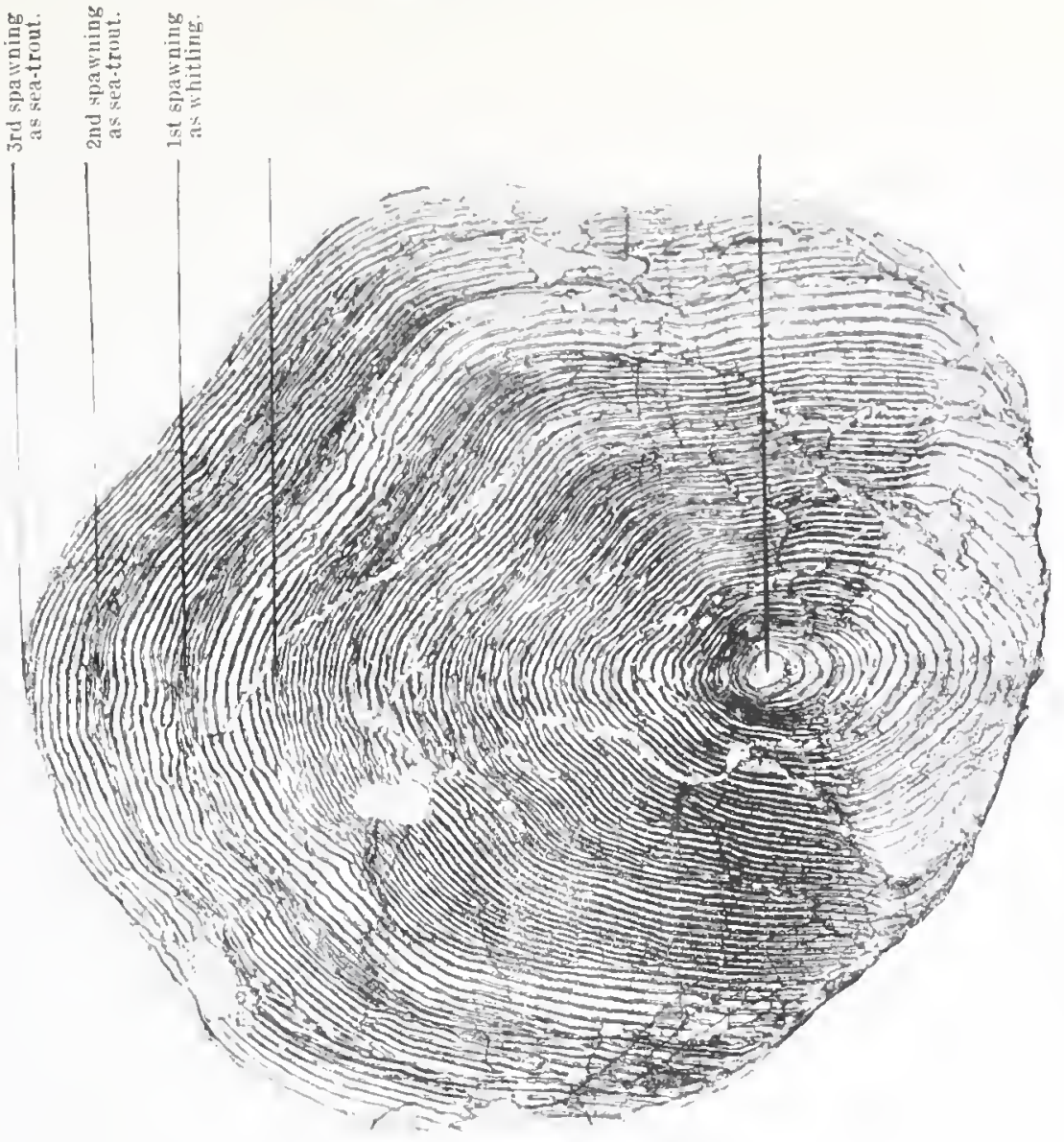

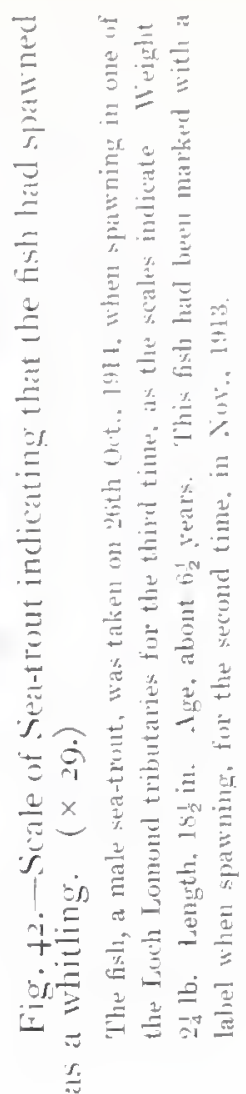

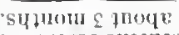

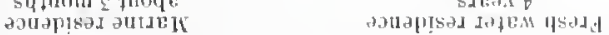

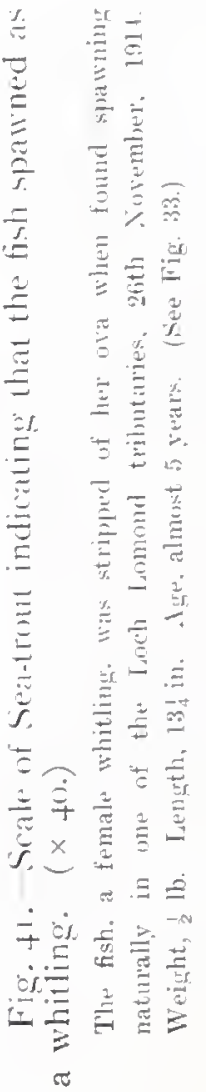

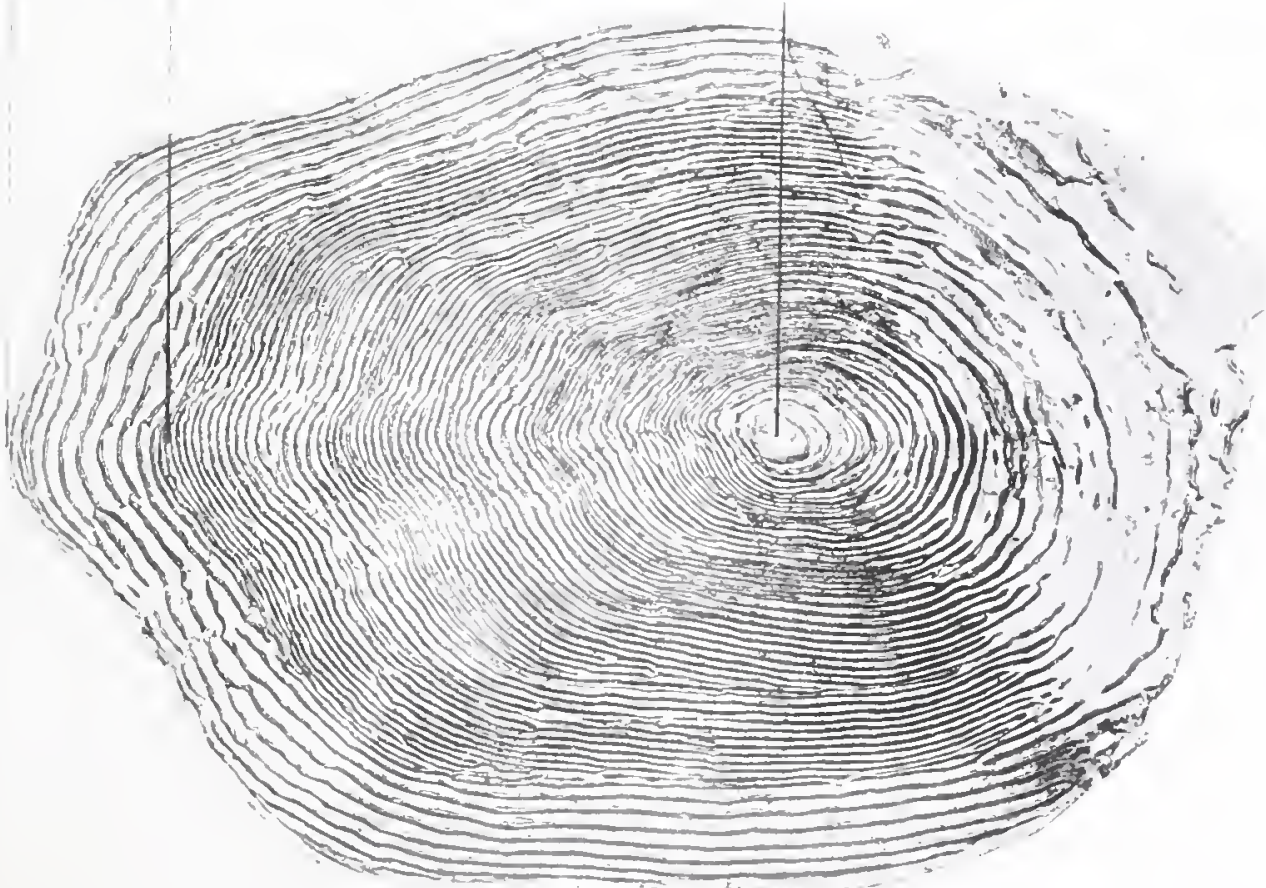



Leven was, if possible, even more polluted than it is now, and during hot weather, in most seasons, whole shoals of whitling (besides mature fish) were simply annihilated in their ascent. Now it was observable in such disastrous years that certain feeding banks of the loch might one year be destitute of fish and that during some other year other banks, formerly fully populated, might prove barren. I have little doubt that the explanation of this fluctuation simply was that the shoals of whitling which ought to have peopled these banks were shoals which had perished in the river Leven.

It may be objected that all this may be very plausible as regards Loch Lomond but need not necessarily represent the habits of the fish elsewhere. But I think on consideration it will be admitted that the "entity of the shoal "-if I may so term it where I have just referred to and presupposed a first great cleavage-is a principle broad enough to be generally applied elsewhere, and that the circumstances of Loch Lomond are peculiar only in this that they give rather special opportunities for observation and deduction.

I have thought it well to leave as they were originally written the foregoing passages with reference to the "homing" proclivities of whitling, because it is interesting, to me at least, that the conclusions at which I had arrived on the evidence submitted above have since been found to be justified by incontrovertible fact.

In a Blue Book issued by the Fishery Board for Scotland towards the end of I9I4, the official reference to which is "Fisheries, Scotland, Salmon Fish., I9I4, I and II (October, I9I4)," there appeared two papers, one of which, by Mr. Ian T. Nelson, the proprietor of the Glenetive deer forest, dealt with "Hatching Results at Glen Etive." I may briefly state that with a view to developing the stock of salmon and sea-trout in the river Etive, Argyllshire, Mr. Nelson constructed an artificial loch in Glen Etive, with increased semi-artificial spawning grounds in connection with it, and erected a small hatchery to 
supplement the natural spawning operations of the fish. In 1908 , there were turned out 87 yearling sea-trout which had been artificially hatched and had subsequently been reared in a pond and artificially fed. Before being liberated these fish were each marked in the dorsal fin with a small piece of silver wire. "In the main river in 19ro," writes Mr. Nelson, "a sea-trout marked with silver wire was caught, which could only be one of the 87 yearlings so marked in 1908." This is the first sea-trout with, so to speak, a completely "artificial " record which has apparently ever been recaptured on its return to the vicinity of its birthplace. It is not with any intention of disparaging the valuable outcome of Mr. Nelson's enterprise if I add that it is only the first instance of a fish being so recaptured because probably it was the first carefully conducted experiment of the kind. There need not now be the slightest doubt that such a return of the whitling, as I had already deduced from observation, constantly occurs under natural conditions.

Still following the fortunes of the ascending section of the shoal of whitling I think it may be accepted that the whitling when they do run, whether in numbers or not, never ascend a river very far. ${ }^{1}$ They certainly never push on to the limits of the furthest tributaries with the perseverance which characterises the mature fish when seriously making for the spawning redds. Failing direct proof, this fact alone might be held sufficient evidence that the main body of whitling does not ascend to fresh water for the purpose of spawning. Mr. Malloch tells us that "The greater number prefer the tidal water, and in the Tay very few are caught more than ten miles above this." Where a great lake like Loch Lomond is within easy run of the sea the whitling scatter throughout its extent, but they do not ascend the tributary streams in any numbers. In any case these whitling whether in river or loch, and whether they propose to spawn or not, intend to remain in fresh water over the winter months.

1. It is fair to state that a correspondent of "The Field" once referred to one instance of a whitling being caught, in some river which he did not specify by name, 40 miles from the sea. 
Whitling feed ravenously, or at any rate they take a lure with avidity, during their ascent which is generally when the water begins to clear after a spate. Gaudy artificial flies and silver Devon minnows are then the most attractive lures, but the truth is they will take readily any kind of bait of which the earth-worm is not the least attractive. When they have settled down in their quarters in river or loch and the waters have become normal, they will still rise freely to the fly and take other lures, but they are more capricious in their tastes then than when fresh-run. At the same time they feed with more regularity than the mature sea-trout do in fresh water, and if it cannot be said that they increase in plumpness it is at least certain that they do not lose flesh, and apparently they even grow in length, if slowly, after leaving the salt water.

Although they soon lose their first brilliancy of scale, whitling do not-or at least by far the greater number do not-assume the spawning colours of the mature male fish, nor do the females darken so much. One might count this as another argument against the universal spawning of whitling. But I shall discuss this vexed question immediately.

I may here describe the appearance of two of these young fish after they had spent the winter months in Loch Lomond-I caught them when trolling on 3 rd March, I9I3. They were to all intents and purposes identical, both being females of three-quarters of a pound in weight and each measuring 14 inches over all. They were fat, plump and in good condition. The back, speckled as usual with black spots, was in colour a dull green with a transparent watery look, the sides and underparts being of a dingy white. One fish had been feeding freely on caddis, the stomach and alimentary canal being distended with the disintegrated cases, though near the gullet some of the large caddis flies were in a fairly perfect state. The other whitling was literally gorged with shell fish, the common physa fontinalis, and yet both these 
young fish attacked a natural minnow. In each the ovaries were considerably developed and had already attained a length of some two inches, though the egg pellets were yet very minute. Clearly, then, they had not spawned (else their ova, if visible at all, would have been hardly apparent), and the appearance of the ovaries rather suggested that they would spawn for the first time in autumn when they had re-ascended from the estuary in one of the later months.

I shall now submit such evidence as I possess for my belief that some whitling at least do spawn on this their earliest and first return to fresh water, and in this matter I may remark I am also indebted to the valuable co-operation of $\mathrm{Mr}$. Hutton.

While engaged collecting sea-trout eggs in the spawning season of I9I4 for the purpose of stocking Luss Hatchery I kept a close watch to see if any fish engaged in spawning had the general characteristic appearance of a whitling. Out of 247 fish actually handled very few were so like whitling as to be unquestionably whitling, but, on 26th November, one of the men who knew what I was searching for, handed me a fish from the net as to which, it might be said, there was no superficial doubt whatever. It was a female fish, $13 \frac{1}{4}$ inches in length, bright and silvery, from which the scales came off readily in handling and were scraped off with ease. The fish was ripe and when stripped of her eggs weighed 8 ounces. The eggs had a curiously immature appearance, they were so small; but the fish was obviously on the redds for the purpose of spawning and the eggs were as readily and successfully fertilised as the larger eggs of larger fish. They were also apparently of fair average number. I sent some of the scales to $\mathrm{Mr}$. Hutton for examination. His report, which I have no reason to question, showed that the fish had spent four years' residence in fresh water and had been about three months in the sea. In other words it had descended as a smolt in spring and was now, as a whitling, spawning on its first return to fresh water in the same year. The reproduction of 


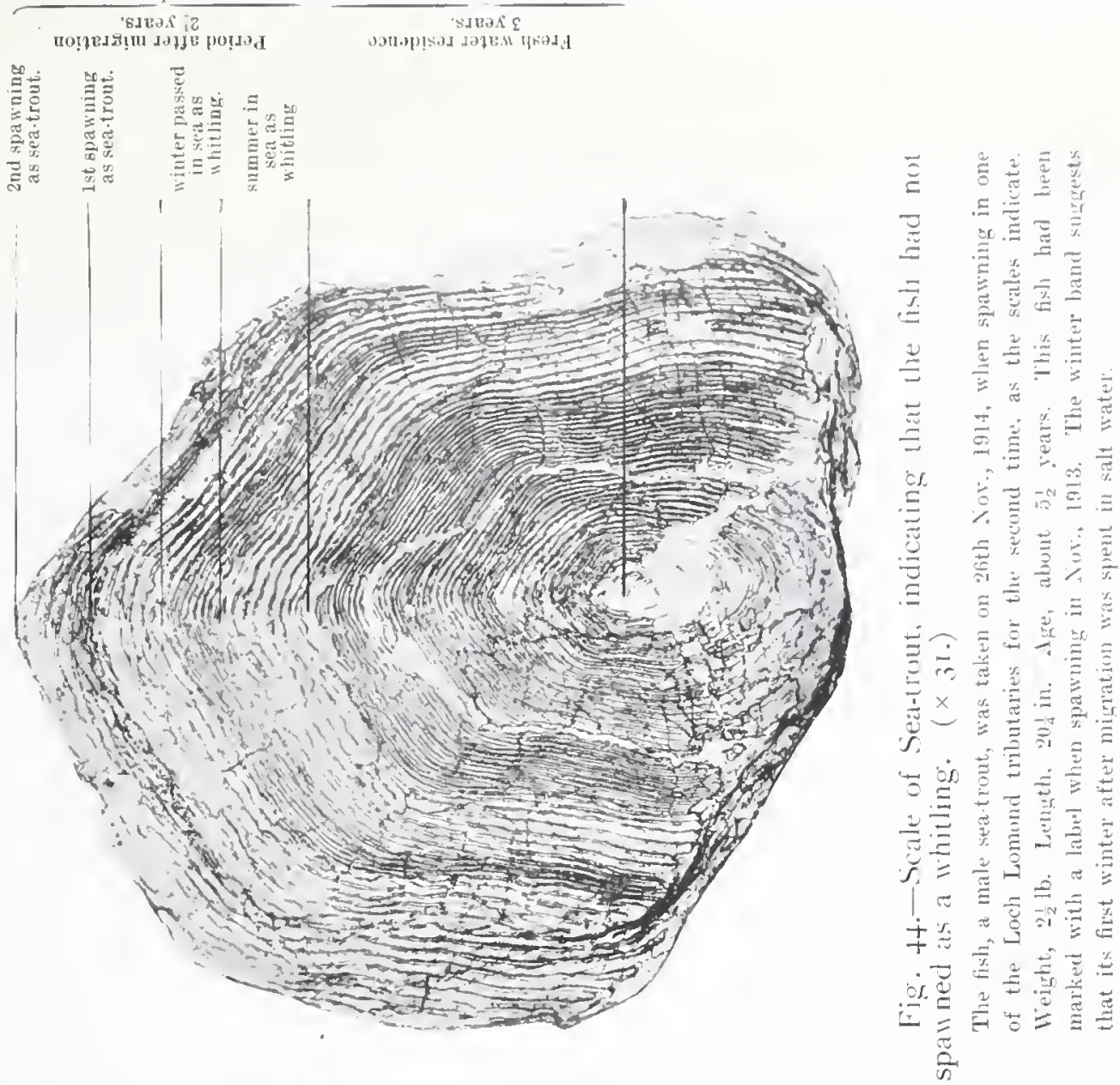

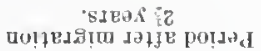

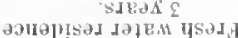

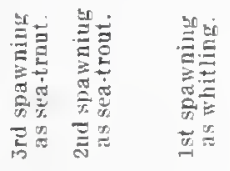

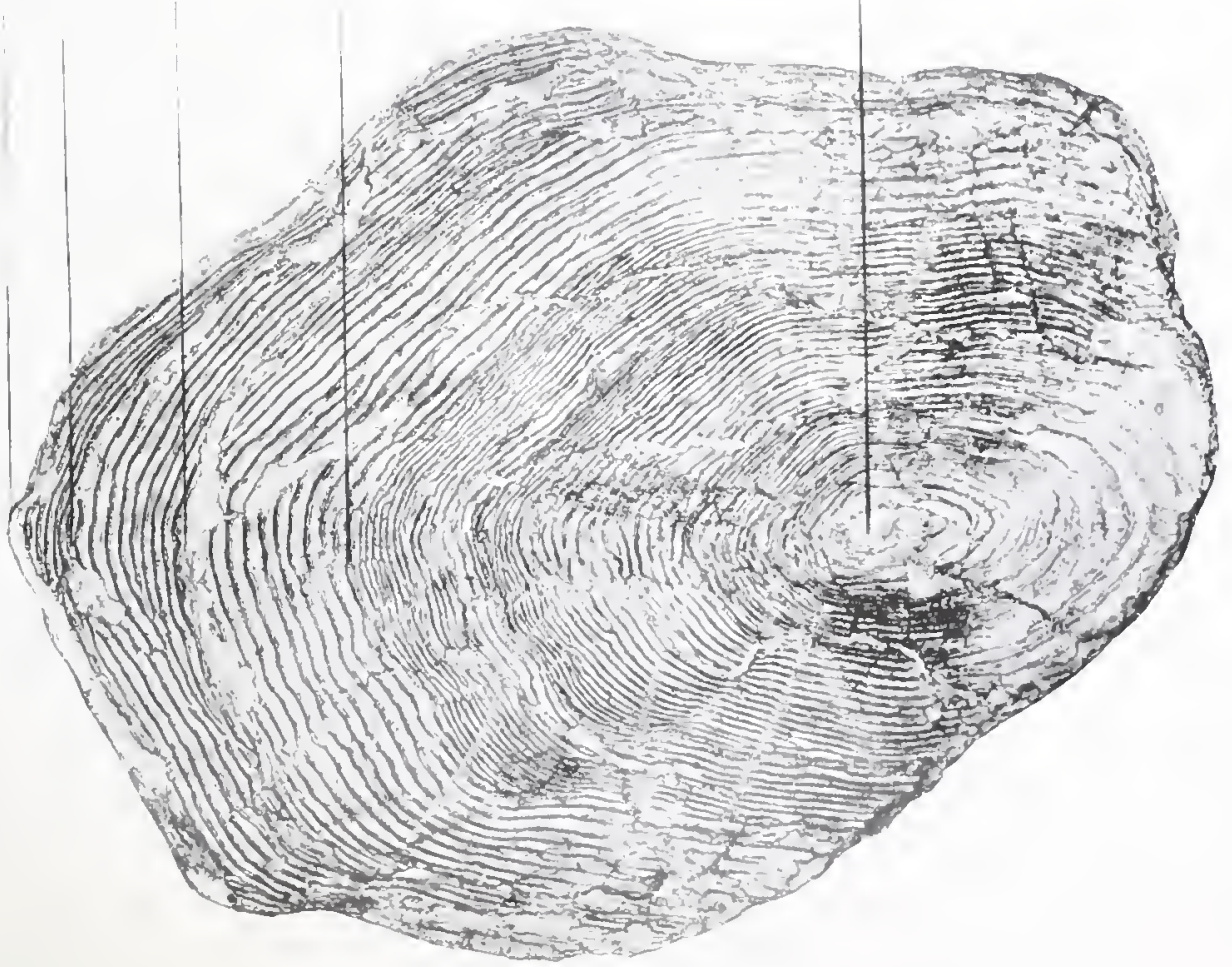

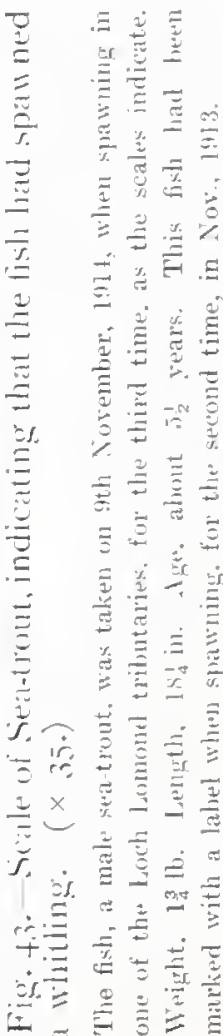



one of the scales of this fish (Fig. 4I) in my opinion puts the fact of its having spawned as a whitling beyond doubt.

I think it may fairly be assumed that others of the fish handled, as to which the superficial appearances were not so convincingly characteristic of whitling as the one selected, were whitling also. At any rate Mr. Hutton pointed out to me that his reading of the scales of another sea-trout which I had sent him, namely, those of a male fish weighing I $\frac{3}{4} \mathrm{lb}$. and measuring $18 \frac{1}{2}$ inches in length, suggested that it too had spawned as a whitling. He interprets the scale (Fig. 42) as showing, subsequent to four years of fresh-water life, a three months' residence in the sea after which a distinct spawning mark occurs; another period of residence in the sea, with a subsequent spawning mark; still another period of residence in the sea, with the capture of the fish occurring on its again visiting the redds-a comprehensive record for so small a fish, but small, possibly, on account of its comprehensive record. This, of course, was an old fish, but the record of its youthful days was clear, and I think that other scales of younger fish like those in the first instance cited, would often show equally an early spawning record during the whitling stage. As a matter of fact out of the series of 45 scales of Loch Lomond fish examined by Mr. Hutton, 5 show evidence of the fish having spawned as whitling.

If the reader will further turn to Chapter VIII he will find the record of two fish hatched in the same year, one of which (Fig. 43) spawned as a whitling, while the other (Fig. 44) remained over winter very probably in the sea. Confirmation is not easily obtained from scale reading of a divided run, but at any rate both fish resided for the same 3 years in fresh water, though one spawned as a whitling while the other did not. I ask the reader to accept such scanty evidence with caution; but, so far as it goes, it confirms the facts which I have otherwise deduced.

I confess to thinking that any prolonged period of prior residence 
in fresh water may have a bearing on the period of spawning, it being more probable that a fish which has spent three, four, or, it may be, five years in fresh water will spawn as a whitling than one which has only spent two years in fresh water, but I can submit no evidence upon which any definite theory can be based. In considering this matter it is worth while perhaps to keep in view that so experienced an observer as $\mathrm{Mr}$. Malloch states regarding whitling:- "My opinion is they do not spawn." Possibly the great majority of the smaller Tay whitling do not.

It may be interjected here that the capture of these young fish in spring, if they have not spawned, and of course similar fish everywhere in Scotland, is strictly legal provided it is not during the close time. They cannot, if they have not spawned, reasonably be held to fall within the statutory prohibition against the capture of "unclean or unseasonable salmon" contained in Section XX of the Salmon Fisheries (Scotland) Act I 868, because, not having spawned, they are not "unclean," or kelts; nor are they "unseasonable," in the sense of being caught within the close time which is the interpretation of that term adopted by the English Law Courts. It should be pointed out, however, that the word "unseasonable" has been several times interpreted in the Sheriff Courts of Scotland as meaning, in the somewhat loose Scottish sense, "not very good according to time and circumstance," and therefore an ill-conditioned fish of this class caught before regaining the sca might cxpose the captor to risk of a prosecution. I think the definition of an "unclean or unseasonable salmon," which I have clsewhere formerly given, ${ }^{1}$ is explicit enough for all practical purposes, namely, "an unclean or unseasonable salmon is a salmon which is on the eve of spawning, is in the act of spawning, or has not fully recovered from the effects of spawning." But I think the taking of these young fish at all at this early period of the year is to be strongly deprecated, if for no other reason than that their capture simply

1. "The Gentle Art," p. 248. Soe also post p. 166. 
leads by a specdy transition to the taking in spring of all sea-trout, whether large or small, clean or kelt, without inquiry, to the detriment of the stock of fish and to the grievous lowering of the standard of sport in a locality.

In rivers uninterrupted by loch basins the shoals of these whitling whether "clean" or "kelt," work down rapidly to the estuary or sea, the descent beginning more or less about the turn of the year and continuing intermittently for some few months. But they seem loth to leave good quarters in a loch and are only finally driven from it by, one may suppose, the rising temperature of the water. In Loch Lomond, I have observed the last of them has disappeared by the end of May. But in their descent, as during their ascent, these greedy young fish eat lustily and their diet, from flics to shell-fish, is as varied as the circumstances allow.

Assuming these whitling to descend in April, with this their second visit to the sea, they are entering upon the mature stage of their existence as "sea-trout."

It is time now to return to that portion of the shoal of whitling which did not ascend to fresh water, and at the outset it is fair to say that my views as to this first separation of the shoal into two portions are largely theoretical, though I believe they will be found to meet the facts of the case in most localities.

The richer marine feeding, which it is to be supposed this section of the shoal will have obtained throughout autumn, winter and spring, will have proportionately encouraged the growth of these whitling beyond that of their contemporaries which migrated. They will also be in far better condition in the spring months, and I think it is worth considering whether these fish, which will in spring vary in weight between I lb. and $2 \mathrm{lb}$. do not form what is called the "spring run" of sea-trout in many districts.

I do not think that this "spring run" is a true run of ascent, as is J 
the Lammas run of whitling, because, as a lawyer would put it, the fish has no animus remanendi and returns again to the estuary before the true autumn ascent takes place. It would be more correctly described as a tentative movement by these maiden fish to the upper tidal reaches, and it is noteworthy that this spring run, so far as my observation goes, is confined to waters where there are long tidal reaches or where there is an immediate entrance from the sea into a loch which is almost on sea-level. In any event, as I have shown that the whitling which did ascend could not unless they had spawned be classed as kelts on their descent to tidal water, so now these fish which did not ascend are not kelts either. Hence in those districts where the sea-trout fishing is practically tidal water fishing there is no reason why the spring months should not furnish legitimate sport with sea-trout of this class, and I think it is with such fish that spring fishing is got in the Beauly, the Ythan and the Tay, and elsewhere.

I confess that I can make no suggestion which seems satisfactory to myself why it is that this movement of the fish to the upper tidal reaches, and even into some western lochs, like Loch Baa in Mull and some of the South Uist lochs, takes place in spring any more than I can definitely state why it is that some of the shoal made a more permanent ascent as whitling in the autumn previously. I cannot believe that it is due to the pursuit of any special food, and would be more inclined to account for the movement by some change of temperature as between river-water and sea-water.

Turning to another matter it would be extravagant to assert that the separated wings of any original shoal re-unite on the return to the estuary of the detachment which had migrated to fresh water. I think it likely, however, that each wing retains its own corporate entity. At such places where sea-trout rise to the fly in salt water, it is not unusual for the angler to pick up shoal after shoal of the feeding fish as he drifts over the ground. There seems no good reason in fact, though 
of course assumption is not proof, why the shoals should get broken up whether in migrating upstream, or migrating down stream, or roving in the estuary. Whether the two wings of the shoal ever re-unite or not, there can be no question that they are again ranging about contemporaneously feeding in the estuary or the sea.

The young sea-trout now find a rich harvest, for they are big enough and swift enough in their movements to prey upon fish of considerable size. Besides small shell-fish and sand-hoppers and other small deer, shrimps and sand-eels form a large part of their dietary. But without question their staple food in the early summer months is herring fry. In May and June enormous quantities of these little fish-they are about three inches long-approach the shores and myriads of them enter our sea-lochs and push up the estuaries as high as the tide will carry them. Sea-trout then feed upon them voraciously, and I am inclined to the belief that, when the sea-trout which enter fresh water are observed to be of poor quality in any season, the explanation is that there has been a deficiency of herring fry in the shore waters during that year. The numbers of these fry that a sea-trout will consume in a day must be very great. I have found in one fish of about a pound weight as many as eleven not wholly digested, besides a mass of scales and bones in the anal canal. It looked as if this sea-trout, while feeding, could, and did, swallow and digest fresh supplies as rapidly as it could pass the unassimilated matter through its body.

There is good reason, beyond the mere growth of the fish, for this extreme voracity, because the sea-trout has now to lay up within its tissues a reserve of energy-making fat sufficient to meet not only the exhausting journey to the upper waters, but the more exhaustive process of the development of the milt and ova. There is at least no question that if the sea-trout ascend to fresh water in this, the second summer since they descended as smolts, they will proceed to spawn before returning to the sea again for they have now reached maturity. 

Maturity 



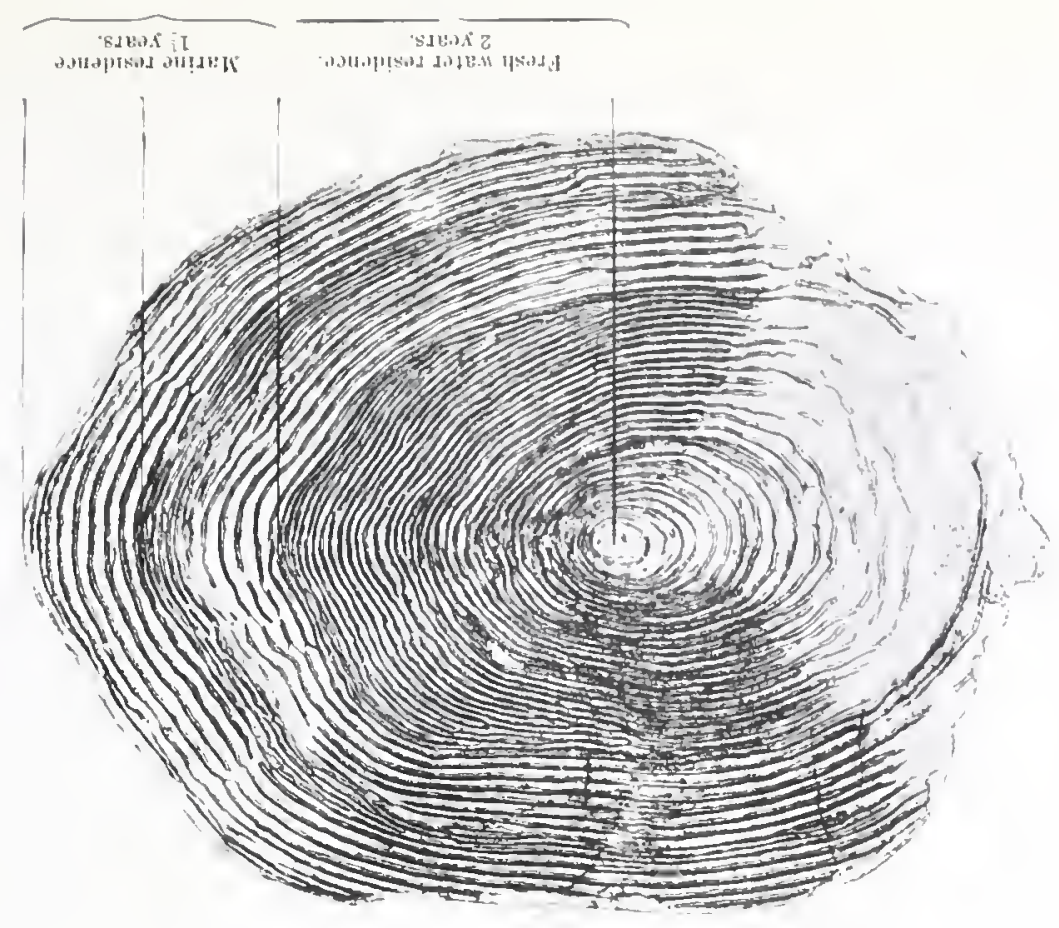

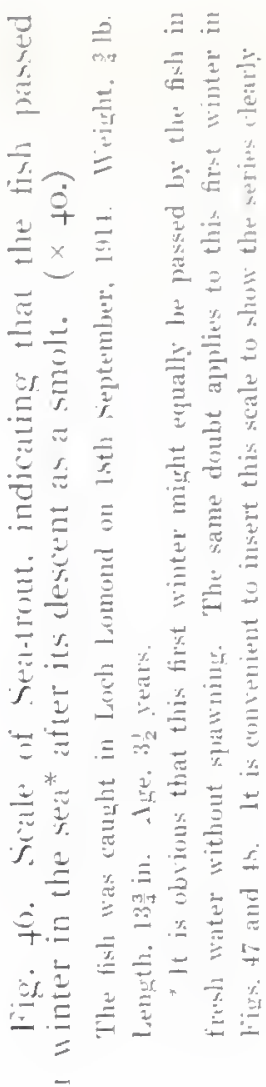

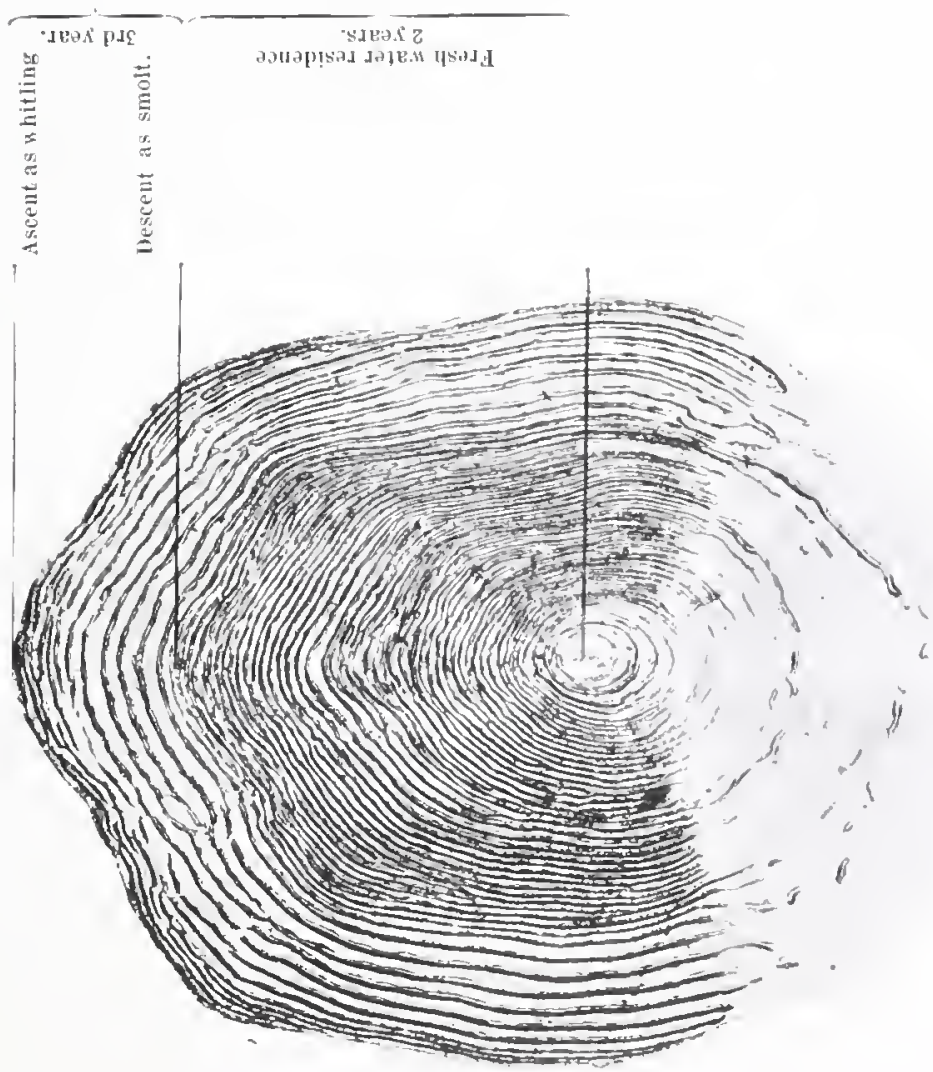

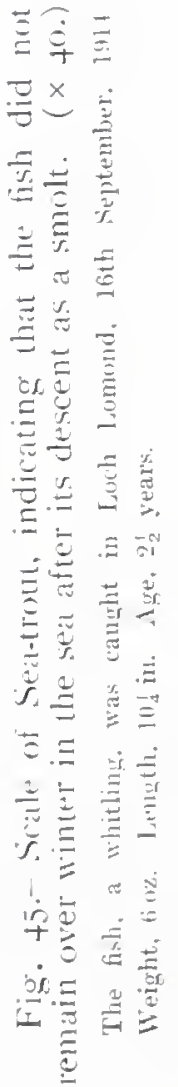

Sec page 143 



\section{CHAPTER VII.}

\section{MATURITY.}

I have already indicated my opinion, though I do not pretend to have conclusively proved, that all the whitling of any year do not ascend together but that only a proportion of them does so. The question has now to be considered whether all, or only some, of the sea-trout which have reached maturity ascend to spawn during the same season.

Mr. W. H. Armistead, in his book on "Trout Waters-Management and Angling," tells us that all the mature trout of any lake ascend the tributary streams each season to spawn. Personally, I should prefer more exhaustive proof than Mr. Armistead offers of this fact though one hesitates to doubt the conclusions of so well-known an expert. On the other hand it is quite clear, as we have seen, that a comparatively small proportion of the stock of salmon at any time in the sea ascends to spawn, and it is not unreasonable to assume in the mature sea-trout a similar habit. Definite proof of this matter is, so far as I know, not yet available, but something may be learned inferentially, and I shall pursue with that object the supposed movements of those whitling (now grown to sea-trout) which did not migrate to fresh water in the autumn of the year in which they descended as smolts.

It seems appropriate to follow these fish first because clearly they will have come earliest into condition to make the ascent owing to their uninterrupted spell of rich marine feeding. In fact we do find in some rivers a fairly early run of such sea-trout. In the Leven, for instance, we find them ascending to Loch Lomond, but in no great numbers, as early as the middle of April--fish of from $1 \frac{1}{2} \mathrm{lb}$. to $2 \frac{1}{2} \mathrm{lb}$. in weight. In 1915, on April 3, a clean run sea-trout, weighing $\frac{3}{4} \mathrm{lb}$., was caught 
with worm bait in Loch Lomond-a very unusual capture. In "The Glasgow Herald " angling report of 23rd May, 19I3, it was noted that "a fine sea-trout weighing $2 \frac{1}{2} \mathrm{lb}$. was caught in the Border Esk," and that "This is the second sea-trout landed with the rod. The previous one weighed $2 \frac{3}{4} \mathrm{lb}$. The opening catches of sea-trout usually consist of fish of $1 \frac{1}{4} \mathrm{lb}$. or $1 \frac{1}{2} \mathrm{lb}$." A Tweed report bears that on $15^{\text {th }}$ February 1915, "a spring sea-trout scaling 2 lb." was caught at Carham; on 4th March in the same year, " a sea-trout, $\mathrm{I} \frac{1}{2} \mathrm{lb}$.," was reported from the Logierait Hotel water on the Tay; while from the Beauly it was reported in 1915 that on 8th March "on the tidal waters an angler had 4 sea-trout," on Ioth March, 26 sea-trout, and on 12 th March, 2 seatrout, but the weights of these were not reported, although one is aware that these early fish in the Beauly are of a small class.

Whatever else these small sea-trout may be they cannot be those whitling which ran the previous summer and descended in spring ready now to run again. Nor is it likely that they are mature fish which, having spawned in the preceding autumn and descended as kelts after January, are now ready to ascend again. They can in fact be nothing else than either, first, members of the detachment of whitling which did not run in the previous year now grown to maturity, or second, possibly fish which have spent two or more years in the sea without spawning.

Mr. Malloch gives an oddly confused account of the fish at the stage which we are considering. "After the whitling goes to sea," he writes, "it remains there for three or four months, and comes up as a sea-trout from I to $2 \frac{1}{2} \mathrm{lbs}$., according to the length of time it remains in the sea. In the earliest rivers they begin to run in January, although only in small numbers, and continue till October, but of course the seasons have a great deal to do with their running early or late. The Tay, I dare say, is the earliest river in Great Britain, and one would expect them in it as early as in any river. Every spring paragraphs appear in the public press stating that most of the sea-trout caught in 
early spring are kelts. I have the numbers caught in our nets on the Tay for the last eight years." Then in giving statistics he continues, "On the 5 th February of this year (1908) we caught more sea-trout at one station-Almond Mouth-in one day than we had caught in a month in some other seasons. Since then they have greatly increased, and we are now (24th April, 1908) getting from roo to 120 daily, all in perfect condition, averaging $1 \frac{1}{2} \mathrm{lbs}$. in weight. None of these have spawned, although all will spawn this season." His final dictum is :"These sea-trout are now a little over three years of age, and are on their second return from the sea." With deference I cannot conceive how with this explanation they can be on a second return from the sea. How Mr. Malloch can hasten the descent of the whitling, bring them into condition by a trip of "three or four months" out to sea, and have them ready to ascend the river again by 5 th February it is a little difficult to comprehend. If it had occurred to him that the whitling do not all ascend to fresh water at once, he would have seen, I think, that those early running fish so caught in the Tay were really members of that body of whitling which elected to remain over winter in the sea, possibly, as I have suggested, along with some fish which had remained for two or more years in the sea without spawning, and were consequently fish on a first return from the sea.

Assuming that I am correct in my surmise that many of them are maiden sea-trout now on a first ascent more and more of these fish will continue to run, some of them right up to the spawning season. When that process is over, and another winter has come and gone, the fish as kelts, will drop down to the estuary in the spring months, the last of them disappearing from fresh water some time in May.

Meantime the detachment of whitling that did run and thereafter returned to the estuary proceeds to recuperate its energies by marine feeding, but there can be little doubt that the individuals which comprise the detachment are not in condition to re-ascend, as mature fish to 
spawn, or, it may be (as we have seen) to spawn a second time, much before July. Indeed I think that it is these fish which largely constitute the great run of small sea-trout that in most sea-trout rivers occurs at and after the middle of July. All those that ascend will spawn and they too will descend as kelts in the ensuing spring.

I have traced-I trust clearly-the supposed ascent and subsequent descent of members of the separated detachments, and it only remains to add that in their descent these fish will pass some of their contemporaries now ascending the river. They will, I think, first of all, pass maiden fish on a first return since their descent as smolts; secondly, they will pass some others on a second return, also maiden fish, as not having spawned when they first ascended as whitling, and I think it possible that those descending latest as kelts may even meet some which, having spawned along with themselves and returned early to the estuary, may have again come early into condition to make a second spawning ascent. Should a kelt sea-trout, for instance, have returned early in January, there is no reason why it should not be in condition again by May until which time some of its companion kelts may have lingered in fresh water before descending. Finally they will also meet that class of fish which I supposed might have remained two or more years in the sea without spawning.

I do not imagine, however, that this apparently complex, but really very simple, running and counter-running takes place in any but the largest of our river systems, and particularly in those where a loch or a series of lochs induces a lengthy stay of the fish in fresh water. In lesser streams the habits of the fish are generally more regular, I mean, the runs of the mature fish are more marked-the first run is in July, spawning takes place in November and the kelts descend in spring. But that the whole stock of contemporaries anywhere ascends en masse to spawn in one year I do not believe for an instant.

That the period of continuous residence of sea-trout in the sea after 
咅

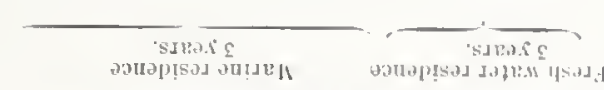

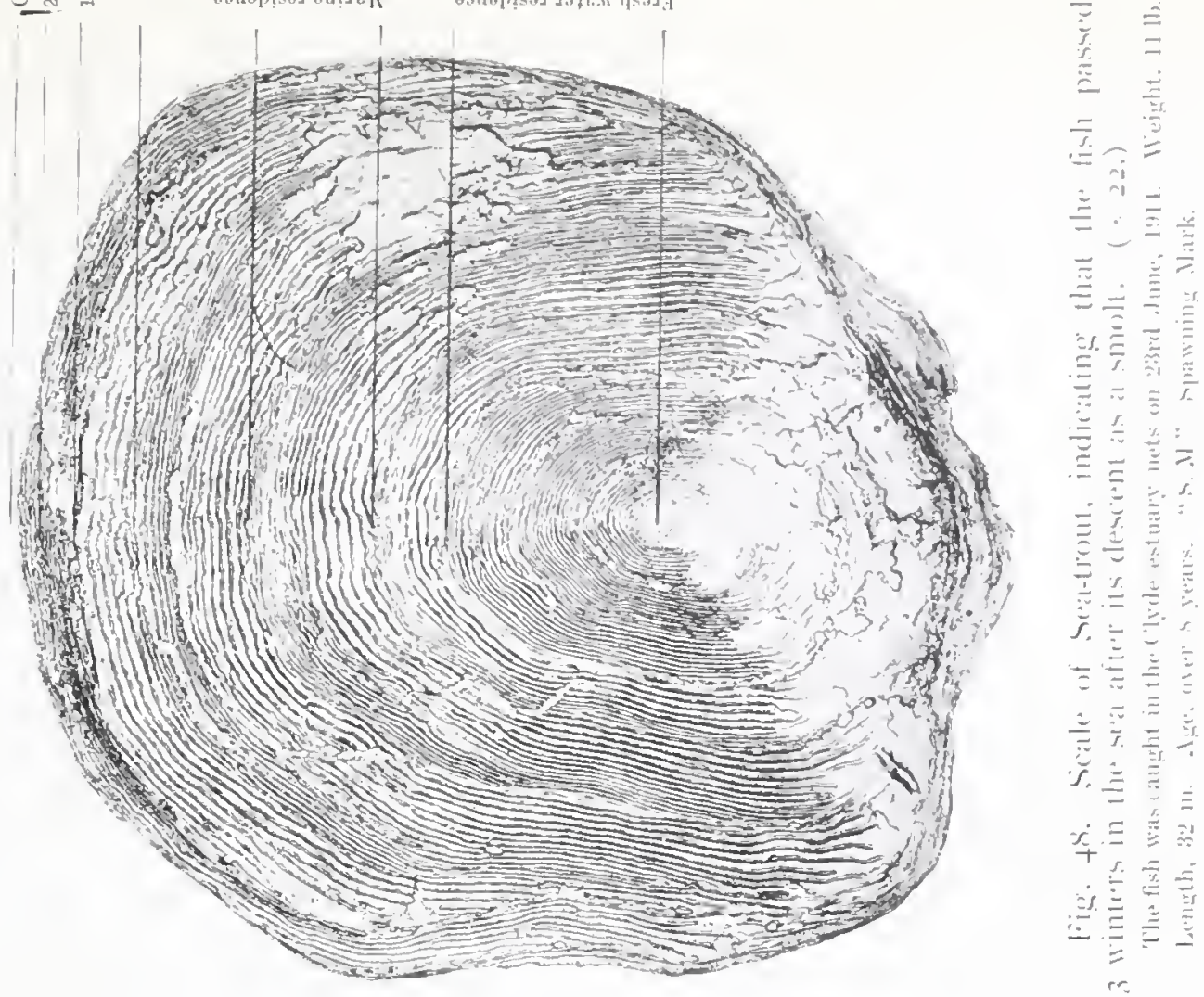

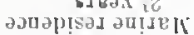

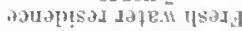

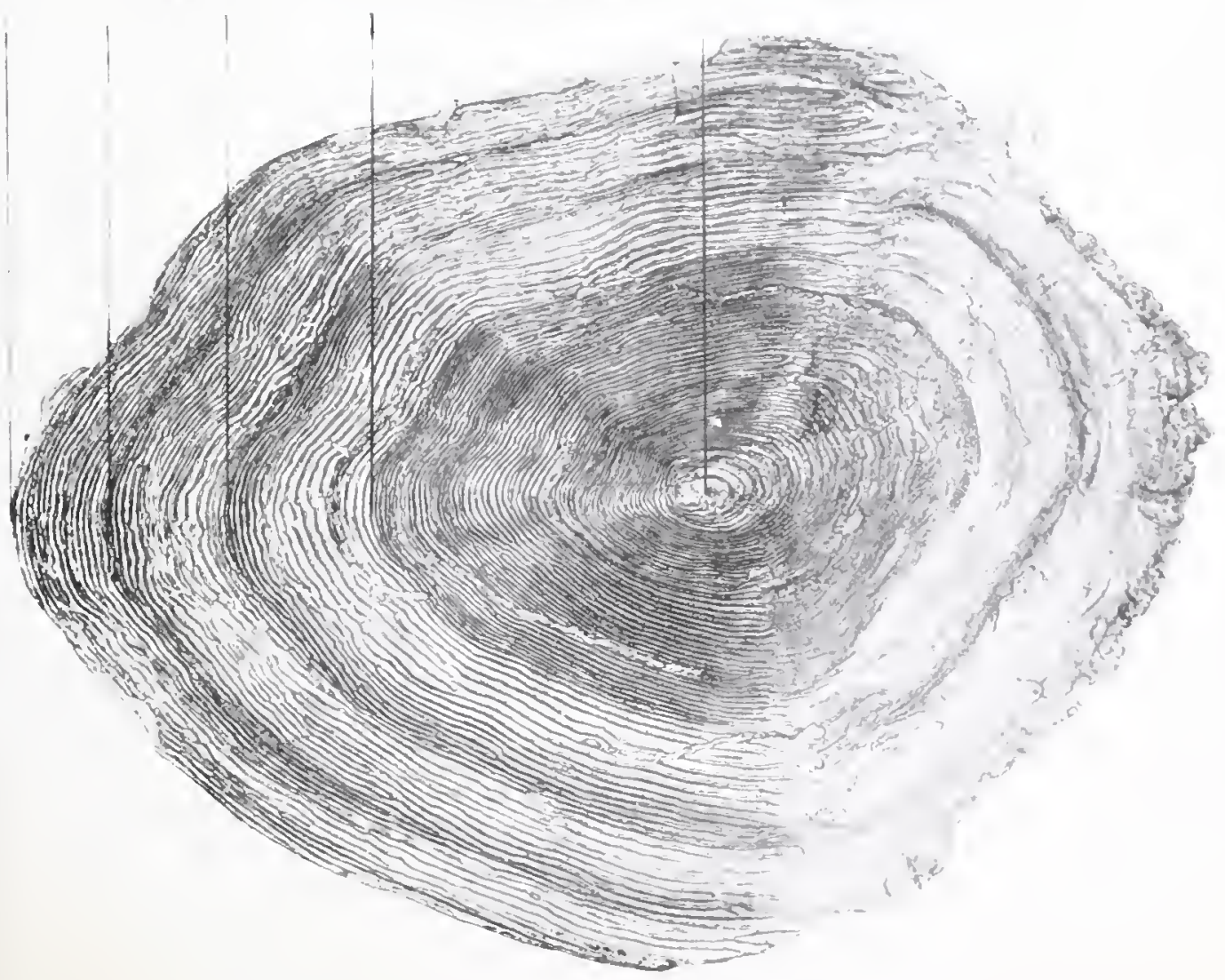

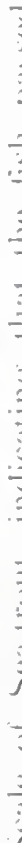

$\overline{7}$

f.

$\Xi$

$\bar{E}$

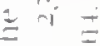

$\equiv-$

装

准

F

E:

ב

$\equiv$

严

는

$\frac{1}{3}=$

r.

$\equiv \equiv$

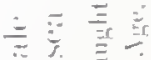

$\bar{x} \equiv$

$\therefore \equiv$

$+\frac{1}{x .7}$

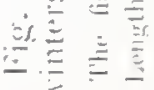




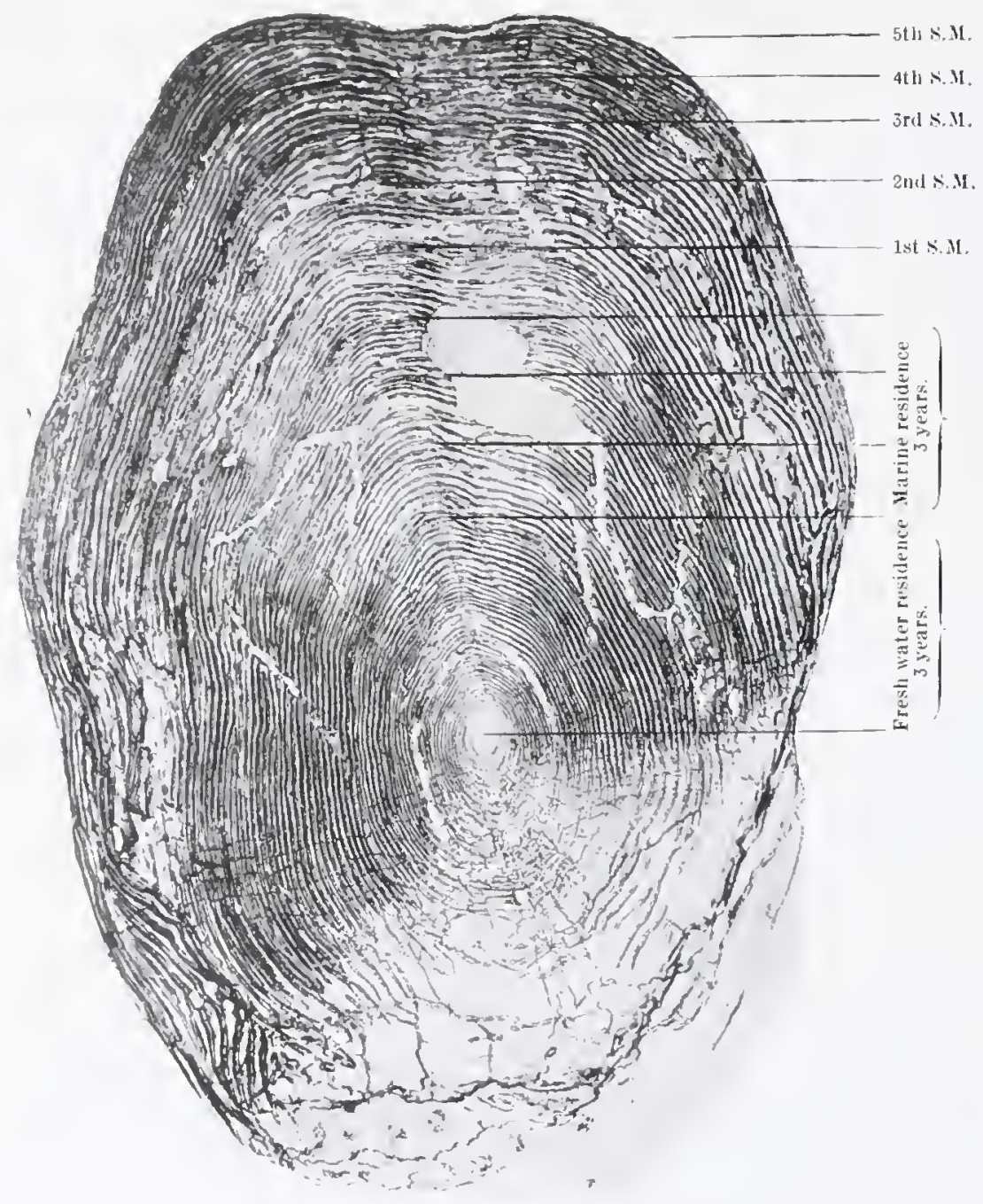

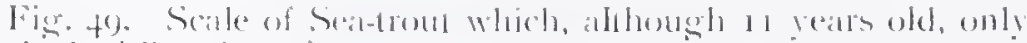
wrighed $2 \frac{1}{2}$ ll). $(\times 32$.

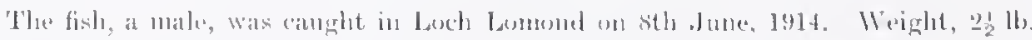

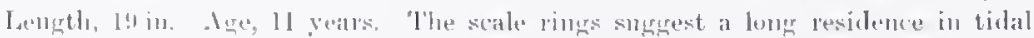

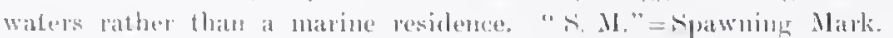


their first descent as smolts may vary is at least suggested, if it is not proved, by examination of the scales. Out of the 45 sets of scales of Loch Lomond fish examined by Mr. Hutton and myself, one fish, a late descending smolt (Fig. 30) had not reached the sea at all. Of the 44 others the scales indicate a residence in salt water subsequent to descent thus :-

$$
\begin{aligned}
& 23 \text { remained in the sea over o winters (Fig. 45). } \\
& \text { I6 remained in the sea over I winter (Fig. 46). } \\
& 4 \text { remained in the sea over } 2 \text { winters (Fig. 47). } \\
& \text { I remained in the sea over } 3 \text { winters (Fig. 48). }
\end{aligned}
$$

The 23 first noted of course ran as whitling in the same year as they descended as smolts, and it is interesting to note that of these, as I have stated, 5 showed evidence of spawning.

I am unable, with the data at my command, to deduce any general principle as to the effect which continuous residence in the sea without spawning may have upon the growth of the sea-trout in contrast to its rate of growth when spawning has early occurred and thereafter been continued each year. The variations are bewildering even in the few data which I possess. For example the fish which remained over 3 winters in the sea without spawning, whose scale is shown in Fig. 48, weighed i $\mathrm{lb}$. Its record is as follows:-

$$
\left.\begin{array}{lllll}
\text { Fresh-water life } \ldots & \ldots & \ldots & 3 \text { years } \\
\text { Sea life without spawning } & \ldots & 3 \text { years } \\
\text { Sea life with spawning } \ldots & \ldots & 2 \frac{1}{2} \text { years }
\end{array}\right\} 8 \frac{1}{2} \text { years= I I lb. }
$$

The fish which remained over 2 winters in the sea without spawning, whose scale is shown in Fig. 47, weighed $4 \frac{1}{4} \mathrm{lb}$. Its record is :-

Fresh-water life $\ldots \quad \ldots \quad \ldots \quad 3$ years

Sea life without spawning $\quad \ldots \quad 2$ years $5 \frac{1}{2}$ years $=4 \frac{1}{4} \mathrm{lb}$.

$$
\text { Sea life with spawning } \ldots \quad \ldots \quad \frac{1}{2} \text { year }{ }^{2} \quad \ldots
$$

But I give (Fig. 49) the scale of a fish which spent 3 winters in the sea without spawning, and although I I years old weighed only $2 \frac{1}{2} \mathrm{lb}$. Its record is :- 
Fresh-water life $\ldots \quad \ldots \quad \ldots \quad 3$ years

Sea life without spawning $\quad \ldots \quad 3$ years 1 I years $=2 \frac{1}{2} \mathrm{lb}$.

Sea life with spawning $\ldots \quad \ldots \quad 5$ years

It would naturally be of great interest if scales of old fish could be found which would show a wide difference in the migratory habits of fish of the same season's hatching, but one can easily understand that the likelihood of securing such scales is not great because such fish are relatively fewer in number; nor are the scales of old fish very easy to read. There is no reason, however, it seems to me, why such variation should not occur. From the set of scales upon which I have so largely drawn for confirmation (so far as it goes) of my various views, I have already cited (Fig. 48) one fish which apparently spent 3 years in fresh water, thereafter 3 years in the sea without spawning, and 2 more years in each of which it spawned, the fish being caught in its ninth year. As a contrast I cite later (Fig. 58) another fish which apparently spent 2 years in fresh water, thereafter $\mathrm{I}$ year in the sea without spawning and 5 more years in each of which it spawned, a total of 8 years.

It is unnecessary to follow any further in detail the individuals of the shoal whose supposed movements we have been endeavouring to trace. The same process of division and sub-division will I imagine continue annually till few of those originally hatched together survive. As the same process is moreover going on with respect to each year's crop of smolts as these descend to the sea it is plain that the fish which at any time are ascending will be of all sizes from the smallest to the greatest.

It would be interesting if one could discover the precise bearing which the presence or absence of a loch, or a series of lochs, has upon the migratory habits of the local sea-trout. I am inclined to think that this matter may ultimately be found to be the key to many of the problems that puzzle one in the life-history of the fish. It is at least suggestive that enormous numbers of sea-trout are found in those 
districts in which lochs are common, districts such as the north-western mainland and islands of Scotland, certain parts of Ireland, and almost all the coasts of Norway. It seems reasonable to suppose that the character of each loch, its accessibility from the sea, and its level relatively to sea level, will help largely to influence the movements of the fish which frequent it, so that the deduction of any general principles must necessarily be extremely difficult. There is a broad resemblance, however, between many of our loch basins which is worth adverting to.

The most common type of loch with which one is familiar in Scotland is of course the "glen-lake." The origin of these glen-lakes has occasioned much controversy amongst geologists, but it is enough to note here in passing that the once popular theory of excavation by ice action is not generally accepted nowadays. Be that as it may these glen-lakes are of all sizes, ranging from inconsiderable tarns to great inland seas. But their most interesting feature-so far as regards our immediate subject - is that, owing to an alternate lowering and raising of the general land surface the waters of some of these lochs, within an almost measurable period of time, have become fresh instead of salt. It is possible that the sea has so far encroached upon others as to make their waters salt or brackish instead of fresh. At any rate it is certain that the character of all those that lie near sea-level has changed within recent geological times, and is now in process of gradual change. They are all in different stages of transition. Some of them, in the West of Scotland, lie wholly submerged and open to the sea as in the case of Loch Fyne and Loch Long. Others are so nearly at tidal level that the tides flow freely in and out of them through a narrow passage, albeit with much commotion as in the case of the Gareloch, or over a rocky barrier which at low tide cuts off the loch from the sea by a considerable fall, as happens at Loch Etive. Others again, like the Dhu Loch, at Inverary, and some small lochs in the Hebrides-Lochs Stenness and Harray in the Orkneys are of the same character though 
not glen-lakes-are so nearly beyond tidal influence that their waters are barely more than brackish. And, lastly, of others near sea-level, many of our great lakes, like Loch Shiel, Loch Maree, Loch Morar, Loch Lomond and Loch Eck, are now wholly beyond tidal influence, although the fact that sea-shells may be gathered in the clay of certain beaches in a state of almost perfect preservation in some of them proves that their fresh-water environment is of no great antiquity.

Now, whether we attribute to trout a marine or a fresh-water origin, it is quite easy to imagine that the trout of any fresh-water loch to which the sea gradually obtained access would adapt themselves to the changing conditions of their environment and become in time, to all intents and purposes, sea-trout. They would still, as such, continue to migrate to their accustomed spawning streams. Similarly the seatrout of any sea-loch which gradually became elevated above tidal influence would not for that reason necessarily abandon their habits of frequenting it, though these habits might possibly change to some extent. For instance, the tentative run to certain lochs in spring may be the survival of some ancient habit which existed when the loch still retained its marine character. At all events the habit of seeking the loch for the purpose of spawning in its streams would almost certainly persist unchanged. It would, one may suppose, be the last habit to be definitely abandoned. My belief is, that it is practically immaterial to the trout of those districts, where such conditions as I have indicated prevail, whether they inhabit at one time or another the fresh-water, brackish, or salt-water loch, whichever it may be, which gives character to the river channel, and that the runs of fish differ locally just because of the variety of local conditions.

But particularly I would suggest that such tidal, semi-tidal, and almost tidal lochs serve as convenient gathering grounds for the seatrout shoals preparatory to their periodical migrations. For example, it is quite plain that Loch Lomond is the natural gathering ground for 
the sea-trout of the Clyde district, because only through it have the fish got convenient access to a considerable number of spawning streams in an estuary where accessible spawning streams are remarkably scarce. By way of contrast Loch Awe holds hardly any sea-trout, and this is possibly because not it, but Loch Etive, is the natural gathering ground of the fish. Loch Etive is a tidal loch in which the fish find convenient spawning streams without being driven to the necessity of making a long and adventurous ascent up the river Awe to the distant Loch Awe spawning tributaries. One might multiply examples, but anglers will be able to see, each for himself, how far this theory will apply to those districts with which he is familiar.

A loch then, fresh, brackish or salt, may be the original and hereditary habitat of the fish; it may, if salt or brackish, be still their actual feeding ground; and it may, in any event, be the gathering ground in which they assemble preparatory to spawning and to which they return as kelts. If we further assume a strongly marked shoal habit in the sea-trout - a habit which I think is beyond question-the loch, if wholly fresh, will afford better than any river will a sanctuary and nursery for the fry and parr until such time as they descend to the estuary as smolts.

It follows that wherever a fresh-water loch, almost at sea-level and within easy access of the sea, serves the fish of a district as both sanctuary and gathering ground, one may there expect to find sea-trout in great numbers, and that is precisely what one does find. $\mathrm{Mr}$. Calderwood has stated that in three seasons 33 ,000 sea-trout were netted in the Echaig, the stream of no great size which drains Loch Eck to the sea. The numbers of sea-trout which throng the Hebridean and Orkney lochs are extraordinarily great, and of course such lochs as Loch Maree, Loch Shiel and Loch Lomond attract anglers from all quarters for the sea-trout fishing they afford.

In the Loch Lomond waters with which I am most familiar the large 
class of sea-trout, that which averages about $4 \mathrm{lb}$., runs in June, and the average weight becomes less as the season advances. Mr. Hutton informs me that the same graduation of the runs occurs in Ireland and in Norway, and I assume it is general. In a broad general view this decrease in the average weight may be attributed, perhaps, not so much to the gradual elimination of the larger fish as to the increasing influx of the smaller whitling class.

I have not overlooked the run of heavy sea-trout which occurs in our East Coast rivers, a run which once again opens out the "bull trout" controversy. The Tweed netting close time, and indeed the Aln close time also, begins on September 15, and the evidence is fairly conclusive that the major part of the run of these large fish occurs after the net close season has begun, with the result that the nets take a comparatively small toll of them and their numbers tend to increase to the prejudice of more marketable fish. I cannot explain why there should be this late run of heavy fish, but it seems to me that it is another pointer to the conclusion (suggested, as I have shown, by the scales) that there is a species of sea-trout on the east coast that, whatever it may be classified as, is not identical with the sea-trout of other waters. I have in my introductory chapter suggested what that sea-trout may ultimately be found to be. ${ }^{1}$

We have already seen that the sea-trout which spawn in October, November and December do not delay their ascent from the sea until these months. In districts where the spawning grounds are close to the tidal reaches many may do so, but in most rivers the heaviest run of sea-trout-if not the run of heaviest sea-trout-is a summer run. As we have scen, too, some fish may actually in some districts have ascended with the intention of remaining till the spawning season as early as April or May, but such early runs at best are always intermittent. In any case, it requires a considerable freshet in the river to induce the fish at any time to leave salt water.

1. See also post, Chapter $\mathrm{X}$. 
If there has been a spell of dry weather prior to the usual time of any run, in cases where a river enters directly on the sea without any great intermediate stretch of tidal water, the sea-trout congregate in numbers at the river mouth. One may see them gambolling and leaping then on any calm evening manifestly showing the keenest anxiety to enter the river proper, but few of them venturing to traverse the dangerous shallows at the river mouth. At such times they fall an easy prey to the splash-netter and, in unprotected districts, the shoals are sadly decimated by unscrupulous persons even now in Scotland, although of late years the officers of the Fishmongers Company of London have done much to stop this illegal traffic.

Where the water is of the normal saltness of the sea off the mouths of such streams, sea-trout seldom take freely any lure the angler can offer them. But in many places, such as narrow channels or sea-lochs, where the water is brackish, they will often take fly or "minnow," although it is not easy to say why in one place they should prefer fly and in another minnow and vice versa, as they often do. Even in the sea an ordinary earth-worm is sometimes an effective bait, but, in truth, the feeding habits of the fish-or at least the lures with which they may be caught-vary so surprisingly in different localities that no rule can be laid down for angling for them in salt water. They will seldom anywhere take at all when actually waiting at a river mouth for the weather to break. When the weather does break the fish eagerly run up with the first of the spate and so closely crowded on each other are they sometimes that the rushing noise of their passage up the shallows can be distinctly heard above the sound of the rising waters.

In greater rivers, where there are tidal reaches, even if the river be under its normal flow, a proportion of fish will always risk the ascent at the top of each tide. They pass up to the fresh-water pools during the darker hours, seldom running at all in daylight. Some of the best 
sport to be got with sea-trout is often to be found in such tidal reaches for the fish as a rule, when they take at all, will take the fly freely.

The shoals for the most part fall back with the receding tide, only a few braving the ascent, but when the river rises they no longer fall back but boldly push upstream. In some places where a bridge spanning the river gives opportunity for observation, hundreds may be seen strung out in a long procession, maintaining a kind of formation, it would seem, under an accepted leadership. Mr. Malloch, it is worth noting here, makes a curious statement about the running habits of sea-trout and salmon. "No matter what its size may be," he writes, "the sea-trout always runs in a zig-zag fashion-first to the one side and then to the other. The salmon, on the other hand, runs in a straight direction." I cannot confirm this, although I do not pretend to dispute the accuracy of Mr. Malloch's observation. The fact seems of no great importance and is hardly a practical method, one would think, of distinguishing a salmon from a sea-trout in which connection Mr. Malloch adduces it.

The sensitiveness-or is it instinct?-which enables sea-trout to anticipate a coming change in the weather is, I think, well illustrated by the following brief extracts taken from a diary which was kept by the late Mr. Alfred Brown of Luss, for the year I897.

"June 25. Fine weather continues. River and Loch very low. Large quantity sea-trout entered the former on $22 \mathrm{nd}$ and are lying in the pools in the meadow. This is supposed to indicate a coming flood.

"June 26. The sea-trout noted above have returned to the loch. No rain has come-dry-bright sun-north wind-very fine.

"June 27. The spate came. Sea-trout ascending the river in great numbers. The fish have thus only been wrong by a few days."

In pushing on to spawning redds there are few obstacles which a sea-trout will not surmount. They show the most astonishing skill in 
negotiating rocky cataracts, and even the bare breast-work of milldams, in low water. I have seen them wriggling successfully up the pitching of the apron of a dam when only a trickle of water ran between the stones; and in one river, where a sloping wooden shoot is placed for their convenience, I have seen them throw themselves on to the boarding when it was no more than wet and scuttle up it by hugging the angle at the side. They run, however, in greatest numbers in a falling water after a spate, and I think they prefer to run then in sunlight.

I cannot say what is the maximum perpendicular height that a seatrout will clear in its leap. Probably five feet is an outside limit, but I fancy the powers of leaping of salmon and sea-trout are very similar in this respect that they are both usually over-estimated.

Many districts have a natural fall or a mill-dam where the fish can be seen leaping in numbers at certain times of the year, and such places are always an attraction to visitors, for there is something intensely interesting in seeing the efforts of the fish to surmount the obstacle. I reproduce here a photograph taken of a salmon leaping at a fall (Fig. 5o). Sea-trout leap in exactly the same way but the fish are too small to be easily photographed. I think I have to thank Mr. H. W. Johnston (indirectly through Mr. Hutton) for the photograph which was taken, I understand, on the river Tummel. The Pot of Gartness, a pool on the river Endrick, which flows westward through Stirlingshire into the lower end of Loch Lomond, lies below a natural rocky obstruction, and this forms one of the best-known "salmon leaps" in the West of Scotland. Sea-trout and salmon both ascend it, but only sea-trout ascend the mill-dam on Luss Water where there is often a remarkable display of the leaping fish, many being in the air at one time along the whole perpendicular face of the dam while the broken water below is seething with others. I have spent many hours watching the fish thus leaping, and have not the least doubt that before making a leap at the obstacle sea-trout carefully take their bearings. If 
watched closely for some time a particular fish will be seen poising itself amid the foam of the pool, sometimes the head alone, but often the head and pectoral fins, being out of water, facing the fall. Then the fish disappears for a few seconds and one may expect it, and not another fish, to be the next to leap. If it fails to surmount the fall and is swept back into the pool, it will swim down to slacker water at the tail of the pool where it rests for a little before making another effort. It is quite easy to identify particular fish even when there are numbers leaping. There is always some difference in size, shape, or colour which distinguishes one from another.

It is an open question whether salmon or sea-trout are the more persevering travellers to the upper waters. I think that if there is a sufficient volume of water the salmon will push furthest up the main stream; but where there is no steady flow the sea-trout only will attain the higher reaches. In the greater river systems sea-trout very often turn aside into the first suitable tributaries they come to. I have heard the theory promulgated that just as sea-tront will not proceed far out to sea so they prefer not to travel far inland, and the theorist placed his inland limit at 30 miles. How much of truth there may be in this I am not prepared to say, but I cannot conceive of there being any fixed natural law in such a matter. ${ }^{1}$

In normal states of the river and in ordinary daylight I think seatrout are not fish that care to expose themselves in open water. They certainly do not love to lie in the sun as salmon seem to do. Rather do they seek the bottom of the deepest pools, or burrow under the overhanging banks, or hide below fringing trees. At nightfall only do they venture upon the shallows, and then one can hear them in the dark plunging in the quieter waters and splashing in the streams. In

1. Mr. Calderwood has kindly informed me that he has himself got two records of sea-tront being captured out at sea, in the one case, 40 miles off Lowestoft, and in the other 45 miles of Montrose. I have already ( $p .128)$ noted a vague reference to a whilling being taken 40 miles inland, and may add that when I was at II ampton Bishop in August, 1915, a sea-trout weighing $41,1 b$. was caught in the Wye by Mr. Hatton, Junr, of Hereford, 60 miles from the ocean-a somewhat unusual capture as $\mathrm{I}$ was told. 


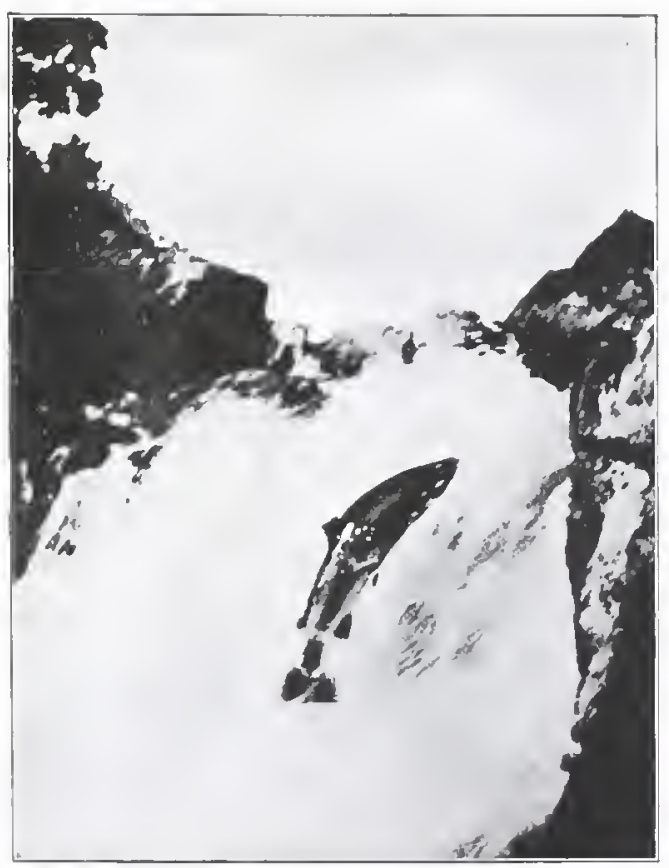

Fig. 50.- . Salmon leaping at a fall. 

many rivers, except during a flood or a half spate, night-time is the only time when sea-trout can be caught, or at least it is the only time when a good basket can be obtained. Even in a loch this preference of the sea-trout for deep dark water is observable, for, while salmon may be caught in a foot or two of water close to shore and trout on every shallow, sea-trout, in such lochs as the conditions will allow of their doing so, will remain outside in the deeper water, and will only rise freely in depths of from eight to fifteen feet or so, unless in the later part of the season as the spawning time approaches. When the bottom is just lost sight of in a loch is usually the best fishing depth for seatrout, while "between the shallow and the deep" is usually the best fishing depth for salmon and trout.

With every recurring spate the sea-trout move higher and higher upstream, and by the time the spawning period is reached many will be on the redds, or in the main stream in close proximity to the small tributaries in which the females prefer to deposit their ova.

In Scottish waters the sea-trout spawns on the whole earlier than the salmon does, the difference in time roughly amounting to one month. The sea-trout in this respect (supporting Mr. Regan's theories) approximates more closely to the trout. These seek the redds no doubt rather earlier than the sea-trout, but in many localities suitable weather and water conditions will find both kinds occupying the redds at the same time. When this occurs the sea-trout, being the stronger fish, ousts the trout from the more favourable positions on the redds. This is another of those serious handicaps already referred to which the trout has to accept in its struggle for existence with the sea-trout, but I shall show later, when discussing the actual process of spawning, that the trout suffers an even more vital handicap.

The actual months over which the spawning period of trout, seatrout and salmon extends in Scotland are September, October, November, December and January, of which September, October and 
November are more particularly favoured by trout; October, November and December by sea-trout; and November, December and January by salmon. Viewing Scotland as a whole I think it will be found that the middle month of each of these triple groups is the one during which the great majority of each kind of fish respectively spawns, namely, trout in October, sea-trout in November, and salmon in December.

The annual reports of the clerks of the District Fishery Boards made to the Fishery Board for Scotland throw less light than is desirable upon this subject, mainly because the Board did not until very recently ask the clerks of the local boards to discriminate between salmon and sea-trout, with the result that the dates of "fish" spawning returned for many years are valueless. Although the term "fish" is quite ambiguous few of the district clerks apparently ever thought of differentiating between salmon and sea-trout in their returns. In the blue book for season I9I , for instance, out of thirty-six reports received bv the Fishery Board only four districts differentiated between the two species as regards the question when fish were first noticed spawning, and only one (and that not even a statutory board) as regards the remaining queries as to when the greatest number spawned, and when spawning ceased. The Alness District Board puts the earliest sea-trout spawning date as at 25 th October; the Tweed District Board puts it as at 22nd October; the Balgay District Board as at i 8th October; and the Voluntary Association, which supervises the Clyde and Leven district (the district where there is no statutory board), as at 9 th October. Only from the latter district, too, was the information sent to the Fishery Board that the great majority of sea-trout spawned in November. It seems almost incredible, in view of the Fishery Board's apparent desire for more precise data regarding sea-trout-and having regard to the fact that nearly all the District Fishery Boards note a falling off in the stock of that fish-that in the latest report (for the year 1914) only one out of the 34 statutory district reports sent in to 
headquarters states definitely when sea-trout were first observed spawning in that year. The Clerk of the Nairn District Board deserves special mention for taking an intelligent interest in his work, and, it might be added, for having a proper appreciation of his duties. As a suitable statutory close time for sea-trout fishing, both by net and rod, but more particularly by rod, can only be satisfactorily arrived at from a close study of precise official statistics extending over a series of years, it seems to me important that the queries now put by the Fishery Board regarding sea-trout should be answered with some care and exactitude by the clerks of the district boards to bring out this information. ${ }^{1}$

It might be appropriate to place on record here my view that the respective close times fixed for salmon are wholly inapplicable to sea-trout, though statutorily they apply to both species of fish. As I have already stated the sea-trout is by about a month the earlier spawner, and in my opinion sea-trout ought not to be permitted to be caught at all in Scotland in October, or at least the close time ought to begin concurrently with the Scottish trout close time on I5th October, and should be universal, just as the trout close time is.

1. Mr. Calderwood, in his latest (1914) Report made to the Fishery Board for Scotland, emphasises the importance of a more accurate study of the life-history of the sea-tront, and in his report he has inchuded what one may term a preliminary sketch of what are generally believed to be the main facts of the sea-trout's career. One nay express the hope that this preliminary sketch is but the forerunner of a series of studies of the fish from his pen based, as Mr. Calderwood's studies of the salmon have invariably been, upon an unchallengable mass of carefully compiled statistics. The clerks of the various Boards can give him much assistance-if they will 

The Spawning Period 




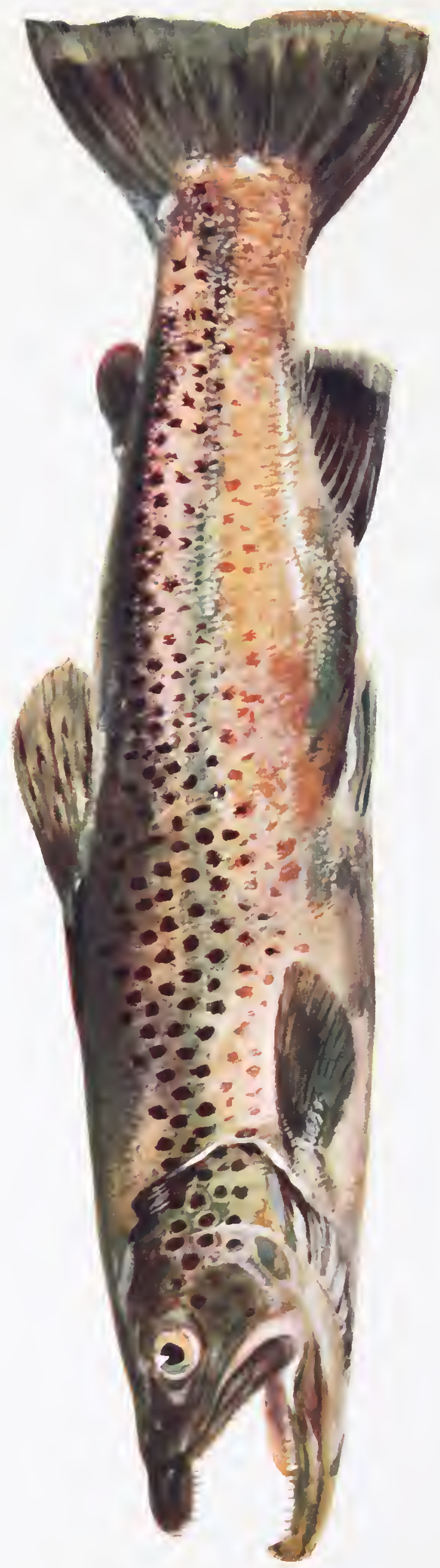




\section{CHAPTER VIII.}

\section{THE SPAWNING PERIOD.}

Given a half flood, then, with perhaps a touch of frost, though that is not essential, any day in November, or, indeed, any night-for if conditions are otherwise suitable the fish seize their opportunity irrespective of daylight-the ripe fish move up out of the pools to the stretch of gravel that may have been selected, females and males together.

By this time the fish, some of which may have been in fresh water since May, are very unlike the beautiful silvery creatures which ascended from the sea. I have heard them at this time pronounced to be repulsive-even loathsome-in appearance by unsympathetic observers. The males (Plate IX) have wholly changed colour; instead of a silvery skin daintily sprinkled with black cruciform spots, the bluish darkness of the back contrasting finely with the gleaming white of the belly, they have now a general yellow tinge mottled all over with reddish brown blotches - I have seen some as yellow as ochre-and the erstwhile silvery scales have sunk deep into their pockets under a coating of mucus while fins and tail alike have become thick and leathery. If the general outline of the body has not yet changed much the head seems to have become elongated, and the lower jaw, which normally projects but slightly beyond the upper, has developed a hooked gristly protuberance like that of the male salmon at spawning time, though in the sea-trout this protuberance is never so prominent. For the sake of the contrast now adverted to I showed on a previous page in rough diagram the outline of the head of a male salmon (Fig. I3 (I)) and the head of a male sea-trout (Fig. I3 (2)) as the spawning season approaches. The female, still shapely enough if a little 
"bagged" in outline, is black but uncomely, for her scales have darkened and all her gleaming white underparts have become dark. In any ordinarily flowing stream the red male fish is a conspicuous object at spawning time, but I have found it generally less easy to pick out the dark grey female in the current. I am able to give here (Fig. 5 I) a reproduction of a very perfect photograph, taken by Mr. Hutton, of the head of a $30 \mathrm{lb}$. Wye salmon which I caught at Hampton Bishop on August 14, I9I5, the fish from which diagram Fig. I3 (I) was drawn. The projection of the lower jaw is admirably shown in the photograph, and I think the spawning livery of the male fish is as clearly indicated as it can possibly be indicated without the assistance of colour. I also show (Fig. 52) a male and female salmon on the eve of the spawning season. With the male fish may be contrasted the male sea-trout which I show (Fig. 53).

There is no doubt I think that some of the sea-trout which ascend from the estuary each season are barren fish and will not spawn. On September 29, 1915, I caught one with fly in Loch Lomond, weighing $\mathrm{I} \frac{1}{4} \mathrm{lb}$., of such a silvery brightness that, concluding it to be fresh run, I looked to see if it had any sea-lice or traces of them on it, but none was found. Subsequent autopsy proved it to be a male fish with the testes wholly undeveloped. The measurements of length, $15 \frac{3}{4}$ ins., and girth, 8 ins., proved it to be in the pink of condition. It could not have already spawned, therefore, and could hardly have spawned later. The questions arise, first, whether the silveriness of its scales was due to the fact of its barrenness, and, secondly, whether this is so far proof that the change of colour of fish at spawning time is directly attributable to the exercise of the spawning function. Examination of the scales showed that the fish was not a whitling but a sea-trout, becausc the scale growth indicated that a period of nearly two years had elapsed since the descent of this fish to salt water as a smolt.

The process of spawning has often been described in the case of 


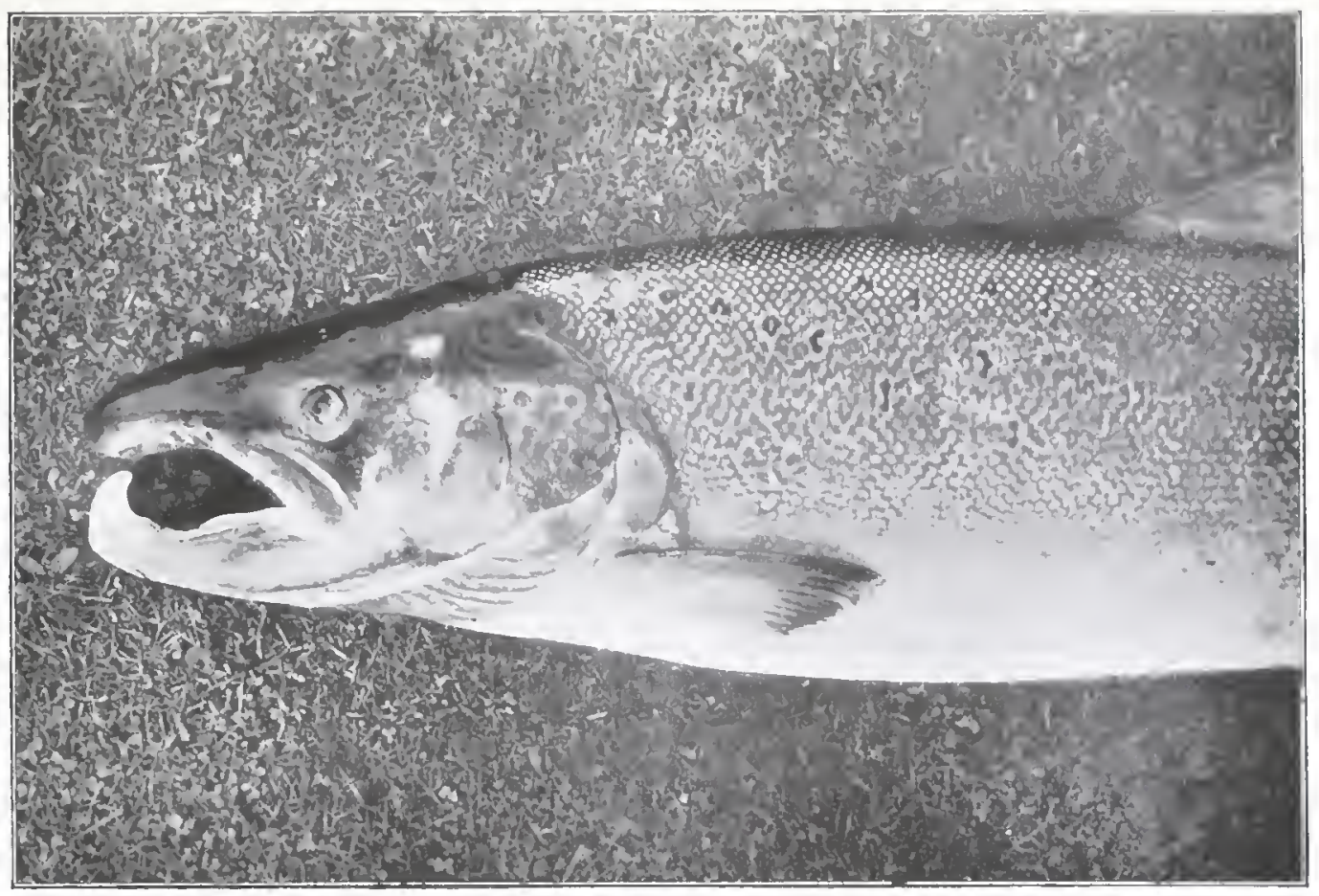

Fig. 51... I male Silmon in spanning dress.

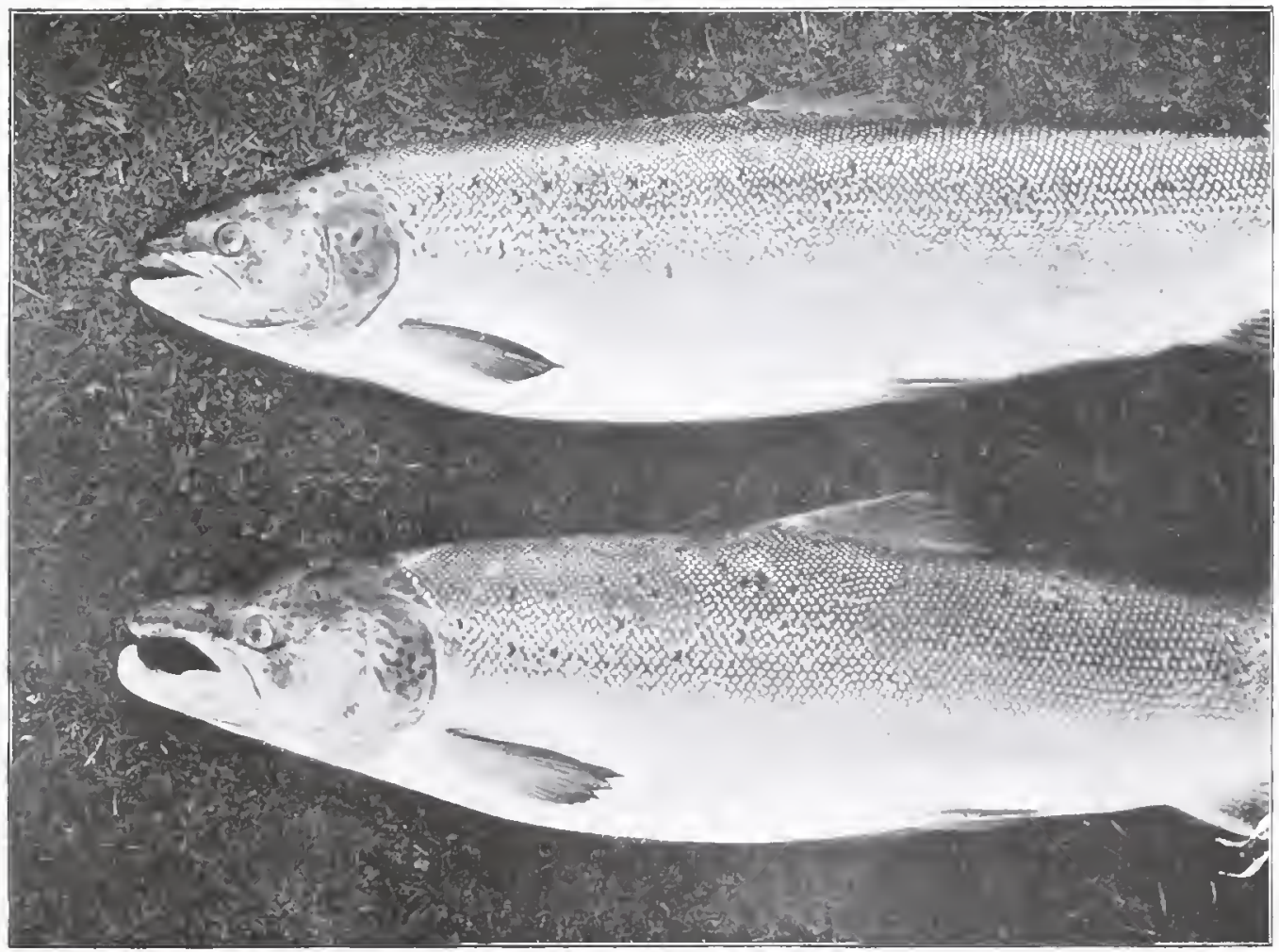

Fig. 52.- I female and male Salmon on the eve of spawning. 

the salmon though not often with unimpeachable accuracy. I think the best description of the process which I have read is contained in $\mathrm{Mr}$. A. H. Chaytor's "Letters to a Salmon Fisher's Sons," one of the best books on salmon angling which has been published for many years. At any rate sea-trout go through much the same procedure. The gravel they select is, however, of finer quality than that in which salmon prefer to spawn, the difference perhaps being fairly represented by mixed gravel, the stones of which, in the sea-trout's case, vary from the size of a hazel-nut to ordinary road metal, and, in the salmon's case, from ordinary road metal to the size of a brick. Objects under water naturally lose much of their specific gravity, but it is surprising notwithstanding how large are the stones which the fish are able to displace.

Having selected a spot for the proposed redd the female sea-trout throws herself on her side and, with a quick spasmodic action of the body, rapidly repeated several times, works a hollow in the gravel into which the ova as they are extruded, being heavier bulk for bulk than water, are carried by the flow of the stream. Working her way slowly upstream she covers the eggs thus deposited with the freshly loosened gravel. The male fish for his part is closely in attendance shedding his milt freely, and this, even when, as it must be, greatly diluted by the stream, is able to fertilise all the eggs with which it comes in contact. Yet the artificial propagation of salmon and sea-trout has shown that all the ova at any time are not necessarily fertilised, and it is reasonable to suppose that even when male fish are not scarce-as they sometimes are-some of the ova shed under natural conditions escape fertilisation. It is impossible to estimate the numbers of these, and probably the net total fertilised varies enormously according as the spawning conditions are favourable or the reverse. At all events any unfertilised eggs ultimately become a dead white and soon perish.

On 28th October, I9I3, I had a specially favourable opportunity of seeing the sea-trout spawn in the Finlas Water, one of the tributary 
streams of Loch Lomond. I watched one female of about $6 \mathrm{lb}$. weight within five paces of me. Before turning on her side she raised her head and opened her mouth wide, then, almost doubling up, she lashed out vigorously with her tail, and with a sort of burrowing motion sideways scattered the gravel and raised a cloud of sediment which almost concealed the male fish swinging to and fro in the current behind her. After repeating the burrowing action several times she would rest, then heading a little upstream she would begin again, the male always being in attendance. The cleansing of the upturned gravel from all sediment makes the redd easily distinguishable in the channel.

I am not certain that the female makes a hollow-I have seen it described as a rudimentary nest - of set purpose, but a hollow is at any rate the outcome of her spasmodic actions, and I imagine that a considerable proportion of the ova finds a resting-place in the loosened gravel behind her, to be effectively covered as the upstream gravel is in turn displaced.

I was at some pains to find out how the stream acted on the ova. From the floating leaves I gauged that the current ran at the rate of nearly three miles an hour, and into a similar stream at more convenience later I flung a quantity of ova. I was greatly struck with the speed with which the eggs found each a resting place. One had the idea that they would be carried initially a considerable distance down stream, but this is not the case; they find bottom almost immediately. The reason, I take it, is that the eggs are compact and materially heavier than water and so sink at once. Then it is surprising to see how effectual an "eddy" is caused by the slightest inequality of the bottom. The surface may appear to be even-flowing, but under the lee of the smallest pebble the water pauses for an instant, and behind every stone an egg may come to rest. Once it is at rest it is also matter for surprise how quickly the egg disappears from vicw. Its semi-transparency makes it a very inconspicuous object in the water, but I think its 
equal compressibility at every part enables it to adapt its shape to any crevice, and so it is "worked" quickly by the motion of the stream into any niche that will contain it.

It is erroneous to suppose that the male fish takes any part in the formation of the redd. His active efforts are confined to protecting his chosen companion from the attention of other males, and to dispersing the small trout which hover near intent upon snapping up such stray pellets of ova as come their way. It has been alleged that in spite of his domestic anxiety there are grounds for suspicion that the male fish is not averse from levying on his own account a food tax on the ova, but in all fairness, I must admit that I have not myself seen him do it.

The male sea-trout does not remain to watch the redds as the male salmon is said to do, but bolts for the shelter of deeper water as soon as his labours are over.

It may occur to the reader that when trout, sea-trout and even salmon are spawning in company, simultaneously and more or less promiscuously (as may easily happen in some districts), a certain amount of cross-breeding will inevitably take place. I do not doubt that such cross-breeding does occur in nature although few hybrids can be detected with any degree of certainty amongst mature fish. I think the explanation probably is that, the three species being so closely interrelated, the attributes of the hybrid become indistinguishable from the general features of the species which most strongly predominates in the cross.

For instance, if salmon ova be fertilised by trout or sea-trout milt, or trout or sea-trout ova by salmon milt, I expect-as the salmon is the stronger fish-that the progeny of the cross would be so like the progeny of true salmon parentage as to be indistinguishable from true salmon. As for trout and sea-trout, however they may be crossed inter se, there can be little doubt (even apart from Mr. Regan's theory) that the progeny in any appropriate environment develop into migratory sea- 
trout. I can adduce very little definite evidence in support of these presumptions, but I am aware that at Luss Hatchery on one occasion the ova of certain female sea-trout were fertilised with the milt of male salmon, there being no inale sea-trout at the moment available for the purpose. These ova thus fertilised took precisely the same time to hatch out as uncrossed salmon ova deposited in the hatchery on the same day, and to all appearance, up to the time of distributing them as fry in the streams, the alevins were just the same in colour, and differed as much in their general aspect from the alevins hatched from pure sea-trout eggs, as did the uncrossed salmon alevins. The manager of the hatchery bears me out in the supposition that any cross between sea-trout and trout would, at any rate in Loch Lomond, result in a migratory fish indistinguishable from a sea-trout. He often uses the one kind to serve the other without anything but sea-trout fry apparently resulting, and I am inclined to think, as trout and sea-trout commonly spawn together in nature, that this is the main factor which results in streams which are favourite spawning haunts of sea-trout holding but few common trout, and these of a poor class.

The reader will make up his own mind in view of all that I have written in these pages as to whether there is only one species of trout in British waters or not. I can only point to this vital matter of interbreeding as being the strongest possible proof of trout and sea-trout (excluding the "bull trout") being so closely related as to be to all intents and purposes indistinguishable the one from the other.

The whole period of spawning, which is an intermittent process in the case of the sea-trout, as it is in the case of the salmon, cannot be calculated with any degree of certainty either for the male or female fish. Mr. Malloch puts it for the individual sea-trout at "from two to four days," and for the individual salmon at "from three to fourteen days," and one need not question his accuracy of observation. But in the spawning season of I9I4 a ripe male sea-trout, whose milt was used 


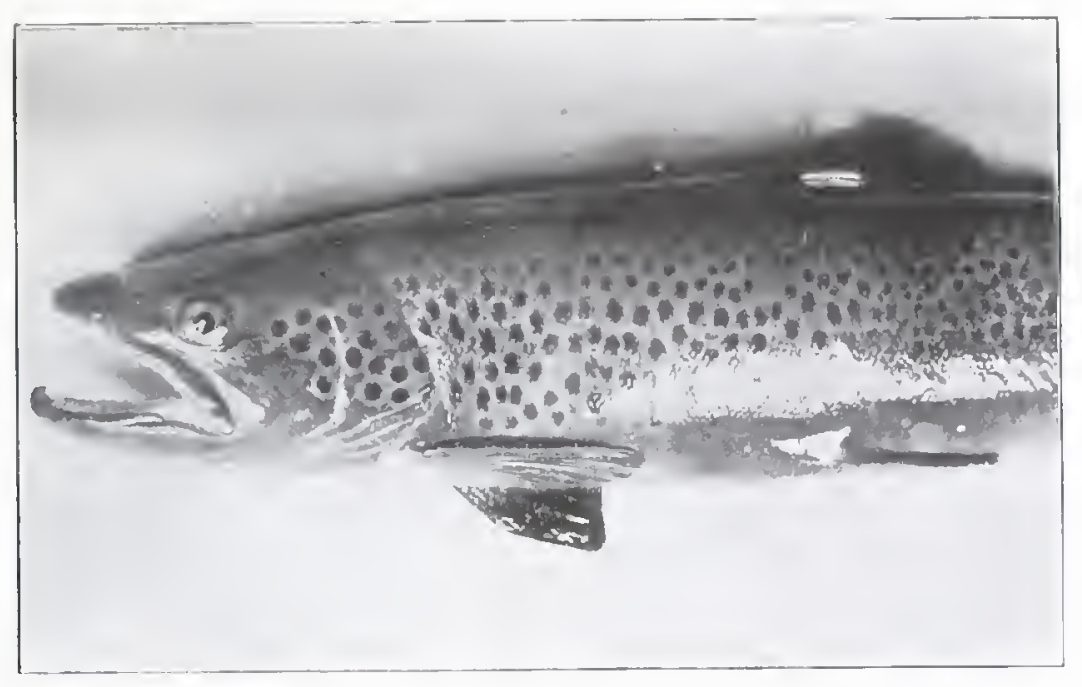

Fig. 53.-A male Sea-trout in spawning dress.

(Notr. Sie Feshery liverd label in dorsul fin.)

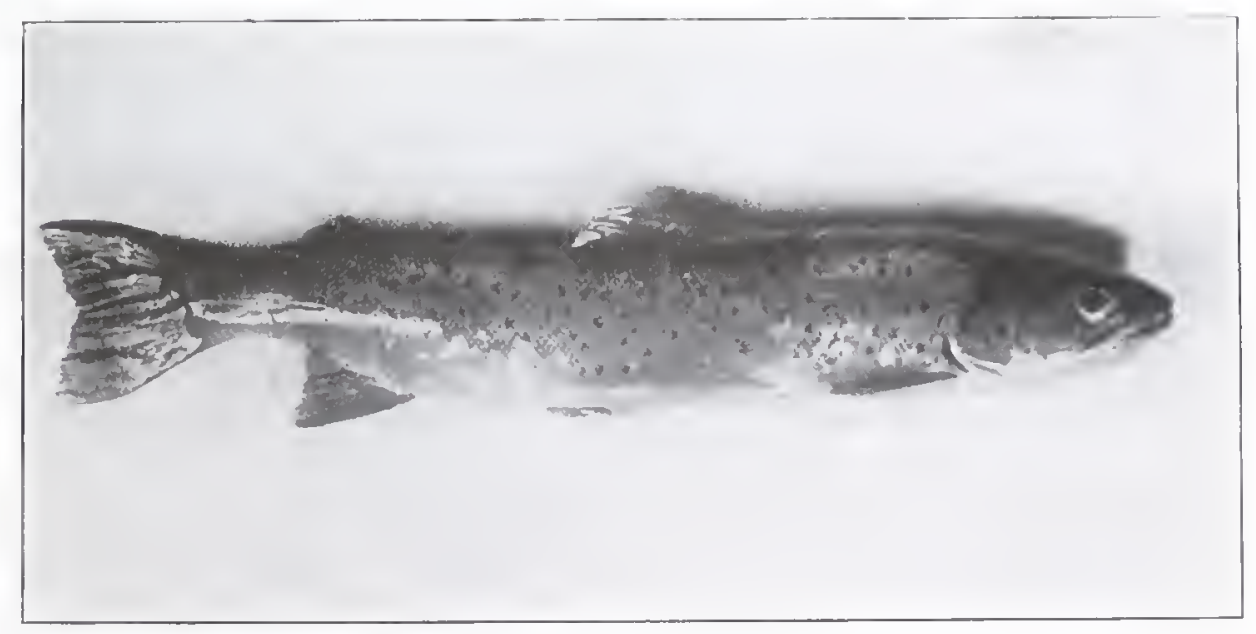

Fig. 54.-A female kelt Seatrout. 

on 9th November to fertilise the ova of some females, and which was released after being marked with a Fishery Board label, was recaptured on 26th November in the same stream, after an intervening period of drought, when his milt was again used to fertilise the ova of other females. This fish was thus engaged in active spawning operations which extended (intermittently no doubt) over a period of 17 days. I have no similar data in regard to female sea-trout, but I fancy from watching them in the streams, that they shed their ova with some regularity over a few consecutive days.

It may be worth while here to interject that in Scotland it is an offence against the Salmon Acts to disturb any "salmon" spawn or any spawning bed, unless for the purpose of artificial propagation or certain other specified purposes. ${ }^{1}$

Badly out of condition as many of the fish are by the time they come to spawn it does not appear that the exhaustive effects of spawning have a fatal result. The male sea-trout, as is the case with salmon, suffer most, but few as compared with male salmon fail ultimately to regain salt water. The female sea-trout suffer very little (Fig. 54). In many years I have never seen, in the Loch Lomond district, a spent sea-trout, either male or female, whose death could be attributed solely to exhaustion following upon the spawning period, and after careful inquiry made throughout a relatively large district such a case has never been brought under my notice. I do not gather, either, from what I know of other districts that such fatalities are anywhere very numerous in the case of the sea-trout. The inference must on the whole be allowed, I think, that only a very negligible proportion, in spite of great emaciation of the fish, fails to survive the spawning period.

In this connection the following extract from the Report of the Tweed Commissioners for I9I5 is interesting:- "The record of salmon, grilse, and sea-trout found dead or dying from disease and

I. See note ante, p. 92.

$\mathbf{L}$ 
taken out of the river and buried from November 19I4, to May 19I5, gave the following particulars:-

\begin{tabular}{llrrrrrr} 
& & \multicolumn{4}{c}{ Spawned. } & \multicolumn{3}{c}{ Unspawned. } & Total. \\
Salmon & $\ldots$ & $\ldots$ & 67 I & $\ldots$ & 57 & $\ldots$ & 728 \\
Grilse & $\ldots$ & $\ldots$ & 90 & $\ldots$ & 8 & $\ldots$ & 98 \\
Sea-trout & $\ldots$ & $\ldots$ & 284 & $\ldots$ & 17 & $\ldots$ & 301 \\
& & & -2 & & - & & \\
& & & 1,045 & & 82 & & 1,127
\end{tabular}

The number for the year I9I3-I4 was I,689, and for the previous year 2,343. Since 1879, when the annual returns of diseased fish were instituted, the numbers of fish buried up to date were:-salmon, I I I,782; grilse, I 7,5 I 5 ; sea-trout, 26,565-total, 155,862." These figures of course seem very alarming, and may be hastily thought to negative my views expressed above, but a known death-rate of 284 spent sea-trout out of the enormous numbers that ascend the Tweed each year is really not a serious matter taking local circumstances into account. It is probable that the river Tweed is responsible for the highest death-rate amongst spent fish of any river, but it is a question how far disease and pollution together accentuate the risks of the spawning period. I am of opinion that the loss due to the exhaustion consequent on spawning alone may in general in Scotland be said to be practically nil in the case of the sea-trout.

I have already referred incidentally to the illegal capture of kelt sea-trout (see page I 32). The law, it may be repeated here, is quite conclusive in Scotland regarding the capture of spent fish whether in fresh water, in the estuary, or in the sea, and whether during close time or in the open season. ${ }^{1}$ The law is, moreover, of general application

1. Every person who shall wilfully take, fish for, or attempt to take, or ald or assist in taking, fishing for, or attempting to take, any unclean or unseasonable salmon, or who shall buy, sell, or expose for sale, or have in his possession, any unclean or nuseasonable salmon, shall be liable to a penalty not exceeding five pounds in respect of each such fish taken, sold, or exposed for sale, or in his possession, and shall forfeit every such fish; but this section shall not apply to any person who takes such fish accidentally, and forthwith returns the same to the water with the least possible injury, or to any person who takes or is in possession of such fish for artificial propagation or scientific purposes. - Salmon Fisheries (Scotland) Act, 1868, § XX. 
in Scotland, for, although at one time the Tweed Acts permitted the capture of such fish, a clause of the general Salmon Act of 1868 specially abrogated that permission. ${ }^{1}$

In some streams where the stock of sea-trout is large relays of fish will occupy the redds in succession, and where good spawning ground is limited the gravel may be trenched again and again. It would not be easy to estimate with accuracy how far the eggs first deposited might suffer from subsequent disturbance, but displacement of the gravel must expose many eggs and cause them to fall a prey to the natural enemies which are always on the outlook for them. It is easy to conceive of a case where the stock of fish may be too great for the accommodation offered by the spawning streams, and, indeed (as an example of this) I can point to the river Fruin, a tributary of Loch Lomond, in the autumn of season I9I2, which was the most productive of sport of recent years. The same redds there, in that year, were trenched three or four times over.

When the spawning operations are completed the sea-trout begin slowly to drop down-stream but they are never in any great hurry to change their quarters. In the short and steep streams of the West Coast it is probable that a succession of floods will carry the fish comparatively quickly to salt water, but in greater streams the sea-trout, though gradually falling back, linger in each deep pool they come to. A curious example of the sea-trout's excessive timidity occurs to me in this connection. In very dry summers, when the river Leven is too low to permit of the working of the ferry boats, temporary wooden bridges are thrown across the stream for the convenience of the artisans going to and from the various works on the banks. During one very dry spring these bridges had to be used at a time when multitudes of kelts were descending. Now, if the sun happened to be shining, not a single

1. This Act shall not extend to England or Treland; and no part of this Act. except the thirteenth. eighteenth, twentieth, and twenty-third sections thereof. shall apply to the River Tweed as defined by the Tweed Fisheries Act, 1859, \&c. Salmon Fisheries (Scotland) Act, 1868, \$XX. 
fish would venture to pass the dark shadow cast by the first of these bridges which hung so closely over their heads, and above it the fish would lie in a mass waiting apparently till darkness came on. One could see them dropping down to the shadow, but they would invariably turn back upstream; none would face the mysterious obstruction.

During their descent as kelts, sea-trout take freely and impartially whatever lure the angler offers to them, fly, worm or "minnow," and they may often be seen plunging at such natural flies as are on the water, the March brown being a special favourite with them as it is with salmon. It is often alleged that they make great havoc amongst the smolts which are migrating to the sea about the same time that they are descending the rivers. Judging from the voracity with which they attack a spoon-bait or artificial minnow, it is reasonable to suppose that many a smolt must fall a victim, but I am disposed to think that the damage done by them in this respect has been much exaggerated. It would be quite easy for a kelt sea-trout to gorge itself on smolts, but I have never seen one so gorged, although I have seen them, when wellmended in the estuary, literally gorged with herring fry.

I do not think that the sea-trout in their progress seaward rapidly regain condition while in fresh water, for, except in one respect, they "mend" but little. They do not put on flesh to any great extent, but they assume a vivid brilliancy of silvery scale which even the ascending "clean" fish can hardly rival. It is, however, meretricious splendour at best-as someone has well expressed it the difference is like that between tin and silver-and the "well-mended kelt" a few hours after death has a general limp look of washy flabbiness which betrays it.

If the kelt sea-trout thus linger in the river pools it is a natural supposition that they will still further protract their descent if any considerable loch has to be traversed in course of the journey. That they do so all anglers in Loch Ness, Loch Awe, Loch Lomond, and such great lakes are aware. It seems to require a specially warm April 


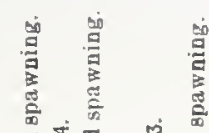

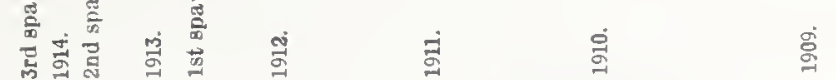

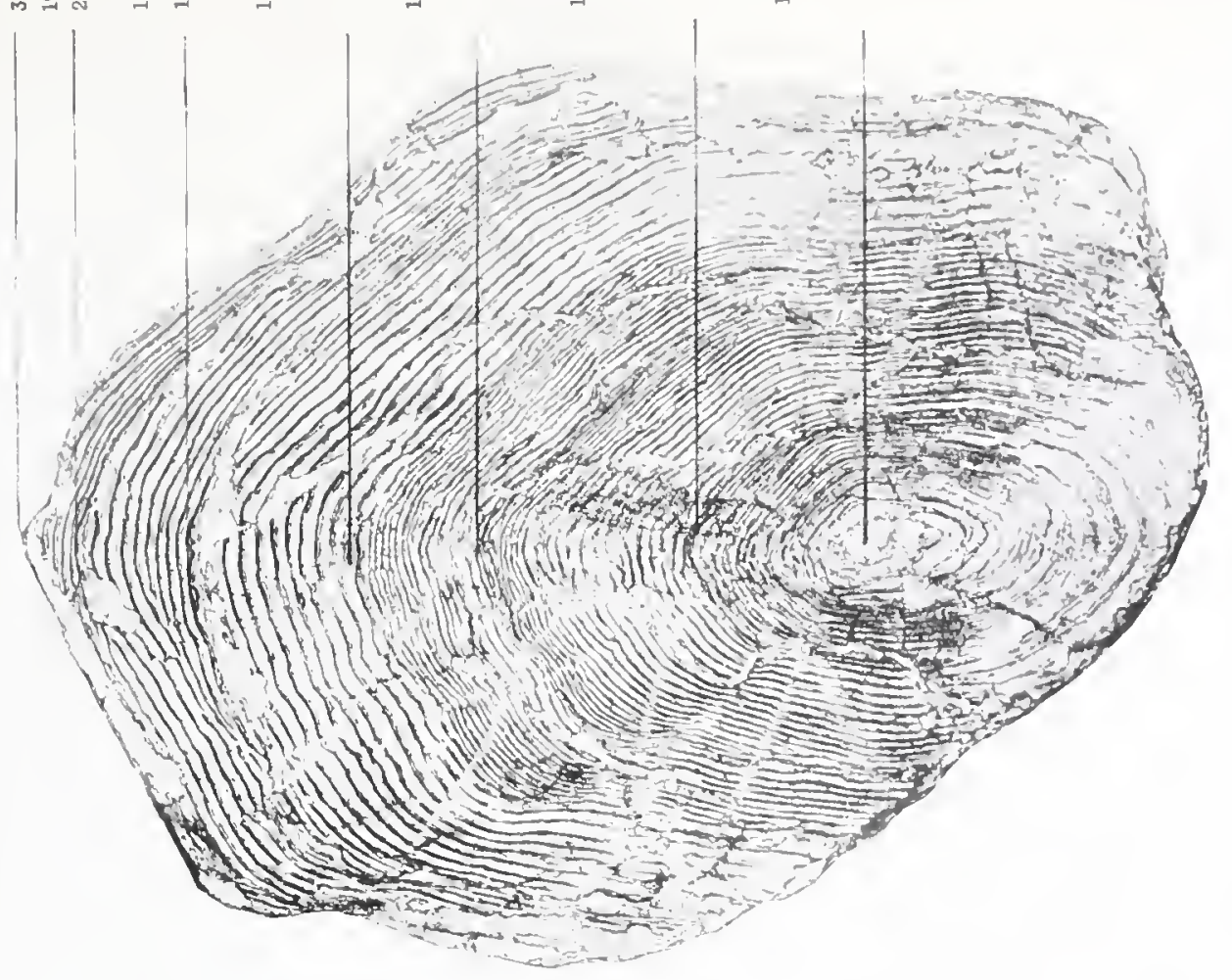

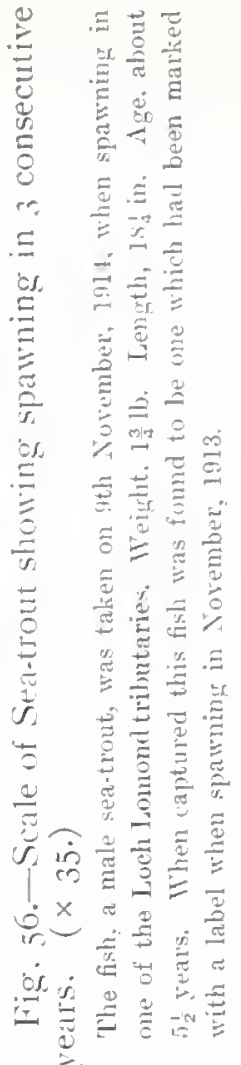

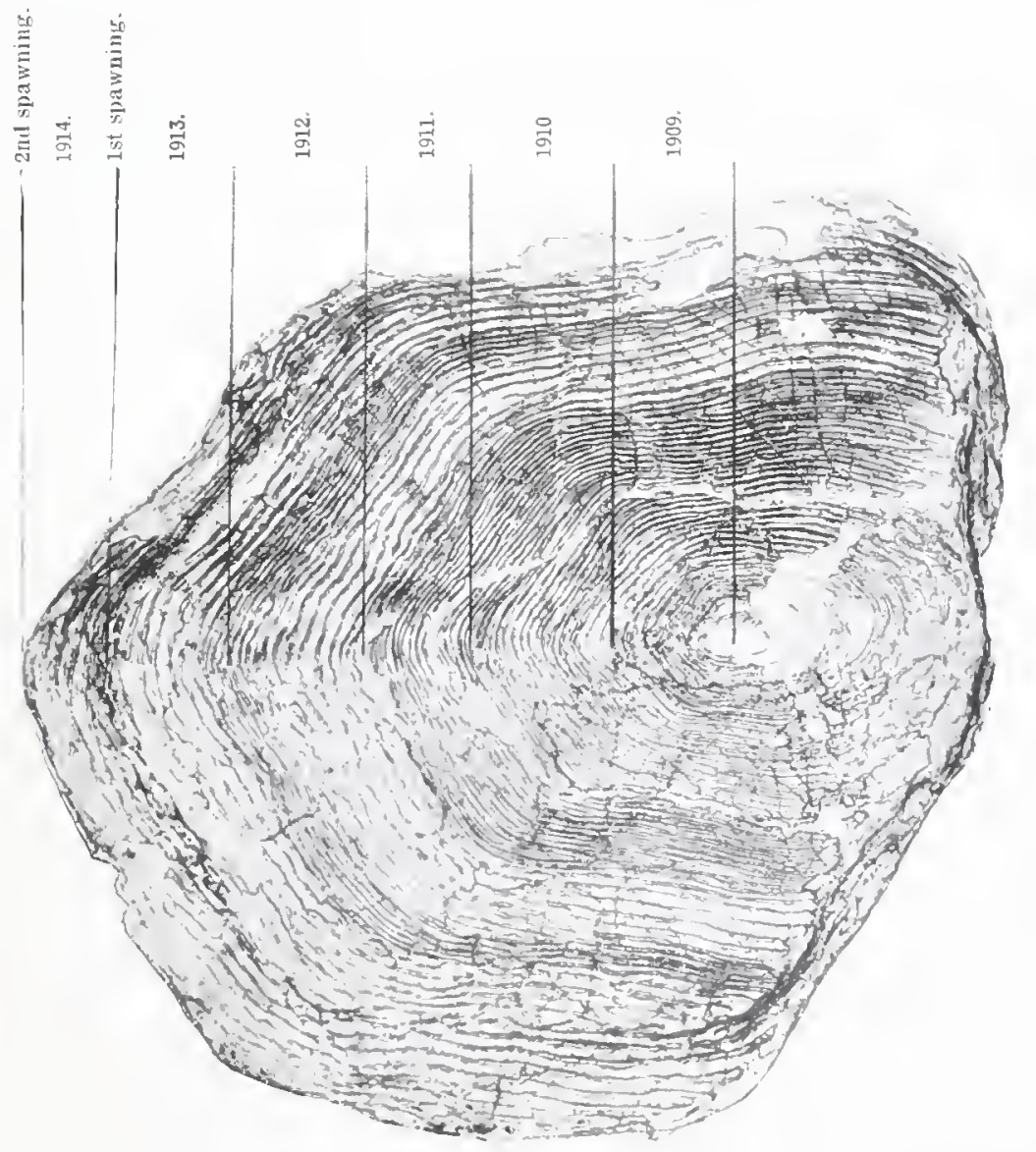

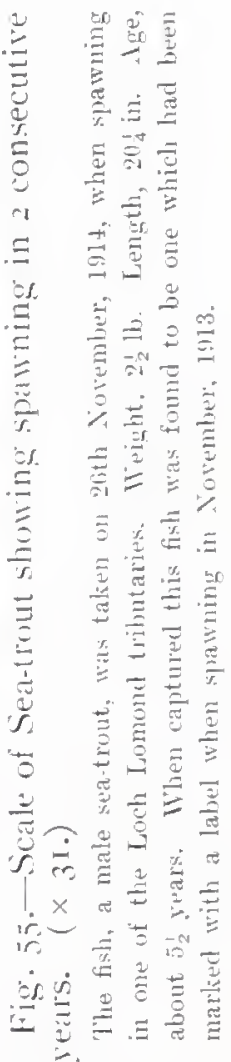



to induce them to leave such lochs at all. In the lower basin of Loch Lomond they congregate in great shoals between the lowest island, Inch Murrin, and the outflowing Leven. I have caught one in Loch Lomond, a fish of about $4 \mathrm{lb}$. in weight, as late as May 24 th, and in Loch Ness I once caught one, a small fish, on June I 3 th.

When the kelts finally reach the estuary or the sea, they rapidly begin to regain their best condition. I have been able to judge of their progress in this respect from the improvement in appearance, as seen from day to day, of those taken in the estuary sweep-nets of the Clyde. I have no proof that any individual fish has been taken and returned day after day until such time as its condition warranted its being killed, although the netsmen aver that such fish can be recognised. But it is generally obvious that the class of fish got in the nets changes gradually each day for the better through the yield of the net containing each day a higher percentage of kelts which have approached more nearly to the condition of takable fish.

It would be difficult without specially collated evidence from many rivers to pronounce upon a further question, namely, whether the mature fish, once they have ascended to spawn, return again each year for that purpose. I cannot find any reliable opinion on the point, and I do not pretend that the scanty evidence from marking which I possess is conclusive. I shall recapitulate the evidence in detail.

In October 1904, the men, when stripping fish in the neighbouring streams to stock Luss Hatchery, marked twenty-one sea-trout with the official labels supplied by the Fishery Board. In October 1905, as many as nine of these marked fish were seen again in the streams, but through an unfortunate misunderstanding the labels were not removed from the fish for purposes of identification. So far the facts point to a return in two consecutive years. But in season 1906 three more of these twenty-one marked fish were recovered as tabulated thus:- 


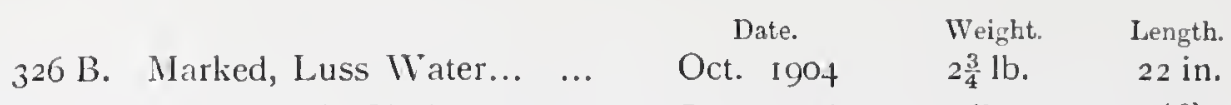

Recaptured, Clyde nets ... July $1906 \quad 4 \mathrm{lb}$ (?)

336 B. Narked, Arn Burn ... ... Oct. $1904 \quad 2 \mathrm{lb} \quad 20 \mathrm{in.}$

Recaptured, Loch, near do. Aug. $1906 \quad 3 \frac{3}{4} \mathrm{lb} . \quad 22 \mathrm{in.}$

340 B. Marlsed, Luss Water ‥ Oct. $1904 \quad 1 \frac{1}{2} 1 \mathrm{~b} . \quad 16 \frac{1}{2} \mathrm{in}$.

Recaptured, Luss Water... Oct. $1906 \quad 3 \frac{1}{2} \mathrm{lb} . \quad 20 \frac{1}{2} \mathrm{in}$.

Several alternatives are here possible. These three fish may have been amongst the nine seen but not identified in October 1905, in which case, if they had been so, a return in three consecutive seasons would have been established. Also they might conceivably have been others of those marked returned in season 1905 without having been observed, which would have equally meant a return in three consecutive years. If, however, they were not any of the nine fish observed, or were not others which had returned unobserved, then a return in alternate seasons is the only inference.

Again, five other fish were marked in the Arn Burn, near Luss, in November I906, of which one was recaptured in the following year, thus :-

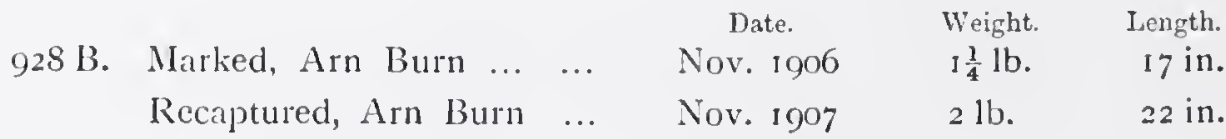

This instance proves a return in two consecutive years.

Further marking was accomplished in the spawning season of I9I3 when, amongst others elsewhere, Io fish were marked in the Finlas Water. Of these, two reappeared in season 19I4, as follows:-

\begin{tabular}{|c|c|c|c|c|}
\hline $8_{349} \mathrm{~B}$. & $\begin{array}{l}\text { Marked, Finlas ... ... } \\
\text { Recaptured, Clyde nets... }\end{array}$ & $\begin{array}{l}\text { Date. } \\
\text { 10 Nov. } 1913 \\
\text { 8 July } 1914\end{array}$ & $\begin{array}{l}\text { Weight. } \\
3 \frac{1}{2} \mathrm{lb} . \\
5 \frac{1}{4} \mathrm{lb} .\end{array}$ & $\begin{array}{l}\text { Length. } \\
22 \frac{1}{2} \mathrm{in} . \\
25 \frac{1}{2} \mathrm{in} .\end{array}$ \\
\hline & 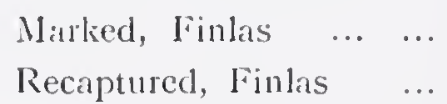 & $\begin{array}{l}10 \text { Nov. } 1913 \\
25 \text { Oct. } 1914\end{array}$ & $\begin{array}{l}1 \frac{1}{1} 1 \mathrm{~b} . \\
2 \frac{1}{1} \mathrm{lb} .\end{array}$ & $\begin{array}{l}17 \mathrm{in.} \\
18 \frac{\mathrm{l}}{2} \mathrm{in} .\end{array}$ \\
\hline
\end{tabular}

These instances, the sccond conclusively, prove a return in two 


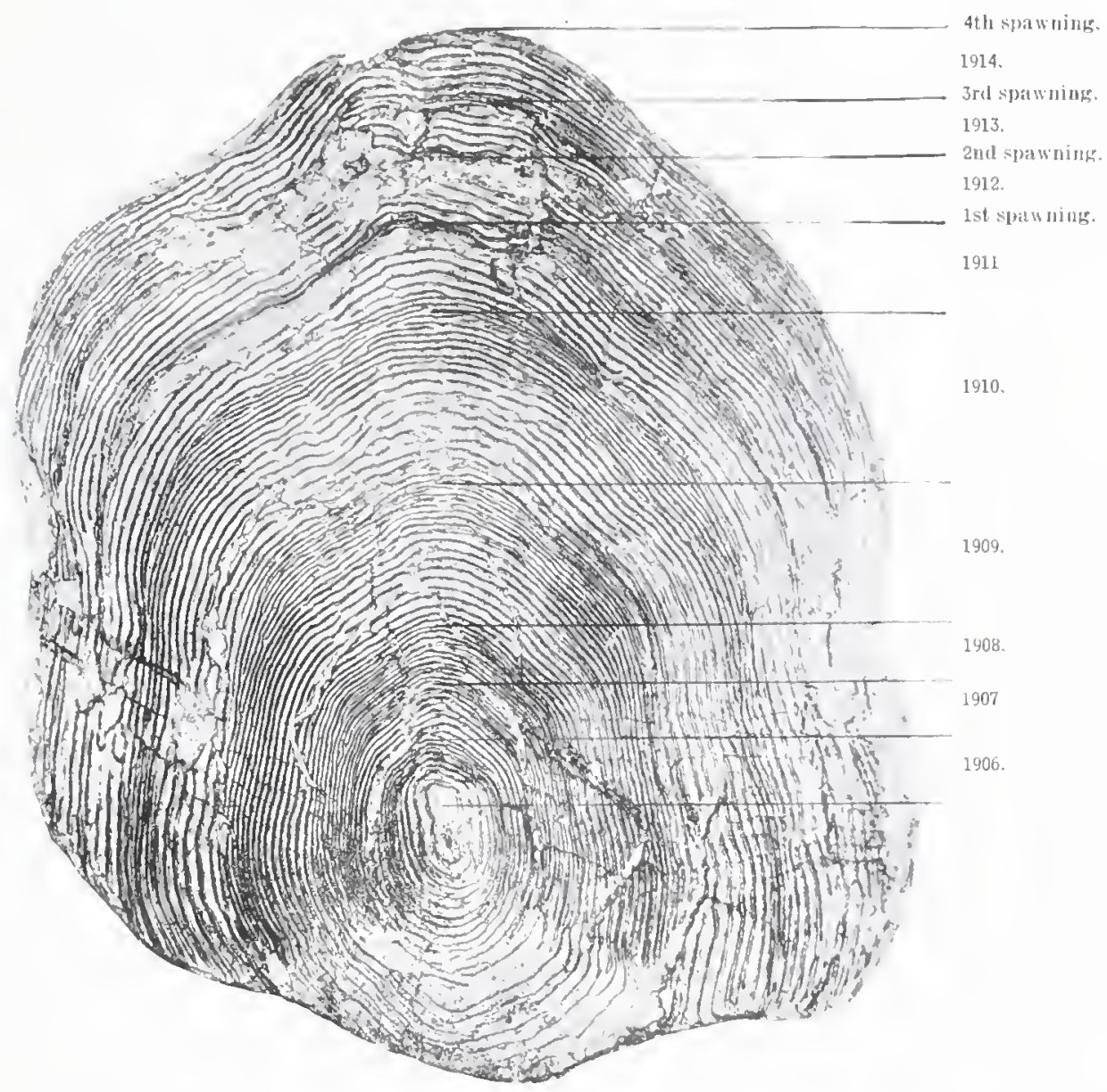

Fig. 57.- Scale of Seatrout showing spawning in + consecutive years. $(\times 30$.

The fish, a male, was taken on Both Novenber, 1914, when spawning in one of the Loch Lomond tributaries. Weight, $2 \frac{1}{4}$ ll. letugtli, $20 \frac{1}{2}$ in. Age, $8 \frac{1}{2}$ years. When captured this fish was found to be one which had been marked with a label when spitwing in November, 1913. 

consecutive years, the first fish, being recaptured in the Clyde estuary, might quite conceivably not have ascended the Leven to the loch.

Of 24 fish marked in the Altnagairoch Burn, a small tributary of Luss Water, in I9I3, two were recaptured:-

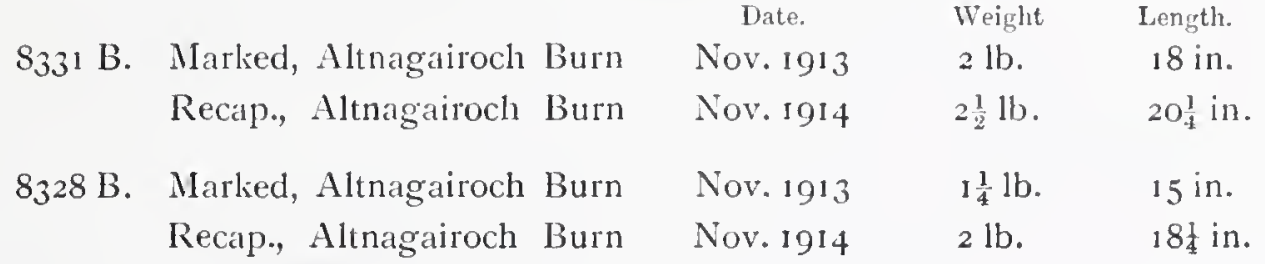

while, again, of 16 fish marked in the Smiddy Burn ${ }^{1}$ in 1913, two were recaptured also in 1914:-

8346 B. Marked, Smiddy Burn(?) ${ }^{1} \quad$ Nov. $1913 \quad 1 \frac{1}{4} \mathrm{lb} . \quad 17$ in.

Recap., Al'gairoch Burn(?) Nov. $1914 \quad 1 \frac{3}{4} \mathrm{lb} . \quad 18 \frac{1}{4} \mathrm{in}$.

8347 B. Narked, Smiddy Burn ... Nov. $1913 \quad 2 \mathrm{lb} . \quad 19 \mathrm{in.}$

Recapt'd, Smiddy Burn ... Nov. $1914 \quad 2 \frac{1}{1} \mathrm{lb} . \quad 20 \frac{1}{2} \mathrm{in}$.

all four of which prove returns in two consecutive years.

It is fair comment, I think, that if fish of varying weights are each found spawning in two consecutive years, there is at least a presumption that all may really spawn over more than two consecutive years.

But what ought perhaps properly to be called secondary proof is furnished by the scales of some of the recovered marked fish and of others unmarked. I shall examine first such scales as I have of marked fish-accepting as correct, as I confidently do, the readings agreed upon between Mr. Hutton and myself-as in their case the evidence obtained from marking is so far placed beyond question.

I. In Fig. 55, I reproduce the scale of the sea-trout, a male fish, which is referred to above as having been marked with label No. $8331 \mathrm{~B}$ in the Altnagairoch Burn, Luss, in November 1913, and recovered in the same burn when spawning again in November I9I4. The photograph shows how greatly the scales of male fish become

1. See note in text, p. 126. 
eroded at spawning time. We have here, first, the known fact of the fish spawning in I914, which fact is represented by the frayed edge of the scale, and second, the known fact of spawning having taken place in I9I3, represented on the scale by the dark band of broken lines occurring first within the margin of the scale. Beyond that nothing in directly known, but, tracing the life-history of the fish, Mr. Hutton recognises three years (I909, I9IO and I9II) spent in fresh water; descent as smolt early in 1912, the winter of I912-I9I3 spent in the sea without spawning, then the first known spawning in the autumn of 1913 , and the second known spawning in autumn I9I4, when the fish was caught. In this case the evidence is, we may say, indirect that the fish did not spawn in its first year of sea-life, but direct that it did spawn in the following two consecutive years.

2. In Fig. 56, I give a reproduction of a scale of the sea-trout, also a male, which was marked No. $8346 \mathrm{~B}$ in one of the Luss burns, in November 1913, and recaptured in November 1914, when the fish was again spawning. This scale also shows great erosion but the history of the fish is fairly clear. It is of the same age as the preceding fish but its record is different. This fish spent three years (1909, 1910 and I9I I) in fresh water; descended as a smolt early in I9I2, and, returning the same year, as the scale indicates, it spawned as a whitling. Thereafter it spawned again, as we know, in I9I3, and a third time, as we also know, in I9I4. The evidence here, partly direct and partly indirect, shows three consecutive years' spawning.

3. In Fig. 57 is shown a scale of the fish, also a male, which was marked No. 8347 B when spawning in the Smiddy Burn, Luss, in November I913, and recaptured when spawning again in November 1914. The earlier stages of growth, as indicated on this scale, are not beyond question plain, but the indications of spawning are, I think, undoubted. My supposition is that the fish spent three years (I906, 1907 and I908) in fresh water and descended as a smolt in spring I909. 


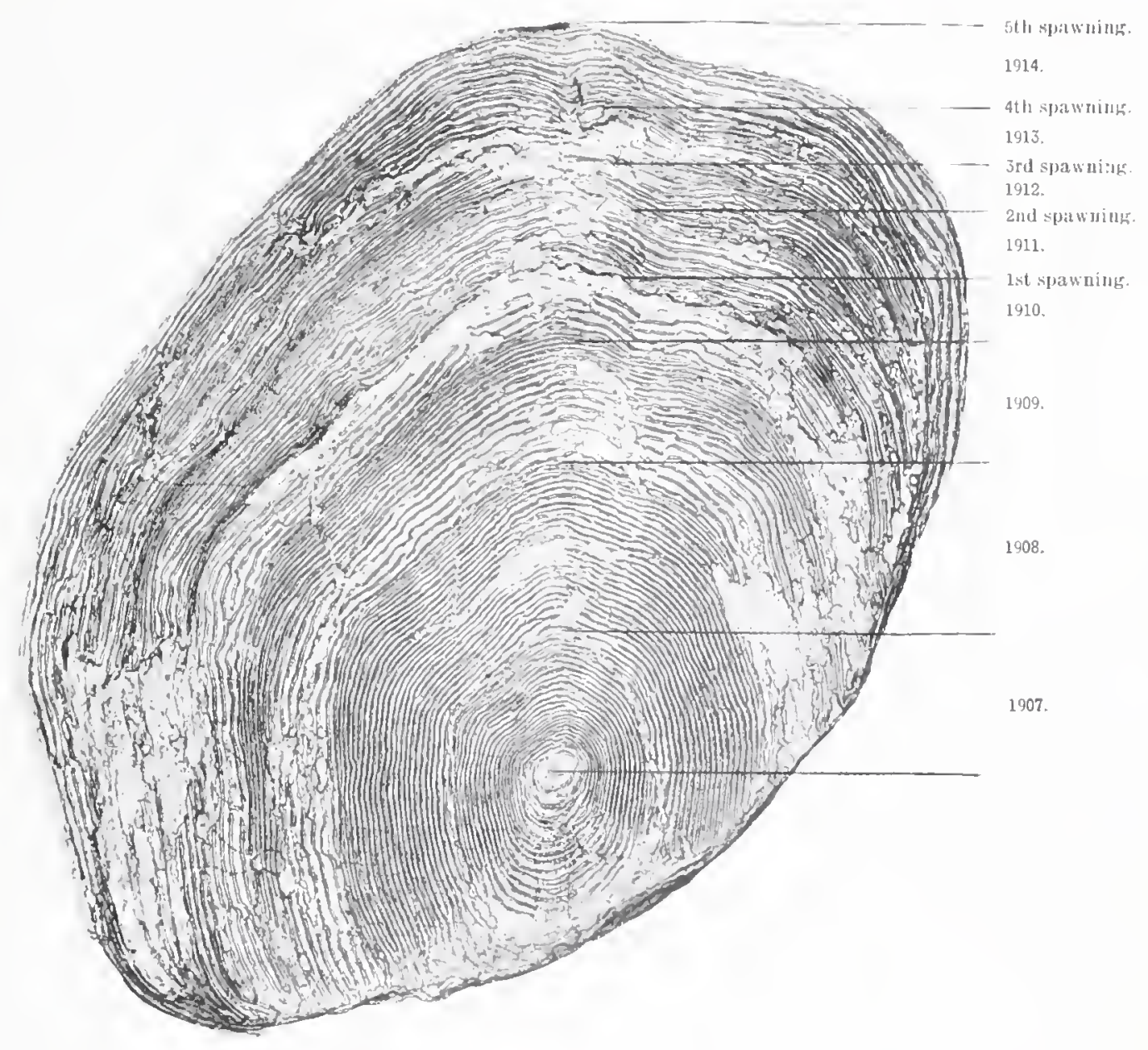

Fig. 58.- Scale of Seathut showing spawning in 5 consecutive years. $(\times 28$. $)$

This fish, a male, was compht in $\mathrm{T}_{\text {uh }}$ Lomond on 11th August, 1914. Weight,

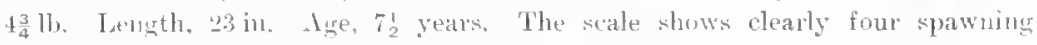
matks, and the fish was evirlently on the eve of spawning for the fifth time. 

It spent the winter of I909-I9Io in the sea, or rather, I believe, in the estuarial waters of the Leven, without spawning, and also the winter I9IO-I9I I in the sea without spawning. It spawned first in autumn I9I I, a second time in I9I2, a third time in 1913 as we know, and a fourth time in I9I4, as we also know. The evidence here, partly direct and partly indirect, points to spawning in four consecutive years.

4. In Fig. $5^{8}$ is shown the scale of an old cock fish weighing $44_{4}^{3} \mathrm{lb}$., which was caught in Loch Lomond by my friend, Sir James HayesSadler, on August I I, I9I4. He very kindly gave me some scales which Mr. Hutton has interpreted for me and one of which photographed by him is here reproduced. The scale indicates, I think without question, that the fish spawned in five consecutive seasons, or at least spawned in four and was on its way to spawn for the fifth time.

5. In Fig. 59, as showing an extreme case, I am able through the courtesy of Mr. Hutton, to submit the scale of a sea-trout which weighed I $\frac{1}{2}$ lb., caught by him in the river Osen, Norway. This scale makes it fairly clear that the fish had spawned in seven consecutive seasons. I reproduce a photograph (Fig. 60) of the fish itself as it is a specially beautiful specimen of a large sea-trout.

Taking now the whole series of 45 sets of scales of Loch Lomond fish I find that 16 show evidence of repeated spawning thus:-

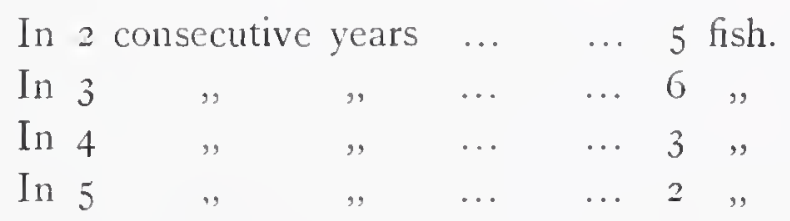

Examining Mr. Hutton's sets of scales from other waters I find :-

(I) In regard to 6 South Uist fish (Scotland) evidence of repeated spawning in 2 instances, thus :-

In 2 consecutive years ... ... 2 fish.

(2) In regard to it Wye fish (England) evidence of repeated spawning in 2 instances, thus:-

In 3 consecutive years $\ldots \quad \ldots \quad 2$ fish. 
(3) In regard to 22 Aa fish (Norway) evidence of repeated spawning in 8 instances, thus:-

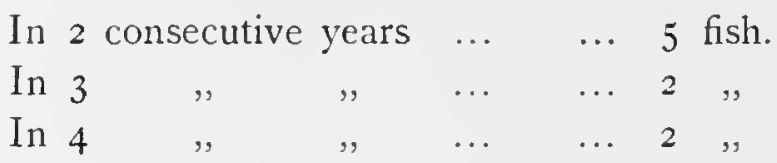

(4) In regard to 25 Osen fish (Norway) cvidence of repeated spawning in I instance, thus :-

In 7 consecutive years $\ldots \quad \ldots \quad$ I fish.

In all these sets of scales the "remainder" fish had either not yet spawned or had only spawned once.

The point which I wish to bring out is, that, so far as this admittedly limited collection of scales shows-and I would urge a cautious acceptance of the results-in no single instance does it appear that, having once spawned, a sea-trout fails to spawn in the ensuing season. In other words sea-trout when they once begin to spawn would appear to be annual spawners.

But it will be agreed that the matter of annual spawning is further confirmed by two recent captures of marked fish. No. $8352 \mathrm{~B}$, a male fish, was marked in the Finlas Water on Ioth November, 1913. It was recaptured on 26th October, 19I4. Being remarked No. $88_{3} 83 \mathrm{~B}$ and returned to the river on that date, it was a second time recaptured on 25th October, I9I5. Unfortunately it did not occur to the men to kcep scales of this interesting fish whose record I give in tabular form thus :-

8352 B. Narked, Finlas … ... 10 Nov. $1913 \quad 1 \frac{1}{4}$ lb. $\quad 17$ in. Recap., Finlas (1st time) 26 Oct. $1914 \quad 2 \frac{1}{4} \mathrm{lb} . \quad 18 \frac{1}{2} \mathrm{in}$.

8383 B. Recap., Finlas (2nd time) 25 Oct. $1915 \quad 2 \frac{1}{2} \mathrm{lb} . \quad 20 \mathrm{in}$.

It may be added that this was the only re-marked Finlas fish, so that its recapture was a somewhat lucky occurrence. An equally interesting recapture was made a fow days later. No. $8328 \mathrm{~B}$ was first marked in the little Altnagairoch Burn, Luss, on 5 th November 1913. It was 


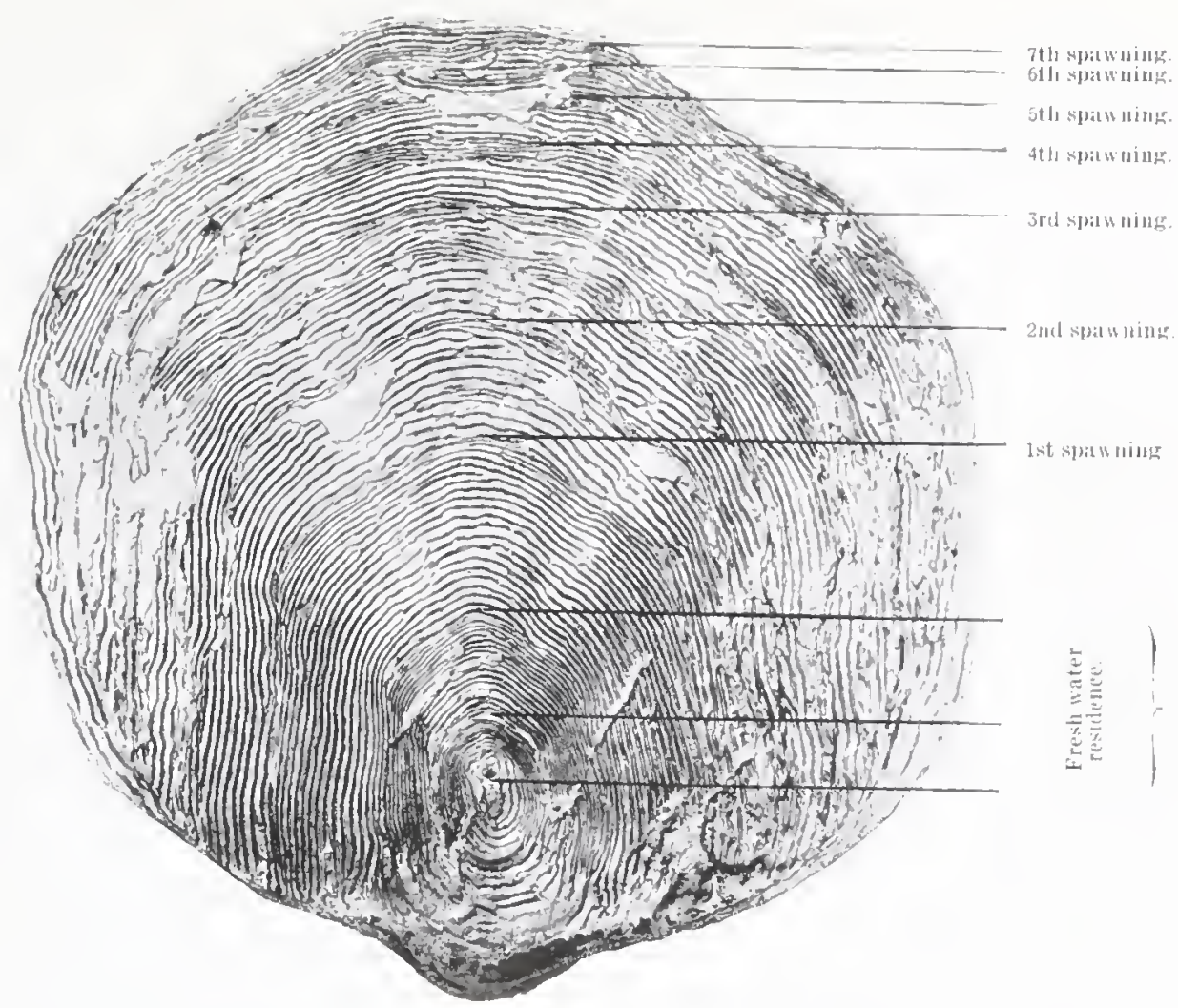

Fig. 59. Scale of Norwegian Seatrout, indicating spawning in 7 consecutive years. $(\times 24$. $)$

The fish, a female, was caught in the river (1sen, (m) 1sth July, 1914. Weight,

$11 \frac{1}{2}$ ib. Length, 293 in. Are, over 9 years.

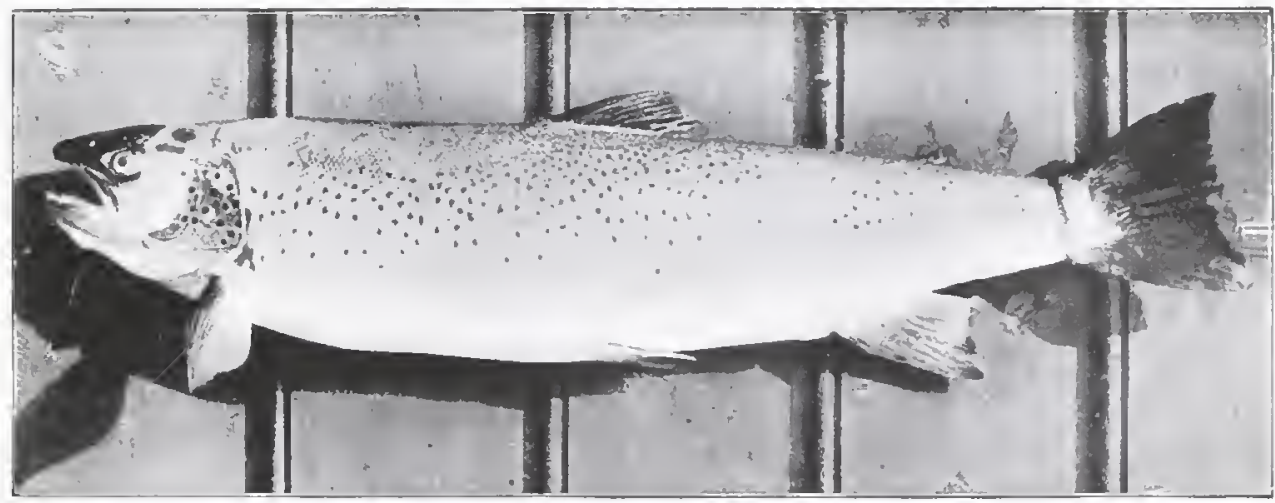

Fig. 60.-A Nonwegian Siezitroul (1 $\frac{1}{2}$ lb.). 

recaptured on 9th November, I914. Being re-marked No. 8399 B and returned to the stream it was a second time recaptured on 9 th November, 1915. Its career is tabulated thus:-

$\begin{array}{llccc} & & \text { Date. } & \text { Weight. } & \text { Length. } \\ 8328 \text { B. Narked, Altnagairoch ... ... } & 5 \text { Nov. } 1913 & 1 \frac{1}{4} \mathrm{lb} . & \text { I5 in. } \\ & \text { Recap., Al'gairoch (Ist time) } & 9 \text { Nov. } 1914 & 2 \mathrm{lb} . & 18 \frac{1}{4} \mathrm{in} . \\ 8399 \text { B. Recap., Al'gairoch (2nd time) } & 9 \text { Nov. } 1915 & 2 \frac{1}{4} \mathrm{lb} . & 19 \frac{1}{2} \mathrm{in} .\end{array}$

This fish was killed, and 1 have obtained a photograph of one of its scales showing clearly the 1913 and 1914 spawning marks (Fig. 6I).

It has been shown conclusively that what used to be called a "Tay bull trout" is nothing but a salmon which has already spawned returning to spawn again in a subsequent season. As Mr. Malloch states, "Their flesh is often whiter and not so well flavoured" as that of a salmon on its first return from the sea, and they fetch an inferior price in the markets. So also it is common knowledge that large sea-trout, which one may generally infer with safety to be old sea-trout, whether we call them "bull trout" or not, command a poor price in comparison with smaller fish chiefly because the dealer expects their flesh to cut whiter and to be much coarser than that of smaller and, as he presumes, younger fish. I can attribute the paler colour of the flesh of particular fish to no other cause than the frequency with which they have spawned since coming to maturity. Hence I would infer that once a sea-trout has spawned it will continue to spawn yearly for a series of years.

It may be contended that what has been formerly stated regarding the divided migration of the shoals argues against a return in consecutive years; that if only a proportion of the stock of sea-trout ascends each year then sea-trout cannot spawn each year, or, alternatively, that if they do spawn each year, then no others than the small and more or less immature fish can remain in salt water over the spawning months. But it is now perfectly certain that salmon may delay their return from 
the sea, after having descended as smolts, for several years, and I see no reason to suppose that the spawning instinct in the sea-trout should not equally lie dormant for one or more years. The scale repeated here as Fig. 62 indicates at any rate a three years' residence in the sea before the spawning instinct asserted itself, and the fact that, in spite of spawning twice thereafter in successive years, the fish weighed i $\mathrm{lb}$. points to a protracted and unbroken early period of rich feeding in the sea. On the other hand I have discovered no scale, out of a not inconsiderable number examined, which indicates that a fish which has once spawned has thereafter passed one or more winters in the sea without spawning. All I would venture to suggest, on admittedly imperfect evidence, is that when the sea-trout has once commenced to spawn it will return each year for that purpose during an indefinite, because unknown, period of sexual activity. 
ming
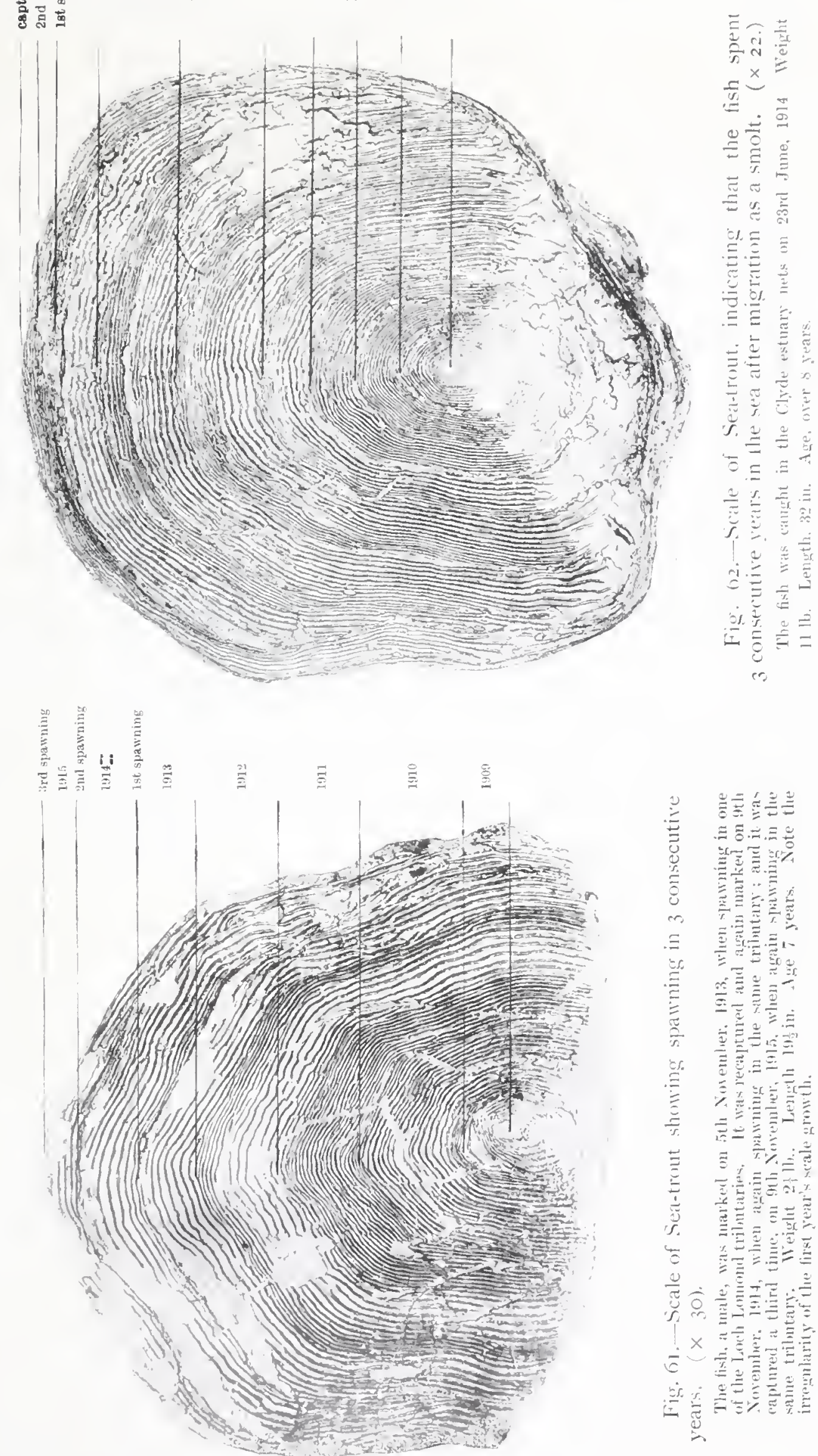
Artificial Propagation 



\section{CHAPTER IX.}

\section{ARTIFICIAL PROPAGATION.}

In the whole wide range of subjects that more or less directly concern the angler there is perhaps no more controversial matter than the artificial propagation of salmon. The bare mention of it seems to affect some people much as a red rag is popularly supposed to affect a healthy bull. Yet I have encountered very few anglers who have had any actual experience of the operations involved in hatchery work.

A good deal of prejudice has, I think, been created by the use in this connection of the term "artificial," which is in some respects misleading. There is no doubt something of artifice in the process of stripping the fish, but there is nothing of artificiality; for, from the collection and fertilisation of the ova to the distribution of the resultant fry, the operator merely assists and does not in any sense run counter to nature. There is no reason why the fish handled should suffer in the least from such handling, and I say so after having had specially favourable and repeated opportunities of seeing fish stripped of their milt and ova. If further proof were needed I might point to the large proportion of marked fish which, marked as they are when being stripped of eggs and milt, return to spawn in subsequent seasons. On purely physical grounds, then, I can see no more objection to artificial propagation in the case of salmon and sea-trout than in the case of trout.

It is in regard to questions of expediency, however, that there is in my opinion room for controversy, and, briefly, I would state my views thus.

In the event of the stock of any of our greater salmon rivers becoming depleted from the effects of pollution, over-netting, poaching, or some other known cause or causes, I would not, where the spawning 
grounds are adequate, attempt to restore or enliance the stock by the establishment of a hatchery. It is extremely doubtful if even very extensive, and therefore proportionately costly, hatching operations would maintain the stock in face of continuing and possibly increasing evils. In the circumstances supposed, expenditure would most economically be devoted to attacking the evil, for, if it were once removed, or minimised, nature would speedily restore the stock without adventitious aid.

But salmon hatcheries have an experimental and educative value which it would be a mistake to under-estimate, and if they did no more than give the anglers of a district a clearer idea of the economies of fish life then money spent upon them, within reason, would I think be money well spent.

There is more to be said in favour of the establishment of sea-trout hatcheries as useful adjuncts to sea-tront waters. Elsewhere in this book I have shown that the sea-trout is essentially a "homing" fish, and, as the species as a rule seldom goes very far afield in the sea, one might say that the stock is as much under the eye of careful and observant management as the stock of non-migratory trout anywhere is.

Now a stock of sea-trout is peculiarly liable to suffer from the vicissitudes of our variable weather. Unlike salmon, sea-trout prefer to spawn in the most trifling little burns, and hardly any year passes in which the deposited eggs do not suffer from floods or frost in winter, or the fry from drought in summer. This was brought sharply home to those in Scotland interested in sea-trout within recent years, for enormous numbers of sea-trout fry perished in the spawning burns in the phenomenally dry summers of I9II, I9I3 and 1914.

There is therefore a good deal to be said for the establishment of a hatchery, in which can be placed the ova taken from ripe wild fish, and whence can be distributed in spring-fed burns, which do not flood and do not dry up, the fry that are reared in security up to that stage. 

PLAN OF LUSS HATCHERY

iRu: SHEWING ARRANGEMENT OF HATCHING BOXES AND WATER SUPPLY.
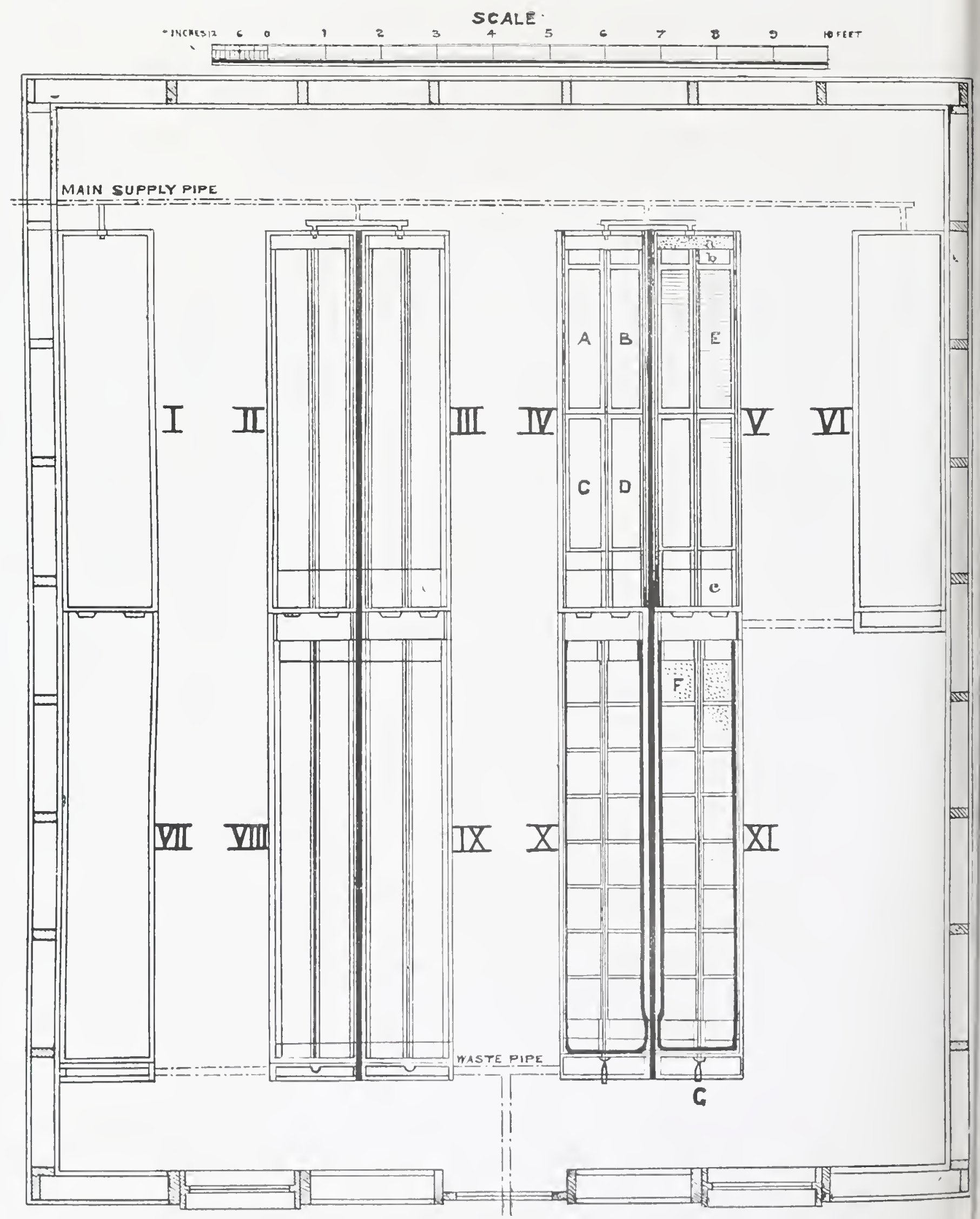
The conditions which I have indicated largely prevail in the West of Scotland, and it is there, and in any similarly circumstanced district, that hatcheries would serve a practical and useful purpose.

I have here and there in this book referred to points which might appropriately fall within a chapter devoted to artificial propagation, and I shall ask the reader to bear such points in remembrance. My present purpose is rather to give a brief description of a hatchery which is at the moment in active operation, and an account of the method adopted to secure the ova of wild fish with which to stock it. I had already, some years ago, written such an account, at the request of Mr. P. Jeffrey Mackie, for his very practical and wholly admirable volume, "The Keeper's Book," and, as Mr. Mackie has very kindly given me the fullest discretion in the matter of utilising that account here, I shall avail myself of the permission so generously given me to repeat much of what I then wrote. If I do not actually use quotation marks to identify any particular passages, it is because I may see reason to amplify some points, or insert fresh observations, but, on the whole, I think I cannot improve much upon the account which I formerly wrote.

That account dealt specially with the Hatchery which the Loch Lomond Angling Improvement Association, with the concurrence of the proprietor of the Luss Estates, installed at Luss in 1903, and in which each season some 300,000 eggs of salmon, sea-trout and trout are treated. As relative to the text I reproduce a plan of the hatchery and append a specification showing the actual initial cost of erection.

The essential requisites of a hatchery, then, are obviously land and water, the first if possible conveniently close to the dwelling of the prospective hatchery manager, and the second ample in quantity. For the site, any gentle sloping plot of ground upon which a wooden house, $20 \mathrm{ft}$. square, can be erected will do. If the subsoil is porous so much the better, but if not, a gravel foundation can easily be laid. The water supply is a more important consideration. It must be ample, pure, 
and not liable to the slightest risk of interruption, for any cessation of the flow at a critical juncture would be disastrous. For these reasons the water supply available will determine the site.

At Luss, where a connection has been permitted with the gravitation water supply, delivery is made by a $\frac{1}{2}$ in. lead pipe, but the head of water in each case will determine the diameter of the pipe necessary to deliver the quantity of water requisite. This, roughly speaking, must be sufficient to give to each hatching box a complete interchange of water every three minutes, but I shall have more to say upon this point later.

In some convenient stream a natural pool must be looked for giving a fall of at least $30 \mathrm{ft}$. to the proposed hatchery. If, however, no such pool can be found, a small dam can easily and cheaply be engineered to form one. In the pool so found, or formed, a small covered chamber should be constructed, guarded at the intake by an iron grating to exclude flotsam. From within this chamber the main water pipe, further protected by a rose, will be led to the hatchery. If the water can first be filtered through an outer chamber of gravel, additional security will be given against danger from the deposited sediment of "spate" water. The pipe will terminate within the hatchery itself.

This, then, is a simple wooden structure, $20 \mathrm{ft}$. long by $\mathrm{I} 7 \mathrm{ft}$. broad. The back wall is $7 \mathrm{ft}$. and the front wall i $\mathrm{ft} .4 \mathrm{in}$. in height, giving the lean-to roof, which is covered with patent roofing felt, sufficient slope from front to rear to throw off the rainfall. The whole structure is thoroughly tarred over. As direct sunlight, or indeed a strong light, is detrimental to the ova, the house faces away from the south, and this front wall alone is pierced with door and windows. Of the latter, one is over the door and one on each side, and all three are obscured by green cloth roller blinds.

The walls, of ordinary white pine, are built double, and the spaces 
between the standards are filled in with sawdust to help to preserve an even temperature.

The floor space, sloping towards the front door, is occupied by eleven hatching boxes, which, as the plan shows, are arranged to allow of convenient working. Against the left wall are two boxes end to end. Two groups of four boxes each, arranged end to end in pairs, occupy the central floor space, while against the right wall, away from the door, is one box. The space left on this side near the door is useful for tackle.

The hatching boxes stand on frames at a convenient height from the floor, and, as at Luss the water supply enters from the rear, the tier of six boxes furthest from the door is on a higher level by the depth of a box than the tier of five nearest it, each upper box draining into its corresponding box on the lower level.

To trace the water system more precisely, the supply is delivered from a continuation of the main $\frac{1}{2}$ in. lead pipe within the hatchery to each of the six upper boxes. Separate connections with this pipe are made for each box, the taps being finished with $\frac{5}{8}$ in. nose-cocks. After serving the upper boxes the water flows over lipped slots to the lower tier, whence each box drains to a common lead waste-pipe carried beneath the flooring through the doorway to a fireclay drain-pipe leading to the river a few paces away.

The supply of the lower tier of central boxes is, at Luss, by a separate connection with the main inside the hatchery, supplemented by spray water for the reason I shall indicate when describing the hatching system. I need only add at the moment that the whole watersupply system within doors permits of each box being worked as an independent unit.

There are two systems of hatching the ova in vogue at Luss, and I shall discuss the respective merits of both, namely, the glass grille system and the perforated zinc basket system, which has, I believe, 
been called the "American" system. But meantime, to get rid of structural details, it will be sufficient now to describe one of the hatching boxes, arranged for the glass grille system (see box marked $\mathrm{V}$ on plan), and one fitted with the perforated zinc baskets (see box marked XI on plan). The glass grille system is the more effective for hatching out ova. It shows a slightly lower percentage of loss than the basket system, but its practical drawback is that it requires more space in proportion to the number of ova dealt with.

The hatching boxes (and the boxes for each system are so far identical) are made of $\mathrm{I} \frac{1}{8}$ in. dressed deal carefully charred inside. Each is $6 \mathrm{ft} .9$ in. in length, I ft. 7 in. broad, and $7 \frac{1}{4}$ in. deep, outside measurements (see box marked I on plan). The box has wooden ledges on each side of the bottom, and a removable wooden runner in the centre placed longitudinally (see box marked II on plan). On these rest the four frames A, B, C, D, carrying the glass grilles (see box marked IV on plan). The grille upon which the ova rest is a series of glass tubes, each tube being $6 \frac{3}{8} \mathrm{in}$. long and $\frac{1}{4} \mathrm{in}$. in diameter. The tubes are set in a row close together, but not touching, across each frame (see frame marked $\mathrm{E}$ in box marked $\mathrm{V}$ on plan), and are kept in position by serrated wood or zinc strips fixed to the inside edges of the frame. The level of the frames in the box is so adjusted that the eggs when placed upon the grille are 3 in. from the bottom of the box, giving that depth of water beneath them, while the water-level is maintained at half-an-inch over them. As it is important to strain the water of all sediment, the nose-cock at the upper end of the box discharges first into a perforated zinc strainer $(a)$ which, with a further inch or two of space $(b)$ before the trays are reached, distributes the inrush of water to the box in a uniform gentle flow. At the lower end of the box a removable perforated zinc screen (c) prevents any egg lapping over into the lower box, and, later, prevents the escape of the alevins and fry when the eggs hatch out. 
The eggs are set uniformly in rows conform to the glass tubes (just as golf balls are in a rack), and each egg is plainly exposed to view making supervision very simple and easy.

The "baskets" used in the basket system of hatching are carefully made of finely and closely perforated zinc sheets, and two rows of eight baskets occupy the available space in each hatching box (see box marked XI on plan), each basket being 9 in. long, 8 in. broad and 3 in. deep (see basket marked F in box marked XI on plan). The whole sixteen baskets rest upon the longitudinal side ledges and central runner already described, at such a level that at least three-quarters of an inch of water will flow freely over three layers of eggs. When it is added that, as in the upper boxes, a strainer is placed at the intake and a screen at the outflow, enough has been said to give an idea of the various fittings of both systems, save in one particular. In discussing the relative merits of the two systems I shall show that the basket system requires a greater delivery of oxygen-laden water to the ova, therefore, at Luss, we had to supplement the water handed on, say from box No. $\mathrm{V}$ to box No. XI, in the lower tier by an independent connection with the main inside the hatchery. From a pipe with stop-cock (marked G on plan) there is fitted within the upper inner edge, and branching along each side, of the box throughout its length, block tin tubing perforated with needle points about one half-inch apart. When the water at stop-cock $\mathrm{G}$ is turned on it is thrown from the perforations of the right-hand tubing to the left-hand row of baskets, and from the left-hand tubing to the right-hand row-a continuous spray bath being thus given to the eggs all along the hatching box. It is a very simple, very neat, and very effective arrangement.

The eggs by this system are massed in the baskets one, two or even three layers deep.

It is a matter of some little practical importance-as well as of interest-to know the relative hatching capacity of glass grilles and 
zinc baskets, and I may here make a rough calculation which is based upon the dimensions of the various fittings described above. One may start with the assumption that 26 salmon eggs, or 26 sea-trout eggs of full size, exactly occupy the space of six inches when laid side by side in line.

To take the glass grilles first. As the glass tubes set close together across the frames in the hatching box (each of the four frames forming a "grille") are $6 \frac{3}{8}$ in. in length, each row of eggs will comfortably number 26 , and, multiplying by 90 , the number of glass tubes in each frame, the total number of eggs per frame will amount to 2,340 , and per box (multiplying by four) to 9,360 .

To take now the zinc baskets. We may count 39 eggs per row along the floor space of the basket and it will be safe enough to allow only 30 per row across the floor space, as there is no attempt made at uniform arrangement as in the case of the grilles. Multiplying therefore 39 by 30 the number of eggs occupying in one tier or layer the floor space of the basket will be 1,170 , and two tiers will comprise 2,340 which is, oddly enough, the exact number per frame by the grille system and makes the contrast very clear. Thus one zinc basket with two tiers, or layers, of eggs in it holds the approximate equivalent of one frame of glass grilles. But just as we had to multiply the contents of each frame by four to arrive at the number 9,360 , the total contents of each hatching box by the "grille" system, we have now to multiply the contents of each zinc basket by sixteen (for there are sixteen baskets) to arrive at the full contents of a hatching box of equal size under the "basket" system. Doing so, we find the total eggs in the box to be 37,440 , rather more than four times the number treated under the "grille" system.

But there is this further to be said. It is not advisable (for convenience of working) to "heap " additional eggs on the glass grilles, but it is perfectly simple, and makes no difference in the ease of 
working, to "heap" additional eggs in the zinc baskets. Indeed with water highly oxygenated, three full layers of eggs can be apportioned to each basket, which would raise the number of eggs treated in each hatching box to over 40,000 . There is, however, little use in taking risks, for, the closer the eggs are massed, the more oxygen and the more constant attention will they require, and, even with the greatest care, the death-rate of eggs would largely increase.

It is clear, then, on a comparison of the two systems, that, neglecting the inevitable death-rate which occurs under both systems-that of the grilles being not so much less as to make it a factor in one's choice-the "grille" system requires at least as much as four times the space required by the "basket" system for convenience of working. Butand this is a very important "but"-while eggs may be hatched out successfully with no more water pressure than will deliver 3 gallons per minute to a box containing 10,000 eggs laid on glass grilles, the same flow of water will not serve the 40,000 eggs distributed in each box over sixteen zinc baskets. Some supplementary system of water aeration or delivery must be adopted, and that can generally and practically be got only from a gravitation water supply giving pressure sufficient to provide independent sprays or jets for each separate basket. The available water supply will therefore be the decisive factor dictating the adoption of one or other system, the question of space being relatively of but secondary importance.

To revert to construction, this has to be added, that all woodwork must be carefully charred; that every separate piece must be carefully smoothed and exactly fitting, without the least projection or crevice; and that all zinc should be varnished by a special varnish which can be obtained from any of our commercial hatcheries.

Let us assume now that everything in the hatchery is prepared for the reception of the ova. All the taps are in working order, ready to be turned on or off as occasion requires; a steady flow is left running; 
the escape pipes are clear of obstruction, and the glass grilles (or the baskets) are all in their places submerged to the proper depth. If the weather is specially severe, we have provided a small oil stove to keep the temperature of the house above freezing-point. Candles or stable lamps are also at hand, as the winter day gives brief light to work by.

It will be locally known where sea-trout are accustomed to spawn, and it can as a rule be anticipated which of the small autumn spates will first bring them on to the redds. Although two or three visits may be required to produce the necessary quantity of ova it is best, if possible, to secure the earlier spawning fish, as these will probably not already have parted with any eggs. One finds many partially spent fish amongst the later runs.

We may suppose, then, that as the burns have "come down" through the night, the fish are to-day likely to be on the redds-and it is àn easy matter for a keeper to bring early word of the fact-and now the dogcart, or, better still, the motor car, is awaiting orders ready to start at a moment's notice, as we may have some little distance to travel. Our hatchery manager - who will be the intelligent employee appointed to that post-has meantime been putting aboard the vehicle two white enamelled tin basins of 15 in. diameter, two white enamelled tin pails with lids, and a couple of kitchen towels, the use of which will appear immediately.

Our man has donned his salmon waders as will also his three or four assistants who are already on the ground. They have with them, or we can bring, the necessary nets, and they will have provided themselves with sticks to beat the water or prod under the banks.

Arrived at our destination we are told that several pairs of fish are lying side by side, or moving about in the shallow gravelly runs in which sea-trout prefer to spawn, and from where we are we can see the spray thrown from the tail of a cock fish as he dashes after an obtrusive burn trout. The stream, we may suppose, is some fifteen or twenty 
paces wide, gravelly runs here and there alternating with slacker water of two or three feet deep. We select a stretch in which we know there are several pairs of fish, and at the lower end of this, at a point where the river narrows somewhat, we fix our principal net.

This is a large bag-net of a $I_{2} \frac{1}{2}$ in. mesh, neither floated with corks nor leaded, but simply reeved to a circle of rope, the diameter of the mouth being $20 \mathrm{ft}$. (or of such smaller width as will serve the spawning stream one has in view), and the bag extending $40 \mathrm{ft}$. tapering to a point where, by means of a slip-knot, we can take out the fish, all at once, or one by one as they are required, when the net is brought ashore. Besides this large bag-net, two smaller bag-nets, ro ft. diameter at the mouth and Io ft. in depth, of a $\mathrm{I}$ in. mesh are used to catch fish which penetrate into the smaller streams in which case one man stands astride the stream holding down the sole-rope with his feet while holding open the mouth of the net with his hands. But the large bag-net is fastened by two guys at the water level with other two made fast to branches, or some projection at a higher level, a few stones being laid along the sole rope to keep the net on the bottom while the inflowing water trails the bag down stream. The men, two, three, or four in number, now enter the water at the head of the reach selected, not more than 200 yards or so upstream (and in most cases conveniently much less), and begin to beat the fish down to the bag-net. Fish often try to break back upstream and a stop net is often useful. This requires to be stretched across stream by two extra "hands," and is of more practical use when capturing salmon than sea-trout. The male sea-trout when alarmed usually make a headlong rush downstream and are caught at once, but the females hide closely under the banks and under bushes and tufts, and all likely hiding places must be well prodded in the downstream progress. So closely do some lie that they are easily taken out by "guddling," when they are carried down to the net by their captor. When the drive is over, the bag-net and its contents are drawn on to 
the bank for inspection, and the fish may be shaken out on the grass till handled, if that is to be done immediately, or left swinging in the current meantime till the operator is ready for them. If he is so, a female is taken from the net and handed to him.

The operator then takes the fish, wraps one of the towels round her to prevent her slipping, leaving the vent clear. Then sitting down, with the clean dry tin basin between his feet, he holds the fish, head towards him (and I may say it is better to have an assistant to hold the tail in case of accidents to fish or ova), when with a slight pressure above the vent the eggs will flow into the basin in practically a continuous stream if the fish is perfectly "ripe." If not, a repeated pressure from the throat towards the vent will bring it away. But no violence should on any account be used. If the eggs on repeated gentle pressure do not flow the fish is not ripe and must be discarded. When all the ova are extracted, the fish, if it has been carefully handled, will swim off. But of ten they lie close to the bank for a time; and always, on returning the fish to the river, they must be gently put into the water, head upstream, and not violently or carelessly thrown in anyhow. If a ripe male is known to be in the bag-net, the ova of half-a-dozen females may be extracted before his milt is used.

The male is then taken and is handled in the same way. His milt, which also responds to pressure, is allowed to flow over the eggs in the basin. If they are numerous, or the male seems a poor fish, the milt of another male may be utilised also. When females preponderate, one should make ccrtain that a male will be at hand when necessary; hence it is useful to retain one or two in one of the small bag-nets. But before returning the male, which we have just used, to the water the operator gently stirs the eggs and milt in the basin with the tail of the fish.

The eggs, which hitherto are all separate pellets, are now covered with water an inch decp, when the milky-looking fluid will practically 
conceal them from view. In a few minutes, three or four, another quarter of an inch of water may be added. The eggs meantime have coagulated in mass. Then the basin must be left perfectly still for a time, which may be anything from twenty minutes to two hours, according to the temperature, the longer time being required in colder weather. With sea-trout, which spawn earlier than salmon, one seldom has to wait longer than half an hour, and the period may be employed carrying out a second "drive" and spawning a second batch of fish.

During the period of quiescence the mass of eggs is disintegrating and any disturbance during this process must be avoided. But now and then, when he thinks "time is up," the operator may gently tilt the basin to one side to see if the eggs are now separated, when, if they are, the process of fertilisation is over. He now washes the eggs clear of all the milky fluid by pouring fresh water into the basin till all is pure and the eggs lie, a beautifully tinted mass (yet all separate), in the bottom of the basin. Each lot of eggs is in turn poured gently into the tin pails for the homeward journey, and no more than an inch or two of water need cover them during transport. Once fertilisation has taken place a reasonable amount of unavoidable disturbance does not seem to be harmful to the eggs, so they are placed beside us on the car when we have got all our traps put together.

Arrived safely at the hatchery the ova has now to be deposited on the grilles or in the zinc baskets. This requires no more than neatness and care, an enamelled cup being used to ladle out the eggs from the pails. If we are working with glass grilles, no more ova must be placed on each frame than will occupy exactly the available space. Each little rack must contain its exact quota of eggs, so that when the frames are filled all the eggs will be uniform in rows, and all the rows uniform in the box, with half an inch of water passing gently over them. If we are using the perforated zinc baskets, each may safely be filled with two or three layers deep of ova in mass, but at least three-quarters of an 
inch of water in this case must flow over the eggs. In the latter case, too, the auxiliary sprays will now be carefully turned on so that they fall into the centre of the opposite baskets in the box. I have already calculated each frame to hold 2,340 eggs. Taking large and small eggs together the number may well be 2,500 per frame, or a total of I 0,000 to each hatching box fitted with glass grilles. The number that is contained in the hatching box fitted with baskets will precisely depend upon the number of eggs that the operator thinks he may safely mass in the baskets.

It may be said at this point that the whole process of netting the fish, stripping the females of their ova, and fertilising the ova with the milt of the male is in principle, and practice also, much the same for salmon, sea-trout, and trout. A female salmon in most books is credited with providing 1,000 eggs for each pound of her weight. This is an over-estimate, but the figure indicates the quantity of ova in round numbers. An average sea-trout or trout provides about 800 eggs for each pound weight of the fish, but I have discussed this matter more particularly in Chapter III. In the operations described there should not be much difficulty encountered, but one must always be prepared for disappointment in the number of fish found ready for stripping, or, indeed, found at all, for there is never any certainty that they will be on the redds where one can most easily capture them, and a sudden rise in the stream may make capture impossible.

It will give the reader some indication of the number of sea-trout handled per day; the proportion of males to females; the number of each sex utilised; and the general uncertainty of each day's operations if I subjoin tables showing these facts for the seasons of 1913 and I9I 4 as noted by me at Luss. 
Table I. Spawning Season of 1913.

\begin{tabular}{|c|c|c|c|c|c|c|}
\hline Date of & Fish & & & & & TotaI \\
\hline Visit. & Taken. & F. & i. & F. & M. & Uned. \\
\hline 28 Oct. & 96 & 45 & $5 \mathrm{I}$ & $3^{8}$ & $2 \mathbf{I}$ & 59 \\
\hline зо Oct. & 25 & 10 & I 5 & 8 & 4 & I 2 \\
\hline 3 Nov. & 44 & 12 & 32 & 12 & 5 & 17 \\
\hline 4 Nov. & 35 & 20 & I 5 & 17 & 4 & $2 \mathrm{I}$ \\
\hline 5 Nov. & 38 & 18 & 20 & I 2 & 6 & 18 \\
\hline Io Nov. & IO & 3 & 7 & o & o & o \\
\hline Total & 248 & I08 & I 40 & 87 & 40 & 127 \\
\hline
\end{tabular}

Thus out of 248 fish netted, I08 were females and I 40 were males. Of the 108 females, 87 were found to be of use, and of the 140 males, 40 were used in fertilisation. Of the whole 248 , only 127 , or about one half, were actually utilised.

Table II. Spawning Season of igi 4.

\begin{tabular}{|c|c|c|c|c|c|c|}
\hline $\begin{array}{l}\text { Date of } \\
\text { Visit. }\end{array}$ & $\begin{array}{l}\text { Fioh } \\
\text { Taken. }\end{array}$ & \multicolumn{2}{|c|}{ F. Sox. } & \multicolumn{2}{|c|}{ Eved. } & $\begin{array}{l}\text { Tota } \\
\text { Usud }\end{array}$ \\
\hline 26 Oct. & 51 & 26 & 25 & 22 & I I & 33 \\
\hline 2 Nov. & 3 & I & 2 & I & I & 2 \\
\hline 3 Nov. & I 5 & 0 & 15 & 0 & 0 & 0 \\
\hline 6 Nov. & 32 & 13 & 19 & I 2 & 7 & 19 \\
\hline 9 Nov. & 56 & 23 & 33 & I 8 & 8 & 26 \\
\hline I 2 Nov. & 53 & 26 & 27 & 22 & I 2 & 34 \\
\hline 26 Nov. & 15 & 7 & 8 & 7 & 3 & IO \\
\hline 30 Nov. & 22 & 7 & 15 & 2 & I & 3 \\
\hline Total & 247 & I03 & I 44 & 84 & 43 & 127 \\
\hline
\end{tabular}

It will be observed, if these tables are compared, that while two more visits were paid to the streams in season 1914 than in season 1913, the data are surprisingly similar for the two years shown. It is particularly interesting to note that the proportion of males to females is again almost the same. It may also be of interest to note that although the 
numbers of fish found spawning in the streams are practically identical in these two years, yet the rod fishing season of I9I4 was a hopeless failure in Loch Lomond, only half the sea-trout taken in 1913 having been got by anglers. The inference may, I think, fairly be drawn that poverty of angling results does not necessarily argue a decrease of stock.

In water with a temperature varying from $40^{\circ}$ to $45^{\circ} \mathrm{F}$, after the thirtieth day, or possibly a little later, the eyes of the embryo fish may be seen. Perhaps sixty days later the eggs will hatch. Trout may be expected to hatch out in about 7o days altogether with water at the above temperature; sea-trout in about 90 days, and salmon in about I 20 days. All these periods will be protracted in proportion as the weather is colder, so that delay in hatching need not necessarily cause anxiety. Throughout the period of incubation nothing requires to be done but to keep the water constantly flowing, and to maintain a careful watch upon the ova for which purpose the hatchery must be visited daily. A few matters of some practical importance may be referred to as applicable to the present stage.

Stress has been laid upon the advisability of keeping the eggs in cxact uniformity on the glass grilles. The reason is that, so arranged, any speck of foreign matter, and any dead or barren or diseased egg, will be detected at a glance, just as a defect of uniform in a soldier will be detected in a regiment drawn up in line. The eggs are almost as casily examined in the baskets as on the grilles. All one has to do is to take each basket in turn, raise it an inch or so in the water, and press it down firmly again. The water, rushing in through the perforations, will cause the eggs to boil and simmer, and any dead or barren egg, being lighter, will come to the top. So, too, any foreign substance will show up at once in the mass.

The eggs themselves should never be handled, but arranged and re-arranged under water by means of a stiff feather. A small glass 
syphon tube, one end, which is cupped, being closed with india rubber, will, by pressure of the thumb and sudden release of the pressure, suck up into the tube any egg for closer examination. If the slightest trace of white fungus is observed upon it, the egg should be at once destroyed, for the fungus growth develops very rapidly if not checked Careful charring of all wood used in the construction of the boxes, cleanliness of all utensils, and careful examination of the eggs, are the best preventatives against the disease appearing or spreading.

A thermometer, several syphon tubes, two or three clear glass wine-glasses, some enamelled cups, a tiny gauze landing-net, and a bunch of seagull wing feathers should be always at hand.

The only occasion for real anxiety at this period is during a spate, when a large proportion of matter held in suspension in the water may be expected to be deposited, if not on the eggs yet in the boxes. Of course the best means to prevent this is careful filtration, first at the source of supply, and again, if convenient, within the hatchery. But, notwithstanding, the boxes will still require occasionally to be cleaned while in service. This can be done without injury to the eggs, but, as great care is necessary in the moving, cleaning with clear water and replacing them, not to mention the cleaning of the boxes, it is a troublesome enough business. The danger of a deposit on the eggs is that it prevents the free absorption of oxygen from the water through the shell of the egg, and the free giving off of the carbonic acid gas generated by the growth within, resulting in the suffocation and death of the embryo. Periodical inspection should also be made at this time of the intake chamber of the water supply, and the rose of the main pipe should be examined to see that no floating matter has got in to foul it. Decayed leaves are often troublesome in this respect.

As presumably is also the case in nature some eggs will escape fertilisation in the process of artificial propagation. They will very soon turn a dead white colour. It is impossible to give any definitely 
known percentage of loss, but one may expect more barren eggs from an old fish than from one in the prime of life. Of the 2,080 eggs shed by the fish described on page 73, only io were found to be dead or barren after two days. But from one cause or another, during the whole period of incubation an egg here and there will be found opaque and whitish when it should at once be destroyed. With careful management the loss in eggs is wholly negligible.

With ordinary care the eggs will duly hatch out at the appointed time when the young fish, or alevins, appear on the scene.

I do not propose to reiterate the description of the alevin formerly given, but some points in hatchery management must be referred to.

In those boxes containing grilles it will be observed that, as the eggs hatch, the alevins drop through between the glass tubes to the bottom of the box, and the syphon tube will now be in constant use removing the empty shells. When the eggs are all hatched, the glass grilles, and the frames which carry them, and the longitudinal runners on which the frames rest, are removed, thoroughly cleaned, and carefully put away. The hatching box has now become a small rearing pond in which the alevins live comfortably until they reach the "fry" stage. Before they leave the hatching box for the outer world, even before the umbilical sac is wholly absorbed, they may be seen all lying head upstream to the inflowing water, and "rising" now and then inquisitively to some tiny floating speck. As with the grille boxes so with the basket boxes. When all the eggs are hatched, the baskets and supporting runners are taken out, cleaned, and put away safely. It is convenient to keep all the alevins of one mass of ova in their own basket till the whole box has hatched out.

During the period of absorption of the umbilical sac, at least in the earlier stages, the instinct of the alevin, which can only wriggle spasmodically on its side, drives it to hide in any minute crevice that it can find. Now it is, therefore, that previous careful smoothing of all 
angles and exact fitting of all fixed and movable parts of the box will be seen to be of the utmost importance. For into every corner and crevice the little creature will attempt to wriggle, and success, or partial success, will almost certainly have fatal results. The best protection for them at this time, beyond careful construction of the boxes, will be absolute darkness in the hatchery.

Not much need be said by way of hint or warning now. Care and cleanliness are still essential. Risks of spate water must still be run and guarded against. But the main thing is to see that the alevins do not find out some new and original method of committing suicide. Hence every joint and junction must be examined in the boxes, and no flaw in the intake or outflow perforated zinc screens must be permitted to remain. So, too, any dead or injured alevins should be removed at once, as should also all "deformities," of which there are always a few. These I have described in an earlier page.

It is again necessary to contemplate a loss of stock up to the stage when the alevin becomes a fry, but for obvious reasons the loss will differ in every hatchery as so much will depend upon the personal carefulness and skill of the hatchery manager, the excellence of his appliances, and possibly the stamina of the brood. There need be little loss in average circumstances.

Two questions now arise. The first is, where are our sea-trout fry to be put? The second, how are they to be conveyed to the spot?

I have not contemplated for our supposed hatchery any supplementary system of rearing ponds. These would doubtless be of enormous advantage, both for the fish and for the education of the owner (as many instances have shown, and are daily showing), but they are costly to construct and the stock is costly to feed and protect. Nor do I think that the practical gain would entirely compensate the outlay, though if money were no object I would certainly recommend their construction. 
Failing their construction, then, the fry must be placed in some small stream, the preferable characteristics of which are that it does not run dry in summer (as so many hill burns do); that it has a brisk clear flow over gravel, and that it provides shelter and food from a fairly luxuriant marginal growth. Wherever there is gravel, running water, and marginal growth, the fry will find both security and food and may safely be left to themselves. They should also be placed in a tributary of a main stream rather than in the main stream itself; and in the feeder of a fresh-water loch rather than in the loch. In both cases they will seek the greater waters in their own good time.

It is said that great loss of stock occurs in the transition stage between the curbed existence of the alevin and the free life of the fry. I have already discussed this matter in Chapter III, and need not refer further to it than to say that loss incurred at this stage has been put as high as 50 per cent. But it is easy to see that with carelessness the loss might equally be a total loss. What is not known is whether loss occurs with fish hatched and so far developed under wholly natural conditions. Mr. J. J. Armistead states of trout hatching that "It is well known that the greatest loss that occurs amongst trout in our streams happens whilst they are in their early stages. Probably some seventy-five per cent. of the ova deposited by wild fish never hatch, and of the remaining twenty-five per cent., more than half are lost during the 'alevin' stage. If, therefore, we can care for them so as to reduce that loss to something less than five per cent., it will be seen that an enormous advantage is gained." This statement applies equally to sea-trout hatching, but I think the loss is rather nearer three than five per cent. at Luss. As to loss incurred during the transition stage I can only say that none is apparent while the fry are in the hatching boxes; and, although careful watch has been kept after the fry have been placed in the streams which for some little time thenceforward will be their home, no single dead fry has been discovered, where if any had perished they might with 
practical certainty have been expected to be seen. But even assuming that there is some loss I cannot see that the hatchery bred stock should suffer a greater loss than the wild stock, the whole conditions, so far as one can judge, being in all essentials apparently identical. Where the hatchery bred stock may suffer more is when hand feeding is resorted to in the hatching box and subsequently in a rearing pond. I understand that, until the little fish become accustomed to the food provided many suffer from an inflammatory affection of the gills.

As to the means of transport it will be found that the fry may be conveyed safely and conveniently to their future home in large glass wicker-covered carboys, such as are used in chemical works. The carboys should be full of water to prevent jarring in transit, and not crowded to excess with fish. Should there be risk of delay anywhere en route, or the journey be long, fresh water should at intervals be introduced. With ordinary luck the whole consignment will arrive at and be transferred to the stream without mishap. We have found at Luss that, if no great distance has to be covered, the fry can be quite conveniently conveyed to neighbouring streams in ordinary galvanised iron pails.

I may conclude by saying that, while these notes are based upon actual experience of hatching out sea-trout ova at Luss Hatchery during some eleven seasons, Mr. Walter McDiarmid, the very intelligent and competent manager of the hatchery, was at first indebted for much of the success of his operations to "A Handy Guide to Fish Culture," by Mr. J. J. Armistead, which was published in 1897 , at the extremely moderate price of one shilling by The Angler Limited, Scarborough. Though dealing specially with trout this little Guide will be found to be equally serviceable for the hatching of sea-trout, one more proof, if any be required, of the close relationship, if not actual identity, of the fish.

In submitting the Plan of the Hatchery, and the original specifica- 
tion and actual initial cost of the work done in construction in 1903, it is only just to state that the whole hatchery arrangements were designed by Mr. Thomas Duff, I.M., Glasgow, a member of the Loch Lomond Angling Improvement Association, who ungrudgingly placed his skill and much of his leisure at the disposal of the committee. The actual initial outlay on the hatchery was as follows:- 
COST OF ARTIFICER's WORK OF HATChERY AT LUSS.

I. The Hatchery.

I. Removing turf and preparing site@95.

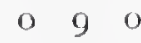

2. $5^{\prime \prime} \times 2^{\prime \prime}$ Sawn standards and runners of walls (red pine), 440 lin.

ft.@2d. .

3. 21 Do stakes in ground under sole runner each $24^{\prime \prime}$ long, to be

charred and well tarred, and the runner spiked to do. @ 5 d. - o $\quad 8 \quad 9$

4. I $\frac{1}{8}$ " White pine tongued and grooved flooring in $6 \frac{1}{2}$ " breadths,

on outside of walls well tarred on outside, 76 sq. yds.@1s. $9 d .6130$

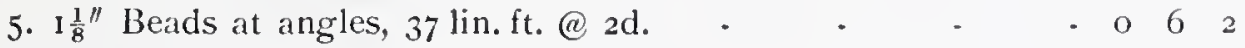

6. 5 " White pine half-checked sarking on inside, 68 sq. yds. (a) 1s. 38 o

7. $6 \frac{1}{2} " \times 2 \frac{1}{2}$ " White pine spars of roof, checked to runners at top

and bottom, 162 lin.ft. 2d. - - . . 170

8. $6^{\prime \prime} \times 2^{\prime \prime}$ Do. dwangs betwixt do., 34 lin. ft. @ 2 d. - - $\quad$ o 58

9. $\frac{5}{8}$ " White pine half-checked sarking on do., include doubling

fillets at sides, 40 sq.yds. @ Is. - - - - 200

10. Tarred felt on sarking in two thicknesses, 40 sq.yds. @ 1s. - 200

II. Packing with sawdust space between flooring and sarking of

walls 5" thick, 69sq.yds. @ 3d. - - - - 0173

12. I $\frac{5}{8}$ " Fixed sashes with astragals glazed with sheet glass, and

primed and painted, 2 coats (red pine),26 sq. ft.@8d. . 0174

13. $\frac{5}{8}$ " Chamfered checks to do. (-do.-), 34 lin.ft.@ 2d. • $\quad 0 \quad 58$

14. $\frac{5}{8}$ " Bevelled weather plate over sashes (--do.--) 8 lin. ft. @ 3 d. . o 20

15. $1 \frac{3}{4}$ " Framed and lined door (-do.-), 20 sq.ft. @ Is. - - 100

16. $\frac{5}{8}$ " Chamfered checks (-do.-), 16 lin.ft.@2d. - - 028

17. Do. facings (-do.-), i lin.ft. 2d. - - - - o 210

18. 1 Pair 6" d.j. hinges and screws@6d. . - . - . o 06

19. I Galvanised iron 6" rim lock with brass mounting and four

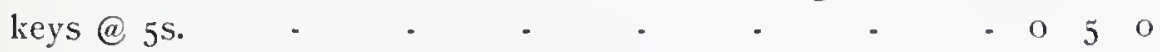

20. Fitting and hanging and onputting mounting of 1 door@2s. - 020

II. Hatching Boxes.-All dovetailed at corners and raggled and jointed with white lead.

21. I $\frac{1}{8}{ }^{\prime \prime}$ Dressed deal bottoms of boxes in boards, $6^{\prime} 9^{\prime \prime} \times 1^{\prime} 7^{\prime \prime}$,

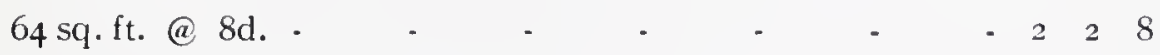

22. Do. sides and ends of do. 6" deep, 50 sq. ft. @ 8d. - - 1134

23. $2^{\prime \prime} \times 2^{\prime \prime}$ Double checked teak framing of grille sliders, scalloped on under edge 40 lin.ft.6 in. @ 8d. - - - $\quad-\quad 170$ 
$311 \times 1$ " Plain do, do., 81 lin.ft. Id. 25. I $\frac{1}{8} " \times I^{\prime \prime}$ Checked teak frame of grilles, I60 lin.ft. @ 2d. $\quad$ I 68 26. $2 \frac{1}{8} " \times \frac{1}{2} "$ Bevelled (pine) fillet at end of box, 9 lin. ft.6 in. (a) Id. 000 27. Fine wire gauze 6 " broad tacked on to box, 9 lin. ft. 6 in. (a) Is. $0 \quad 96$ Note.-Superseded by perforated zinc screen.

28. $3^{\prime \prime} \times 2^{\prime \prime}$ Mill dressed framing under boxes, 162 lin. ft. @ I $\frac{1}{4} \mathrm{~d}$. - o 1610 29. $\frac{7}{8} "$ Deal boxes for overflow, 14 sq. ft. 6 in. @ $6 \mathrm{~d}$.

\section{Water Supply.}

30. $\frac{1}{2}$ " Lead 7 lb. supply pipe and laying in track where required,

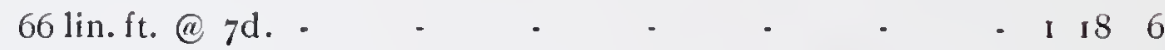

31. 8 Solder joins of branch supplies@ 1s. - - - - o 8 o 32. I Brass $\frac{1}{2} "$ screw down stop-cock (c) 5s. - - - - - 050

33. 10 Brass $\frac{5}{8} "$ screw down nose-cocks @ 5s. 6d. - - - - 2150

34. Forming connection of lead pipe to $3^{\prime \prime}$ iron pipe, include boring and tapping and brass ferrule @ I7s.6d. - $\quad \cdot \quad \cdot 0176$

35. 2 "Lead $5 \mathrm{lb}$. waste pipe, include laying in track where required, 60 lin.ft. @ Is. - . - . - - - 30 o

36. 4 Lead flanges in bottom of boxes @ 9d. - - - 030

37. $4^{\prime \prime}$ Fireclay drain pipe, include digging track and filling up, r2 lin.yds.@2s.

38. 2 Bends on do. (a) 2 s.

39. 2 Eyes on do. (1) 2 s.

40. 1 Y. junction piece @2s. .

41. Connecting drain with lead waste @ 2s.6d. - . - . 026

42. Charring timber of boxes. - - - - - o 50

43. Executing all jobbings and removing rubbish at completion (a) 10 .

\section{Total Contract Price}

IV. Glass Grille System.

44. 2,500 Glass tubes $6 \frac{3}{8} " \times \frac{1}{4}$ " (carriage 2s. 6d.) per $100 @ 4$ s. $\quad 5 \quad 26$ 45. 1,200 Glass tubes $6 \frac{3}{8} " \times 1_{4}^{\prime \prime}$ (carriage 2s.) per $100 @ 3$ s. $8 \mathrm{~d}$. • 260

V. Basket System.

46. Cost of perforated zinc baskets

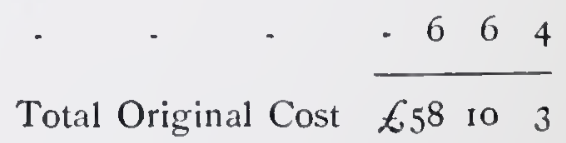


Concluding Remarks 



\section{CHAP'TER X.}

\section{CONCLUDING REMARKS.}

I Do not think that I can usefully add anything to the foregoing pages. The reader who has traced the life-history of the sea-trout as I have given it in these chapters will, if he is an angler, be able to test the description of each stage from facts which he has himself personally observed. If he is a student of fish life as well as an angler-the one interest does not always necessarily involve the other-he will be able to recognise how far I have followed accepted beliefs and how far I have departed from them. He will, I am afraid, find no great store of facts and ideas that can pretend to be original or even novel. But there is this to be said in extenuation, that while it is comparatively easy to air original views in regard to the more or less abstruse problems which one encounters in the study of fish life, it is not so easy to substantiate them by facts derived from actual investigation. I have tried as far as possible to support my theories with facts, and the reader will judge how far these are to be accepted as evidence. In any case it has been my care to distinguish between matters which are certain, those which are uncertain, and those again which are simply theoretical in the life-history of the sea-trout.

There is one matter, however, as to which I think a final word may here be added. However greatly we may extend our present knowledge regarding the details of the sea-trout's career, it seems to me that no real progress can be made until it is determined with certainty just exactly what a sea-trout is.

My views upon this subject must inevitably lack the authority which an exact scientific training, if I could claim such, would have given them, but, for whatever value they have, they may be brought within the scope of the following brief summary. 


\section{What is a Sea-trout?}

(I) Legally. According to the statutory law of Scotland, and indeed of Great Britain, a sea-trout is a salmon, because the Acts declare that the word "salmon" shall mean and include "salmon, grilse, sea-trout, bull trout, smolts, parr, and other migratory fish of the salmon kind." In case any person may suppose that the definition is wide enough to include ordinary trout within its meaning it may be stated that another series of Scottish stath:es, affecting only fresh-water fish, is conceived to apply to "common trout (Salmo fario)." Inferentially it may be supposed that the sea-trout is not a bull trout in the eye of the law, but both are "migratory fish of the salmon kind," and both are "salmon" in the sense of the Acts, though in this case things which are equal to the same thing are not necessarily equal to one another.

(2) Scientifically. Whatever scheme of classification the reader may see fit to follow he will of a certainty encounter in it the family Salmonida. In this family there is comprised, amongst other accepted genera, the genus Salmo. Some doubt exists, however, as to the number of species that should properly fall within this genus. $\mathrm{Mr}$. Regan, as we have seen, admits two, namely (I) Salmo salar, and (2) Salmo trutta. I may say at once that no difficulty arises with regard to Salmo salar, because, so far as investigation has yet been carried, the Atlantic salmon is the sole representative of the species. Whatever difficulty there is arises with regard to Salmo trutta.

It is conceivable, as I have shown, that a claim may reasonably be made for the inclusion in the genus Salmo of three species, namely (1) Salmo salar, (2) Salmo trutta, and (3) Salmo fario. This is not by any means an original, or even a novel claim. There are many who have so sub-divided the genus Salmo, but they have done so, or rather many accept the classification, mainly on the ground that they seek to differentiate between trutta as a migratory trout, and fario as a nonmigratory trout. But Mr. Regan, very properly as I think, dismisses 
the migratory habit as a test of the trout's nature, because it may be broadly said that all trout are migratory in a greater or less degree. The suggested classification is, however, worthy of support on other grounds, but these involve the recognition of two distinct and separate kinds of sea-trout.

Mr. Regan, as we have seen, admits in his classification only one species of trout, Salmo trutta, to which fish he ascribed a marine origin. In other words he presumes that the trout is a sea-trout.

I may interject here two definite statements of fact :-

(1) Common Ancestor. The common ancestor of the salmon and trout has not yet been discovered.

(2) Original Habitat. It is not yet proved whether salmon and trout, or one or other, have a marine or a fresh-water origin.

Mr. Regan, however, in company with other recognised authorities, finds that two "races" of sea-trout are distinguishable, though with difficulty. In much the same way Mr. Calderwood distinguishes two "varieties" of sea-trout. I have already given, I hope impartially, the views of those who are most competent to speak on this subject which of course involves the identity, and therefore the proper classification, of the "bull trout." The reader may take it that the problem of the bull trout is not yet definitely solved. Such definite light as I have been able to throw upon the subject is of the faintest, but I think that some grounds have been given for the belief that further systematic scale examination will help to guide us to more definite conclusions. The scales which I have examined (they could hardly be fewer in number) suggest a rate of growth in a sea-trout typical of certain rivers which is far more akin to the characteristic growth of the salmon than it is to the growth of that other type of sea-trout which is perhaps most familiarly recognised in our rivers. Taking this fact-if it be a factalong with other characteristic differences noted by various authorities, the "bull trout" would seem to me to be so distinct from that other 
type of sea-trout to which I have referred as to entitle it to rank rather as a species per se than as a mere race, or variety, of another species. In other words the bull trout may fairly claim to be the species Salmo trutta of the genus Salmo.

What, then, is that other type of sea-trout? I think the foregoing life-history suggests that the fish which we familiarly call a sea-trout is no other than the common trout of these islands which has developed the migratory habit to an extreme extent. Carrying the matter to its necessary conclusion, if we recognise as a distinct species "the common trout (Salmo fario)" we shall find within the species certain trout which do not migrate at all, certain other trout which haunt estuarial waters, and still other trout which frankly migrate to and from the sea. Well may it be said that the trout is a variable and plastic species, but it is mainly so as the species Salmo fario and in relationship only to the environment it elects to frequent.

These are then briefly the grounds on which I would suggest for the genus Salmo the three species of (I) Salmo salar, with its sole representative the salmon, (2) Salmo trutta, with, as its sole representative, the "bull trout," and (3) Salmo fario, with, as its representatives, trout both migratory and non-migratory. In suggesting this classification I would warn the reader that the whole subject still remains very much in the region of theory.

If besides being an angler the reader happens to be practically interested in the development of either a trout or a sea-trout fishery, he will recognise the importance of having this matter definitely elucidated, and no doubt he will wonder, as I do, why the matter has not long ago been cleared up. My hope is that these chapters will develop a more active interest in the subject, because none of us at present can say with any degree of assurance just precisely what a trout is, and what is a sea-trout. 
Index 



\section{INDEX}

A

Aborted (or rudimentary) fins, 53

Acts of Parliament referred to-

Act of 1318 , fry of fishes, 9

Act of 1426 , " " thit fische," 9

Act of 1469, "fisch1," 9

Salmon Fisheries (Scotland) Act, 1828 , " fish of the salmon kind," 9

Salmon Fisheries (Scotland) Act, 1844, "fish of the salmon kind," 9

Saltnon Fisheries (Scotland) Act, 1862, Statntory definition of "salmon," 9 , 67 (note), 206

Salmon Fisheries (Scotland) Act, 1868, eggs and spawn, 92, 165

fry, 92

kelts, 132, 166, 167 (note)

smolts, 92

Tweed Fisheries Act, 1859, kelts, 167

Adipose fin, 53, 54, 95

Age and Growth of Salmon and Trout in Norway as shown by their Scales, Knut Dahl, 92 (note), I08-110

Alevins, $74-76,79,80$, 121, 196-198

salmon, 76

sea-trout, description, 75

distinctions, salnon, sea-trout and tront tabulated, 76

eye, 75

hatching out, $74-76,80,196$

mortality, 79, 197, 198

nomenclature, 121

trout, 76

Auadromous habit, char, 29

salmon and sea-trout, 24, 29

Anal fin, 53, 55

Angler-Naturalist, The, H. CholmondeleyPennell, 16, 33, 56, 78

Armistead, J. J., authority on hatchery work, 199

mortality of trout eggs, etc., 78,198

Armistead, W.H., spawning trout, I39

Artificial propagation, 179-200

alevins, 196

basket system, 185, 186

collection of ova, 188-190

cost of hatchery, 201, 202

cross breeding, $15,23,36,164$
Artificial propagation, dead eggs, 195

disposal of fry, 197, ro8

fertilisation, 190,191

filling the boxes, 19t, 192

fish handled, table showing data, 193

glass grille system, 184,186

handling ova, 194

incubation, 194

Li1ss Hatchery described, 181-187

mortality of eggs, etc., 195-198

nets, 189

ontput of boxes, 186

spate water, 195, 197

stripping fish, 190

transport of fry, 199

value of hatchery work, 179, 180

B

Bickerdyke, John, sea-tront fishing, in

"Black-11ebs," II9, I2I

Book of the All-Round Angler, The, John

Bickerdyke, II

Book on Angling, $A$, Francis Francis, II

Boulenger, George A., bull-trout, 40, 63;

Salmonida, original habitat, $3 \mathbf{r}$

Brachymystax, genus, 18

British and Irish Salmonida, Dr. Francis

Day, 15, 22, 32, 40, 60

British Fresh-water Fishes, Rev. W.

Honghton, 40

Bull Trout, Aln fish, scales, 65, 66

classification, $13,17-19,42,206,208$

distinct species suggested, 42, 208

one species with sea-trout (Malloch), 16

"race" of $S$. trutta (Regan), 38

variety $S$. eriox of $S$. trutta (Calderwood), 40

Crown's rights in Scotland, 7

gill-covers, 56, 62

"grey tront" (Yartell), 56

Hebridean, 25

late ascent, 64,148

Norwegian, 66

Salmo eriox, 14, 25, 39, 40, 41

scales, 42, 64-66, 207

sea-trout, distinguished from, 38, 40,42, $56,61-67,175,207$

Calderwood, 40, 207 
Bull Trout, sea-trout, flesh, 63, 175

Regan, 38, 62, 207

scales, 42, 64-66, 207

tail, $41,42,63$

Walton, 4I

Yarrell, 56, 62

size, 64

species discussed, $3^{8-43,6 I-67}$

statutory definition, 9, 67 (note), 206

tail, $41,42,63$

Tweed fish, 63,148

weight, 49

Bull Trout of the Tay and of Tweed, The,

W. I. Calderwood, 40 (note)

\section{C}

Calderwood, W. L., " hull trout or round tail," 40, 40 (note), 207

" common brown trout" in Tay estuary, $25,27,34$

New Zealand trout, 24

parr, juvenile appearance, III shoal habit, 106

Salmo eriox "variety" of $S$. trutta, 40 , 207

salmon, divided ruv, 123, 124

Salmonida, original habitat, 31, 32

Scottish Fishery Board reports, II I 55 (note)

sea-trout, caught at sea, 152 (note)

decrease, 43

netted in Ecliaig, 147

smolts, estuarial habits, 114, 1 I5

"Tay bull trout," 50

whitling migration, 123

Caudal fin, 42, 53, 54

Chat, anadromous, 29

Chaytor, A. H., spawning salmon, I6I vigour of parr, 96

Cholmondeley-Pennell, H., Salmonida, classification, 18

salmon and sea-trout, distinction, 56

trout, deformity, 78

trout and sea-tront, colouration, 33

Chondrostei, sub-class, 18

Classification, fislies, 12

Salmonide, Cholmondeley-Penuell, 18 Regan, 18, 19

suggested, 42, 206-208

Close seasons, for sea-trout criticised, 155

Common ancestor, of Salmonidee, 32, 207

Compleat Angler, The, Izaak Walton, 36,41

Coregonus, genus, 19

"Corrigeen," decrease of sea-trout, 43
Cross-breeding, artificial, 23, 164

Darwin, 36

Day, 15

natural, 163

Walton, 36

\section{D}

Dalıl, Knut, Salmonida, growth of, 92 smolts, estuarial habits, 114 migration, 105

scale evidence, tabulated, I ro

trout, rapid development, 112

Darwin, Charles, cross-breeding, 36

Day, Dr. Francis, bull tront, 40, 49 (note)

Howietoun experiments, 22

Salmonidce, original habitat, 32

teeth, 60

trout, varieties, 15,42

Days and Nights of Salmon Fishing in the Tweed, William Scrope, Ior

Deformities, trout, 42 sea-trout, $77,78,197$

District Fishery Boards in Scotland, amnual reports defective, 154, 155

data desirable, I55 (note)

sea-tront returns, io

I Dorsal fin, 5o, 53, 54, 95

\section{E}

Eggs, 71-76, 78-80, 130, 162, 179-200

salmol1, 71-74, 76, 192, 194

sea-tront, artificial propagation (q.v.), $179-200$

colour, 71, 72, 195

development, 74, 75, 194

tabulated, 80

distinctions, salmon, sea-trout, and trout, tabulated, 76

" eyed ova," 74, 194

mortality, hatchery, 195, 196

natural, 79

trout (Armistead), 198

number, 72-74, 192

shape, 72

size, 71

weight, 162

whitling, I 30

trout, 71, 72, 74-76, 78, 79, 192, 194, 198

Encyclopedia Britannica, Art. Ichthyology, 12

Estuarine tront, $24-27$

" Eyed ova," 74, 194 
F

Field, The, 34, 41, 128

Finnock (or phinock), 121

Fishery Board for Scotland, Annual reports, IO, I54, 155, I55 (note)

Glenetive IIatching Results, paper 011, 127, 128

grilse, 123 (note)

sea-trout, ro

Fishing Gazette, The, 34, 41, 56

Francis, Francis, sea-tront fishing, in

Fresh-water Fishes of the British Isles, The, C. Tate Regan, $16-20,38,53-56,62,206$, 207

Fry, $76-87,121,196-199$

salmon, $76,83,84,86,8_{7}$

sea-trout, artificial propagation (q.v.), 196-199

eye, 76

feeding labits, $8_{3}, 8_{5}-S_{7}$

growth, 86

hibernation, 86,87

nomenclature, 121

"parr marks," 76,83

rivalry between salmon, sea-trout and tront, $s_{3}, 84$

salmon, sea-tront and trout, distinctions, 76

scales, 87

shoal habit, 84,85

tront, $76,78,79,83,84,198$

\section{G}

Gathering grounds, lochs as, I44-147

Gemmill, Dr. James F., Salmonida, deformities, 77

Gill-covers, 56, 62

Glacial epoch, 28, 29

"Glen-lakes," I45

Grilse, early rutuning, 123 (note)

maxillary, 55

scales, 58

statutory definition, 9, 67 (note), 206 tail, 55

Günther, Dr., bull tront, 40, 63

\section{$\mathrm{H}$}

Handy Guide to Fish Culture, A, J. J. Armistead, 78, 198, 199

Hardy, John James, bull trout, 4I, 65

Harvie-Brown, J. A., age of tront, 49
Hatching Results at Glenetive, Ian T. Nelson, 127,128

Hebricles, bull trout, 25

lochs and streanis, 27

tidal tront ( $S$. orcadensis), 24

true fresh water fishcs absent (Regan), 28

Herling, Crown's rights in Scotland, 8 nomenclature, I21

Herring, sea-trout food, 135

trout food, 25

Ifistory of British Fishes, A, William Yarrell, 56, 57, 62, 78

"Homing" instinct, sca-trout, 125-128, $169-175$

whitling, $125^{-128}$

Houghton, Rev. W., bull tront, 40

Howietoun Fishery, sca-tront experiments, $22,23,112,113$

Hucho, genus, is

Hüitfeldt-Kaas, Hartig, salmon and trout, distinctions between young, 93, 102-104

Hutton, J. Arthur, acknowledgment of indebteduess, 2

lochs in river channels, III

salmon, leaping, I5I

spawning dress, 160

salmon and trout, translation of distinctions by Hartig Hüitfeldt-Kaas, 102104

sea-tront and grilse scales contrasted, 58

sea-trout, descent of smolts, evidence from scales, I08-III

Norwegian specimen fish, 173

opinion as to a doubtful fish, 34

recaptures, scales examined, $171-176$

residence in sea, evidence from scales, 143

run of fish of graduated weights, 148

scales, examination undertaken, 108

smolt, late running, evidence from scales, 105

whitling, first return, evidence from scales, rig

scales of small Norwegian fish, 122

spawning, evidence from scales, $130,13 \mathrm{I}$

Hvorledes adskilles lakse-örret-og roieyngel fra hinarden, Hartig Hüitfeldt-Kaas, $93,102-104$

Hybrids, Hebridean (Stuart), 25

occurrence in nature, $16_{3}$

produced artificially, 15, 23, 36, 164

\section{I}

Isospondyli, order, is 


\section{$\mathrm{J}$}

Johnston, H. W., salmow, divided run, 123, 124

leaping, I5I

"Tay bull trout," 50

K

Katadromons habit, eels, 24

Keeper's Book, The, P. Jeffrey Mackie, ISI

Kelts, capture illegal, I32, I66 (note), I67 (note)

descent, 142, 167-169

description, $159,160,168$

feeding habits, 168

recuperation, 169

timidity, 167,168

" unclean or unseasonable," statutory expression interpreted, 132

whitling, 132, 133

I.

Iateral line, 54

Letters to a Salmon Fisher's Sons, A. H. Chaytor, 96, 161

Life-History and Habits of the Salmon, SeaTrout, Trout, and Other Fresh-water Fish, P. D. Malloch, 16, I7, 50, 56, 86, IOI, $120,121,128,132,140,141$, $150,164,175$.

Life of the Salmon, The, W. I. Calderwood, $24,25,27,31,32,34,50,106$, III, 114 , $123,124,207$

Iochs referred to-

Awe, descending kelts, 168 searcity of sea-trout, 147

Baa, sea-trout spring run, I34

Dhuloch, brackish waters, 145 tidal tront, 26

Eck, little above sea-level, I46 netted sea-trout, 147

Etive, sea-trout gathering ground, 147 tidal loch, I45

tidal trout, 26

Freisa, " parr-marked " tront, 94

Fyne, sea-loch, 145

Gareloch, sea-loch, 145

Iallan, trout become tidal (Stuart), 25

Harray, brackish waters, 145

I,och-r1a-Maorachan, tailless trout, 42

I,omond, " black-nebs," I 19, 12 I

Clyde river basin, 34

little above sea-level, 146

I.uss Hatchery, 181-187
Lochs referred to (continued) -

lomond, parr, exceptional size, 107

" parr-marked " trout, 94

sea-trout, descending kelts, 168,169

gathering ground, 146

" homing" fish, 125-127, 169-175

recaptures, I 70-I 75

residence in sea, 143, 144

spawning annual, 170-176

spring ruw, I39

silvery trout, 100

smolts, exceptional size, ro5

migration, I05, 108-II I

spawning tributaries, $85,161,170-175$

trout descend to sea, 27,37

spots, 52

whitling, delayed ascent, 124

descent, 133

exceptional size, 104, I08

first return, II9

" homing " fish, 125-127

main run, 120

shoal habit, 125-127

spawning, 130, 131

Long, sea-loch, I45

Maree, little above sea-level, 146 sea-trout fishing, 147

Morar, little above sca-level, I46

Ness, descending kelts, 168,169

Shiel, little above sea-level, I 46 sea-tront fishing, 147

South Uist lochs, sea-trout spring run, 134

Stenness, brackish waters, I 45

Tay, " parr-marked " trout, 94

Lochs and Loch Fishing, Hamish Stuart, 25, 32

I $115 s$ Hatchery, description, $I S_{1-1} 8_{7}$

M.

Mackie, P. Jeffrey, acknowledgment of indebtedness, $18 \mathrm{r}$

Maitland, Sir Jannes, Howictoun Fislery, 22

Malloch, P. D., parr, hibernation, 86

salmon distinguished from sea-tront, $5^{6}$, I5O

sea-trout, nomenclature, 16, 120, I21

Salmo trutta, one species, 16

smolt dress, Ior

spawning period, duration, I6 4

"Tay bu1l trout," 50

flesh, I 75

trout, Salmo fario, one specics, 17

whitliug, ascent, 120, 125

do not spawis, 132

return as sea-trout, 140,141 
Marine origin of Salmonida, $30-32$

Marsipobranchii, class, is

Marvels of Fish Life as revealed by the Camera, Dr. Francis Ward, 51, 79

Maxillary, of salmon aud trout, 55, 97

Maxwell, Sir Herbert, Bart., Edito Scrope, Ior

leavy sea-trout, $5^{\circ}$

Salmonida, original habitat, 32

sea-trout fishiug, II

Migratory habit, as affecting legal rights, 8 , II

no test of species or race (Regan), 20-38

" Monsters," 77

Morphology of fishes, 12

Morphologists and systematists, 12-14

\section{$\mathrm{N}$}

Nelson, Ian T*, Glenetive Hatchery, 127, I2S sea-trout recaptures, 128

New Zealand trout, 24

Nomenclature, sea-trout (Malloch), 120 suggested, I2I

whitling, localisms, 107-109

\section{$\mathrm{O}$}

Origin of Species, On the, Charles Darwin, 36

Orkney and Shetlands, sea-trout, 28

trout, $24,26,28$

true fresh-water fishes absent (Regan), 28

\section{$\mathrm{P}$}

Pacific salmon and trout, I9

Parr, 9, 67 (note), 84, 86, 91-99, 102-104, 106, II, II 3,206

salmo11, 9I-99, 106, 113

sea-trout, capture illegal, 92

colouration, 96,98

Dahl, 92

distinctions tabulated, 99, 102-104

eye, 97

feeding habits, 9 I

fins, 97,98

growtli, 9r, 92

hibernation, 86,91

Hüitfeldt-Kaas, 93, 102-104

maxillary, 97

" parr marks," 96, 97

salmon, distinctious, $96-98$

scale formula, 97

shape, 95

shoal habit, $84,106,113$

size, 93,96, ro7
Parr, sea-trout, spots, 97, gs

statutory definition, 9, 67 (note), 206

tail, $9 \mathrm{~s}$

trout, clistinctions, 97, 9S

vigour (Cliaytor), 96

of Paton, Dr. A. Noel, Salmonide, original habitat, 31

Pectoral fins, $53,75,95,97,98$

Pelvic (or ventral) fins, 53

Plinock (or finnock), 121

Pisces, class, 18

Prehistoric river chauncls, 39

Protective colouration, 51

\section{R}

Regan, C. Tate, migratory habit no test of species or race, 20-38, 206

Salmonide, classification, 18, I9

structural features, $53-56$

sea-trout, two races, $38,62,207$

young indistinguishable from young trout, 17,97

trout, one species, 16

young indistinguishable from young sea-trout, 17,97

Rivers referred to-

Aa, Norway, sea-trout, antual spawning I74

smolt migration, 109

Add, age and size of salmon, Io7

Al11, bull trout, $39,41, \mathrm{r}_{4} 8$

estuary not extensive, 64

Alness, sea-trout spawning, I54

Altuagairoch Burn, recaptures, marked sea-trout, 17 r, 175

sea-trout, " homing," 126

Anuan, whitling, main run, 120

Arn Burn, recaptures, inarked sea-trout, 170

sea-tront “ homing," 125, I 26

Awe, sea-trout ascent, I47

Balgay, sea-trout spawining, I54

Beauly, sea-trout, spring run, 134, I40

Clyde, marked sea-trout recaptured, 170

river system, 34

sea-trout in estuary, 115

spawning sea-trout, ${ }^{154}$

trout in estuary, 27

Coquet, bull trout, $38-42,65$

estuary not extensive, 64

sea-trout versus salmon, 84

Ecliaig, sea-trout netted, 147

Endrick, salmon leap, 15I

Esk, sea-trout, spring run, 140 
Rivers referred to (continued)-

Etive, Hatchery results, 127,128

Finlas, recaptures, marked sea-trout, 170, I 74

sea-tront " homing," 125

spawning sea-tront, 161, 162

Forth, bull tront, 39

sea-trout at Howietonn, 22

Gloppen, Norway, bull trout, 66

Hebridean rivers, tidal trout, 24 parr, 106

Howmore, bull trout, 25

Leven, parr, 106

pollution, 127

sea-trout, spring ru11, 139

sinolt described, to4

spawning sea-tront, 154

Little Osen, Norway, 122

I,nss, sea-trout " homing," I25

leaping, 151

recaptures, marked sea-trout, iło

Nairn, sea-tront spawning, I55

Nith, whitling, main rnn, I2O

Orkney rivers, tidal trout, 24,26 parr, 106

Osen, Norway, sea-trout annual spaw11ing, 173

smolt migration, to9

prehistoric river channels, 39

Smiddy Burn, recaptures, marked seatront, 171

sea-trout " loming," 126

Sonth Uist, tidal trout, 25

Strome Dearg, trout, 25

Tay, parr, to6

salnon, age and size, 107

sea-tront spring run, $134,140,141$

smolts in estuary, dx 5

"Tay bull trout," 40

tront in estuary, 25, 27, 34

whitling, ascent, limits of, $x 28$

main run, I20

return as sea-trout, 140, I4I

Towey, monstrosity, $7 \delta$

Tummel, salmon leaping, 15 r

Tweed, bull trout, $38-42,62,63,148$

close time, ${ }_{14} \mathrm{~S}$

estuary, 64

kelts destroyed, 166

parr, 106

sea-trout, spring run, 140

spawning sea-trout, 154

Tyue (England) estuary, 64

trout, 39
Rivers referred to (continued) -

Tyne (Scotland) estuary, 64 trout, 39

Wye, sea-trout, ascent, 152 (note)

annual spawning, 173

smolt, migration, Iog

Ythan, spring sea-trout, 134

Royal Commission, 1902, bull trout, 40

sea-tront, io

Rudinxentary (or aborted) fins, 53

\section{$\mathrm{S}$}

Salmo, genus, 13,14

albus, $14,38,62$

cambricus, $14,38,62$

criox, $13,14,39,40$

estuarius, 24,25

fario, 14, 39, 42, 100, 206, 208

ferox, 14,24

fontinalis, 23

levenensis, 14, 23

nigripinnis, 14

orcadensis, 15,24

salar, $14,19,42,54,77,206,208$

stomachicus, I4

trutta, 14, 19, 39, 40, 42, 54, 77, 206, 208

Salmon, alevins, 76

colonration, 47, 93, 100

cross-breeding, 163,164

eggs, $71-74,76,192,194$

eye, $58,76,95$

fins, $53,54,95,96$, го1

fry, tivaliy with sea-trout and trout, $8_{3}$, 84

gill-corers, 56, 57

maxillary, 55, 95

Pacific, I9

pair, 9I-99, 106, II 3

"parr marks," 94, Ior

scales, $54,96,97$, 101

sea-trout, distinguislsed from, 53-59, 76 , $96-98,99,100-107,150$

shape, 53, 95

smolts, 100-107, III, 114, II5

spawning dress, 50, 159, 160

spots, 49, 95, xо1

statutory definition, 9, 67 (note), 206

tail, 54,96

"Tay bull trout," 40, 49

teeth, 57

trout, distiuguished from, $54,55,76$, $93-96,99,102-104$

" unclean or unseasonable," 132

Salmon and Sea-Trout, Sir Herbert Maxwell, Bart., II, 32, 50 
Salmon fishery legislation, 43,44

Salmon fishing, common law, Scotland, 8 Crown's rights in Scotland, 7

Salmon Rivers and Lochs of Scotland, The, W. I. Calderwood, 40, 147

Salmonide, classification, 13-15, 18, 19, 42, $206-208$

conmmon ancestor, 32, 207

distribution, 30

marine origin, $30-32$

Salvelinus, genus, I8, I9

Seales, bull tront, A1n, 65, 66

erosion, 5, I71, I72

examination urged, $42,64,66,113$

fry, 87

growth, 87

patr, $87,96,97$

salmon and trout distinguished, 54

scale fornula, salmon, 54-56, 96, 97 sea-tront, 54-56, 97

sea-tront, annual spawning, I 7 I-I 76 grilse, distinguished from, $5^{8}$

marine residence, 143,144

recaptures, 17 I-I 76

salmon, distinguisled from, 59

trout, distinguished from, 6I

smolt, I0I, I05

exceptional size, 105

migration, I08-I I I

whitling, ascent, I 19

small Norwegian, I 22

spawning, I3O, I3I

Scrope, William, parr and smolts, IOI

Sea-trout, age, 49

alevins (q.v.), 74-76, 79, So, 121, 196-198

anadromous habit, 24,29

artificial propagation (q.v.), $179-200$

bull trout, distinguished from, $38,40,42$, $56,61-67,175,207$

classification, 12, 17-19, 42, 206-208

one species (Mallocli), 16

two races (Regan), 38, 62

two species suggested, 42, 208

two varieties (Calderwood), 40

close season criticised, 155

colouration, $33,35,47,50,51,52,59,6$ r

cross-breeding, 23, 163, I64

Crown's rights in Scotlaud, 7

deformities, $77,78,197$

distribution, $28,30,47,48$

eggs (q.v.), $71-76,78-80,130,162,179-200$ eye, 58

feeding habits, $\delta_{3}, \delta_{5}-\delta_{7}, 91,129,135,149$, $16 S$

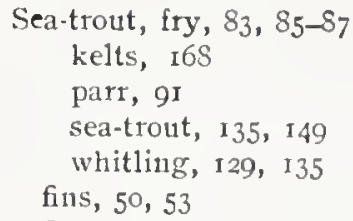

first return, I40-144

evidence from scales, 143,144

"Fordidge," 39

fry (q.v.), 76-87, 121, 196-199

gatlering grounds, $144-147$

grill-covers, 56, 57

Hebridean, 25, 28

" homing " iustinct, I 25-128, 169-I75

Howietoun experiments, 22, 23, 112, 1 I3

kelts (q.v.), 132, I33, I42, 159, I60, I67-160

la11-locked, 2I-24, II2, I1 3

leaping, $149,15 \mathrm{I}, \mathrm{I} 52$

limits of ascent, 152

lochs as gathering grounds, 144-I47

maxillary, 55, 97

" monsters," 77, 78

Norwegian, 66, 102-104, 108-111, 122, 14S, I73, 174

numbers decreasing, 43

original habitat, 29-32

Orkiey and Shetland, 28

parr (q.v.), 9, 67 (note), 84, 86, 91-99, 102-104, 106, 112, I13, 206

runuing habits, I $47^{-1} 53$

salmo11, distinguished from, 53-59, 76 , 96-98, 99, 100-107, I 50

scales (q.v.), 42, 52, 54-56, 58, 59, 61, $64-66,87,96,97$, IO1, 105, 108-I I I, 1 I 3 , 119. $122,130,131,171-176$

sexes, 6I

shape, $47,53,59,98,159,160$

shoal habit, $S_{4}, 85,106,113,123-127,147$, I5O

smolts (q.v.), 9, 67 (11ote), 91-116, 206

spawning (q.r.), 50, 61, 92 (uote), 132, 148, $153-155,159^{-1} 76$

spots, 49, 50, 51, 52, 53, 97, 98

spring rt111, 133, I34, 139, 140

statntory definition, 9, 67 (note), 206

tail, 50, 54,63

teeth, 57,60

timidity, 152, 153, 167, I68

trout, no structural differences from (Regan), I7, 20, 59, 97

"young" indistinguisluable (Regan), 17, 21, 97

distinctions noted, 76, 98, 99

"unclean or unseasonable," 132 
Sea-trout, weather, I5o

weight, $38,48,49,50$

whitling (q.v.), 9, I04, I08, II3, II5, I19-135, I39

Sea-trout fishing, commou law of Scotland, S

Crown's rights in Scotland, 7

Sewen, 38,62

Slob trout, 24,25

Smolts, 9, 67 (uote), 91-116, 206

salmon, IOo-I07, III, II4, I15

sea-trout, age at time of descent, IO5-II3

capture illegal, 92

colouration, IOI, IO4

Dah1, 92, IoS-IIO

descent, IO4, IO5

description, I04

distinctions tabulated, I02-IO4

distinguished from salmon, I00, IOI

estuarial habit, II4

fins, 101, I04

Hüitfeldt-Kaas, 93, 102-104

lochs, influence of, III, I44-I47

migration, scale evidence, I05, IoS-II2

inigratory instinct dormant, II2

" parr marks," IOI, IO4

scales, I0I, I04, I05, I08-1I2

shoal habit, II3

size, IOI, IO4, II 5

spots, IOI, IO4

statutory definition, 9, 67 (note), 206

tail, IOI, 104

vigour (Chaytor), 96

Spawning period, I59-I76

annual function, $169-176$

ascent, 148

barren fish, I60

cross-breeding, I63, I64

dress, 50, 61, 159, 160

duration, I 64,165

effects on fish, I65

kelts, $132,165^{-1} 69$

capture illegal, I32, 166

mortality, 165,166

inonths, 153-155

ova, 161,162

process described, I60-163

redds, I6r, I6 3

disturbance illegal, 92 (note), 165

scaso11, I48, 153-155

Splash nets, 149

Stuart, Hamisli, Iebridean trout, 25

Salmonida, origiual liabitat, 32

Stewart, Charles, Scottisli law of fisluing, 7
Systematic Arrangement of the Fishes of the Family Salmonida, The, C. Tate Regan, 18

Systematists and morphologists, 12-14

Tail, bull trout, coutrasted with sea-trout, $40-42,63$

parr, 96,98

salmon contrasted with tront, 54

salmon contrasted with sea-tiout, 54,55

stmolts, 55, IOI, IO4

Tailless trout, 42

" Tay bull trout," 40, 49, I 75

Teeth, 57, 60

Telcostei, sub-class, I 8

Teratology of Fishes, The, Dr. James F. Gemmill, 77

Thomson, John, Howietonn experinents, 22

Thymallus, genus, ig

'idal tro11t, 24-27, 34

Treatise on the Law of Scotland relating to the Rights of Fishing, Charles Stewart, 7

'Trout, age, 49

bull-noscd, 42

classification, I2, 17-I9, 42, 206-20S

Salmo fario, one species (Malloch), i7

Salmo trutta, one species (Regan), i6

Clyde, 34

colotration, $33,34,35,50,51,52,59,93-96$

cross-breeding, $15,23,36,163,164$

deformities, 42

distribution, 28, 47

cggs, 71, 72, 74-76, 75, 79, 192, 194, I9S

estuarine, $24-27,34$

fins, 53,95

" Fordidge," 4 I

fry, $76,7 S, 79,8_{3}, S_{4}, 198$

Mebridean, 24, 25, 27, 28

liybrid (Stuart), 25

I ocli Ifounoud, 27, 34, 37, 52, 100

nurine origin, 28,29

maxillary, 55

New Zealaud, 24

Orkney and Shetland, 24, 26, 28

Pacific, 19

" part-marked," 94

salmon, distinguished from (Regan), 54, 55

scales, 54,61

sea-trout, no struetural differences from (Regai1), 17, 20, 59, 97 
Trout, sea-trout "young" indistinguishable Whitling, characteristics, I19, 129, I30

from young of (Regan), 17, 21, 97

distiuctions noted, $76,98,99$

shape, $53,59,95$

silvery, 25, 100

slob, 24,25

spots, 50, 51, 52, 53, 95

tailless, 42

teeth, 57,60

ticlal, $24-27,34$

transplanting, 24,48

weight, 49, 49 (note)

Trout Waters: Management and Angling,

W. H. Armistead, 139

Tweed Acts, kelts, 167

Tweed Commissioners, Anumal Report, 1915, diseased fisl destroyed, 165,166

\section{U}

Umbilical (or yolk) sac, 75

"Unclean or unseasonable," statutory expression discussed, 132

\section{V}

Ventral (or pelvic) fins, 53

Vomer, 57,60

IV

Walton, lzaak, cross-breeding, 36

bull trout, $4 \mathbf{I}$

Ward, Dr. Francis, colouration, 51 mortality of eggs, etc., 79

Whitling, 9, 104, 108, 113, II5, 119-J35, 139 age, II 3

ascent, limits of, 128

time of, 119 colouration, I19, 129

descent, I33

eggs, 130

divided run, 123

feeding habits, $115,119,122,129,130,133$, 135

fins, 119,121

growth, I19, 133

"homing " instinct, 125-128

legality of capture, 132

maturity, 133, 139

migration, 122-1 24

nomenclature, $119-121$

Norwegian, 122

" parr marks," I19

scales, I19, I30

shoal habit, I24

size, 104, 108, I19, 121, 122, 129

spawning, 128-132

dress, 129

evidence from scales, 130, 131

Mallocli's opinion, I32

spring tun, I33, 134

statutory definition, 9

Wonderful Trout, The, J. A. Harvie-Brown, 49 (note)

Woodward, Dr. A. Smith, Salmonidee, common ancestor, 32

\section{Y}

Yarrell, William, salmon, sea-trout and "grey tront" distinguished, 56, 62 teeth, 57

tront deformity, 78

"Yellow-fins," I 20

Yolk (or umbilical) sac, 75 

PLEASE DO NOT REMOVE CARDS OR SLIPS FROM THIS POCKET

UNIVERSITY OF TORONTO LIBRARY

BioMrd 
